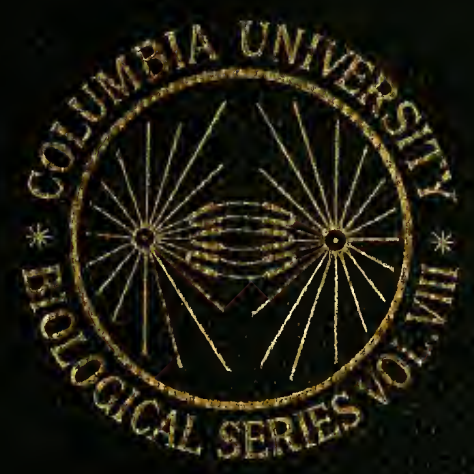




\section{BOSTON}

MEDICAL LIBRARY

8 THE FENWAY 
Alec Aprie 18 .

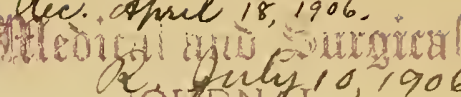
JOIRNAL10,1906 
Digitized by the Internet Archive in 2010 with funding from

Open Knowledge Commons and Harvard Medical School 
THE DYNAMICS OF LIVING MATTER 


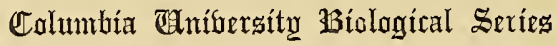

\author{
EDITED BY \\ HENRY FAIRFIELD OSBORN \\ AND \\ EDMUND B. WILSON
}

I. FROM THE GREEKS TO DARWIN

By Henry Fairfield Osborn

11. AMPHIOXUS AND THE ANCESTRY OF THE VERTEBRATES

By Arthur Willey

111. FISHES, LIVING AND FOSSIL. An Introductory Study

By Bashford Dean

IV. THE CELL IN DEVELOPMENT AND INHERITANCE

By Edmund B. Wilson

V. THE FOUNDATIONS OF ZOÖLOGY

By W. K. Brooks

V). THE PROTOZOA

By Gary N. Calkins

VII. REGENERATION

By T. H. Morgan

VIII. THE DYNAMICS OF LIVING MATTER

By Jacques Loeb

IX. STRUCTURE AND HABITS OF ANTS. (In preparation)

By W. M. Wheeler

X. BEHAVIOR OF THE LOWER ORGANISMS. (In preparation)

By H. S. Jennings 


\title{
THE DYNAMICS OF LIVING MATTER
}

\author{
$B Y$ \\ JACQUES LOEB \\ PROFESSOR OF PHYSIOLOGY IN THE UNIVERSITY \\ OF CALIFORNIA
}

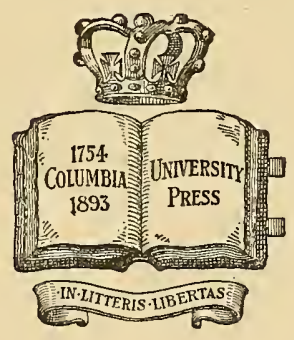

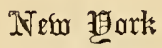

THE COLUMBIA UNIVERSITY PRESS

THE MACMILLAN COMPANY, AGENTS

LONDON: MACMILLAN \& CO., LTD.

1906 


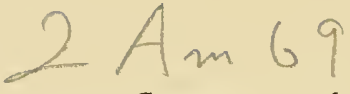

COPYRIGHT, I906,

By THE MACMILLAN COMPANY.

Set up and electrotyped. Published March, Igo6.

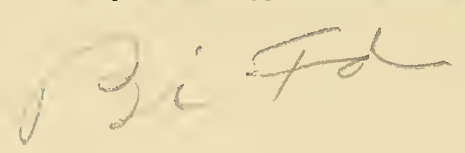

Normood 租ress

J. \$. Cushing \& Uo. - Berwick \& Smith Co.

Norwood, Mass., U.S.A. 
$\pi$

ANNE LEONARD LOEB 



\section{PREFACE}

THIs book owes its origin to a series of eight lectures delivered upon the invitation of Professor E. B. Wilson and Professor H. F. Osborn at Columbia University in the spring of 1902. The aim of the lectures was to give a presentation of my researches on the dynamics of living matter and the views to which they had led me. In preparing the book I have tried to give a somewhat more complete survey of the field of experimental biology than was possible in the lectures, without, however, trying to alter their character. In the introductory lecture use was made of my address at the International Congress at St. Louis.

To Dr. S. S. Maxwell, who has undertaken the main burden of reading the proof and preparing the index, and to Professor J. B. MacCallum, who also assisted me in the reading of the proof, my sincere thanks are due.

Berkeley, California,

January I, 1906. 



\section{CONTENTS}

\section{LECTURE I}

INTRODUCTORY REMARKS

PAGE

\section{LECTURE II}

\section{Concerning the General Chemistry of Life Phenomena}

I. Historical Remarks

2. Reversible Enzyme Action - Lipase Action - Reversible Enzyme Action in the Carbohydrate Group - The General Occurrence of Protein-splitting Enzymes 9

3. Respiration as a Catalytic Process . . . . . . . . . . . I3

(a) The Oxidases . . . . . . . . . . . . . . . . I3

(b) Further Remarks on the Significance of Oxygen in Life Phenomena . $\quad$ I6

(c) Death in Lack of Oxygen and the Protective Action of Oxygen . . 18

(d) Changes of Structure in Lack of Oxygen . . . . . . . . 19

4. The Production of $\mathrm{CO}_{2}$ through Enzymes . . . . . . . . . $2 \mathrm{I}$

5. Concerning the Theory of Enzyme Action . . . . . . . . 24

(a) Stereochemical Attempts . . . . . . . . . . . 24

(b) The Theory of Intermediary Reactions . . . . . . 26

\section{LECTURE III}

The General Physical Constitution of Living Matter

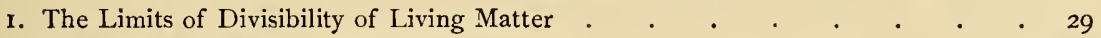

2. Foam Structures and Emulsions . . . . . . . . . . . 3 . 3

3. The Colloidal Character of Living Matter . . . . . . . . . $\quad$. 33

4. The Formation of Surface Films and Traube's Membranes of Precipitation -

Overton's and Meyer's Work on Narcotics and the Nature of Surface Films . ${ }_{3} 8$

5. Osmotic Pressure and the Exchange of Liquids between the Cells and the Sur-

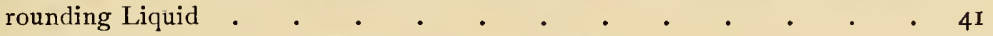

6. Further Limitations of Traube's Theory of Semipermeability . . . . . 45

7. The Antagonistic Effects of Salts . . . . . . . . . . 46

\section{LECTURE IV}

On Some Physical Manifestations of Life

I. Hypotheses of Muscular Contraction . • • • • . • • 53

2. Quincke's Theory of Protoplasmic Motion . . . . . . . 55

3. Concerning the Theory of Cell Division . . . . . . . . $\quad 5^{8}$

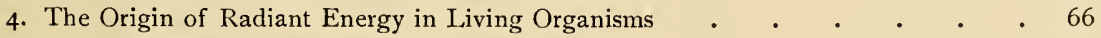

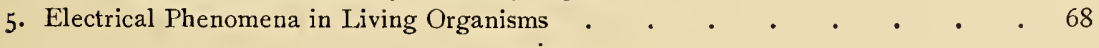




\section{LECTURE V}

The Rôle of Electrolytes in the Formation and Preservation of Living MatTer

I. On the Specific Difference between the Nutritive Solutions for Plants and Animals

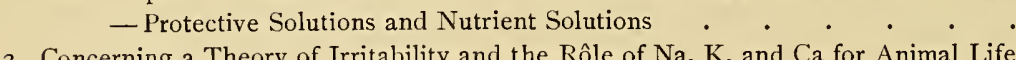

PAGE 71 - Rhythmical Contractions in Skeletal Muscle, in Medusæ, and the Ventricle of the Heart - Contact Irritability in Muscle-Analogies to the Rôle of Salts in Coagulation of Milk - Significance for the Understanding of Functional Nervous Diseases - The Action of Purgatives . . . .

3. The Reaction of Living Matter and the Rôle of Bicarbonates in the Preservation of Life

4. Electrical Stimulation

\section{LECTURE VI}

\section{The Effects of Heat and-Radiant Energy upon Living Matter}

I. Effects of Heat - Upper Temperature Limit of Life - Influence of Reactionvelocity upon Biological Processes - Lower Temperature Limit - Other

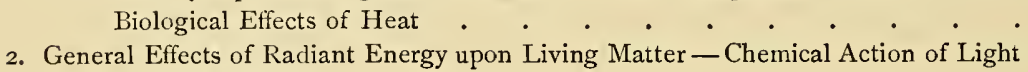
upon Organisms

\section{LECTURE VII}

\section{HELIOTROPISM}

I. The Heliotropism of Sessile Organisms . . . . . . . . . II7

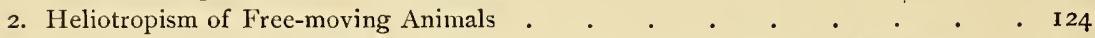

3. The Control of the Precision and Sense of Heliotropic Reactions in Animals . - I 30

4. The Reaction of Animals to Sudden Changes in the Intensity of Light . . . 135

\section{LECTURE VIII}

Further facts concerning Tropisms and Related Phenomena

I. General Theory of Tropisms .

2. Galvanotropism

3. Geotropism

. . . . . . . . . . I 147

4. Chemotropism and Related Phenomena . . . . . . . . . I52

5. Stereotropism . . . . . . . . . . . . . . 155

6. Concluding Remarks concerning Tropismlike Reactions . . . . . . $\mathbf{1}_{58}^{8}$

\section{LECTURE IX}

\section{Fertilization}

I. The Specific Character of the Fertilizing Power of the Spermatozoön-Hybrid Fertilization . . . . . . . . . . . . . I6I

2. Artificial Parthenogenesis and the Theory of Fertilization . . . . . 164 


\section{LECTURE $\mathrm{X}$}

\section{HEREDITY}

I. The Hereditary Effects of the Spermatozoön and Egg - The Prevailing Influence of the Egg in the Early Stages of Development - Merogony - Toxicity of the Blood of Forms not closely Related - Mendel's Experiments . . . I 79

2. The Determination of Sex and the Secondary Sexual Characters . . . . I86

3. Egg Structure and Heredity . . . . . . . . . . . I9I

\section{LECTURE XI}

On the Dynamics of Regenerative Processes

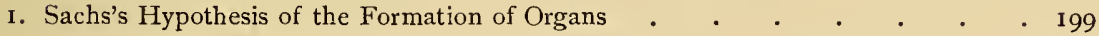

2. Heteromorphosis and Regeneration in Tubularia . . . . . . . $20 \mathrm{I}$

3. Regeneration in an Actinian (Cerianthus membranaceus) . . . . . 207

4. Regeneration and Heteromorphosis in Planarians . . . . . . . 210

5. On the Influence of the Central Nervous System upon Regeneration and on Phenomena of Correlation in Regeneration . . . . . . . . 213

6. The Effect of Some External Conditions upon Regeneration and the Transformation of Organs . . . . . . . . . . . . 2I7

7. The Rôle of Reversible Processes in Phenomena of Regeneration - The Distribution of the Power of Regeneration in the Animal Kingdom . . . . 218

I,ECTURE XII

Concluding Remarks 



\section{LECTURE I}

\section{INTRODUCTORY REMARKS}

In these lectures we shall consider living organisms as chemical machines, consisting essentially of colloidal material, which possess the peculiarities of automatically developing, preserving, and reproducing themselves. The fact that the machines which can be created by man do not possess the power of automatic development, self-preservation, and reproduction constitutes for the present a fundamental difference between living machines and artificial machines. We must, however, admit that nothing contradicts the possibility that the artificial production of living matter may one day be accomplished. It is the purpose of these lectures to state to what extent we are able to control the phenomena of development, self-preservation, and reproduction.

Living organisms may be called chemical machines, inasmuch as the energy for their work and functions is derived from chemical processes, and inasmuch as the material from which the living machines are built must be formed through chemical processes. It is therefore only natural that the dynamics of living matter should begin with an analysis of the specific character of the chemical processes in organisms. It is neither our intention nor is it possible for us to give an exhaustive analysis, and we shall only go far enough to satisfy ourselves that no variables are found in the chemical dynamics of living matter which cannot be found also in the chemistry of inanimate nature.

The material of which living organisms consist is essentially colloidal in its character. Graham introduced the discrimination between colloidal and crystalloidal substances: the latter diffuse easily, the former only with difficulty, or not at all, through animal membranes. The colloidal substances may be in solution or fine suspension, or they may appear in a jellylike or coagulated or precipitated form. In the former case where they are liquid we speak of sols, in the latter of gels. The structures which we find in living matter originate mostly through a gelation or coagulation of liquid colloids. We shall see in these lectures that liquefactions and gelations or coagulations may possibly play a great rôle in various physical manifestations of life; but as the physics of colloids is still in its beginning, we must not be surprised that it is as yet impossible to carry its application to life phenomena very far. 
As the chemical character of life phenomena and the physical structure of living matter form the basis for the understanding of the dynamics of living matter, it is natural that they should be the starting-point in our lectures.

As far as the specifically biological phenomena are concerned, namely, the phenomena of development, self-preservation, and reproduction, it will be our aim to analyze them as much as at present possible from a physicochemical point of view. It may perhaps be desirable before undertaking this task for us to state, as simply as possible, some of the individual problems that will present themselves for discussion, and the general method of their solution.

We know that the eggs of the majority of animals cannot develop unless they are fertilized, i.e. unless they are entered by a spermatozoön. We do not know how the spermatozoön causes the egg to develop, but it is not to be expected that we shall gain an insight into these causes except by trying to imitate by purely chemical and physical means the effects which a spermatozoön has upon the egg. We shall see that this has been accomplished in some forms. Under ordinary conditions, the egg of Strongylocentrotus purpuratus, a sea urchin of the Pacific coast, does not develop unless a spermatozoön enters it; but the fertilizing effect of a spermatozoön can be imitated in all essential details by putting the egg for a minute into sea water to which a certain amount of a fatty acid has been added and by subsequent exposure of the egg for about half an hour to sea water whose concentration has been raised by a certain amount. Similar results can be obtained in other forms.

From a given egg can arise a specific organism only, the morphological and physiological qualities of which can be predicted with certainty, if we know the organism from which the egg is derived. We call this fact heredity. Modern embryology has shown that the complicated adult forms develop gradually from simpler forms, and by following the development from the egg we readily understand how it happens that the adult form is so much more complicated than the egg from which it arises. The question which has recently puzzled biologists is whether the egg has any structure which can be related to the adult form. This seems to be true in the eggs of some forms, to the extent at least that from the various regions of the egg somewhat different parts of the embryo arise. We do not know the causes which determine this relatively slight differentiation inside of the egg, but we shall see that everything indicates that these causes may be of a simple physicochemical order. In studying the mechanism of heredity, it is perhaps of importance to realize that as far as the heredity of the earliest embryonic stage is concerned, it is almost, or exclusively, determined 
by the egg. This is beautifully illustrated in the case of the hybridization of the egg of the sea urchin with the sperm of the starfish. The development of the pure breed of the sea urchin is after a certain stage (the gastrula stage) typically different from the development of the starfish, inasmuch as the sea urchin's egg forms at that point a skeleton and goes into the characteristic pluteus form, while the starfish egg forms no skeleton, but undergoes a different development. When the sea urchin's egg is fertilized with starfish sperm, the egg always develops into a pluteus, never into the corresponding starfish form. If we examine the adult forms of hybrids, however, we find that it makes no difference which of the two forms furnishes the spermatozoön or the egg. This difference in the influence of the spermatozoön and egg upon the early embryonic and the adult form of the offspring is possibly due to a difference in the mass of the egg and the spermatozoön, the latter being as a rule much smaller than the former. As soon, however, as the embryo grows and its mass becomes large in comparison with that of the egg, the original difference in the hereditary effects of the two sex cells must diminish or disappear.

The foundations of a theory of heredity in the adult were laid by Gregor Mendel in his treatise on the hybrids of plants, and this theory is atomistic in its character. He showed that certain simple characteristics of plants, e.g. the round or angular form of the seeds of peas, or the color of their endosperm, must already be represented in the germ by definite determinants. His experiments on the hybridization of various forms of peas indicate that each hybrid contains two kinds of sexual cells, one possessing the determinants for the discriminating fatherly characteristic only, the other for the discriminating motherly characteristic. Both kinds of sexual cells seem to exist in equal numbers in such a hybrid. A similar fact has been discovered in other cases of hybridization, although it does not hold good for all cases. Hugo de Vries and others have begun to build up the physiology of heredity on the basis of Mendel's discovery.

It is obvious that no theory of evolution can be true which disagrees with the fundamental facts of heredity. It is the merit of De Vries to have shown that a mutation of species can be directly observed in certain groups of plants, and he has further shown that the changes occur by jumps, not gradually. This fact harmonizes with the consequence to be drawn from Mendel's experiments that each individual characteristic of a species is represented by an individual determinant in the germ. This determinant may be a definite chemical compound. The transition or mutation from one form into another is therefore only possible through the addition or disappearance of one or more 
of the characteristics or determinants. If this view can be applied generally, it is just as inconceivable that there should be gradual variations of an individual characteristic and intermediary stages between two elementary mutations, as that there should be gradual transitions between one alcohol and its next neighbor in a chemical series.

The fact that, as a rule, at a definite stage of development, larger masses of sexual cells are formed, is one of the automatic phenomena of development. The mechanism of this formation is unknown. Miescher tried to solve this problem in the salmon. In this animal the sexual cells seem to be formed at the expense of the substances of the muscles, and it was the disappearance of the muscles at the time the sexual organs began to grow which aroused Miescher's interest. But this seems to be after all of only secondary importance, inasmuch as with our present knowledge of the chemistry of living organisms it is immaterial whether the animal's own muscles furnish the material for the sexual cells or the muscles of the animal it devours. The real problem is, how it happens that at a certain stage in the development of the animal the sexual glands take away so much material from the blood. From our present knowledge we must suspect that the mechanism of such a process is a transformation of liquid constituents of the blood into solid constituents inside of those cells which show a rapid growth or a transformation into different compounds.

We possess a little more knowledge concerning sexual dimorphism. It has been known for a long time that it is possible to produce in plant lice (Aphis) either females exclusively, or both sexes, at desire. In bees and related forms, as a rule, only males originate from unfertilized eggs, and females only from fertilized eggs. It is known, moreover, that in higher vertebrates such twins as originate from the same eggs are also uniform in sex, while twins originating from different eggs may be different in sex. All that we know thus far concerning the origin of sex seems to indicate that the sex of the embryo is already determined in the unfertilized egg, or is determined very soon after the impregnation of the egg.

Sexual maturity is sooner or later followed by death. Is death determined just as automatically by the processes of development preceding it, e.g. the maturation of the sexual products, as are these processes by the previous processes of development, or as is the development of the egg by the entrance of a spermatozoön? The fact that most higher animals, at least, die by bacterial infection, and that certain plants, e.g. the Sequoia, which are more free from bacteria, can reach an almost fabulous age, renders the answer to this question somewhat uncertain or prevents the generalization of an answer. It is not 
impossible that further experiments on the egg may aid us in solving this problem. In certain forms, e.g. the starfish, the mature egg, if not fertilized, dies rapidly, while the fertilized egg continues to live. For this egg the act of impregnation is a life-saving act.

We shall now attempt to give a short sketch of the phenomena and problems of self-preservation similar to that just given of the phenomena of development. Among the phenomena of self-preservation are such facts as the existence of automatic mechanisms for the union of the sexual cells wherever there exist separate sexes, or the existence of automatic mechanisms for the deposition of eggs in places which furnish food for the young larvæ, and so on. What do we know concerning the nature of these automatic mechanisms? Metaphysics has supplied us in these cases with the terms "instinct" and "will." We speak of instinct when an animal, apparently unconsciously, executes motions or actions which are necessary for the preservation of the individual or the species; while we speak of will when motions are executed consciously. We call it instinct when the female fly deposits her eggs on meat on which the young larvæ can feed. An analysis of the instinctive actions has yielded the result that the purposeful motions of animals frequently depend upon mechanisms which are a function of the symmetrical structure and the symmetrical distribution of irritability on the surface of the body of the organisms. Symmetrical points on the surface of an animal have usually an equal irritability, i.e. if such spots are stimulated equally the same amount of motion, but in opposite directions, is produced. Points on the surface which are nearer the oral pole of the animal usually have a higher irritability than, or a different irritability from, points which are nearer the aboral pole. If lines of force, e.g. rays of light, current curves, lines of gravitation, lines of diffusion, strike one side of an animal in greater density than the other side, the tension of the muscles, or contractile elements, on both sides of the organism does not remain the same, and if the animal moves, a tendency to turn to one side must result. This will continue until symmetrical points on both sides of the animal are again struck at the same angle by the lines of force. As soon as this occurs the tension of the muscles, or contractile elements, on both sides of the animal becomes equal, and there is no more reason why the animal should deviate toward the right or the left; it will therefore continue to move in the original direction. This automatic orientation in a field of force toward or away from the center of force is called a tropism. It has been possible to dissolve a number of animal instincts into tropisms. The analysis of various tropisms has shown that there exists a great variety, and often a great complexity due to the combination of several 
forms of tropisms in the same individual, and to the changes of these tropisms under the influence of internal and external factors. In these lectures we shall discuss some of the elementary tropisms and their rôle in the animal instincts and in the preservation of the individual and the species.

The will actions of animals, i.e. those motions which are executed consciously, will not be discussed here as I have already analyzed them in another book.* I will simply state here that I consider consciousness the function of a definite machine or mechanism, which we may call the mechanism of associative memory. Whatever the nature of this machine may be it has one essential feature in common with the phonograph, namely, that it reproduces impressions in the same chronological order as that in which they were received. The mechanism of associative memory seems to be located - in vertebrates - in the cerebral hemispheres. It follows from the experiments of Goltz that one of the two hemispheres is sufficient for all the phenomena of memory and consciousness. As far as the chemical or physical mechanism of memory is concerned, we have at present only a few vague data. H. Meyer and Overton have pointed out that substances which are easily soluble in fat are also, for the most part, strong anæsthetics, e.g. ether, chloroform, etc., and that the ganglionic cells are especially rich in lipoids. It is possible that the mechanism of associative memory depends in part upon the properties and activities of the fatty constituents of the cerebral hemispheres. Another fact which may be of importance is the observation of Speck that if the partial pressure of oxygen in the air is lowered to below one third of its normal value, the fundament of mental activity, namely, memory, is almost instantly interfered with, and total loss of consciousness rapidly follows.

In those animals which possess the mechanism of associative memory, a number of the automatically regulated processes may become conscious. Respiration is purely an automatic process, yet we may at any time become conscious of it. This has misled a number of authors to believe that such automatic processes as in ourselves may become conscious must be accompanied by consciousness in any animal in which they occur. These authors overlook the fact that the automatic mechanisms of self-preservation must occur in every organism, while an apparatus for associative memory may be found only in a limited number of organisms. Without such an apparatus, consciousness is impossible. The fact that a physiological process may become conscious in ourselves does not therefore prove that it is accompanied by consciousness in every organism.

* Loeb, Comparative Physiology of the Brain and Comparative Psychology. G. P. Putnam's Sons, New York. 


\section{LECTURE II}

\section{CONCERNING THE GENERAL CHEMISTRY OF LIFE PHENOMENA}

\section{Historical Remarks}

To-DAY every one who is familiar with the field of chemical biology acknowledges the fact that the chemistry of living matter is not specifically different from the chemistry of the laboratory. We owe the certainty of this fact essentially to three publications, which may be mentioned briefly. The first contained the proof furnished by Lavoisier and La Place in $\mathrm{I} 780$, that animal heat is produced by a process of slow combustion, and that for a certain amount of heat produced a certain amount of oxygen is consumed in the production of $\mathrm{CO}_{2}$. A measurement of the quantity of $\mathrm{CO}_{2}$ formed and the amount of heat produced gave approximately identical results in the case of a burning candle and a living guinea pig.*

A second step in this direction was taken when Woehler showed that an organic substance like urea, which is a product of metabolism, can be made artificially in the laboratory. $\dagger$ To-day so many of the compounds produced in the living body can be produced artificially that we can hardly understand that in 1828 Woehler's discovery was considered sensational.

The discovery of Lavoisier and La Place left a doubt in the minds of scientists as to whether after all the dynamics of oxidations and of chemical reactions in general is the same in living matter and in inanimate matter. The oxidation of food stuffs could indeed be imitated outside the body, but only at such temperatures as were incompatible with life; phenomena of digestion could be imitated, but only with the aid of acids too strong for life to continue. The way out of the difficulty was shown in a remarkable article by Berzelius. $\ddagger \mathrm{He}$ pointed out that in addition to the forces of affinity, another force is active in

* Lavoisier et De la Place, Mémoire sur la Chaleur, 1780. Euvres de Lavoisier, Vol. 2. (Also in Ostwald's Klassiker der Naturwissenschaften, Nr. 40.)

† Woehler, Ueber künstliche Bildung des Harnstoffs. Poggendorf's Annalen, Vol. 12, p. $253, \mathbf{1} 828$.

\pm Berzelius, Einige Ideen ïber eine bei der Bildung organischer Verbindungen in der lebenden Natur wirksame aber bisher nicht bemerkte Kraft. Berzelius u. Woehler, Jahres. bericht, 1836 . 
chemical reactions: this he called catalytic force. As an example he used Kirchhoff's discovery of the action of dilute acids in the hydrolysis of starch to dextrose. In this process the acid is not consumed, hence Berzelius concluded that it did not act through its affinity, but merely by its presence or its contact. Another instance quoted by Berzelius was the decomposition of $\mathrm{H}_{2} \mathrm{O}_{2}$ which had been investigated by Thénard. In acid solution this body is stable; in alkaline solution, or in the presence of platinum, silver, or gold, or in the presence of fibrin of the blood, it is rapidly decomposed. In this decomposition apparently neither the fibrin, the gold, nor the platinum acted through the force of affinity, but catalytically. He then suggests that the specific and somewhat mysterious reactions in living organisms might be due to such catalytic bodies as act only by their presence, without being consumed in the process. He quotes as an example the action of diastase in the potato. "In animals and plants there occur thousands of catalytic processes between the tissues and the liquids." The idea of Berzelius has proved fruitful, and the catalytic agencies which in his opinion are responsible for the characteristic reactions in living matter are the enzymes of modern biological chemistry. In some details, however, Berzelius's idea was erroneous. We now know that we have no right to assume that the catalytic bodies do not participate in the chemical reaction because their quantity is found unaltered at the end of the reaction. On the contrary, we shall see that it is probable that they can exercise their influence only by participating in the reaction, and by forming intermediary compounds, which are not stable. The catalyzers may be unaltered at the end of the reaction, and yet participate in it.

In addition we owe to Wilhelm Ostwald* the conception that the catalyzer does not as a rule initiate a reaction which otherwise would not occur, but only accelerates a reaction which otherwise would indeed occur, but too slowly to give noticeable results in a short time.

Thus the existence of catalytic agencies, the so-called enzymes in living matter, explains the fact that chemical changes may occur very rapidly in the body at a comparatively low temperature and at a practically neutral reaction. Catalyzers are used extensively in chemical factories, e.g. in the manufacture of sulphuric acid, so that it is impossible to see in their presence in living matter a specific difference between the chemistry of living and inanimate nature. The only difference is, perhaps, that living matter manufactures its own catalyzers. This, however, is part of that peculiarity mentioned in the introductory lecture, that living machines possess the peculiarity of automatically preserving themselves.

*W. Ostwald, Lehrbuch der allgemeinen Chemie, Vol. II, 2d part, p. 248, 1902. 


\section{Reversible Enzyme Actions}

Reversible chemical processes are characterized by the fact that the reaction comes to a standstill before all the substances on one side of the equation are transformed into those on the other side. The reason is, that a point is reached when, in the unit of time, the change in one direction is just as great as the change in the opposite direction. When this occurs we say that chemical equilibrium has been established. Inasmuch as, according to Ostwald, enzymes do not inaugurate chemical reactions, but only accelerate them, it follows that the action of enzymes must also be reversible, if the process itself is reversible. It is the merit of Arthur Croft Hill to have first shown a few years ago that an enzyme, maltase, which accelerates the hydrolysis of maltose into dextrose, also accelerates the synthesis of dextrose into maltose when added to pure dextrose. It is no exaggeration to say that Hill's paper entirely changed the conceptions of the physiology of metabolism. We shall return to Hill's experiments later, and first discuss the reversible action of a fat-splitting enzyme, lipase.

It had been known for some time that the pancreas secretes an enzyme which digests fat in the intestinal canal. Kastle and Loevenhart* showed that in all tissues and liquids of the body which contain fat, lipase can be found. A watery extract of pancreas contains a substance in solution which is capable of hydrolizing fats, i.e. of splitting fats into fatty acid and alcohol. Kastle and Loevenhart showed, moreover, that the watery extract of any tissue which contains fat acts in a similar way. The chemical character of this catalytic substance is unknown, except that its efficiency is rapidly destroyed if it is heated in water. According to Taylor, $\uparrow$ it does itself, at a high temperature, undergo a hydrolytic cleavage.

Kastle and Loevenhart showed that lipase not only accelerates the hydrolysis of fat, but also the synthesis of fat, when added to a mixture of fatty acid and alcohol. Their experiments were made on ethylbutyrate. If an extract from the pancreas or liver was added to a mixture of ethylalcohol, and butyric acid, ethylbutyrate was formed. This reversible action of lipase has the effect that the process of digestion of fat can only be completed if the products of digestion are removed. In the intestine this occurs through absorption.

The velocity of the hydrolysis of ethylbutyrate was found to be in proportion to the concentration of the lipase. This explains the fact

* Kastle and Loevenhart, Am. Chem. Journal, Vol. 24, p. 491, I90o.

$\dagger$ A. E. Taylor, University of California Publications, Pathology, Vol. I, p. 33, 1904. 
that those tissues which possess most fat, as a rule, also possess most lipase.* The more lipase a cell possesses the quicker it will be able to convert the fatty acid and alcohol, which diffuse or are absorbed into it from the blood, into fat; and hence more fatty acid and alcohol must diffuse into such a cell in the same length of time from the blood than into a cell with less lipase.

We understand how it happens that in times of abundant fat supply our tissues are able to store up fat, while in times of want fat disappears from them. If the blood receives no fat from the intestine, and if the other sources of fat formation, which we shall mention later, cease, the digestive effect of the lipase in the cells must outweigh its synthetical action.

The experiments of Kastle and Loevenhart were not tried with the fats occurring in the body. A. E. Taylor $t$ has filled this gap by showing that the lipase extracted from the castor bean, which digests fats, is able to produce synthetically the triglyceride of oleic acid. The process is a very slow one, inasmuch as in six months only $3.5 \mathrm{~g}$. of the fat were formed. Taylor concludes that in the body other agencies than mere enzymes must contribute toward the acceleration of the hydrolytic, as well as the synthetical processes. These conditions are, however, not of a vitalistic character, but may be due to the presence of certain other substances. Thus Hewlett has recently found in Taylor's laboratory that the addition of lecithin to lipase accelerates the hydrolysis of fat considerably. Taylor found also that the lipase from the castor bean cannot synthetize every fat, but only the triglyceride of oleic acid. Experiments with palmitic and stearic acid and glycerine as an alcohol gave negative results, as gave also experiments with oleic acid and mannit or dulcit as alcohol. This is in harmony with the theory of intermediary reactions, which will be discussed later.

It is, however, worth mentioning that fat may be produced in the body from carbohydrates, and that lipase has, as far as we can tell, nothing to do with this mode of fat formation. The most striking case of such an origin of fat is found in the leaves of the olive tree, which synthetize it from the carbohydrates formed from the $\mathrm{CO}_{2}$ of the air. The fact that a reduction must form part of the process of the formation of fat from carbohydrates may explain why so often a hypertrophic heart has a tendency to fatty degeneration, inasmuch as the hypertrophic heart is as a rule an overworking heart, and is thus liable to suffer from lack of oxygen.

* Loevenhart, Am. Jour. Physiology, Vol. 6, p. 331, 1902.

† A. E. Taylor, University of California Publications, Pathology, Vol. I, p. 33, 1904. 
Neilson* has shown that the catalytic action of lipase on ethylbutyrate can be imitated by platinum-black. The latter not only accelerates the hydrolysis, but also the synthesis of ethylbutyrate. Kastle and Loevenhart found that certain poisons like hydrocyanic or salicylic acid weaken the action of lipase. Neilson found that these poisons act similarly on the digestion of ethylbutyrate by platinum-black.

The study of the reversible action of enzymes in the carbohydrate group is complicated by the fact that the digestion of starch to sugar occurs in a series of successive stages, and that apparently each stage requires a different catalyzer. According to Duclaux, $\dagger$ we possess specific enzymes for the transformation of solid into liquid starch; the liquid starch is then split by amylase or diastase into a disaccharide, i.e. maltose. Maltose is split by the enzyme maltase into $d$-glucose. In case another disaccharide is formed in the place of maltose, other enzymes are required, e.g. in the case of cane sugar, invertase, whereby dextrose and lævulose are formed. In the animal body, glycogen is formed in the place of starch. It is obvious that the synthesis of dextrose into glycogen or starch requires the presence of several catalyzers. The action of these catalyzers must be studied individually.

Hill $\ddagger$ found that the hydrolysis of maltose in the presence of the enzyme maltase is retarded if dextrose is added to the maltose; that, moreover, the hydrolysis of maltose under the influence of maltase is complete only in very dilute solutions, while the reaction otherwise comes to a standstill before all the maltose is transformed into glucose. The following table shows the point at which the hydrolysis comes to a standstill at various concentrations:-

Concentration of Maltose

$$
\begin{array}{r}
40 \% \\
10 \% \\
4 \% \\
2 \%
\end{array}
$$

Percentage of Maltose which is SPLIT INTO Glucose

$84 \%$
$94.5 \%$
$98 \%$
$99 \%$

Hill convinced himself that if the enzyme maltase is added to a solution of glucose, maltose is formed, and that, moreover, equilibrium is reached at the same point as in the case of hydrolysis. When he added fresh maltase to a 40 per cent solution of dextrose in one experiment, I 4.5 per cent, and in another I 5.5 per cent, maltose was formed. It has since been shown that the synthetical product formed in this case was isomaltose instead of maltose, but this slight deviation does not alter the principal result.

* Neilson, Am. Jour. Physiology, Vol. ro, p. I9r, 1903.

† Duclaux, Traité de microbiologie, Vol. 2, Paris, 1899.

$\ddagger$ A. C. Hill, Jour. Chem. Society, Vol. 73, p. 634, 1898 . 
Hill raises the question, as to whether or not a synthetical formation of maltose under the influence of maltase may occur in the living cell. He points out that for such a result a high concentration of dextrose in the blood is by no means necessary; that it is sufficient if the product of the synthesis is removed immediately, possibly through a further synthesis into a higher carbohydrate by another enzyme in the cell. In this way the concentration of the maltose is kept at zero, and the tendency toward the establishment of the chemical equilibrium must favor the further synthesis.

The synthesis of sugar into glycogen is of general importance, inasmuch as glycogen is the form in which the carbohydrates are stored in our liver and muscles. Max Cremer* immediately after the appearance of Hill's paper published the important observation, that the juice pressed out from yeast, which had previously been rendered free from glycogen, is capable of forming glycogen from sugar. When ro per cent of a fermentable sugar was added to the juice, the latter gave the glycogen reaction after from twelve to twenty-four hours, but this result was not obtained in all cases.

It may perhaps not be unnecessary to call attention to the fact that in all the cases we have discussed the enzymes are soluble substances, which can be extracted from the cells, and therefore can exist independently of the life or structure of the cell from which they are obtained.

In the group of proteins we not only meet with the same difficulties which are found in the group of carbohydrates, but also with the additional difficulty, that we know considerably less about the constitution and configuration of the various protein molecules than of the carbohydrates. These two conditions probably account for the fact that a direct reversion of the action of a hydrolytic enzyme has not yet been satisfactorily proven for proteins.

It is hardly necessary to mention especially the fact that hydrolytic enzymes, e.g. of the type of trypsin, acting on proteins, are found not only in the intestine, but also in tissues, probably generally. Thus Salkowski has shown that if yeast cells or muscles are kept aseptically in an incubator, an autodigestion occurs in which leucin and tyrosin, i.e. typical end products of proteolysis, are formed.

Kutscher $\dagger$ has completed the proof by showing that, in addition to the acids, the other end products of proteolysis are formed in the autodigestion of yeast; namely, the hexonbases, e.g. arginin and lysin. $\mathrm{He}$ found, moreover, that in starving yeast the above-mentioned end

* Cremer, Ber. der deut. chem. Gesell., Vol. 32, p. 2062, 1899.

† Kutscher, Hoppe-Seyler's Zeitsch. für physiolog. Chemie, Vol. 32, p. 59, 1901. 
products of tryptic hydrolysis are found in considerable quantities, while these products could be obtained in fresh and well-nourished yeast only in minimal quantities. In this he sees, and probably correctly, an indication of the reversible action of the proteolytic enzymes. There is, however, one essential link missing, i.e. the proof that the hydrolytic action of the proteolytic enzymes is retarded, and finally inhibited, when the products of digestion are not removed.

R. O. Herzog has recently made an attempt to prove the reversible action of enzymes in a very interesting way upon the discussion of which, however, we cannot enter here.

\section{Respiration as a Catalytic Process. Oxidation and Oxidases}

By respiration we mean the taking up of oxygen and the giving off of $\mathrm{CO}_{2}$. We shall see later that the latter process can exist independently of the taking up of oxygen.

Since the days of Lavoisier and La Place the real problem of oxidation has consisted in the explanation of the fact that at the body temperature our food stuffs are not oxidized at all, or only infinitely slowly, outside the body, while in the body they are oxidized rapidly. The solution "of the problem was found in the discovery of "oxidizing ferments" in living organisms. This conception is chiefly due to Moritz Traube,* who was also the first to recognize that the oxidations occur in the cells, and not, as had been assumed before, in the lungs or the blood.

Traube's idea was that there exist in the cells autoxidizable substances, i.e. substances which bind loosely the free oxygen at a comparatively low temperature, and which are capable of giving off their oxygen to disoxidizable substances, such as our food stuffs. It is obvious that Traube's idea of the action of an oxidizing ferment was that of intermediary reactions. He realized also that these oxidizing ferments exhibited no effects which could not be produced in inanimate nature, as the following quotation shows: "The ability to transfer oxygen ... is found in many, even inorganic bodies. There are substances like nitrogenoxide, platinum, various coloring matters, copper salts, which are capable of transferring free oxygen upon neighboring substances." $\dagger$

* M. Traube, Ueber die Beziehung der Respiration zur Muskelthätigkeit und die Bedeutung der Respiration überhaupt, I861. Gesammelte Abhandlungen von M. Traube, p. I57, Berlin, I899. (In this paper Traube showed also that the work of the muscle is normally done at the expense of carbohydrates. His arguments induced Fick and Wislicenus to try the classical experiment by which this theory was proved.)

$\dagger \mathrm{M}$. Traube, Die Chemische Theorie der Ferment wirkungen und der Chemismus der Respiration, 1878. Gesammelte Abhandl., p. 384 , Berlin, I 898. 
I think Jacquet* was the first to separate a "ferment of oxidation" from the living organism, and to obtain it in a watery extract from tissues. The oxygen of the air oxidizes benzylalcohol $\left(\mathrm{C}_{6} \mathrm{H}_{5} \mathrm{CH} \mathrm{OH}\right)$ only slowly to benzoic acid $\left(\mathrm{C}_{6} \mathrm{H}_{5} \mathrm{COOH}\right)$ at body temperature; the same is true for the oxidation of salicylaldehyde $\mathrm{C}_{6} \mathrm{H}_{4} \mathrm{OH}$ to salicylic acid $\mathrm{C}_{6} \mathrm{H}_{4} \mathrm{OH}$. SOH $\mathrm{OH}^{\circ}$ Schmiedeberg had already shown that the animal tissues accomplish this oxidation comparatively rapidly. Jacquet proved that this energetic oxidation of benzylalcohol is not dependent upon living protoplasm, as he found that it occurred also in dead tissues. Tissues poisoned with carbolic acid continue to accelerate these oxida tions, and even tissues which have been preserved in alcohol are capable of so doing. Nor are these oxidations dependent upon the structure of the cells, as watery extract from the cells also had oxidative effects upon benzylalcohol. The action of the oxidizing enzymes is annihilated when they are heated to a temperature of about $100^{\circ}-$ possibly through a hydrolysis of the enzyme itself.

Engler and Wild $\dagger$ have found that there exists a group of substances which behave like Traube's autoxidizable substances. These substances have the peculiarity of easily forming peroxides of the following type:-

$$
\begin{aligned}
& \dot{\mathrm{R}}-\mathrm{O} \\
& \dot{\mathrm{R}}-\mathrm{O}
\end{aligned}
$$

or

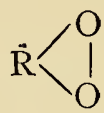

These peroxides are capable of giving off one atom of oxygen to disoxidizable substances. Through the loss of this atom of oxygen the peroxides are transformed into oxides. This view is supported by an important observation which was first made by van't Hoff and Jorissen. If the quantity of oxygen which disappears in the oxidation of a known quantity of a disoxidizable substance is measured, it is found to be in most cases exactly twice as large as the quantity required for the oxidation of the disoxidizable substance. $\ddagger$ This finds its explanation in the fact that for every molecule of oxygen which is taken up by the autoxidizable substance, only one atom is transferred to the disoxidizable substance.

The view of Engler and Wild is also supported by the investigations of Kastle and Loevenhart $\S$ on the -oxidizing effects of plant tissues, e.g. the potato, and their watery extracts. They found that organic

* Jacquet, Arch. für experimentelle Pathologie und Pharmakologie, Vol. 29, p. 386, 1892.

† Engler und Wild, Ber. der deutsch. chem. Gesellsch., Vol. 30, p. 1669, 1897. Engler und Weissberg, Kritische Studien über die Vorgänge der Autoxydation, Braunschweig, 1904.

+ See also Manchot, Zeitsch. für anorganische Chemie, Vol. 27, p. 420, I90I.

$\S$ Kastle and Loevenhart, Am. Chem. Journal, Vol. 26, I90I. 
peroxides, e.g. benzoylperoxide, phthalylperoxide, and succinylperoxide, or inorganic ones, like lead peroxide and manganese peroxide, produced the same blue color in the tincture of guaiacum as the tissues of plants, or watery extracts from the same. The production of this blue color is due to oxidation. The same authors showed, moreover, that the same poisons which in plants prevent the action of oxidases - this is the name given to the enzymes of oxidation - prevent also the oxidizing action of the above-mentioned organic and inorganic peroxides upon tincture of guaiacum. Kastle and Loevenhart therefore conclude that the oxidases, or oxidizing enzymes, in the tissues of animals and plants, are organic peroxides.

Here we meet with a difficulty, however. Oxidations occur incessantly on a large scale in the living body, especially at the temperature of the warm-blooded animals. The peroxides, however, are not capable of transferring oxygen in unlimited quantities to disoxidizable substances, but as soon as a peroxide molecule has given off one atom of oxygen, its oxidizing power is at an end. This difficulty can be overcome in the following two ways: it is possible that new autoxidizable substances are formed incessantly in the body; the second possibility is the existence of a second class of oxidizing enzymes which act more in the sense of true enzymes than the peroxides, inasmuch as they are able to take up and give off oxygen indefinitely. Hæmoglobin is capable of binding and setting free oxygen indefinitely, but it is not capable of transferring its oxygen to disoxidizable substances, and hence does not act as an oxidase.

The question of localization of the oxidizing enzyme in the cell was raised by Spitzer.* He found that the proteins which can be extracted from the cells do not possess the qualities of Jacquet's oxidase, but that these qualities are found in such extracts as contain nucleoproteids. The nucleoproteids are typical constituents of the cell nucleus, and they differ from the proteins proper in that they contain $\mathrm{PO}_{4}$ and Fe. Spitzer was able to show, moreover, that of the products of cleavage of nucleoproteids only those constituents were able to act as oxidases which contained the $\mathrm{Fe}$ group. Two years ago I pointed out that if Spitzer's researches are correct, the cell nucleus must be regarded as the essential respiratory or oxidizing organ of the cell. $\dagger$

It is possible that we have two groups of oxidizing catalyzers in the tissues: first, those of the type of peroxides which are possibly present in the protoplasm; and second, substances which can act indefinitely as oxidases, and are found in the nucleus. There are, indeed, a number

* Spitzer, Pfüger's Archiv, Vol. 67, p. 615, I897.

† Loeb, Zeitsch. für Entwickelungsmechanik, Vol. 8, p. 689, I899. 
of facts which seem to harmonize with the idea that the nucleus is the main oxidizing organ of the cell. Processes of regeneration demand oxygen. Nussbaum* has shown that if an Infusorian be cut in such a way as to divide it into two pieces, one containing the nucleus, and one without any nuclear matter, only the former is capable of regenerating the lost parts. The other piece lives but a comparatively short time and is not capable of regeneration; it dies under symptoms which are rather similar to death from lack of oxygen.

Ralph Lillie $\dagger$ tried to test the idea that the nucleus is the main oxidizing organ with the aid of staining substances which diffuse into the cell, and change color when they are oxidized. He worked with the cells of the blood, the liver, and the kidneys of frogs, and found that the oxidation seems to occur most rapidly in the nucleus and on its surface. He found, moreover, that the oxidations were most rapid in those organs and those regions of organs where the nuclei were densest.

It has been noticed that if cells containing chlorophyll are deprived of their nucleus, they keep alive longer if exposed to the light than if kept in the dark. This may be connected with the fact that in the light the chlorophyll is capable of liberating the oxygen from the $\mathrm{CO}_{2}$.

It is stated, as a rule, that the rôle of the oxygen is to supply the energy for the production of heat and of mechanical work, but it is evident that this statement does not take into consideration the fact that sessile plants, in which the loss of heat does not need to be compensated by a production of heat, and in which no energy is spent in mechanical motion, are in need of oxygen and possess oxidases. With the exception of a limited number of anaërobic bacteria, the statement can be made that oxidations and the presence of oxidases is a general characteristic of living matter. There are, however, other vital processes which are more general than those of locomotion and heat production, which also require oxygen, i.e. cell division and growth. Pasteur made the fundamental discovery $\ddagger$ that with lack of oxygen the yeast cells continue to produce lively fermentations of sugar, - in fact, Pasteur stated that their fermentative action is more energetic than in the presence of oxygen, - but that they grow and multiply very little or not at all. If, however, oxygen is added freely, the yeast cells multiply and grow considerably, provided the necessary nutritive salts are present. According to Hoppe-Seyler and Duclaux, the absence of oxygen favors the formation of the catalyzer for the alcoholic fermenta-

* M. Nussbaum, Arch. für mikroscop. Anatomie, Vol. 26, I886.

$\dagger$ Ralph Lillie, Am. Jour. Physiology, Vol. 7, p. 4I2, 1902.

$\ddagger$ Pasteur, Etudes sur la bière, Paris, 1876 . 
tion in the yeast cell, the zymase; * but we are here chiefly concerned with the fact which nobody has failed to confirm, that the presence of oxygen favors cell division and growth in yeast cells; that without oxygen these processes soon come to a standstill. The same is true for animals. I made a large number of experiments on the effects of lack of oxygen on the newly fertilized eggs of sea urchins and fishes (Fundulus and Ctenolabrus). $\dagger$ The eggs were kept in small Engelmann gas chambers through which a current of hydrogen was sent to drive out the oxygen and the $\mathrm{CO}_{2}$ formed by the eggs. In the eggs of sea urchins and Ctenolabrus, the segmentation stopped in less than an hour after the beginning of the current of hydrogen. When the air was again admitted, the eggs began to divide, provided they had not remained too long without oxygen. The eggs of Fundulus, also a marine fish, do not respond as quickly, inasmuch as it required about twelve hours before they stopped segmenting in the current of hydrogen. Similar results were obtained by Godlewski $\ddagger$ on the eggs of frogs. As far as growth and regeneration are concerned, I have found that without oxygen both are impossible in Hydroids (Tubularia). $\$$ In plants, conditions are the same; seeds require a comparatively abundant supply of oxygen for germination.\| The question arises, as to what connection exists between the oxidations in living tissues, and cell division and growth. We cannot answer this question as we do not know into which form of energy chemical energy must be transformed in order to produce cell division and growth. But another point may be settled. For the process of growth an increase in the quantity of living matter is required, and this requires synthetical processes. Schmiedeberg has called attention to the fact that oxygen is especially fitted to serve as a connecting link between organic radicals, and that through the intervention of oxygen a great many syntheses in the body may occur. He mentions, as an example, the combination in which sulphuric acid may appear in the urine. When a dog is fed with benzol, the benzol appears in the urine as benzolsulphate, provided that enough free oxygen is present. According to Schmiedeberg, this synthesis occurs in the following way:-

$$
2 \mathrm{SO}_{2} \mathrm{OH}+{ }_{2} \mathrm{C}_{6} \mathrm{H}_{6}+\mathrm{O}_{2}=2 \mathrm{SO}_{2}-\mathrm{O}-\mathrm{CH}_{6} \mathrm{H}_{5}+2 \mathrm{H} \mathrm{O} \text {. }
$$

* H. Buchner denies that lack of oxygen increases the rate of alcoholic fermentation by yeast, although the facts seem to speak in favor of Pasteur's statement. E. Buchner, H. Buchner, und M. Hahn, Die Zymasegärung, München und Berlin, 1903.

† Loeb, Pfïger's Archiv, Vol. 62, p. 249, I 895.

$\ddagger$ Godlewski, Zeits. fiir Entwickelungsmechanik, Vol. I1, p. 585, 1901.

$\$$ Loeb, Untersuchungen zur physiologischen Morphologie der Tiere, II, Würzburg, $189 \mathrm{I}$.

II M. Traube, Gesammelte Abhandlungen, p. 148. 
It is quite possible that the idea of Schmiedeberg will prove extremely fertile in further work in this direction.*

But even this addition does not exhaust the rôle of oxygen in life phenomena; there are indications which make it appear as though the oxygen acted as a protective substance. When respiration is interrupted for but a short time in mammals or birds, loss of consciousness, and very soon death, follow. Lack of oxygen therefore affects first the cerebral hemispheres, and especially the ganglion cells. The blood supply to the nerves is either lacking, or is so meager that we must conclude that the functions of the nerves require very little oxygen. The experience in drowning shows that lack of oxygen leads in a limited number of minutes to death. In the case of death through lack of oxygen, the respiratory ganglia evidently undergo irreversible changes, which make attempts at revival futile. The heart retains its irritability much longer than the respiratory ganglia. Kuliabko has recently shown that the heart of a child can be caused to beat, or to show fibrillary contractions, eighteen hours after death. $\dagger$ This shows that death was not due to the inability of the heart to resume its beat, but to the inability of the respiratory ganglia to work properly. It has often been observed in my laboratory that in dying larvæ of fish or frogs the respiration stopped sooner than the heartbeat. The irreversible changes which mark death occur with unequal rapidity in the various tissues of an animal.

When the egg of a Fundulus is kept in an atmosphere of pure hydrogen, segmentation comes to a standstill in about twelve hours, but permanent death occurs much later. The time required for permanent death to occur in the absence of oxygen is the longer the younger the egg. When eggs were deprived of oxygen immediately after fertilization, they remained alive in the absence of oxygen for three or four days (at a temperature of about $22^{\circ}$ ). When embryos of three days were exposed to the same condition, death occurred in about thirtyfour hours.

The higher the temperature the sooner lack of oxygen seems to cause death. I make this statement on the basis of casual observations, and I do not know whether or not any definite experiments exist on this point; should further investigation confirm this idea, it would seem to indicate that the changes in the tissues which cause death are produced by noxious substances formed in the absence of oxygen. Araki $\ddagger$ found that in the active muscle dextrose and lactic acid are found when the

* O. Schmiedeberg, Archiv fiir experiment. Pathologie und Pharmakologie, Vol. I4, pp. 288 and 379, $188 \mathrm{r}$.

$\dagger$ Kuliabko, Pfüger's Archiv, Vol. 97, p. 539, 1903.

¥ Araki, Zeitsch. für physiol. Chemie, Vol. 15, p. 335, 1891 . 
muscle works in lack of oxygen, while these substances are not found in the presence of abundant oxygen. They are probably formed in the latter case also; but if atmospheric oxygen is present, are immediately oxidized, while in the case of lack of oxygen they remain in the muscle. This may serve as an example of the fact that metabolism in the presence of abundant oxygen is different from that in lack of oxygen. Richet and Broca have shown that if an excised muscle is stimulated in the presence of oxygen until fatigue sets in, it will recover, but not if stimulated in the absence of oxygen. It stands to reason that in the latter case the recovery is prevented by noxious substances which would have been oxidized and rendered harmless in the presence of oxygen.

Bacteriology furnishes examples of the fact that in the case of lack of oxygen more virulent substances may be formed, or exist, than in the presence of atmospheric oxygen. Kastle quotes the statement that the toxin of the diphtheria bacillus is weakened under the influence of light in the presence of free oxygen, while the light has no such effect in the absence of oxygen. Pasteur observed that cultures of the anthrax bacillus and of chicken cholera become less poisonous when exposed to the air. Recent experiments by Kastle and Elvove* have shown that substances which have a high reducing power are especially toxic, and these authors are inclined to assume that many toxins belong to the group of reducing poisons.

The fact that lack of oxygen is capable of producing irreversible changes, and thus death, is rendered more easily comprehensible through the direct observation of physical changes of living matter under such conditions. I have made such observations in the segmenting egg of a teleost fish, Ctenolabrus. $\dagger$ When these eggs are deprived of oxygen at the time they reach the 8 or 16 cell stage, it can be noticed that the membranes of the blastomeres are transformed into small droplets within half an hour or more, according to the temperature. These droplets begin to flow together, forming larger drops. Figures $\mathrm{I}$ to 5 show the successive stages of this process. When the eggs are exposed to the air in time, segmentation can begin again; but if a slightly longer time is allowed to elapse, the process becomes irreversible and life becomes extinct. Such cleąr structural changes cannot be observed in the eggs of other animals under the same conditions. Are these changes of siructure (apparently liquefactions of solid elements) responsible for death under such conditions? In order to obtain an answer to this question, I investigated the effect of the lack of oxygen upon the heartbeat of the embryo of Ctenolabrus. The egg of this fish is perfectly trans-

* Kastle and Elvove, Am. Chem. Journal, Vol. 31, p. 195, I904.

† Loeb, Pfï̈ger's Archiv, Vol. 62, p. 249, 1895. 
parent and the heartbeat can easily be watched. When such eggs are put into an Engelmann gas chamber and a current of pure hydrogen is sent through, the heart may cease to beat in fifteen or twenty minutes; the heart stops beating suddenly before the number of heartbeats has diminished noticeably: it ceases beating before all the free oxygen may have had time to diffuse from the egg. In one case the heart beat ninety times per minute before the hydrogen was sent through; four minutes after the current of hydrogen had passed through the gas chamber, the rate of the heartbeat was eighty-seven per minute, three

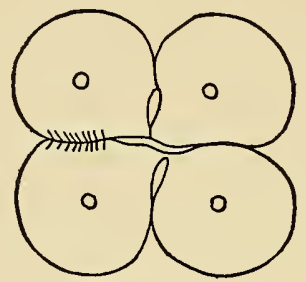

FIG. I.

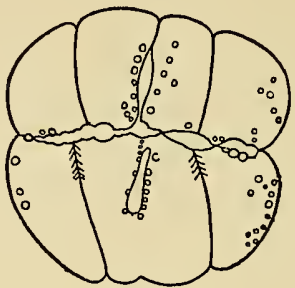

FIG. 2.

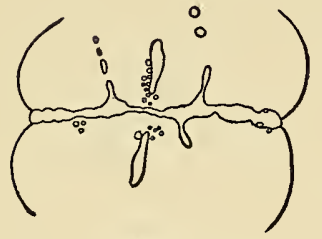

FIG. 3.

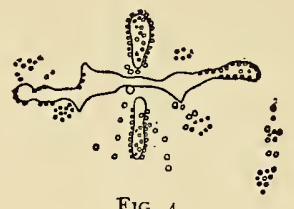

FIG. 4 .

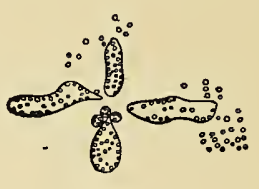

FIG. 5.

FIGS. I-5. Liquefaction of the cell walls of the egg of Ctenolabrus due to lack of oxygen. (From Nature.) The eggs were exposed to a current of hydrogen. The liquefaction of the cell walls and the formation of droplets began when the egg was in the 8 cell stage (Fig. 2). These droplets fuse into larger drops and finally nothing but these drops indicates the existence of the germinal disk. Figures 2, 3, and 4, are drawn in intervals of 15 minutes.

minutes later it was seventy-seven, and then the heart suddenly stopped beating. It is hard to believe that this standstill could have been caused by lack of energy. Hydrolytic processes alone could furnish sufficient energy to maintain the heartbeat for some time, even if all the oxygen had been used up. The suddenness of the standstill at the time when the rate had hardly diminished seems to correspond much more to a sudden collapse of the machine; it might be that liquefactions or some other change of structure occurs in the heart or its ganglion cells, comparable to that which we mentioned before. In another fish, Fundulus, where the cleavage cells undergo no visible changes in the case of lack of oxygen, the heart of the embryo can continue to beat for about twelve hours in a current of hydrogen. In this case the rate of the heartbeat sinks during the first hour in the hydrogen current 
from about one hundred to twenty or ten per minute: then it continues to beat at this rate for ten hours or more. In this case one might believe that during the period of steady diminution of the tension of oxygen in the heart (during the first hour), the heartbeat sinks steadily, while it keeps up at a low but steady rate as long as the energy for the beat is supplied solely by hydrolytic processes; but there is certainly no change in the physical structure of the cells noticeable in Fundulus, and consequently there is no sudden standstill of the heart.

Budgett has observed that in many Infusorians visible changes of structure occur in the case of lack of oxygen;* as a rule the membrane of the Infusorian bursts or breaks at one point, whereby the liquid contents flow out. Hardesty and I found that Paramœcium becomes more strongly vacuolized when deprived of oxygen, and at last bursts. Amœbæ likewise become vacuolized and burst under these conditions. Budgett found that a number of poisons, such as potassium cyanide, morphine, quinine, antipyrine, nicotine, and atropine, produce structural changes of the same character as those described for lack of oxygen. As far as $\mathrm{KCN}$ is concerned, Schoenbein had already observed that it retards the oxidation in the tissues, and Claude Bernard and Geppert confirmed this observation. For the alkaloids, W. S. Young has shown that they are capable of retarding certain processes of autoxidation. This accounts for the fact that the above-mentioned poisons produce changes similar to those observed in the case of lack of oxygen.

\section{The Production of $\mathrm{CO}_{2}$ through Enzymes}

It seems that organisms are pretty generally capable of producing $\mathrm{CO}_{2}$ from certain organic compounds, without the presence of free oxygen. The classical case of the production of $\mathrm{CO}_{2}$ through a process of cleavage is the alcoholic fermentation of sugar under the influence of yeast cells. In this case one molecule of dextrose is split into two molecules of $\mathrm{CO}_{2}$ and two of ethylalcohol. The process occurs in the absence of oxygen as well as in its presence, or, according to Pasteur, even better in the absence of oxygen than in its presence. The catalyzer in this case is an enzyme, the zymase, which Buchner succeeded in liberating from the yeast cell. This discovery is of special interest, as for years it was impossible to separate this enzyme from the cell. Pasteur even went so far as to maintain that the process of alcoholic fermentation was of an altogether different kind from that of the inversion of cane sugar, as the latter was due to an enzyme, soluble in water, which could easily be extracted from the cell; while this was not so in

\footnotetext{
* Budgett, Am. Jour. Physiology, Vol. I, p. 210, 1898.
} 
the case of the alcoholic fermentation. Buchner* showed that Pasteur $\dagger$ was mistaken, and that the only difference was a technical one, inasmuch as it requires a greater pressure to force the zymase out of the yeast cell than other enzymes, e.g. invertase. Through the discovery of Buchner, Biology was relieved of another fragment of mysticism. The splitting up of sugar into $\mathrm{CO}_{2}$ and alcohol is no more the effect of a "vital principle" than the splitting up of cane sugar by invertase. The history of this problem is instructive, as it warns us against considering problems as beyond our reach because they have not yet found their solution. The enzyme for the alcoholic fermentation of sugar is not confined to yeast, but seems to occur more generally. Thus Pasteur had already mentioned that certain kinds of fruit in the absence of air produced alcohol besides $\mathrm{CO}_{2}$; it is possible, however, that in fruits alcohol forms only an intermediary product which is oxidized further, or undergoes further changes, in the presence of oxygen, while it remains unaltered in the absence of oxygen. Godlewski and Polzeniusz demonstrated an alcoholic fermentation in seeds of plants which germinated in the absence of oxygen.t The fact that in these cases the alcoholic fermentation occurs only in the absence of oxygen seems to favor Pasteur's statement, that lack of oxygen increases the velocity of the fermentative action of yeast in the case of alcoholic fermentation.

Stoklasa $\S$ and his pupils showed that in a number of plants and germinating seeds $\mathrm{CO}_{2}$ and alcohol are formed in the absence of oxygen in the same proportion in which these substances appear in the alcoholic fermentation of sugar, and that just as much dry substance from the plants disappeared as corresponded to the sugar that was fermented. They succeeded in extracting from these plants (roots of sugar beets, potatoes, seeds of peas, seedlings of barley) an enzyme which acted like Buchner's zymase.

As far as animals are concerned, G. von Liebig had already shown that the muscles continue to produce $\mathrm{CO}_{2}$ in the absence of air, and that the production of $\mathrm{CO}_{2}$ is increased when the muscle becomes active. Hermann repeated these experiments, and made sure that the muscle continues to produce $\mathrm{CO}_{2}$, even if it does not contain any free oxygen which can be extracted in the vacuum. Inasmuch as glycogen disappears during activity, it looks as if the $\mathrm{CO}_{2}$ formed in the absence

* E. Buchner, H. Buchner, und M. Hahn, Die Zymasewirkung, München und Berlin, 1903.

† Pasteur, Etudes sur la bière, Paris, 1876. Annales de chimie et de physique, Vol. 58 , p. 323, 1860. See also Liebig, Ueber Gährung, über Quelle der Muskelkraft und Ernährung, Leipzig und Heidelberg, 1870.

$\ddagger$ Godlewski et Polzeniusz, Bulletin de l'Acad. de Cracovie, r 90 I.

$\S$ Stoklasa, IIofmeister's Beiträge zur chemischen Physiologie, Vol. 3, p. 460, 1902. Pfïger's Archiv, Vol. 101, p. 311 , 1904. 
of oxygen were produced from glycogen or sugar. If this be correct, a process must, under such conditions, occur which bears a certain resemblance to the alcoholic fermentation of sugar, although in the place of alcohol another product may be formed.

It was remarkable that in spite of these observations and the wellknown fact that the muscles are the main seat for the production of $\mathrm{CO}_{2}$, nobody was able to show that a muscle extract is able to decompose dextrose. This gap seems to have been filled recently by Cohnheim.* Von Mering and Minkowski had found that extirpation of the pancreas causes the most serious type of diabetes. This fact and subsequent discoveries suggested that the pancreas must secrete a substance into the blood, by which the oxidation or cleavage of sugar is accelerated. The place of the decomposition of the sugar must evidently be the muscles. Starting from these arguments, Cohnheim tested whether the muscle and the pancreas together do not contain a glycolytic power which neither contains alone. Cohnheim succeeded in showing that, by a process similar to that used by Buchner, liquids free from cells can be extracted from muscles and pancreas which, if mixed, cause dextrose, when added to the mixture, to disappear from it. The liquid extract from the muscle or the pancreas alone has no such action. "This observation may be analogous to the discovery of Pawlow, that the mucous membrane of the intestine secretes a substance, enterokinase, which activates the trypsinogen of the pancreatic juice, or to the observation made in the case of the hemolysins by Bordet and Ehrlich, that this process requires two different substances, - the so-called complement and Zwischenkoerper."

All these facts show that the production of $\mathrm{CO}_{2}$ in the body may occur without the presence of free oxygen, that these processes are evidently accelerated by special enzymes.

In regard to the energetics of these processes, it may be said that the energy which can be obtained by the complete oxidation of dextrose is about ten times as large as that which can be obtained from it by alcoholic fermentation. Bunge has calculated that it would not be possible for a man to do the average amount of muscular work at the expense of energy derived solely from the alcoholic fermentation of sugar. For this process the oxidation of dextrose is necessary, and therefore the presence of oxygen is required.

* O. Cohnheim, Hoppe-Seyler's Zeitsch. für physiol. Chemie, Vol. 39, p. 336, 1903. 


\section{Concerning the Theory of Enzyme Action}

\section{a. Stereochemical Attempts.}

Liebig expressed the idea that ferments or catalytic substances, in general, were bodies in a process of decomposition, and that their condition of motion was communicated to the fermentable body. Schoenbein, Pasteur, and Traube showed the untenability of this view by pointing out that platinum or the yeast cell cannot be well considered as bodies in a condition of rapid decomposition. To-day we do not value it so highly if an author tries to explain phenomena by vague statements concerning the vibration of atoms. Now and then an author still makes the statement that "life is motion," but as Driesch has pointed out, this statement is about as valuable as the information that the philosopher Kant was a vertebrate.

Certain observations by Pasteur and Emil Fischer seemed, for a time at least, to arouse the hope that the theory of enzymatic action might be found in the field of stereochemistry. Pasteur had observed in the beginning of his scientific career that while the right-handed tartaric acid is easily decomposed by fermentation, the same was not true for left-handed tartaric acid. Pasteur assumed that the geometrical shape of the tartaric acid molecules exercises an influence upon the fermentability of their solution. From the point of view of stereochemistry the forms of the right- and left-handed tartaric acid molecules show the same relation of symmetry as our right and left hand, or some asymmetrical object and its mirror image. It appears from Pasteur's biography that he expected important discoveries to be made concerning the nature of life from this relation between the form of the asymmetrical molecules and their biological effect. Pasteur's discovery found little consideration until it was taken up by E. Fischer.* He found that the alcoholic fermentation through yeast, e.g. Saccharomyces cerevisia, depends upon the molecular constitution and configuration of the various sugars. Saccharomyces cerevisia brings about an alcoholic fermentation only with triose and hexose, possibly also with nonose. Tetrose, pentose, heptose, and octose undergo no alcoholic fermentation with this form of yeast. It is evident that only those monosaccharides are fermentable by yeast which have three or a multiple of three atoms of carbon in the molecule. As far as the influence of the stereochemical configuration of the sugars and glucosides upon their fermentability is concerned, a similar relation as that found by Pasteur exists. Of the hexoses or hexaldoses there exist sixteen

* E. Fischer und Thierfelder, Berichte der deutsch. chem. Gesellsch., Vol. 27, pp. 2036 and 2985, 1894. Fischer, Zeitsch. für physiolog. Chemie, Vol. 26, p. 6o, 1898. 
stereoisomeres, of which, however, only three are fermentable by Saccharomyces cerevisice, namely, $d$-glucose, $d$-mannose, and $d$-galactose. The relation between fermentability and configuration will be rendered a little clearer by the following diagrams:-
$\begin{array}{llll}\mathrm{H} & \mathrm{H} & \mathrm{OH} & \mathrm{H}\end{array}$
I. $\mathrm{CH}_{2} \mathrm{OH} \underset{\mathrm{C}}{\mathrm{C}} \mathrm{C} \underset{\mathrm{C}}{\mathrm{C}} \mathrm{COH}$ d-glucose (fermentable) $\mathrm{OH} \mathrm{OH} \quad \mathrm{H} \mathrm{OH}$
2. $\mathrm{CH}_{2} \mathrm{OH} \underset{\mathrm{C}}{\mathrm{C}} \mathrm{C} \quad \mathrm{C}$ COH l-glucose(nonfermentable) $\mathrm{H} \quad \mathrm{H} \quad \mathrm{OH} \quad \mathrm{H}$
3. $\mathrm{CH}_{2} \mathrm{OH} \quad \mathrm{C} \quad \mathrm{C} \quad \mathrm{C} \quad \mathrm{C} \mathrm{COH} d$-mannose (fermentable) $\mathrm{OH} \mathrm{OH} \quad \mathrm{H} \quad \mathrm{H}$
4. $\mathrm{CH}_{2} \mathrm{OH} \stackrel{\mathrm{C}}{\mathrm{C}} \mathrm{C} \quad \mathrm{C} \mathrm{COH}$ l-mannose (nonfermentable) $\mathrm{H} \mathrm{H}$ OH OH
$\mathrm{H} \mathrm{OH} \mathrm{OH} \mathrm{H}$
5. $\mathrm{CH}_{2} \mathrm{OH} \quad \mathrm{C} \quad \mathrm{C} \quad \mathrm{C} \quad \mathrm{C} \quad \mathrm{COH}$ d-galactose (fermentable) $\mathrm{OH} \quad \mathrm{H} \quad \mathrm{H} \mathrm{OH}$ etc.

Fischer gave a metaphorical illustration of these facts which was taken rather literally by some biologists, and which has had a decided influence upon the formation of biological hypotheses. For this reason it may be mentioned here. "Inasmuch as the enzymes are in all probability proteins, and inasmuch as the latter are formed synthetically from carbohydrates, it is probable that their molecules also have a dissymmetrical structure, and one whose dissymmetry is, on the whole, comparable to that of hexoses. Only if enzyme and fermentable substance have a similar geometrical shape can the two molecules approach each other close enough for the production of a chemical reaction. Metaphorically we may say that enzyme and glucoside must fit into each other like key and lock."

Max Cremer* has expressed the idea that in all these cases in reality one and the same sugar undergoes alcoholic fermentation; namely, $d$-glucose. It is, indeed, not impossible that the alcoholic fermentation of $d$-mannose and $d$-galactose occurs in two stages, the first stage consisting in the transformation of these two substances into dextrose. This would be in harmony with the observations concerning the alcoholic fermentation of disaccharides, e.g. cane sugar, which must first be 
hydrolized into dextrose and lævulose by a special enzyme, namely, invertase. The dextrose and lævulose undergo alcoholic fermentation by zymase. It has indeed been shown by Lobry de Bruyn that $d$-mannose, $d$-galactose, and $d$-fructose can easily be transformed into dextrose. If this view is correct, the relation between stereochemical configuration and fermentability is only an apparent one.

b. The Theory of Intermediary Reactions.

The facts that the catalyzer is unaltered at the end of the reaction, and that apparently a small quantity of the enzyme can catalyze infinitely or comparatively large quantities of the fermentable substance, harmonize with the assumption of intermediary reactions. As an example of the theory of intermediary reactions of enzymes, the oxidation of sulphurous acid to sulphuric acid in the presence of nitric acid may be mentioned. Without the presence of nitric acid, sulphuric acid is oxidized but slowly; but in the presence of nitric acid the latter gives off oxygen to the sulphurous acid, and afterward takes up oxygen again. The intermediary processes seem to be rather complicated and are perhaps not fully known, but it seems that the successive transfer of oxygen from the nitric acid to the sulphurous acid and the reoxidation of nitrous acid to nitric acid occur with much greater velocity than the direct oxidation of sulphurous acid by free oxygen.

Inasmuch as the chemical nature of the enzymes is unknown, it is impossible to ascertain positively whether or not their efficiency is due to intermediary reactions. But there are inorganic catalyzers whose action resembles that of the enzymes, e.g. platinum and other metals, like iridium, osmium, silver, etc. We have already mentioned the fact that platinum acts like lipase in the hydrolysis of ethylbutyrate. The oxidation of alcohol to acetic acid is accelerated by Bacterium aceti as well as by platinum.* A striking analogy between the catalytic action of platinum and enzymes exists in regard to hydrogenperoxide. O. Loew has shown that there is a specific enzyme catalase, which is very general, and which accelerates the decomposition of $\mathrm{H}_{2} \mathrm{O}_{2}$. If this decomposition occurs in the presence of oxidizable substances, the latter, too, are often oxidized. As a rule the process is represented by the equation-

$$
\mathrm{H}_{2} \mathrm{O}_{2}=\mathrm{H}_{2} \mathrm{O}+\mathrm{O}
$$

The free atom of oxygen is said to be responsible for the oxidizing action of $\mathrm{H}_{2} \mathrm{O}_{2}$, although Kastle and Loevenhart have expressed a different view. $\dagger$ They quote a number of observations made by previous authors,

* Bredig enumerates these analogies in his interesting pamphlet on "Anorganischt Fermente," Leipzig, 1901.

$\dagger$ Kastle and Loevenhart, Am. Chem. Journal, Vol. 29, p. 563, I903. 
which indicate that $\mathrm{H}_{2} \mathrm{O}_{2}$ is capable of adding itself to a large number of compounds and forming bodies like the following: $\mathrm{B}_{2} \mathrm{O}_{2} \mathrm{H}_{2} \mathrm{O}_{2}$ or $\mathrm{K}_{2} \mathrm{O}_{2} 2 \mathrm{H}_{2} \mathrm{O}_{2}$. Jones and Carroll found that certain acids and salts show in water with solutions of $\mathrm{H}_{2} \mathrm{O}_{2}$ an abnormal depression of their freezing point. They conclude that in this case a combination between the molecules of the salts and the $\mathrm{H}_{2} \mathrm{O}_{2}$ is formed. From this and similar observations Kastle and Loevenhart draw the conclusion that those substances which like platinum accelerate the decomposition of $\mathrm{H}_{2} \mathrm{O}_{2}$, first combine with $\mathrm{H}_{2} \mathrm{O}_{2}$, and that this combination is unstable and rapidly falls apart into molecular oxygen, water, and the catalyzer, i.e. platinum. If this occurs in the presence of reducing bodies which do not act directly on $\mathrm{H}_{2} \mathrm{O}_{2}$, they may be oxidized in this process. The platinum may afterwards combine again with another molecule of $\mathrm{H}_{2} \mathrm{O}_{2}$, and the process be repeated.

These views find a nice confirmation through the investigation of the action of certain poisons like $\mathrm{HCN}$ on the decomposition of $\mathrm{H}_{2} \mathrm{O}_{2}$ by platinum or catalase. It is well known that $\mathrm{HCN}$ kills warm-blooded animals rather rapidly under the symptoms of lack of oxygen. Schoenbein had already shown that prussic acid inhibits the decomposition of $\mathrm{H}_{2} \mathrm{O}_{2}$ through animal tissues (or the catalase contained in them). Geppert showed that $\mathrm{HCN}$ prevents them from consuming the free oxygen, hence the animals die under symptoms of asphyxiation. HCN prevents also the decomposition of $\mathrm{H}_{2} \mathrm{O}_{2}$ through platinum. Bredig has continued the experiments of Schoenbein. As the velocity of the catalytic action of platinum must be in proportion to the surface of the metal, Bredig, in order to get a maximal surface, made colloidal solutions of platinum and other metals. He showed that extremely small doses of $\mathrm{HCN}$ are sufficient to prevent the catalytic action of colloidal platinum upon $\mathrm{H}_{2} \mathrm{O}_{2}$. Kastle and Loevenhart made it probable that this "toxic" effect of $\mathrm{HCN}$ upon the catalytic action of platinum upon $\mathrm{H}_{2} \mathrm{O}_{2}$ is determined by the fact that platinum forms an insoluble combination with $\mathrm{HCN}$. The formation of a film of this insoluble compound on the surface of the platinum prevents the latter from forming the unstable combination with $\mathrm{H}_{2} \mathrm{O}_{2}$ which must precede the decomposition of the latter. The reason why so little of the poison is required for this effect is due to the fact that the film which is formed on the surface of the metal may be infinitely thin. Kastle and Loevenhart were able to put their hypothesis to a test. Silver and thallium act much like platinum upon the hydrogenperoxide, inasmuch as both accelerate its decomposition. While silver forms a combination with $\mathrm{HCN}$ which is insoluble in water, thallium forms a soluble combination. Kastle and Loevenhart showed that while hydrocyanic acid inhibits the decomposition 
of $\mathrm{H}_{2} \mathrm{O}_{2}$ by silver, the catalytic action of thallium upon $\mathrm{H}_{2} \mathrm{O}_{2}$ is not diminished by HCN.*

The same authors could show, in general, that the anions of those salts which form insoluble compounds with the metal diminish also the catalytic action of this metal, while the same salts have no inhibiting effect if the catalyzer is a metal which forms soluble compounds with the anion of the salt.

Kastle and Loevenhart found that certain salts accelerate the action of platinum on the decomposition of hydrogenperoxide. They are inclined to assume that this class of salts acts directly upon the $\mathrm{H}_{2} \mathrm{O}_{2}$, and not upon the catalyzer.

Everything seems to indicate that the enzymes accelerate the reactions in the body by forming intermediary, unstable combinations with the bodies whose reactions they accelerate. These unstable compounds are rapidly decomposed, and this makes the catalyzer free to repeat the action. This makes it clear that a small quantity of the catalyzer can decompose indefinite quantities of the substance. The fact that many enzymes act specifically also harmonizes well with this view. The enzymes, being themselves organic compounds of a complex character, will not form unstable compounds equally well with any organic compound.

Inasmuch as the enzymes are necessary for the chemical processes in living matter, the formation of enzymes is one of the essential functions living matter has to perform. Spitzer and Friedenthal were inclined to assume that the nucleo-proteids act as enzymes. This view, while possible, is not yet proven.

* Kastle and Loevenhart, Am. Chem. Journal, Vol. 29, p. 397, 1903. 


\section{LECTURE III}

\section{THE GENERAL PHYSICAL CONSTITUTION OF LIVING MATTER}

\section{The Limits of Divisibility of Living Matter}

THE preceding lecture has shown that living matter is a mixture of various compounds, namely proteins, fats, carbohydrates, and salts. The fact that the reaction velocity for a number of oxidative and hydrolytic processes is so great, in spite of the low temperature and the practically neutral reaction of the tissues, has found its explanation through the presence of specific enzymes and the intermediary reactions determined by them. If we ask whether it would suffice for the purpose of making living matter to try to find a mixture of the above-mentioned substances, including the enzymes, the answer would have to be no, for the reason that living matter is characterized by another peculiarity not yet mentioned, namely, a definite structure.

Whatever may be the physical structure of living matter, it is certain that in most cases its complete destruction means the cessation of life phenomena. A brain or kidney which has been ground to a pulp is no longer able to perform its functions; yet it is evident from the facts mentioned in the previous lecture that certain chemical functions can still be performed by such pulps, e.g. the catalytic processes. The question now arises as to how far the divisibility of living matter can be carried without interfering with its functions. Are the smallest particles of living matter which still exhibit all its functions of the order of magnitude of molecules and atoms, or are they of a different order? The first step toward an answer to this question was accomplished by Moritz Nussbaum,* who found that if an Infusorian be divided into two pieces, one with and one without a nucleus, only the latter will continue to live and perform all the functions of self-preservation and development which are characteristic of living organisms. This shows that not only more than two definite substances, but two different structural elements, are needed for life. We can understand partly from this why an organ after being reduced to a pulp, in which the differentia- 
tion into nucleus and protoplasm is definitely and permanently lost, is unable to accomplish its functions.*

The observations of Nussbaum and those who repeated his experiments showed that although two different structures are required, not the whole mass of an Infusorian is needed to maintain its life. I tried to solve the question as to how small a fraction of the original cell must be preserved in order to maintain life in the sense of the definition given at the beginning of these lectures. Will the smallest possible element be of the order of an aggregate of a few molecules, or will it be of the order of a small fraction of the original mass? I tried to decide this question in the egg of the sea urchin, immediately after its fertilization. The egg divides and reaches successive larval stages, first a blastula, then a gastrula, and finally a pluteus stage. Without especial efforts the eggs cannot be raised beyond this stage in the laboratory. I had found a simple. method by which the unsegmented eggs of the sea urchin (Arbacia) can easily be divided into smaller fragments. When the egg is brought from five to ten minutes after fertilization (long before the first segmentation occurs) into sea water which has been diluted by the addition of an equal part of distilled water, the egg takes up water and the membrane bursts. Part of the protoplasm then flows out, in one egg more, in another less. If these eggs are afterward brought back into normal sea water those fragments which contain a nucleus begin to divide and develop. $t$ In this case the degree of development such a fragment reaches, is clearly a function of its mass; the smaller the piece, the sooner on the whole its development ceases. The smallest fragment which is capable of reaching the pluteus stage possesses the mass of about one eighth of the whole egg. Boveri has since stated that it was about one twenty-seventh of the whole mass. Inasmuch as only the linear dimensions are directly measurable, a slight difference in measurement will cause a great discrepancy in the calculation of the mass.

These results are in harmony with experiments made by Driesch $\ddagger$ for a different purpose. Driesch isolated the first blastomeres of the segmented egg of a sea urchin by shaking the egg and thus bursting its membrane. He found that an isolated cell of the two- or four-cell stage of the egg of a sea urchin is still capable of developing into a normal pluteus, but that an isolated blastomere of the eight- or sixteencell stage no longer possesses this power. This experiment, however,

* It must not be overlooked that in bacteria and the blue algæ no distinct differentiation into nucleus and protoplasm can be shown. To these organisms, therefore, the experiments of Nussbaum cannot be applied.

$\dagger$ Loeb, Pfï̈ger's Archiv, Vol. 55, p. 525, 1893.

$\ddagger$ Driesch, Zeitsch. für wissenschaftlische Zoologie, Vol. 53, I891. . 
cannot be used as an unequivocal answer to our question, inasmuch as the possibility exists that in later stages of segmentation the different cells undergo different chemical changes, whereby they no longer remain equal in quality.

If we raise the question why such a limit exists in regard to the divisibility of living matter, the answer is possibly given by Boveri's observation that the unsegmented egg of the sea urchin (Strongylocentrotus lividus) possesses three different layers.* It is possible that these three layers contain chemically different material, and that only those fragments of an egg are capable of development which contain material of each of the three layers. If this be correct, it will certainly not suffice to mix the chemical constituents of the egg in order to produce the phenomena of development; but we must provide for a definite arrangement or structure of this material. We shall see later on that this structure may be very simple and capable of

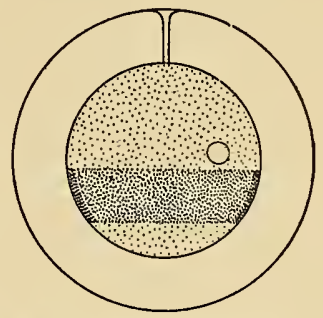

FIG. 6. - AFTER BOVERI.

Structure of the unfertilized egg of a sea urchin. The contents of the egg are divided into three distinct layers. a physicochemical definition. The limits of divisibility seem therefore to depend upon the physical structure of the cells or organs. These limits vary for different organisms and cells. The smallest piece of a sea-urchin egg that can reach the pluteus stage is still visible with the naked eye, and is therefore considerably larger than bacteria or many algæ, which also may be capable of division.

\section{Foam Structures and Emulsions}

Living matter seen through the microscope invariably offers the same characteristic appearance which has caused biologists to designate it with one general term; namely, protoplasm. Yet the common physical features of living "protoplasm" are still a matter of controversy. Some authors maintain that the protoplasm is a network of fine fibers, while others say, and apparently justly, that the network does not occur in living protoplasm, but is caused by the coagulation of the colloids contained in the cells and liquids of the tissues. It is a fact that the proteins which are dissolved in the living body are precipitated by the fixing reagents of the histologists, and when they are precipitated they form net structures which do not exist during life when the proteins are held in solution. $\dagger$

* Boveri, Die Polarität des Seeigeleies. Verhandl. der physik.-med. Gesellsch., Würzburg, Vol. 34, rgor. 
Bütschli * has expressed a view concerning the structure of living protoplasm which is more probably correct than the assumption of the net structure. According to him, living protoplasm has the structure of a microscopic emulsion. His view is shared by E. B. Wilson and other authors, while it is accepted, but not unconditionally, by Hardy and Pauli. Bütschli's conception, however, seems to harmonize with a great many facts, and therefore we may discuss some features of the theory of emulsions. Emulsion and foam are, according to Quincke, only different names for the same (diphasic) physical system. An emulsion like milk consists of a large number of spherical droplets of fat, which are distributed in a watery liquid. $\dagger$ We speak of a foam in the case of an emulsion of a gas in a liquid. The foam in a soap solution consists of spherical masses of air which are distributed in a watery liquid. Foams and emulsions have therefore the same physical structure. The peculiarity of emulsions and foams which interests us in this connection is their durability, and the theory of foams is concerned with this side of the problem. According to Lord Rayleigh, an absolutely pure liquid cannot form a durable foam.t When a gas bubble rises in pure water it is surrounded by a liquid film which, however, does not possess any durability, and therefore bursts. If, however, the water is contaminated by another substance, these liquid films become more durable. This influence upon the durability varies with the nature of the contaminating substance. It is known that the addition of small quantities of colloidal material, e.g. soap, saponin, a solution of gelatine, is capable of making the liquid films very durable.

This influence of the contamination is due to its effect upon surface tension. Experiments have shown that those substances which make these liquid films more durable decrease the surface tension which exists at the limit between water and the emulsified substance. In consequence of this latter fact, these substances have a tendency to collect at the common surface between water and air, or whatever the emulsified substance may be. The surface acts like a trap on such particles, inasmuch as it requires an outside force to bring them back to the interior, if they have once collected at the surface. $\$$ The consequence is that a film of this contaminating material is formed at the surface, between the water and the oil droplets, or whatever the substance held in emulsion may be. In the case of oil emulsions in water, the contaminating substance is a trace of soap formed through the hydrolysis of fat 1892.

* Bütschli, Untersuchungen über microscopische Schäume und das Protoplasma, Leipzig,

$\dagger$ Quincke, Pfïger's Archiv, Vol, 19, p. I 29, 1879.

† Lord Rayleigh, Scientific Papers, Vol. 3, p. 35 I, 1902.

§ F. G. Donnan, Zeitsch. für physikal. Chemie, Vol. 3I, p. 42, 1899. 
or oil. Soap solution diminishes the surface tension between water and oil. The question arises as to how this circumstance can make the emulsion more durable. The answer is as follows: If a film of water separates two oil drops, the soap particles gather at the surface on either side of the water film. If these soap particles be now brushed aside on one spot of this watery film, the water will come in direct contact with the oil. The surface tension between oil and water is greater than that between soap solution and water. Hence, in a spot where the soap is removed the surface tension or tendency to contract will be greater than in the rest of the film, and the consequence will be that this spot will contract and thus mend the hole in the layer of soap. In this way the diminution of the surface tension by the contaminating substance makes the emulsion more durable, and prevents the fusion of two neighboring droplets in an emulsion. It is not impossible that the existence of such a film may explain why it is that the cleavage cells of an egg do not easily fuse.

As far as the thickness of the contaminating layer is concerned, Lord Rayleigh has measured it, and found that the contaminating layer of oil on the surface of water which suffices to prevent the motion of particles of camphor on the surface of water, need be only $\overline{150} \frac{1}{0000}$ $\mathrm{mm}$. thick. It is hardly necessary to mention that such a film is far below the limits of microscopic visibility.

Bütschli assumes that living protoplasm is an emulsion of two liquids: a viscous one, which is insoluble in water; and a watery liquid, which possesses little viscosity.*

\section{The Colloidal Character of Living Matter}

Hardy as well as Bütschli assumes that living matter is essentially liquid. The most common observations on living organisms, which are sufficiently transparent, show that this is undoubtedly true for a large part of the material contained in such organisms. Certain elements, however, are apparently solid, e.g. the surface films of cells and nuclei, and possibly certain structures in the interior of the cell, such as centrosomes. The observations of Traube, as well as Hardy, show how solid constituents can be formed from liquids in living matter. We are dealing here with a chapter of the physics of colloids, which is just at present the object of many investigations.

The substances in living matter which occur in a liquid as well as in a solid condition are the colloids. The name was given by Graham, who discriminated between two kinds of soluble substances, - crystal- 
loids and colloids. The former diffuse easily through animal membranes, the latter only with difficulty, or not at all. It is, however, well to remember that there exist transitions between both groups. According to Krafft,* the colloidal character of sodium soaps increases with the size of the acid molecule. Thus sodium acetate possesses the qualities of a crystalloid in a watery solution, while sodium stearate belongs to the colloids. The proteids, certain carbohydrates like starch or glycogen, and higher fats, belong to the colloids; while their products of cleavage, e.g. dextrose, may belong to the crystalloids. According to Krafft, there is therefore a steady transition from the crystalloids to the colloids. $\dagger$

In physical chemistry, as a rule, a different idea of the colloidal solution is given, i.e. that they are no real solutions, but suspensions of small particles in a liquid, or a system of two phases. We have already mentioned the fact that not only organic substances may form colloidal solutions, but also many inorganic substances, and even pure metals, such as platinum, gold, silver, etc. All these colloidal substances alter the freezing point or boiling point of the liquid not at all or but little. From this the conclusion is drawn that no work, or but little, is required to separate the solvent from the dissolved colloidal particles. It must, however, be stated that according to some authors the proteins dissolved in the blood serum have a definite osmotic pressure which is far from being a "quantité négligeable." Starling $\ddagger$ found by a direct measurement - the freezing-point determinations fail in such cases - an osmotic pressure of the colloids of as much as 30 to $40 \mathrm{~mm}$. of mercury. This pressure plays, according to Starling, a definite and important rôle in phenomena of lymph formation, œdema, etc. In view of Starling's observations it is doubtful whether we still have a right to maintain that colloidal solutions behave like suspensions, inasmuch as the latter differ from real solutions through the fact that they possess no measurable osmotic pressure. $\$$

A second argument in favor of a principal difference between colloidal and crystalloidal solutions lies in the fact that dissolved particles in a colloidal solution have, as a rule, a definite electrical charge. The same is often found in the particles which form suspensions in water. The existence of the electrical charge can be demonstrated if an

* Krafft, Zeitsch. für physiologische Chemie, Vol. 35, pp. 364 and 376, 1902.

$\dagger$ This idea receives still further support from the fact that if a salt solution is exposed to the action of a centrifuge, the concentration at the periphery becomes larger than at the center.

† Starling, Jour. of Physiology, Vol. 19, p. 312, I 895.

$\S$ More recently Reid has reached the conclusion that the colloids in Starling's experiments were not free from salts, and that he in reality measured the osmotic pressure of the latter. 
electrical current be sent through a colloidal solution; in this case, the particles move in the direction of the negative or positive current, according to the chemical character of the colloid. This charge of the colloidal particles is generally held to be due to the formation of a double layer of electricity at the surface, between particle and water. A similar explanation was given to the charge of particles suspended in water; and this is considered another argument in favor of the idea, that colloidal solutions are diphasic systems. It is, however, possible, as Freundlich * has already mentioned, that the charges of the colloidal particles are due to the electrolytic dissociation of the latter. It had generally been noticed that the colloids of an acid character are negatively charged when in solution, while colloids of an alkaline character are positively charged. This is exactly what should be expected if the charges of the colloidal particles in solution are due to electrolytic dissociation. If the colloid is an acid, it will dissociate into one or more positively charged hydrogen-ions and a negatively charged colloid-ion; if the colloid is an alkali, it will dissociate into one or more negatively charged hydroxyl-ions and a positively charged colloid-ion.

Hardy $\dagger$ has shown that dialyzed white of egg (from the white of a hen's egg) is electro-positive when a trace of acid is added, while a trace of alkali makes it electro-negative. He believes that in the former case, the hydrogen-ions are caught in the meshes of the colloidal particles of the white of egg and carry the latter with them when they migrate in an electrical field. When alkali is added, the hydroxylions are caught in the meshes of the particles and drag the latter with them in an electrical field. I have called attention $\ddagger$ to the fact that Hardy's observations allow of a different interpretation, namely, that they may be due to the electrolytic dissociation of the white of egg. The proteins have an amphoteric character, i.e. they are able to give off $\mathrm{HO}$-ions, as well as $\mathrm{H}$-ions, to the surrounding solution. If we add a trace of acid to the solution of dialyzed white of egg, the degree of dissociation of the acid part of the molecule is diminished, and it will dissociate chiefly into $\mathrm{HO}$-ions and a colloid cation, and the latter will migrate in an electrical field to the cathode. If a trace of alkali, however, is added to the surrounding solution, for the same reason, the white of egg will be prevented from sending as many HO-ions into solution as $\mathrm{H}$-ions, and the molecule will dissociate mainly into $\mathrm{H}$-ions and a colloid anion. Hence, the addition of a trace of acid will give

* Freundlich, Zeitsch. für physikal. Chemie, Vol, 44, 1903.

$\dagger$ Hardy, Proceedings of the Royal Society, Vol. 66, p. I I0, I90I.

$\ddagger$ Loeb, University of California Publications, Vol. I, p. I49, I904. 
the colloidal particles a more positive charge, while a trace of alkali will give them a more negative charge.

Hardy was the first to call attention to the fact that the electrical charge of the colloidal particles -- or, in his opinion, the difference of potential between the particles and the surrounding solution - is a prerequisite for the stability of many colloidal solutions.* If in these solutions the charges are removed from the particles, a precipitation occurs through the clumping together of the small colloidal particles to larger aggregates and the falling of these aggregates. Hardy proved this in two ways: first, by carefully neutralizing acid white of egg with $\mathrm{NaHO}$, until the particles no longer migrated with the positive or negative electric current. As soon as this occurred, a slight mechanical agitation of the particles was sufficient to produce a precipitation of the white of egg. The second proof consisted in showing that when a constant current is sent through the solution, the particles that are carried to the electrode are precipitated. At the pole the particles lose their charge and become isoelectric with the surrounding water. It is, however, not impossible that acid or alkaline white of egg is soluble, while the neutral white of egg is insoluble, or less soluble, in water.

It had been known for a long time that water which was rendered opaque through a suspension of small particles could be made clear if salts were added to the suspension. A similar experience had been made in connection with the precipitation of colloidal particles. It was further known that the precipitating power of various electrolytes is a function of only one of the two ions, - mostly the cation, and that it increases with the valency of the active kind of ions. The fact that Freundlich found in experiments with a sol of arsenic sulphide, whose particles have a negative charge, that the precipitating force of salts with a bivalent cation was about seventy times as large as that of salts with a univalent cation, while salts with a trivalent metal possessed a precipitating force five hundred times as large as that of a univalent cation, may serve as an example. Hardy added the important fact that in the case of sols with negatively charged particles, the precipitation is due to the cations; while in the case of positive colloids the precipitation is caused by the anions of the precipitating salt. Hardy states that the precipitating power of an ion is an exponential function of its valency. $\uparrow$ Freundlich, however, has shown clearly that where the cation of a salt causes the precipitation, the anion is not without some effect. It seems quite possible that the facts found by Hardy indicate a purely chemical action of the precipitating salt.

* Hardy, loc. cit. † Hardy, Jour. of Physiology, Vol. 24, p. 288, 1899. 
A negatively charged colloid can form salts with metals; and it is in harmony with the general facts concerning the solubility of salts, that the latter decreases with the valency of the ion with which the colloid combines. Hardy, Bredig, and many other authors believe, however, that in this case the ions act only through their electric charges. Hardy has recently found that electro-negative globulin solutions are rapidly precipitated by the positive electrons sent out by radium.* It is possible that the radiation, in this case, causes a precipitation only indirectly, while its direct action is a chemical change in the globulin solution.

If we accept the view of Hardy and Bredig, that we are dealing in the action of sols with an effect of an electrical charge of the ions, we shall do well to adopt Bredig's $\dagger$ explanation of this effect. The surface tension at the limit of two media reaches a maximum, when the difference of potential between the two media becomes a minimum. This is due to the fact that the electrical charges are antagonistic to the surface tension. The higher the surface tension between colloidal particle and surrounding liquid, the easier will the slightest agitation cause a clumping of the smaller particles into larger aggregates. Those who hold this view have thus far not yet shown how it. happens that the valency of an ion has so great an effect upon the precipitation of the colloidal particles, although each precipitating salt carries equal quantities of positive and negative charges into the solution.

Not all the colloidal solutions show cataphoresis. Hardy mentions that globulins which are held in solution by salts do not migrate when a constant current passes through them.

Life depends upon the existence of these colloidal solutions in the cells. All agencies which bring about a general gelation, bring life to a standstill; and such a standstill is permanent in case irreversible gels are formed, such as originate if proteins are heated. The liquid proteins of our body coagulate at a comparatively low temperature, and this is the reason that at a temperature of about $45^{\circ}$ the cells of our body die very rapidly. The heavy metals also transform the proteins of our body into irreversible gels, and this may be a reason why they are so poisonous. There are, however, conditions in which the transformation of sols into gels does not lead to death, but to the formation of important morphological structures, e.g. Traube's membranes of precipitation. The astrospheres also originate, according to the botanist, Alfred Fischer, through a process of coagulation. It is, moreover, possible that a series of manifestations of life in cell- 
division and protoplasmic motion, rhythmic contractions, etc., depend upon alternating gelations and liquefactions. It is, however, useless to discuss such possibilities until more definite proofs of their real existence have been furnished. Such proofs thus far exist only in regard to membranes of precipitation.

\section{The Formation of Surface Films and Traube's Membranes of Precipitation}

It is a general rule that every free cell is surrounded by a solid film. The pseudopodia of many Infusorians could not exist were they entirely liquid. Liquid circular cylinders begin to fall apart into droplets as soon as their height becomes greater than the periphery of their base. The length of the pseudopodia of rhizopods is, however, very often a multiple of their circumference. As the interior of the pseudopodia shows phenomena of streaming, the solid part of the pseudopodia can only be at their surface. Such solid surface films may be exceedingly thin, according to Quincke's observations.

Ramsden has recently shown why masses of protoplasm must form solid films at their surface. He had formerly observed that the white of a hen's egg can be caused to coagulatè by mere mechanical agitation.* The explanation of this fact was subsequently found in the further observation, that without any evaporation at the free surface of the protein solutions, solid or extremely viscous films are formed very rapidly. $\dagger$ If such solid particles be removed from the surface, i.e. by mechanical agitation, new particles will come to the surface and form membranes. This is in harmony with what was stated earlier in regard to the gathering of contaminating particles at the surface between two media.

What has been said here with reference to the formation of solid films at the surface of free cells, may also hold with regard to the formation of solid films at the surface of nuclei.

Traube has shown that where two liquid colloids come in contact, solid membranes may be formed. He investigated the mechanism of the formation of the membranes of plant cells and was led to the conclusion that the formation of these membranes, and the peculiarity of the cell to grow, depend upon a simple physical process. Certain colloids form a precipitate where they come in contact with each other, and this precipitate is impermeable for either colloid. The precipitate must therefore assume the shape of a thin film, which prevents the

* Ramsden, Archiv fiir Anatomie und Physiologie, Physiologische Abteilung, p. 51 7, 1894. $\dagger$ Ramsden, Zeitsch. für physik. Chemie, Vol. 47, p. 336, 1904. 
further action of the two colloids upon each other. He called this film the membrane of precipitation.* The following example may be quoted: "A solution of a certain gelatine - $\beta$-gelatine - was prepared, and a drop taken out of this solution with a glass rod. The drop remained hanging at the end of the rod, and was exposed to the air for several hours; it was then dipped in a 5 per cent solution of tannic acid. In about ten minutes a thin iridescent solid film formed at the surface of the drop. The $\beta$-gelatine and the tannic acid had formed a membrane of precipitation at the common surface, which was impermeable for both colloids and thus prevented any further reaction between the two." But it is not necessary for the formation of membranes of precipitation that two colloids act upon each other. A crystalloid and a colloid may form a membrane of precipitation, as is the case when a drop of tannic acid is dipped into a neutral solution of lead acetate. Two crystalloids can also form such membranes if they only form an amorphous precipitate which is impermeable for both crystalloids, e.g. ferrocyanide of potassium and ferric chloride. While these membranes are impermeable for certain substances, they are not so for others; and Traube recognized the fundamental importance of this fact for life phenomena, "The cell membrane $\dagger$ makes a diminutive chemical factory of the contents of this cell by shutting it off from its surroundings, and enables each cell to lead a specifically different life from the neighboring cells." The substances which can permeate the membranes of precipitation vary according to the nature of the latter. All of them allow water to pass through; while they do not allow sugar or salts to pass through at all or not equally well. Traube pointed out that this semipermeability also explains the mechanism of cell growth. When the drop of $\beta$-gelatine (or any other substance used for the experiment) had a greater concentration than the solution into which it was dipped, the drop began to grow in size as soon as the membrane of precipitation was formed. Traube thus became the originator of the modern theory of the growth of cells, which assumes that the growth is caused by the cell absorbing water in consequence of its osmotic pressure being higher than that of the surrounding solution.

Traube was inclined to explain the semipermeability of his artificial membranes on the basis of the assumption that they possess very small pores or interstices which allowed only small molecules, such as water, to permeate; while the larger molecules, such as salts, could not pass through them. This assumption was no longer tenable after

* M. Traube, Reichert's und Du Bois Reymond's Archiv, 1867. Gesammelte Abhandlungen, p. 213, Berlin, 1899 .

$\uparrow$ We should now say, the surface film of protoplasm. 
Overton found that the alcohols, even those having large molecules, could pass into the cells much more readily than the salts with smaller molecules. Nernst had given another theory of semipermeability which is generally accepted; namely, that the substances which go through the semipermeable walls must first be dissolved in this membrane, and that therefore such substances must be absorbed most rapidly by these cells as are most soluble in the cell walls, or surface films of the cells. Overton * found that plant and animal cells which show the properties of semipermeability are generally most permeable for those substances which are most soluble in oil or fat, e.g. alcohol, ether, chloroform. He accepts Nernst's theory and draws the conclusion that the cells, or the protoplasm of the cells, are surrounded by a film of a fatty substance, such as lecithin or cholesterin, and that these substances give protoplasm the quality of semipermeability.

A similar conclusion had already been drawn by Quincke, who had noticed that protoplasm assumes a spherical shape when squeezed out of its cell into a watery liquid. This, he said, was only intelligible when protoplasm is surrounded by a film of oil or fat. $\dagger$ Quincke also pointed out that such films of oil must show the phenomenon of semipermeability.

Hans Meyer and Overton $\ddagger$ have noticed independently of each other that all narcotics have one property in common; namely, a comparatively great solubility in fat, or lipoids like lecithin or cholesterin. The special importance of this lies in the fact that the narcotic effect of a substance increases, on the whole, with the degree of its solubility in fat. They are inclined to believe that the chemical nature of the narcotic is otherwise of no or only minor importance, as they find that chemically inactive bodies may be very powerful narcotics, if only their solubility in oil is comparatively high. It seems to me, however, that in view of the presence of so many enzymes in our cells, substances may be very active in our body, which in the absence of such enzymes may appear rather inert. This does not, however, contradict the fact that the solubility of narcotics in fat plays a rôle in the absorption of narcotics. Those cells in our body which are richest in lipoids, namely, the ganglionic cells, also feel first the effects of narcotics.

Meyer and Overton assume that the narcotics, such as alcohol, ether, etc., act merely by altering the physical properties of the cells in whose lipoids they dissolve. The fact that anæsthetics like ether and chloroform dissolve fat was utilized for an explanation of their

* Overton, Vierteljahreschrift der naturforschenden Gesellsch. in Zïrich, Vol. 44, p. 88, 1899. (The original was not accessible to me.)

† Quincke, Sitzungsberichte der Berliner Akademie der Wissenschaften, p. 791, 1888.

‡ Overton, Studien ï̈ber die Narcose, Jena, I90I. 
physiological action immediately after the discovery of this action. At that time the various authors, e.g. von Biebra and Harless, explained the action of ether and chloroform on the assumption that these substances caused the fat to leave the cells by dissolving it. This does not seem to harmonize with the fact that a person so soon recovers from the effects of a narcosis. Overton showed, moreover, that ciliary cells, when narcotized in water by ether or chloroform, may resume their activity when brought back into pure water. This would not be possible if the narcotic effect of ether or chloroform had been due to the diffusing of fats from the cell; but the fact that a person can recover from the action of narcotics does not prove that their action is a purely physical one. A person who becomes unconscious from the lack of oxygen may also recover, if oxygen is admitted again; soon enough, and yet no one would conclude from this that the action of oxygen is purely physical. The rapidity of the absorption of narcotics may be due to their solubility in oil, and yet the effect they produce may be due to something entirely different.

\section{Osmotic Pressure and the Exchange of Liquids Between the Cells ANd the Surrounding Liquid}

The observations of Traube, Quincke, Ramsden, and Overton have given us some hints as to the nature of the surface films which surround protoplasm. Their importance lies in the fact that the contents of the cells are chiefly liquid, and that an exchange of dissolved substances occurs steadily between these substances and their surroundings. Animal cells are surrounded by a liquid which resembles sea water in its constitution, though its osmotic pressure is in land and fresh-water animals, and in some marine animals, less than that of sea water. The main force for the exchange of dissolved substances between the cells and the surrounding solution is the osmotic pressure. Inasmuch as the cells take up the salts, proteins, fats, and carbohydrates that are dissolved in the blood, we cannot accept Overton's view that only water and those substances which are soluble in fat pass through the membranes, and that salts generally cannot pass through. We hold that the cell walls are not impermeable to salts, and that there is only a difference in the rate of diffusion of the various substances, many salts diffusing only very slowly into the protoplasm. The consequence is that for short experiments the cells act as if they were impermeable for salts and permeable for water only. When cells are put into salt or sugar solutions, whose osmotic pressure is higher than that of the liquid of the cells, the cell loses water; and in the case of 
most plant cells a condition ultimately arises in which the protoplasm becomes separated from the cellulose wall, the so-called plasmolysis. Nevertheless it cannot be said that plant cells are impermeable for salts, inasmuch as the building up of the living matter of the plant depends upon the diffusion of certain salts from the soil into the plant, e.g. nitrates, phosphates, sulphates, potassium salts, etc. For the animal cell this can be demonstrated still more strikingly. The common striped muscle of the heart loses its excitability rather rapidly when put into a physiological salt solution to which a certain (but not too small) amount of $\mathrm{KCl}$ is added; but if the muscle is taken out in time and put back into a pure $\mathrm{NaCl}$ solution, its excitability returns. The velocity with which the inhibiting effect of the potassium salts upon the irritability occurs, depends upon the concentration of the potassium salts in this solution; it is therefore certain that the potassium salts diffuse comparatively rapidly into the muscle and out of it. The same can be shown for $\mathrm{Na}, \mathrm{Ca}$, and many other, if not all salts. When the muscle is put into an isotonic solution of any sodium salt, rhythmical contractions begin, and the sooner the higher the concentration of the sodium salts. The same is true for solutions of barium salts. The velocity with which the sodium salts produce these twitchings varies with the nature of the anion of the salt. If to the solution of the sodium salt a small but definite quantity of a calcium salt be added, these contractions are suppressed. These facts are only conceivable if we assume that muscle cells are permeable for $\mathrm{Na}, \mathrm{Ca}$, and $\mathrm{Ba}$ salts, or ions. They must, however, be permeable for other salts also, e.g. Li, Cs, and Rd salts, as they begin to twitch in these solutions.* The more toxic salts, e.g. those of the heavy metals, must also be able to diffuse into the cells, as otherwise they could not be so toxic.

The salts diffuse more slowly into the muscle than water. If muscles be put into salt solutions of various concentrations, it will be observed that during the first hour or hours, the muscle absorbs water and swells in hypotonic solutions, while it loses water in hypertonic solutions. This phenomenon is, in wide limits, independent of the nature of the salt in solution. $t$ If the muscle remains longer in the solution, however, the influence of the osmotic pressure diminishes, and the specific effects of the salt appear. I found that in a 0.7 per cent solution of $\mathrm{NaCl}$, or an equivalent solution of $\mathrm{NaBr}$ or $\mathrm{NaI}$, a muscle does not materially change its weight during eighteen hours. If there is

* Loeb, Festschrift fiur Professor Fick, I 899. Pfïger's Archiv, Vol. 91, p. 248, 1902. See also the numerous papers of Ringer in this field of investigation.

† Loeb, Pfïger's Archiv, Vol. 69, p. I, 1897; and E. Cooke, Jour. of Physiology, Vol. 23, p. $137, \mathbf{1} 898$. 
an increase in weight, as a rule, it does not exceed 7 per cent of the initial weight of the muscle. In the corresponding equimolecular solutions of potassium salts, the muscle increases its weight in the same time 40 per cent or more, while in an equimolecular solution of $\mathrm{CaCl}_{2}$, it may lose water, sometimes as much as 20 per cent.* In all these solutions the weight of the muscle changed but immaterially during the first hour. These facts become intelligible on the assumption that the salts diffuse into the muscle, although with less rapidity than the water. As far as the specific action of $\mathrm{K}, \mathrm{Na}$, and $\mathrm{Ca}$ salts upon the absorption of water by the muscle is concerned, it is somewhat analogous to the behavior of various soaps. Potassium soaps are extremely hygroscopic, and absorb water in such quantities as to make them liquid, while calcium soaps absorb but little water; and sodium soaps occupy a position between these two. Soaps contain water in a form in which it can be squeezed out by a slight pressure. The same is also true for some, perhaps most of the water absorbed by muscles, and this holds also, according to Van Bemmelen and Hardy, for the water which is contained in irreversible gels, such as coagulated white of egg or a gel of silicic acid. Such gels evidently contain the water in capillary spaces. Evidently the $\mathrm{Na}$-, K-, Ca-ions ultimately bring about a coagulation in the muscles; but the structure and size or other physical properties of the interstices in the coagulated material change with the nature of the metal which brings about the coagulation. This is further corroborated by putting the muscle into solutions of a salt, e.g. $\mathrm{NaCl}$, of various concentrations. During the first hour or so the volume of the muscle changes, as one would expect if the muscle were permeable for water, but impermeable or little permeable for salts; but after a longer period a paradoxical result is obtained. In solutions of higher osmotic pressure than the muscle, the latter increases in volume and weight, and within certain limits, the more so the higher the concentration of the solution, as the following table shows:-

Concentration of the NaCl Solution

$$
\begin{aligned}
& \text { I. } 05 \% \\
& 1.4 \% \\
& 1.75 \% \\
& 2.1 \% \\
& 2.45 \% \\
& 2.8 \%
\end{aligned}
$$

INCREASE IN WEIGHT OF MUSCLE IN TWENTY-FOUR Hours in Per Cent of its Original Weight

$$
\begin{aligned}
& +0.7 \% \\
& +\quad 6.7 \% \\
& +13 \% \\
& +17.7 \% \\
& +19 \% \\
& +23.8 \%
\end{aligned}
$$

This experiment might at first suggest that the osmotic pressure is not the force active in this case; but this is not true. The osmotic pressure

* Loeb, Pfïger's Archiv, Vol. 75, p. 303, r899. (A dead muscle absorbs no water in a physiological salt solution, thus showing that the above-mentioned effects of $\mathrm{K}$ or $\mathrm{Ca}$ cannot be attributed merely to the death of the nuuscle.) 
is the active force, but through the slow but gradual entrance of $\mathrm{NaCl}$ into the muscle, and possibly the loss of water and salts, on the part of the muscle, new conditions for the absorption of water are created which correspond with Van Bemmelen's observations on gels.

If a little acid be added to a 0.7 per cent solution of $\mathrm{NaCl}$ (which is about isosmotic with the gastrocnemius of a frog), the gastrocnemius will absorb considerable quantities of water from such a solution. The quantity of water absorbed increases with the quantity of acid used. For inorganic acids it can be shown that the effect is chiefly determined by the hydrogen-ions, and not by the anions. Organic acids, however, act considerably stronger than should be expected, if the effect were purely due to the free hydrogen-ions.* The cause of this anomaly is not yet known. If, however, acids are added to a hypertonic solution of $\mathrm{NaCl}$, the effect is the reverse; the acid diminishes the amount of water absorbed by the muscle. $\dagger$ Alkalis increase the absorption of water under all circumstances. In these cases the acids and alkalis act probably through their combination with the proteids, whereby the conditions for the absorption and giving off of water are changed. It is therefore obvious that other forces than the mere osmotic pressure play a rôle in the absorption of liquids by tissues.

The same seems. to be true for the reverse process; namely, the secretion of liquids from the cells. In these cases work is often done against the osmotic potential. It is evident that another force must be at work besides the mere osmotic pressure. The fact discovered by MacCallum, that the same salts which increase the peristaltic motion of the intestine also increase the secretory action of the glands of the intestine, $\ddagger$ seems to indicate that this force may be of the nature of the contractile forces. The same salts which increase the secretion of liquid from the blood into the intestine also increase the secretory action of the kidneys.

Höber $\S$ has recently called attention to another possibility. Hamburger had found that acids, e.g. $\mathrm{CO}_{2}$, increased the permeability of red blood corpuscles for certain anions. Höber has shown that such an increased permeability for anions must lead to a difference of potential between the inner and outer surface of the semipermeable elements, the inner surface assuming a positive charge. It is possible that such differences of potential, in case they lead to an electric current, may

* Loeb, Pfüger's Archiv, Vol. 69, p. I, I897; Vol. 71, p. 457, 1898.

† Loeb, PAiuger's Archiv, Vol. 75, p. 303 , i 899.

$\ddagger$ J. B. MacCallum, University of California Publications, Vol. I, p. 5, 1903; and pp. 8I and 125, 1904. Pfïger's Archiv, Vol. 104, 1904.

$\S$ R. Höber, Pfiiger's Archiv, Vol. 102, p. 196, 1904. 
bring about a cataphoresis of the water or the particles dissolved in it, into or out of the cell.

But in view of the observations of MacCallum I am more inclined to believe that contractile phenomena inside the cell furnish at least part of the energy of secretion and absorption in those cases where the osmotic forces alone cannot explain these phenomena. To illustrate what possible form these forces may assume, I may point out the rhythmical squeezing out of the liquid contents of the vacuole in Infusorians. Here the work of secretion is obviously done by protoplasmic contraction, and not by osmotic pressure. It is quite possible that, mutatis mutandis, something similar may occur in all cells, although this is only a surmise.

\section{Further Limitations of Traube's Theory of Semipermeability}

Traube's idea that all living cells are surrounded by a membrane which is absolutely permeable for water, does not seem correct for a number of marine animals. Fundulus heteroclitus, a marine fish, lives and develops exclusively in sea-water, i.e. in a solution whose osmotic pressure is, roughly estimated, like that of a half-grammolecular $\left(\frac{m}{2}\right)$ solution of $\mathrm{NaCl}$. I have found that this fish as well as its eggs can be put permanently into distilled water without the least injury. No swelling of the eggs or the tissues occurs under these conditions.* It may also be put into sea water whose osmotic pressure has been increased by the addition of a certain percentage of $\mathrm{NaCl}$ without perceptible shrinkage. This shows that water does not diffuse rapidly through the skin of the animal or the membrane of the egg. It cannot be stated, however, that it does not diffuse at all, since it is possible that a slight diffusion of water into the cells may be compensated by an increased secretion of water from the cells. In addition, the egg and animal must be but slighly permeable for salts, as otherwise the salts would diffuse from the blood and the tissues of the animal into the distilled water, and this would cause the death of the animal. The skin and the egg cannot be said to be absolutely impermeable, since gases like $\mathrm{O}$ and $\mathrm{CO}_{2}$ diffuse into the eggs, and since the latter rapidly dry out and die when taken out of the water and exposed to dry air. Moreover, $\mathrm{K}$ and other toxic salts are able to diffuse slowly into the egg, as can be shown by the fact that if potassium salts are added to sea water, the heart of the embryo soon stops beating.

* Loeb, Pfüger's Archiv, Vol. 55, p. 530, 1893. Am. Jour. Physiology, Vol. 3, pp. 327 and 383 , 1900; and Vol. 6, p. 411,1902 . 
The behavior of Fundulus to distilled water is not the rule for marine animals, as most of them when subjected to it die rapidly. I have recently made a series of experiments with a marine Crustacean Gammarus, of the Bay of San Francisco.* The osmotic pressure of the sea-water of the bay varies at different times of the year between that of about an $\frac{m}{4}$ and a $\frac{3}{8} m \mathrm{NaCl}$ solution. When Gammarus is brought suddenly from bay water into distilled water, its respiratory motions stop, as a rule, in about half an hour. This standstill becomes permanent, unless they are put back into sea water within a short time (about ten minutes). If, however, Gammarus be put into a cane sugar, dextrose, or lactose solution of any concentration from $\frac{m}{8}$ to $\frac{3}{4} m$ upward, they die just as rapidly, if not more so, than in distilled water. The same is true when the animals are put into a pure $\mathrm{NaCl}$ solution isosmotic with the sea water. They die still more rapidly when put into distilled water, to which all the other salts found in the sea water are added, with the exception of $\mathrm{NaCl}$, and in the concentration in which those salts occur in sea water. If they are put, however, into a solution of $\mathrm{NaCl}, \mathrm{KCl}$, and $\mathrm{CaCl}_{2}$, in that proportion in which these salts occur in the sea water, the animals may live as long as fortyeight hours; and if some $\mathrm{MgCl}_{2}$ is added to this solution, the animals may live as long as in sea water. If we prepare solutions composed of only two of the salts contained in the sea water; namely, $\mathrm{NaCl}+\mathrm{KCl}$, or $\mathrm{NaCl}+\mathrm{CaCl}_{2}$, or $\mathrm{NaCl}+\mathrm{MgCl}_{2}$, the Gammarus lives only a few hours. These experiments prove that the medium surrounding the Gammarus must not only have a definite osmotic pressure, but that this pressure must be supplied by specific salts. Perhaps the following data may explain, in part at least, why this lack of specific salts leads to the death of the animal.

\section{The Antagonistic Effects of Salts}

When the eggs of Fundulus are put immediately after fertilization into a pure solution of $\mathrm{NaCl}$, whose concentration roughly equals that in which this salt is contained in the ocean, $\frac{m}{2}$, or $\frac{5}{8} m$, no egg is able to form an embryo. The eggs begin to segment and may go as far as the 64-cell stage, but after this they die. But if to the $\mathrm{NaCl}$ solution a small but definite amount of a bivalent metal (with the exception of the most poisonous ones, like $\mathrm{Hg}$ ), is added, just as

\footnotetext{
* Loeb, Pfiüger's Archiv, Vol. 97, p. 394, 1903; Vol. IOI, p. 340, 1904.
} 
many eggs form embryos as in normal sea water.* It is a striking fact that not only the salts of such bivalent metals which occur in the sea water or the body, e.g. $\mathrm{Ca}$ and $\mathrm{Mg}$, render the pure $\mathrm{NaCl}$ solution harmless; but also such salts as do not occur in the body, or are positively poisonous, e.g. $\mathrm{Sr}, \mathrm{Ba}, \mathrm{Co}, \mathrm{Zn}, \mathrm{Pb}$, and others. An example will illustrate these antagonistic effects between the salts of the univalent and bivalent metals.

NAtURE OF THE Solution

roo c.c. $\frac{5}{8} m \mathrm{NaCl}$

100 c.c. $\frac{5}{8} m \mathrm{NaCl}+\frac{1}{2}$ c.c. $\frac{m}{64} \mathrm{CaSO}_{4}$

I00 c.c. $\frac{5}{8} m \mathrm{NaCl}+$ I c.c. $\frac{m}{64} \mathrm{CaSO}_{4}$

IOO c.c. $\frac{5}{8} m \mathrm{NaCl}+2$ c.c. $\frac{m}{64} \mathrm{CaSO}_{4}$

roo c.c. $\frac{5}{8} m \mathrm{NaCl}+4$ c.c. $\frac{m}{64} \mathrm{CaSO}_{4}$

I00 c.c. $\frac{5}{8} m \mathrm{NaCl}+8$ c.c. $\frac{m}{64} \mathrm{CaSO}_{4}$
Percentage of the Fundulus Eggs WHICH FORM AN EMBRYO IN THIS SOLUTION

$$
\begin{array}{r}
0 \% \\
3 \% \\
3 \% \\
20 \% \\
75 \% \\
70 \%
\end{array}
$$

It is remarkable how small a quantity of calcium suffices to render the $\mathrm{NaCl}$ solution harmless. The anion has nothing to do with this effect of the calcium salt, as the result remained the same when any other soluble calcium salt was used, e.g. $\mathrm{Ca}\left(\mathrm{NO}_{3}\right)_{2}$ or $\mathrm{CaCl}_{2}$. The results also remained the same when in the place of the $\mathrm{Ca}$ salts, $\mathrm{Sr}, \mathrm{Ba}$, $\mathrm{Co}, \mathrm{Zn}$, or $\mathrm{Pb}$ salts were used, and even the quantities of the salt required to make the $\mathrm{NaCl}$ solution harmless were about the same for all the salts. I think it is one of the most striking facts known in toxicology that a pure solution of $\mathrm{NaCl}$ of that concentration in which this animal lives is poisonous, while this solution can be rendered less harmful or harmless by adding so poisonous a substance as $\mathrm{Ba}, \mathrm{Co}, \mathrm{Zn}, \mathrm{Pb}$, etc.

If the eggs of Fundulus are raised in a solution of a salt with another univalent cation than $\mathrm{Na}$, e.g. $\mathrm{K}, \mathrm{Li}$, or $\mathrm{NH}_{4}$, we find that beginning with a certain concentration a solution of each of these salts becomes a poison for the eggs of Fundulus, that is to say, does not allow any egg to form an embryo. If, at that concentration of one of these salts, a small but definite amount of a salt with a bivalent cation is added, the eggs form embryos and they are able to develop. Trivalent cations, like $\mathrm{Al}$ and $\mathrm{Cr}$, were also able to render the toxic concentrations of salts with a univalent metal less harmful. The antitoxic effect of a tetravalent cation, Th, however, was found to be only slight.

* Loeb, Pfïger's Archiv, Vol. 88, p. 68, 1901. Am. Jour. Physiology, Vol. 3, p. 327, I900; Vol. 6, p. 4I I, 1902. Loeb und Gies, Pfiuger's Archiv, Vol. 93, p. 246, 1902. Loeb, Pfïger's Archiv, Vol. 107, p. 252, 1905. 
While a small quantity of a salt with a bivalent metal thus suffices to render a solution of a salt with a univalent cation harmless, it was found that it was not possible to produce similar antitoxic effects through the addition of a salt with an anion of higher valency. If sodium sulphate, sodium citrate, etc., was added to a $\frac{m}{2} \mathrm{NaCl}$ solution, the latter continued to remain toxic for the Fundulus egg.

It is remarkable that not only the solutions of a salt with a univalent cation, like $\mathrm{NaCl}$, can be rendered harmless by a salt with a bivalent cation, e.g. $\mathrm{ZnSO}_{4}$, but that also the reverse is true; namely, that a toxic solution of $\mathrm{ZnSO}_{4}$ can be rendered harmless by a solution of $\mathrm{NaCl}$, provided the concentration of the $\mathrm{ZnSO}_{4}$ is not too high. In IOO c.c. of a $\frac{5}{8} m \mathrm{NaCl}$ solution no Fundulus egg forms an embryo. When from 2 to 8 c.c. $\frac{m}{64}$ solution of $\mathrm{ZnSO}_{4}$ are added to this $\mathrm{NaCl}$ solution, just as many eggs form embryos as in sea water or distilled water. If, however, from 4 to 8 c.c. of a $\frac{m}{64} \mathrm{ZnSO}_{4}$ solution are added to 100 c.c. distilled water, not a single egg is able to form an embryo, although in pure distilled water these eggs live and develop as well as in sea water. The $\mathrm{Zn}$-ions are therefore not only able to prevent the toxic effects of a pure $\mathrm{NaCl}$ solution, but the $\mathrm{NaCl}$ of this solution also prevents, in this case, the toxic effects of the $\mathrm{Zn}$-ions.

The quantitative relations are of some interest. About 4 c.c. $\frac{m}{64}$ solution of a salt with a bivalent metal are required to render Ioo c.c. of a $\frac{5}{8} m \mathrm{NaCl}$ solution harmless. We may therefore say that for this concentration of $\mathrm{NaCl}$ one ion of the bivalent metal suffices to render I000 molecules of the salt with the univalent metal harmless. When a $\mathrm{NaCl}$ solution of a lower concentration, namely, $\frac{3}{8} m$ or $\frac{m}{2}$ is used, less salt with a bivalent metal is required for the antitoxic effect than in the case of a $\frac{5}{8} \mathrm{~m}$ solution. If we use a $\mathrm{NaCl}$ solution with a concentration of or below $\frac{m}{4}$, it is no longer harmful for the eggs of Fundulus. If we use stronger solutions than $\frac{5}{8} m$, we soon reach a limit where the addition of a salt with a bivalent metal no longer renders the solution harmless. It is possible that, at this limit, the loss of water on the part of the egg acts harmfully, and this effect, of course, cannot be antagonized by the addition of another salt. If we try to determine how much $\mathrm{NaCl}$ is needed in order to render a solution of $\mathrm{ZnSO}_{4}$ harmless, we find that a comparatively large amount of $\mathrm{NaCl}$ is required for 
this purpose. In order to prevent the poisonous effect of a $\frac{m}{400} \mathrm{ZnSO}_{4}$ solution, so much $\mathrm{NaCl}$ had to be added that the concentration of the $\mathrm{NaCl}$ in the solution was about $\frac{m}{8}$. About 50 molècules of $\mathrm{NaCl}$ were therefore required to render one molecule of $\mathrm{ZnSO}_{4}$ harmless. The fact that the antitoxic effects of the salts with bivalent cations are so much greater than those of the salts with univalent cations is possibly responsible for the fact that I did not succeed in rendering a $\frac{5}{8} m \mathrm{NaCl}$ solution harmless through the addition of a salt with a univalent cation. The concentration of the solution would become so high that this might be sufficient to kill the eggs. The salts of certain metals are especially toxic, it being impossible to use those like $\mathrm{Cu}$ or $\mathrm{Hg}$ for antitoxic effects, as they cause coagulation of the contents of the egg in smaller concentrations than are required for the antitoxic effects of such a solution.

The development of the egg of Fundulus requires at summer temperature from about twelve to twenty-four days. If we use a $\mathrm{Ca}$ salt to render a $\frac{m}{2}$ or $\frac{5}{8} m \mathrm{NaCl}$ solution harmless, an embryo can be formed, and it may hatch, but will then die; if, however, a $\mathrm{Zn}$ or Ba salt be used for this purpose, an embryo is formed, and it may develop for a number of days quite normally; but it dies before its development is complete. If we allow the egg to complete its development in distilled water or sea water, and put the larva, after it has hatched, into a mixture of IoO c.c. $\frac{m}{2} \mathrm{NaCl}$, and a small amount of a $\mathrm{Ba}$, or $\mathrm{Co}$, or $\mathrm{Zn}$ salt, the embryo dies even more quickly than if put into the pure $\mathrm{NaCl}$ solution. These facts indicate that for this fish the $\mathrm{ZnSO}_{4}$ remains toxic even in the presence of the $\mathrm{NaCl}$, and that these two salts are only antagonistic as long as the fish is surrounded by the egg membrane. This suggests the idea that the antagonism between these two salts is due only to the fact that they retard each other's rapidity of diffusion into the egg.* If the egg is put immediately after fertilization into a $\frac{m}{2} \mathrm{NaCl}$ solution, very soon so much $\mathrm{NaCl}$ diffuses into the egg that it poisons the fish. The same is true if a small amount of $\mathrm{ZnSO}_{4}$ is put into distilled water. But if both salts are put together into the distilled water, neither the $\mathrm{NaCl}$ nor the $\mathrm{ZnSO}_{4}$ can diffuse as rapidly into the egg, and the germ lives long enough to form an embryo. In a few days, however, death occurs, showing that the diffusion of the $\mathrm{ZnSO}_{4}$ was not prevented, but only retarded. Another fact corroborates the idea that it is only 
the rate of diffusion of salts through the membrane which is retarded in this case. A pure $\mathrm{NaCl}$ of the concentration $\frac{m}{2}$ or $\frac{5}{8} m$ only prevents the formation of an embryo when the egg is put into the solution immediately after fertilization. If, however, the egg is put for the first twentyfour hours after fertilization into normal sea water and then into the pure $\mathrm{NaCl}$ solution of the above-mentioned concentration, the $\frac{m}{2}$ or $\frac{5}{8} m$ $\mathrm{NaCl}$ solution is not so toxic. In all probability the membrane of the egg or the cells becomes more hardened or less permeable during the first twenty-four hours.

The antagonistic effects between two salts with a bivalent cation are not so general, yet $\mathrm{I}$ found that $\frac{1}{2}$ c.c. of a $\frac{5}{16} m \mathrm{SrCl}_{2}$ solution diminished somewhat the toxicity of a $\frac{5}{\mathbf{1 6}} \mathrm{m}$ solution of $\mathrm{MgCl}_{2}$.

While in the case of the membrane of the newly laid Fundulus egg, the addition of a trace of a salt with a bivalent cation sufficed to annihilate or diminish the toxic effect of a pure $\mathrm{NaCl}$ solution, we never find such simple relations for the Fundulus after it is hatched or for any living cell that is exposed directly to the solution without the interference of a dead membrane, like the one which surrounds the fish egg. For such directly exposed living tissues or animals, it is a rule that a pure $\mathrm{NaCl}$ solution of sufficient concentration requires, besides the $\mathrm{CaCl}_{2}$, a trace of $\mathrm{KCl}$, in order to become harmless, as was shown in the above-mentioned case of marine Gammarus. Besides, it is not possible to substitute in that case for the $\mathrm{Ca}$ any bivalent cation; only $\mathrm{Sr}$ can serve as a substitute for $\mathrm{Ca}$ in these cases. These limitations become intelligible on the assumption that the surrounding salts diffuse slowly into the cells. As long as this diffusion is so slow that the secretory activity of the cells or glands of an animal may remove them as fast as they enter, the cell or the animal may live in such a solution. I consider this the reason why a Fundulus may live in a $\frac{m}{8} \mathrm{NaCl}$ solution, while it cannot live in a $\frac{m}{2} \mathrm{NaCl}$ solution. A second condition for the maintenance of life is, according to this hypothesis, the continuation of the action of the secretory mechanism. If the latter depends on the contractile power of the protoplasm, as I believe it does, we can understand that, in order to make a $\mathrm{NaCl}$ solution harmless, not only $\mathrm{Ca}$ but also $\mathrm{K}$ are required. We shall see in a later lecture that apparently $\mathrm{Na}$, $\mathrm{Ca}$, and $\mathrm{K}$ are required for the contractile phenomena of protoplasm.

Höber and Gordon* have pointed out the existence of an antago-

* Höber und Gordon, Hofmeister's Beiträge zur chemischen Physiologie und Pathologie, Vol. 5, p. 432, 1904 . 
nism between the precipitating effects of salts of univalent and bivalent metals, which Linder and Picton had already found. If arsenic sulphide is precipitated with a mixture of two salts with a univalent cation, or of two salts with a bivalent cation, the effects of the two salts are added to each other. If a mixture of a salt with a univalent cation and a salt with a bivalent cation is used, however, for the precipitation, the result is an inhibition instead of a summation of the effects. Höber and Gordon have repeated and confirmed this observation. In addition, they have found that, just as in my own experiments, the valency of the anion plays no rôle. I am not able to state whether this explains the observations made on Fundulus.

It is rather remarkable that many authors have found distilled water to be poisonous for fresh-water animals. Locke showed that some authors had been deceived by the fact that their distilled water contained traces of copper salts, owing to the fact that the water had been distilled in copper vessels. But Bullot* found that for fresh-water Gammarus distilled water is toxic even if distilled with all necessary precautions in Jena glass or quartz or platinum vessels, and if care is taken that it is free from ammonia. He found that if a trace of $\mathrm{NaCl}$ is added to the distilled water (so that the concentration of the latter was $0.00008 \mathrm{~N}$ ) fresh-water Gammarus could live indefinitely in the distilled water. The presence of a trace of $\mathrm{NaCl}$ in the distilled water possibly preserves the membrane better, or maintains better the secretory activity of the cells so that the animal can be freed from the excess of water which diffuses into it.

Dr. Wolfgang Ostwald $†$ investigated the duration of life of the same fresh-water Gammarus in solutions of higher concentration. He found that these animals live longer in a mixture of one hundred molecules $\mathrm{NaCl}$, two molecules $\mathrm{KCl}$, and two molecules $\mathrm{CaCl}_{2}$, than in a pure sugar or $\mathrm{NaCl}$ solution of the same concentration. This is in harmony with the assumption that the absorption as well as the secretive action of the cells requires the presence of $\mathrm{Na}, \mathrm{Ca}$, and $\mathrm{K}$ in definite proportions, as we shall see more fully later.

In connection with these experiments I made an observation which possibly may become of some use in the study of the phenomena of adaptation. When marine Gammarus is put into sea water, which has been diluted with various quantities of distilled water, one notices that, with increasing dilution of the sea water, the duration of life of the Gammarus at first diminishes but little; that, however, at a certain degree of dilution (about ten times that of the normal sea water) the duration of life

* Bullot, University of California Publications, Physiology, Vol. I, p. I99, I904.

† W. Ostwald, Pfizger's Archiv, Vol. 106, p. 568, 1905. 
decreases quite suddenly. It is obvious that the discontinuity in the curve of duration of life means that here a new condition, or a group of new conditions; enters which before that time were not noticeable. What are these conditions? Experiments which I have recently made on the eggs of sea urchins showed that up to a certain degree the dilution of the sea water with fresh water killed the eggs only slowly, but that beyond a certain degree of dilution death was rather sudden. This sudden death was due to a process of cytolysis in which the eggs were transformed into "shadows." I am inclined to believe that something similar occurs in certain cells of marine Gammarus and of marine animals in general, when the dilution of the sea water falls below a certain limit.

This idea receives some support from the fact that Wolfgang Ostwald found that a rise in the concentration of the sea water above a certain limit also caused a sudden decline in the vitality curve of fresh-water Gammarus. If the concentration of the sea water be raised above a certain point, the eggs of the sea urchin also undergo cytolysis.*

* Loeb, Pflüger's Archiv, Vol. 103, p. 257, 1904. 


\section{LECTURE IV}

\section{ON SOME PHYSICAL MANIFESTATIONS OF LIFE}

\section{Hypotheses of Muscular Contraction}

- THE phenomena which allow us to discriminate between dead and living matter are physical processes, e.g. in higher animals, the contraction of the heart, the respiratory and other muscular motions. If the chemical processes in living matter and the physical changes they bring about in the colloids were entirely known, the physical manifestations of life would also be clear to us. The periodic character of many of the manifestations of life suggests the idea that these processes occur in several phases which are probably connected, partially at least, in a catenary way, so that the preceding process has effects which cause the subsequent phase of the process.

These catenary mechanisms are for the most part still unknown. Inasmuch as the number of possible changes in the condition of colloids seems limited, the impression might be gathered that by a guess the whole secret of the physical manifestations of life might be unraveled. Such surmises find their way occasionally into print. As a rule, those who are familiar with the specific case for which the guess is made are not helped by it. It is not worth while to devote any time to the pointing out of the futility if not open absurdity of most of these attempts.

The origin of animal heat from chemical energy offers no further mystery. We know that a kilo of sugar yields about four thousand calories of heat, if burned in the laboratory, and that it gives the same heat if oxidized in the body. In our modern theory of nutrition, the heat value of the various kinds of food is justly used as the basis for the calculation of their nutritive value. The times are gone when physicians and biologists dared to raise the objection - as they did against Robert Mayer - that our body inherits its heat.

As far as the transformation of chemical energy into mechanical energy in the muscle is concerned, Robert Mayer and Helmholtz considered the muscle as a thermodynamical machine. They assumed that in the muscle the heat produced by chemical processes is partly 
transformed into mechanical energy; but they refrained from stating how this transformation occurs. Engelmann tried to fill this gap.* Striped muscle consists of alternating stripes of optically isotropic and anisotropic substance. Engelmann observed that in the contraction of the muscle the anisotropic substance increases in volume, while the isotropic substance decreases. As the total volume of the muscle does not change during the contraction, Engelmann concluded that part of the liquid of the isotropic substance diffused into the anisotropic during contraction. He showed by experiments on violin strings (made of catgut) that such a process of absorption can be produced by heat. The violin strings show the same double refraction as the anisotropic stripes in the muscle. When a violin string is suspended in water, and the latter suddenly heated, the string contracts, and is able to lift a weight in this contraction. This shortening of the string is caused by an absorption of water by the string; and this imbibition is caused by the increase in temperature. Like the contracting muscle, the violin string, in this case, becomes shorter and thicker. The process is reversible as the string elongates again upon cooling.

In the case of the muscle, Engelmann assumes that through the stimulus which causes muscular contraction, heat is produced (through the oxidation of carbohydrates); and that the increase in temperature causes the anisotropic substance to absorb water from the isotropic substance. This causes the change of form in the muscle - the thickening and shortening - by which it is able to lift a weight.

For such a shortening of the violin string through heating, an increase of about $10^{\circ}$ in the temperature of the water is necessary, while the temperature of a frog's muscle during a single contraction increases only by $0.00 \mathrm{I}^{\circ}$. Engelmann points out, however, that the increase in the temperature of the whole muscle does not indicate the rise in temperature in individual spots in the muscle, which may be considerably higher. The foci of combustion heat the whole mass of the muscle, and we measure only the latter increase of temperature, which may of course be quite small. Provided we grant this, it is necessary to assume that the heat is sufficiently rapidly dissipated by conduction to allow the rapid succession of relaxation and contraction of the muscle in tetanus. We know that the muscles can contract and relax many times a second, e.g. the muscles of the wings of insects contract and relax more than a hundred times a second. I do not believe that the process of dissipation of heat in liquids is rapid enough to make Engelmann's hypothesis probable, or even possible. It is, however, conceivable that with a slight modification his hypothesis may be rendered free

* Engelmann, Ueber den Ursprung der Muskelkraft, Leipzig, I893. 
from objections such as we have mentioned; namely, by assuming that chemical, not thermal conditions determine the absorbtion of fluid by the anisotropic substance. The action of the nerve upon the muscle might consist in facilitating a chemical change which increases the absorption of water by the anisotropic substance of the muscle.

\section{Quincke's Theory of Protoplasmic Motion}

The thermodynamic conception of muscular contraction has been abandoned by many authors, and the surface energy has been considered in its stead as the cause of muscular contraction and work. D'Arsonval, Imbert, and more recently Bernstein, have tried to offer a hypothesis of this kind. We shall understand these hypotheses better if we first consider Quincke's theory of protoplasmic motion.*

When a drop of oil is put on the surface of water which is in contact with air, the oil spreads in an extremely thin layer at the limit between water and air. This process continues until a film of oil exists between water and air. The conditions for the spreading of the oil on the surface of the water are as follows: the particle of oil $O$ at the left end of the oil drop (Fig. 7) is under the influence of three surface tensions which pull at it in three different directions, $O A, O B$, and $O C$, and with different force. One is the

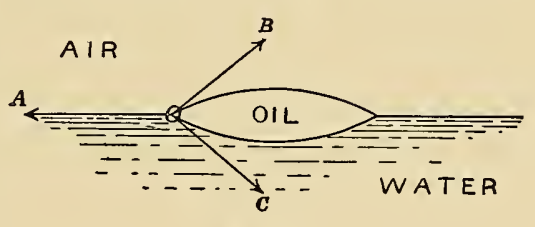

FIG. 7. surface tension between air and water, which tends to pull the particle from $O$ in the direction $O A$. The second is the surface tension $O B$ at the limit of oil and air, which tends to pull the particle $O$ in the direction of the tangent $O B$ from $O$. The third force is the surface tension at the limit of oil and water, which tends to pull the particle in the direction of the tangent $O C$ from $O$. The surface tension at the limit of water and air is greater than the sum of the surface tensions at the limit between oil and air, and oil and water. The surface tension between air and water is $8.25 \mathrm{mg}$., between oil and air $3.76 \mathrm{mg}$., and between oil and water $2.73 \mathrm{mg}$. The particle $O$ will therefore be pulled toward the left; and the same will happen with the next particle of oil, until the surface water air is substituted by the surface oil air.

These phenomena of spreading are accompanied by motions in the neighboring particles of liquid. If oil spreads at the surface of water,

* Quincke, Sitzungsberichte der Berliner Akademie der Wissensch., p. 791, I888. 
the moving oil will, through friction, set the adjoining particles of water also in motion. The superficial layers of water, therefore, will move away from the center of spreading, and water will move toward the

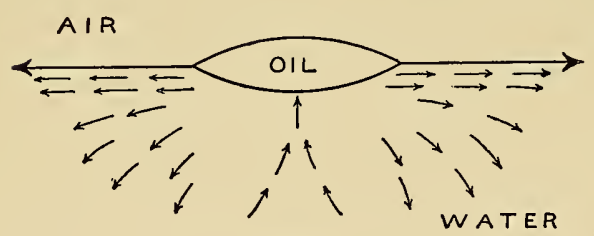

FIG. 8. center from the interior, and from below. The arrows in Fig. 8 represent the currents in the water caused by the spreading of the oil.

Quincke holds that such phenomena of spreading are the cause of all protoplasmic streaming. Such a streaming occurs constantly in the cells of Chara or Nitella. Quincke gives the following explanation for this process: all protoplasm contains oil or fat, and the surface layer of each cell must, therefore, be surrounded by a film of oil or fat. The oil will form through hydrolysis traces of fatty acid. The protoplasm contains. substances which form soaps with the fatty acid. A soap solution must spread at the limit between oil and water, as the surface tension between oil and water is greater than the sums of surface tension between oil and soap solution, and between water and soap solution (which is zero). When the soap solution spreads, it must pull with it the adjacent particles of protoplasm. In this phenomenon of spreading, new particles of the surface of oil come in contact with protoplasm, new soap is formed, and the process is repeated. These phenomena of spreading, which constantly repeat themselves, furnish the energy for the constant streaming of protoplasm. The protoplasmic streaming occurs in the case of Chara or Nitella in one direction only. Quincke believes that this is due to an asymmetry in the structure of the cell, which renders the resistance to the streaming greater in one direction than in the opposite direction. Hence, the streaming occurs in one direction only; namely, that of least resistance.

The motion of an Amœba can be imitated by bringing a drop of olive oil which contains a trace of fatty acid upon a one half to two per cent solution of $\mathrm{Na}_{2} \mathrm{CO}_{3}$. The oil, in this case, forms at its surface a film of solid soap. As soon as this dissolves at one spot, soap solution must spread at the surface of water and oil, and the moving soap solution must set also the neighboring layer of oil into motion. In the oil drop, therefore, two movements must occur, one at the periphery, which is directed away from, and one in the center, which is directed toward, the center of spreading. The arrows in Fig. 9 indicate these streams. The particles that flow from the interior toward the periphery produce a bulging out, and this is the analogue of the formation of a pseudo- 
podium. According to Berthold,* the phenomena of streaming in the interior of an Amœba in the process of the formation of a pseudopodium are such as to agree with the ideas of Quincke. Bütschli has come to the same conclusion. It seems to me, however, that if it is true that the Amœba is covered with a solid surface film, one condition for the formation of a pseudopodium must be a local liquefaction of protoplasm. In consequence of such a liquefaction, new protoplasm must flow out, which, subsequently, will form a new solid film at its surface. This may again be liquefied, and a new streaming may occur, etc. Such liquefactions can be caused by lack of oxygen, as we saw in a previous lecture; but they may also be caused by other chemical

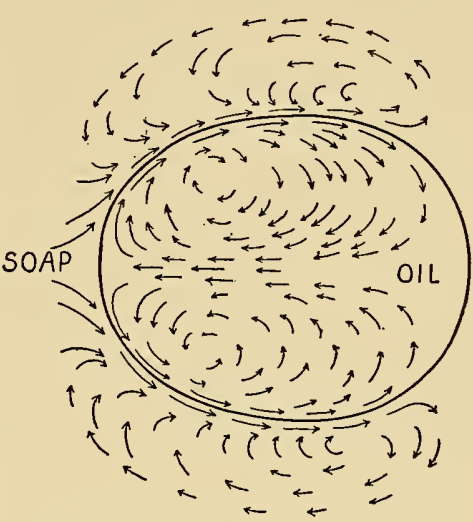

FIG. 9. - AfTER BüTSCHLI. changes. I am inclined to believe that phenomena of liquefaction play at least some rôle in these processes of protoplasmic motion.

Imbert $\dagger$ published several years ago a hypothesis concerning the contraction of smooth muscle fibers, which assumes that the "stimulus" which causes the contraction of smooth muscles produces an increase in the surface tension between the longitudinal fibrils and the surrounding liquid of the muscle cell. These fibrils are long and thin cylinders; every increase in surface tension must have a tendency to make these fibrils more spherical, i.e. thicker and shorter. Such a change of form occurs indeed during contraction, but it is difficult to understand why the fibrils do not assume this form under the influence of surface tension alone, without stimulation. To meet this difficulty, Imbert assumes that smooth muscle fibers cannot contract unless they are stretched passively. He presupposes that their arrangement in the body is such that this prerequisite is generally fulfilled.

Bernstein has tried to explain away some of the weak spots in this hypothesis. $\ddagger$ The surface energy at the limit between two media is equal to the product of surface tension into the surface. The work which surface tension can do is measured by the product of the decrease in surface, times the surface tension. From this it follows that the surface energy can do considerable work only, when the decrease in surface

* Berthold, Studien über die Protoplasmamechanik, Leipzig, I886.

$\dagger$ Imbert, Archives de physiol., 5th series, Vol. 9, p. 289, 1897.

‡ Bernstein, Pfïger's Archiv, Vol. 85, p. 271, 19o1. 
is large. From this Bernstein justly argues that Imbert's assumption is incorrect, inasmuch as the area required for the work the muscle really does, must be much larger than that between the fibrils and the neighboring liquid. Bernstein therefore assumes that the fibril consists of a row of quite small ellipsoids, whose long axis is in the direction of the fibrils, and whose form is determined by elastic forces. An increase in the surface tension must make these ellipsoid elements more spherical, and thus the fibril becomes shorter and thicker.

How can the nerve impulse or an artificial stimulation of the muscle increase the surface tension? There are several possibilities. Substances might be formed in this case which increase the surface tension at the limit between Bernstein's hypothetical ellipsoids and the surrounding liquid. Another possibility might be that, through the process of innervation or stimulation, an existing difference of electrical potential between the ellipsoids and the surrounding liquid might be diminished. D'Arsonval explains the efficiency of electrical stimuli in this way.* Hermann has offered another hypothesis; namely, that the contraction is a process of coagulation, and the relaxation, a process of liquefaction. $\dagger \mathrm{He}$ was led to this idea by the fact that the change in form which the muscle undergoes in the case of rigor mortis is similar to that in contraction, and that moreover a number of other features are common to both. Although all these hypotheses concerning muscular contraction have been known for a number of years, none has led to a new discovery. The reason lies possibly in the fact that one or more links in the catenary series of processes which underlie muscular contraction have been ignored in these hypotheses. It is well known that a muscle gains in mass through contractions, and that it undergoes atrophy when it remains at rest. This fact indicates, in my opinion, very clearly that phenomena or reactions which directly or indirectly lead to growth form a part in the process of muscular contraction. I consider it quite possible that no hypothesis concerning muscular contraction will prove fertile until this relation between activity and growth of the muscle is recognized.

\section{Concerning the Theory of Cell Division}

Were scientists with a purely physical training to be asked to give a hypothesis concerning cell division, I believe that their hypothesis would not take into consideration the phenomena of growth. Nevertheless, these phenomena form an obvious link in the catenary series of processes

* D'Arsonval, Archives de physiol., 5th series, Vol. I, p. 460, 1889.

† Hermann, Handbuch der Physiologie, Vol. I, Part I, p. 332. 
which result in the division of the nucleus and the cell. It had been tacitly recognized by botanists that the growth of a cell precedes its division and is possibly the cause of the division. The botanist J. Sachs was the first to definitely state that in each species the ultimate size of a cell is a constant for each organ, and that two individuals of the same species but of different size differ in regard to the number, but not in regard to the size of their cells.* Amelung, a pupil of Sachs, determined the correctness of Sachs's theory by actual counts. Sachs, in addition, recognized that wherever there were large masses of protoplasm, e.g. in Siphoneæ and other cœloblasts, many nuclei were scattered throughout the protoplasm. He inferred from this that "each nucleus is only able to gather around itself and control a limited mass of protoplasm." $\dagger$ He points out that in the case of the animal egg the reserve material — fat granules, proteins, and carbohydrates - are partly transformed into the chromatin substances of the nuclei, and that the cell division of the egg results in the cells reaching that final size in which each nucleus has gathered around itself that mass of protoplasm which it is able to control. Morgan $\ddagger$ and Driesch $\S$ tested and confirmed the idea of Sachs for the eggs of Echinoderms. Driesch produced artificially larvæ of sea urchins of one eighth, one fourth, and one half their normal size by isolating a single cleavage cell in one of the first stages of segmentation of the fertilized sea-urchin egg. He counted in each of the dwarf gastrulæ resulting from these partial eggs the number of mesenchyme cells and found that the larvæ from a $\frac{1}{2}$ blastomere possessed only $\frac{1}{2}$, those from a $\frac{1}{4}$ blastomere only $\frac{1}{4}$, and those from a $\frac{1}{8}$ blastomere only $\frac{1}{8}$ of the number of cells which a normal larva developing from a whole egg possessed. Moreover, he could show that when two eggs were caused to fuse so as to produce a single larva of double size, the gastrulæ of such larvæ had twice the number of mesenchyme cells. Driesch drew from his observations the conclusion that each morphogenetic process in an egg reaches its natural end when the cells formed in the process have reached their final size.

Gerassimow\| found that by exposing dividing cells of Spirogyra to a low temperature the division became irregular, and it happened that the nuclear material instead of being divided between the two

* J. v. Sachs, "Physiologische Notizen," VI, Flora, I893.

+ Sachs, "Physiologische Notizen," IX, p. 425, Flora, I895.

‡ Morgan, "Studies of the "Partial' Larvæ of Sphærechinus," Arch. für Entwickelungs. mechanik, Vol. II, 1895. "The Proportionate Development of Partial Embryos," ibid., Vol. XIII, I90I. "The Gastrulation of the Partial Embryos of Sphærechinus," ibid., Vol. XVI, I903.

\$ Driesch, "Von der Beendigung morphogener Elementarprocesse," Arch. fïr Entzoickelungsmechanik, Vol. VI, I898. "Die isolirten Blastomeren des Echinidenkeims," ibid., Vol. $\mathrm{X}, \mathrm{I} 900$.

|| Gerassimow, Zeitsch. fur allgemeine Physiologie, Vol. I, p. 220, I902. 
masses of protoplasm remained in one of the two daughter cells; sometimes all the chromosomes were united into one nucleus and sometimes he obtained two nuclei. He found that cells with an increased mass of chromatin only began to divide after their protoplasm had reached a much greater mass than that found in the normal cells with half the mass of the chromosomes. This fact seems to indicate that cell division is determined by the ratio of the mass of the chromosomes to that of the protoplasm. If the mass of the chromosomes in a cell is increased, the tendency for cell division does not develop until the mass of protoplasm is increased also. It is the merit of Boveri to have found the law which governs this condition for cell division.* $\mathrm{He}$ compared the process of segmentation in normally fertilized fragments of sea-urchin eggs, which contained the normal number of chromosomes, with that of enucleated fragments which contained only the sperm nucleus, and whose mass of chromatin was only one half of that of the normal fertilized egg. In order to understand his results, the reader's attention should be called to the following fact: in the process of cell division each daughter nucleus of the egg contains just as many chromosomes as the mother nucleus, but the mass of chromatin (and possibly the other constituents of the nucleus) of each chromosome in the daughter nucleus is only one half of that of the corresponding chromosome of the mother nucleus. The next phase - the resting stage between two divisions - consists in the growth of the chromosomes of the two daughter nuclei until they have reached the mass of the original chromosomes and then a new nuclear and cell division begins. The material for the growth of the chromosomes is furnished by the protoplasm and according to the above-quoted idea of Sachs by the reserve material included in the protoplasm and not by the "living" part of the latter itself. It is, however, questionable whether this latter discrimination has any real basis. In this way the process of cell division in the egg consists in the gradual transformation of protoplasmic into chromatin material of the nucleus until a definite ratio between the mass of the chromosomes and the protoplasm is reached. When this is established, no new cell divisions are possible until the mass of the protoplasm is increased again through the absorption of food stuffs on the part of the cell. The process of the transformation of protoplasm into chromatin is necessarily rendered discontinuous through the fact that the chromosomes cannot grow indefinitely, but that growth will stop as soon as they have reached a certain size, and this fact leads apparently to the process of nuclear divisions. I

* Boveri, Zellen-Studien, Heft 5. Ueber die Abhängigkeit der Kerngrösse und Zellenzahl der Seeigel-Larven von der Chromosomenzahl der Ausgangszellen, Jena, 1905. 
have thought of the possibility that the continuation of the synthetical process which leads to the formation of nuclear material from certain constituents of the protoplasm gives rise to the formation of astrospheres as soon as the maximal growth of the chromosomes is reached. But this does not need to enter into our consideration for the present.

Since each daughter nucleus of a dividing blastomere has the same number of chromosomes as the original nucleus of the egg, it is clear that in a normally fertilized egg each nucleus has twice the mass of chromosomes as the nucleus of a merogonic egg, i.e. an enucleated fragment of protoplasm which has only the sperm nucleus. Boveri has not only ascertained this fact but he has also ascertained the further fact that the final size of the cells after the cell divisions have come to a standstill is always in proportion to the original mass of the chromatin contained in the egg; the cells of the merogonic embryo, e.g. the.mesenchyme cells, are only half the size of the same cells in the normally fertilized embryo. Driesch has just furnished a further proof of Boveri's law, that the final ratio of the mass of the chromatin substance in a nucleus to the mass of protoplasm is a constant in a given species. He compared the size of the mesenchyme cells in a sea-urchin embryo produced by artificial parthenogenesis with those of a normally fertilized egg and found them half of the size of the latter. When the fertilized eggs and the parthenogenetic eggs are equal in size from the start, which is practically the case if eggs of the same female are used, - the process of the formation of mesenchyme cells comes to a standstill in the normally fertilized eggs when the number of mesenchyme cells is half as large as the final number of mesenchyme cells found in the parthenogenetic egg.* As a matter of fact, Boveri's results as well as those of Driesch were obtained by counting the cells formed by eggs of equal size and not by only measuring the size of the cells. It is most remarkable that certain apparent exceptions to Boveri's law which Driesch has actually found have been predicted by Boveri.

The fact that the process of cell division comes to a standstill when the ratio of the mass of the chromosomes in the nuclei of an egg or an organ to that of the surrounding protoplasm reaches a certain limit, suggests in my opinion the possibility that this ratio is determined by the laws of mass action and chemical equilibrium. If this is correct, the synthesis of nuclein compounds from the protoplasmic constituents must be a reversible process. This suggestion would gain in probability if it could be shown that a reduction of size in protoplasm in the case of starvation is also followed or accompanied by a reduction in the size of the nuclei.

\footnotetext{
* Driesch, Archio für Entwickelungsmechanik, Vol. 19, p. 648, 1905.
} 
The fact that the cell division is as a rule preceded by a synthetical process explains possibly the fact mentioned in the second lecture that the phenomena of cell division in a fertilized egg come soon if not immediately to a standstill when the atmospheric oxygen is withdrawn from the egg. We have mentioned Schmiedeberg's view in regard to the rôle of oxygen in synthetical processes. But even if this view were not correct, we can understand that lack of oxygen might indirectly interfere with the synthesis of the nuclein compounds.

E. P. Lyon has shown that the chemical conditions and processes in the cell differ in the various phases of cell division. He found that during different stages of cell division the egg of the sea urchin shows a different resistance to the effects of $\mathrm{HCN}$, and this difference repeats itself during each of the successive segmentations. More recently he has added the important fact that the production of $\mathrm{CO}_{2}$ on the part of the egg of the sea urchin also undergoes periodic variations during segmentation.

If we now turn to the physical side of the phenomena of cell division, we shall meet almost the same uncertainty which confronted us in the case of muscular contraction. We shall therefore confine ourselves to the enumeration of a few facts, with occasional hints for possible further work.

When we watch the process of cell division in an egg, we can discriminate at least three distinct phases of this process: first, the appearance of systems of radiation - the so-called astrospheres - in the protoplasm of the cell. The second phase is the disappearance (liqucfaction?) of the nuclear wall, and the division and migration of certain constituents of the nucleus, namely, the chromosomes toward the centers of the astrospheres, and the formation of two new nuclei. The third phase consists in the separation of the protoplasm into two pieces in a plane, which, from the position of the astrospheres, as a rule, can be predicted. This latter separation is the process of cell division proper.

If newly fertilized eggs of the sea urchin are put into sea water, whose osmotic pressure has been adequately raised by the addition of some salt, e.g. $\mathrm{NaCl}$, or sugar, no segmentation occurs as long as the eggs remain in this solution. If they are brought back from this solution into normal sea water, they will segment, provided they have not been left too many hours in the hypertonic sea water. There is, however, a characteristic difference between this segmentation and the normal segmentation. If the eggs are brought back into normal sea water after two hours, they do not divide, as a rule, first into two, and then into four cells, but into three or four cells simultaneously. If they are left for three or four hours in the hypertonic solution, and then 
brought back into normal sea water, they break apart into from six to sixteen cells simultaneously in about ten or twenty minutes after being put back into normal sea water. If they remain for five or six hours in the hypertonic solution, many eggs suffer. If they do not suffer they soon break up, when put into normal sea water, into a still larger number of cells than if they remained only for three or four hours in the hypertonic sea water. I have seen such eggs divide simultaneously into about forty cells, or more, in from ten to twenty minutes after being put back into normal sea water. These phenomena of segmentation are accompanied by violent phenomena of streaming or protoplasmic motion at the surface of the egg. From these facts I concluded that while the hypertonic sea water inhibits the cell division, it allows the division of the nucleus, which precedes the segmentation of the protoplasm.* W. W. Normant undertook a histological examination of the eggs under these conditions. He found that if the concentration of the sea water be adequately, but not excessively, raised through the addition of a definite amount of $\mathrm{NaCl}, \mathrm{KCl}$, or $\mathrm{MgCl}_{2}$, the nuclei of the eggs divide in the hypertonic sea water karyokinetically, into two, four, and eight successively, while no cell division occurs. When such an egg with eight nuclei is put back into normal sea water, it divides as a rule into more than eight cells simultaneously. If a slightly too high concentration is used, the distribution of the nuclei in the egg does not become so regular; if the concentration is still a little higher, an excessive number of astrospheres is formed, as Morgan and Norman found. In this case, the nuclcar material is often not scattered in the egg, although the nucleus seems to be broken into smaller fragments, for if brought back into normal sea water such eggs break up rapidly into a larger number of cells. R. Hertwig had already observed the formation of astrospheres in the unfertilized eggs of the sea urchin when he added a little sulphate of quinine to the sea water, and Morgan applied the method used by myself and Norman to the unfertilized egg and found an excessive number of astrospheres, just as Norman had observed in the fertilized egg. $\ddagger$

It is obvious from these and other experiments not mentioned here that the loss of water on the part of the fertilized egg ultimately retards all the phases of nuclear and cell division, but not all quantitatively alike. It seems that the chemical process of transformation of protoplasmic into chromatin material is less interfered with than the cell division proper. This follows from the fact that the chromosomes may divide without

* Loeb, Jour. of Morphology, Vol. 7, p. 253, 1892.

$\dagger$ W. W. Norman, Archiv für Entwickelungsmechanik, Vol. 3, p. I06, I896.

¥ Morgan, Archiv für Entwickelungsmechanik, Vol. 8, p. 448, I899. 
cell division. Under normal conditions, the growth of the chromo. somes is followed by a formation of astrospheres and division of the nuclei, and this in turn is followed by a cell division. The loss of water which the egg undergoes in the hypertonic sea water seems to interfere mostly with the cell division. It is possible that the viscosity of the protoplasm is increased by the loss of water, and that this condition interferes somewhat with the migration of chromosomes after they have divided and still more with the segmentation of the protoplasm. The growth of the chromosomes and the subsequent formation of astrospheres seem, however, to continue for some time in the hypertonic sea water.

O. and R. Hertwig (as well as Roux) have noticed that as a rule the plane of division of a non-spherical cell is at right angles with the direction of the greatest diameter, or extension of the cell. Driesch has given a nice experimental proof for this rule. If the newly fertilized egg of the sea urchin be gently pressed under a cover glass, so that it is slightly flattened, the plane of division is at right angles to the slide. The position of the plane of cleavage is determined by the position of the nuclear spindle, and the latter depends upon the position of the centrosomes or astrospheres. The question hence arises, How does it happen that in most cases the common diameter of the two astrospheres coincides with the longest diameter of a cell? This position of the astrospheres or centrosomes becomes comprehensible on the assumption that these organs not only repel each other, but are also repelled by the external surface of the nuclei and the inner surface of the cell limit. The forces involved in this repulsion must be forces such as occur in liquids, as the contents of the egg of the sea urchin is mainly liquid. It must, moreover, be taken into consideration that the space in which the process of cell division occurs, is generally of microscopic and always of capillary dimensions. It is therefore quite possible that the repelling forces in this case are capillary forces. There is, however, another fact to be considered; namely, that in the process of cell division the egg of some animals becomes elliptic, with its long axis falling in the direction of the common diameter of both astrospheres. This has given rise to the idea that the spindle or the astrospheres elongated the egg. I have often noticed - as others have undoubtedly done before me - an elongation of the egg of the sea urchin in the direction of the spindle, but this always occurred immediately before the cell division. It gives easily the impression as if contractile forces were active in radial directions in the astrospheres and that these forces had something to do with the process of cell division. Certain deviations from Hertwig's law may be only apparent. 
Such exceptions occur in epithelial cells, but it is quite possible, that not the whole cell but only one part of it is in this case the seat of the processes which cause the orientation of the astrospheres or the centrosomes.

R. Lillie has expressed the idea that electrical forces play a rôle here. Were this idea correct, it should be an easy matter to control the orientation of the plane of cleavage in the cell by means of a galvanic current; such is, however, not the case, at least as far as our present experience goes. If hydrodynamic and "contractile" forces are responsible for the orientation of the astrospheres or centrosomes in the cell, it should be expected that these latter organs are solid or at least more viscous than the rest of the liquids of the cell. If the centrosomes are fixed organs of the cells, and multiply by division, they must naturally be solid or at least possess a solid surface. Alfred Fischer assumed that the formation of astrospheres depended upon a process of coagulation. This has not yet been proved, although this author has imitated the well-known figures of astrospheres in coagulated proteins.

If the process of nuclear division in transparent cells, e.g. egg cells, is observed, the impression is easily gathered that the astrospheres cause a liquefaction of the nuclear membrane and an emulsification of certain constituents of the nucleus. If this observation be correct, the phenomena of spreading and the phenomena of streaming connected with such a process might be the forces which carry the chromosomes of the nucleus toward the center of the astrospheres. This assumption is in harmony with the fact that the withdrawal of water from the egg cell diminishes the velocity of the nuclear division,* inasmuch as the loss of water may easily increase the viscosity of protoplasm, and thus diminish the velocity of the process of streaming, finally rendering it entirely impossible.

The phenomena of streaming can be demonstrated most beautifully in the experiment described above in which eggs of the sea urchin were put into hypertonic sea water, whose concentration was just adequate to prevent the cell division, without preventing the nuclear division. When such eggs are put back into normal sea water after about three hours, the most powerful phenomena of streaming may be witnessed, resulting in the formation of knobs. The streaming seems to occur around the chromosomes or fragments of nuclear material as a center. Afterwards, each such knob, or projection, formed by the streaming becomes a separate cell. $\dagger$

* Loeb, Am. Jour. of Morphology, Vol. 7, p. 253, 1892.

$\dagger$ This amoeboid, character of cell division had been observed and described before by O. and R. Hertwig and called "Knospenfurchung." 
In my earlier experiments on artificial parthenogenesis, I frequently had opportunity to observe cell divisions of a character which made it clear that phenomena of streaming underlie cell division, at least, in these cases. Figures I0-I 3 give an illustration of such a case. The egg had been treated with hypertonic sea water, and when put back

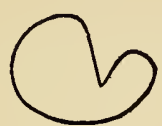

FIG. Io.

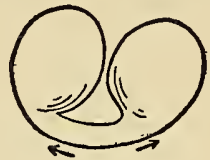

FIG. Ir.

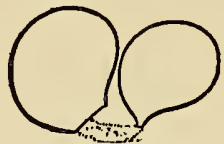

FIG. 12.

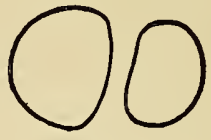

FIG. 13.

into normal sea water divided as represented in these drawings. The division began (as was frequently the case) on one side (Fig. Io), and the protoplasm then flowed in the direction of the two arrows (Fig. II) in opposite directions toward the two nuclei. The connecting piece becomes empty of protoplasm and only the pigmented solid surface film is left (Fig. I2), and finally this also disappears (Fig. I3). It is, however, possible that contractile forces acting in a radial direction in an astrosphere might bring about similar results.

The process of the cell division proper seems to consist also of several phases. A reduction of volume seems to occur in this process, inasmuch as the combined volume of the two daughter cells appears immediately after the division, smaller than the volume of the mother cell. This diminution of volume may be due to a loss of water, or watery liquid, on the part of the cell. There may also be a process of gelation on the part of certain constituents of the cell, e.g. the nucleus, which at this stage appears to form a solid mass, or possesses at its surface a solid wall.

\section{The Origin of Radiant Energy in Living Organisms}

The first investigation of animal phosphorescence that was of any consequence goes back to Faraday, who showed that the phosphorescent part of a glowworm continues to send out light if it be made into a pulp. This observation speaks against the view of Kölliker and Pflüger that the phosphorescence of animals is a function of "living" matter, and even, in certain cases, under the control of the nervous system. They were led to their view by the observation that "stimulation" could call forth the process of phosphorescence, while poisons and high temperatures caused it to disappear. From this Pflüger*

* Pfiugger's Archiv, Vol. Io, p. 251, 1875. 
drew the conclusion that phosphorescent matter is irritable, and "irritability" is considered a sign of life. We must not, however, overlook the possibility that stimulation of an animal may produce the process of phosphorescence indirectly, e.g. by causing motions on the part of the animal which bring the phosphorescent matter into contact with oxygen. Giesebrecht * has furnished an absolute proof for the fact that phosphorescence may be produced in animals by non-living material. He found that certain pelagic copepods, e.g. Pleuromma gracile and Leuckartia flaviensis show phosphorescence, and that this phenomenon is confined to definite points of their body, which correspond to the ducts of certain glands of the skin of the animals. These glands secrete drops of a greenish yellow substance. As long as the animals lie quiet there is no phosphorescence visible, but they show this phenomenon when pressed or heated, or if brought in contact with ammonia, alcohol, or glycerine. This might easily be interpreted as signifying that the phosphorescence of these animals is a phenomenon, which is produced by the stimulation of the animal. Giesebrecht found, however, that the phosphorescence occurs only when the secretion of the glands is brought to the surface of the animal, and comes in contact with the sea water. He proved, moreover, that the secretion even retains its power of phosphorescing after the death of the animal. Dead copepods, which had been preserved in a dry condition for three weeks, still showed the phosphorescence at the opening of the glands, whenever they were put into water. The above-mentioned "stimuli" caused the phosphorescence only indirectly, by causing the squeezing out of the secretion of the glands from the duct.

How the contact of the secretion with water can cause the phosphorescence is not yet clear. Radziszewski $\dagger$ has found that a number of organic compounds show phosphorescence at a comparatively low temperature, e.g. $10^{\circ} \mathrm{C}$., when they come in contact with atmospheric oxygen, and the reaction is alkaline. Among these substances are the soaps of oleic acid, a number of alcohols, etc. This author assumes that the phosphorescence of animals is caused in the same way. Traces of the phosphorescent substances and of oxygen suffice for the production of the phenomenon. We can readily understand that motions of an animal are favorable for the production of phosphorescence, as they tend to bring the oxygen (e.g. in the tracheæ of insects) in contact with new particles of the phosphorescent substance. Giesebrecht questions the importance of oxygen for this process, inasmuch as in I895.

* Giesebrecht, Mittheilungen aus der zoologischen Station zu Neapel, Vol. 2, p. 648, $\dagger$ Radziszewski, Liebig's Annalen der Chemie, I880. 
his experiments the animals also showed phosphorescence in boiled water; but as very little oxygen suffices for the phenomenon, it is possible that in Giesebrecht's experiments sufficient oxygen was present for the process. The experimenters agree, in general, that free oxygen is necessary for phosphorescence. It is possible, however, that the conditions for phosphorescence may vary with the nature of the substance.

\section{Electrical Phenomena in Living Organisms}

When Galvani noticed that the muscles of the leg of a frog twitch when touched with two metals, he believed that this phenomenon indicated the production of electricity in living organisms. Volta subsequently showed that the nerve-muscle preparation only acts as a sensitive rheoscope. Thus a misunderstood biological observation became the germ for the development of electrochemistry. It was found afterward that living organisms produce indeed some electrical energy, but in spite of the most diligent search nobody has yet been able to prove that the electrical energy thus produced plays any rôle in an essential life phenomenon, although this may be the case.

The liquids of the body must be the cause of the differences of potential in the tissues as only the electrolytes dissolved in these liquids are capable of producing differences of potential. The most common instances of the production of a difference of electrical potential are

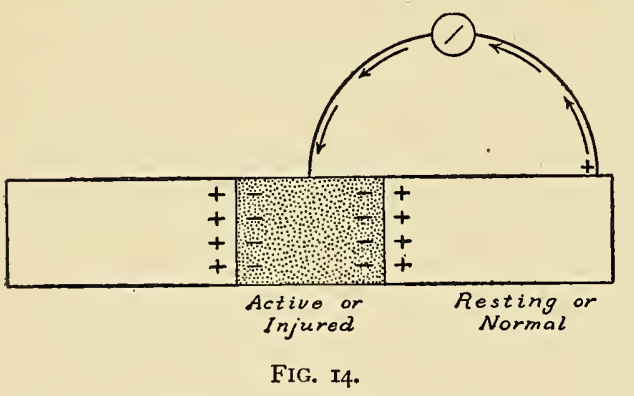
the cases of an active or dying nerve or muscle. When an element of a nerve is active or injured, and one electrode of a galvanometer is applied to the active or injured spot (Fig. I4), another to the neighboring resting, or normal element of the nerve or muscle, a current of positive electricity travels through the galvanometer from the resting, or normal, to the active, or injured element of the nerve or muscle. The activity of the muscle, or its injury, is accompanied by a production of acid, i.e. carbonic, and possibly, lactic acid. According to Waller $\mathrm{CO}_{2}$ is also produced in the active nerve.* I concluded from this that these currents might be due to the formation of acid. The $\mathrm{H}$-ions have a much greater velocity of migration than any anion, and hence,

* Waller, Lectures on Physiology, I. On Animal Electricity, London, 1897. 
if in an active or injured element of the nerve or muscle acid is formed, the hydrogen-ions must migrate faster into the neighboring tissue than the anions. Consequently, the active element will have an excess of free negatively charged ions, while the neighboring resting elements will assume a positive charge (Fig. I4). I published this explanation of the origin of currents of action in a preliminary way in an address at the Naturalists' meeting in $1897 . *$ Oker-Blom $\dagger$ has since expressed a similar view in regard to the current of demarcation; and he mentions that Tschagovetz has published a similar view in a Russian journal.

Ostwald $\ddagger$ has pointed out that the semipermeable membranes may possibly be permeable for only one class of ions, positive or negative, and "not only the currents in muscles and nerves, but also the mysterious effects of electrical fishes might find their explanation by such a property of the semipermeable membranes." Bernstein $\S$ and Brünings $\|$ have recently adopted this view. Bernstein pointed out that, in order to explain the above-mentioned current of action, a specific permeability of the semipermeable membranes for cations must be assumed. It is hardly possible that differences in electrical potential can arise in any other way in the tissues than by a separation of anions and cations of the electrolytes dissolved in the tissues. As the difference in the rate of diffusion for different ions always exists, especially when acids or alkalies are formed, and as a difference of the permeability of the protoplasm for oppositely charged ions may also easily exist or arise, it is not difficult to understand that so many life phenomena are accompanied by electrical changes and currents, e.g. when light falls upon the retina, or when glands secrete.

Plants also show such currents, especially such plants, as are distinguished by a comparatively quick conduction of stimuli, e.g. Mimosa or Drosera. This lends, perhaps, support to the idea expressed by Hermann that the current of action is the cause, or means, of the propagation of the nerve impulse. When a nerve or muscle is stimulated, the stimulated spot becomes negatively electrical as compared with the neighboring resting spot. In the next element of time this latter .spot becomes the seat of activity, and now becomes negative toward the more distantly situated piece of nerve, etc. A region or wave of negative potential is thus propagated from the original seat of stimulation in both directions, through the nerve. Bernstein has found that this negative wave is propagated with the same velocity as the

* Loeb, Science, N.S., Vol. 7, p. 154, 1898.

† Oker-Blom, Pfiüger's Archiv, Vol. 84, p. I9I, I9or.

$\ddagger$ Ostwald, Zeitsch. für physik. Chemie, Vol. 6, I89o.

$\S$ Bernstein, Pfïger's Archiv, Vol. 92, p. 521, Igor.

il Brünings, Pfiiger's Archiv, Vol. 100, p. 367, I903. 
nerve impulse, so that there exists a possibility that this difference of potential which originates upon stimulation is the cause, or the means, of propagation for the nerve impulse. Hermann has given a more detailed sketch of such an assumption.* The axis cylinder of the nerve is surrounded by a liquid conductor of electricity, i.e. a solution of electrolytes. If a certain element $A$ of the axis cylinder be stimulated, it will assume a negative charge, while the neighboring parts $B$ assume a positive charge. This leads to the formation of a microscopic current from $B$ through the liquid conductor to $A$. This current may be considered as a stimulating current for the axis cylinder with an anode at $A$ and a cathode at $B$. We shall see in a later lecture that if a current be made, the stimulation occurs at the cathode, while the anode is put into a condition of diminished irritability. Therefore, the region $A$ now returns to a condition of rest, while $B$ becomes active. Then the same process is repeated for $B$ and its neighboring element, etc.

Waller has been able to determine the beginning of life in the hen's egg and in seeds of plants by galvanometric tests; he has also determined the cessation of life in the same manner. $\dagger$ These facts may serve as a further indication that all life phenomena are accompanied by electrical phenomena. We shall see later that salts play a great rôle in life phenomena; and it is obvious that if changes in the nature and number of ions in a solution accompany life phenomena, electrical currents must also be a necessary consequence.

* Hermann, Handbuch der Physiologie, Vol. 2, Ist part, p. I93, I879.

$\dagger$ Waller, C. R. de l'Academie des Sciences, Vol. I3I, pp. 485 and II73, I900. Proceedings of the Royal Society, Vol. 68, p. 79, I9OI. 


\section{LECTURE V}

THE RÔLE OF ELECTROLYTES IN THE FORMATION AND PRESERVATION OF LIVING MATTER

\section{On the Specific Difference Between the Nutritive Solu- tions FOR Plants AND ANIMAls}

THE green plants are the factories in which the material for the nutrition for animals and fungi is prepared. The green plant, however, manufactures also, as long as it grows, its own living matter out of the electrolytes of the soil and the $\mathrm{CO}_{2}$ of the air. The $\mathrm{CO}_{2}$ is utilized for the formation of carbohydrates and probably fats; the salts of ammonia, nitrates, phosphates, and sulphates are used for the building up of nitrogenous compounds. One of the nutritive solutions* which is most commonly used for phanerogamic plants is as follows :-

$$
\begin{aligned}
4 & \text { g. } \mathrm{Ca}\left(\mathrm{NO}_{3}\right)_{2} \\
\text { I } & \text { g. } \mathrm{KNO}_{3} \\
\text { I } & \text { g. } \mathrm{MgSO}_{4}+7 \mathrm{H}_{2} \mathrm{O} \\
\text { I } & \text { g. } \mathrm{KH}_{2} \mathrm{PO}_{4} \\
0.5 & \text { g. } \mathrm{KCl}
\end{aligned}
$$

The whole is dissolved in from 3 l. to 7 l. of water. A few drops of ferric chloride are added to this solution. This solution may vary within certain limits. It contains besides the anions $\mathrm{CO}_{3}, \mathrm{NO}_{3}$, $\mathrm{SO}_{4}$, and $\mathrm{PO}_{4}$, which are necessary for the synthesis of the essential compounds of the plant, the cations $\mathrm{K}, \mathrm{Ca}, \mathrm{Mg}$, which do not seem equally necessary for the synthesis of living matter. In addition to these, free oxygen is absolutely necessary for the formation of living matter in green plants.

For the fungi the nutritive solutions are similarly constituted, with this difference only, that they cannot make carbohydrates of $\mathrm{CO}_{2}$; and they are therefore compelled to get their sugar from plants or animals. If raised in a solution containing sugar or certain organic acids (e.g. acetic, tartaric acids) and certain salts, they can also make

* Knop's Solution. See Pfeffer, Pfanzenphysiologie, 2d edition, Vol. I, p. 4r3, r897. 
all the constituents of living matter, e.g. fats, proteins, nucleins. Raulin, a pupil of Pasteur, has investigated with unparalleled thoroughness the optimal nutritive solutions for a fungus, Aspergillus niger. Raulin * determined which nutritive solution gave the greatest development of living matter from a given quantity of spores, and found that it possessed the following composition:-

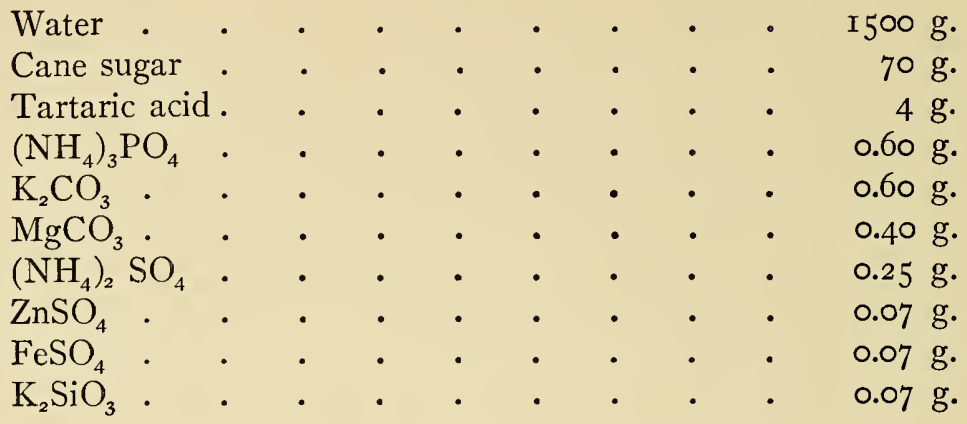

Of course, to this list must be added atmospheric oxygen.

Part of the free acid in Raulin's solution is neutralized by the $\mathrm{HO}$ ions due to the presence of $\left(\mathrm{NH}_{4}\right)_{3} \mathrm{PO}_{4}$ and $\mathrm{K}_{2} \mathrm{CO}_{3}$ in the solution. The sugar, fatty acid, ammonia, $\mathrm{SO}_{4}$, and $\mathrm{PO}_{4}$ are used for the building up of living matter; but it is not clear what the rôle of $\mathrm{K}, \mathrm{Mg}, \mathrm{Zn}$, and $\mathrm{Fe}$ is. It is remarkable that $\mathrm{Ca}$ is not required, and it seems to be a general fact that $\mathrm{Ca}$ is not of great importance for the fungi, while it is of great importance for animals, and apparently also for the higher plants. But what is the rôle of the cations?

It has been noticed that the living tissues of plants, as well as of animals, possess a selective power for certain salts, especially for K-salts. Although in fresh-water streams the concentration of $\mathrm{K}$-salts is often very low, the plants which live in it are capable of storing up a comparatively large amount in their tissues. The muscle of animals shows the same phenomenon, inasmuch as it contains a much higher percentage of potassium than the blood. This "selective power" admits of only one explanation; namely, that the potassium is used for the building up of more complex compounds in which the $\mathrm{K}$ cannot be dissociated as a free ion. If a tissue utilizes one kind of metals in this way, e.g. $\mathrm{K}$, while another metal, e.g. $\mathrm{Na}$, is chiefly used for the formation of dissociable compounds with $\mathrm{Na}$ as a free ion, the consequence will be that the ashes of a tissue contain $\mathrm{K}$ and $\mathrm{Na}$ in altogether different proportions from what they are contained in the surrounding solu-

* See Duclaux, Traité de microbiologie, Vol. I, p. I76, I898. 
tion. I think we may take it for granted that, at least, $\mathrm{K}$ forms a nondissociable constituent of the protoplasm of a number of tissues of animals and plants, and that it therefore may be considered a building stone for living matter in the same sense as the above-mentioned anions.

This fact explains the so-called oligodynamic effects. This term was applied to the fact that certain heavy metals like $\mathrm{Cu}$, or, as I believe, traces of their salts, can produce a toxic effect. Obviously the $\mathrm{Cu}$-ions form upon their entrance into the cell undissociable or practically undissociable compounds with protein substances, and thus their concentration is kept lower in the cell than in the surrounding solution. The consequence is that in due length of time enough $\mathrm{Cu}$ may diffuse into the cell to act toxically. There is therefore no reason why we should continue to set aside the oligodynamic effects as a distinct group of phenomena in biology. It is quite possible that an ion may be utilized in two ways by a tissue; namely, for the synthesis of molecules from which it can no longer be dissociated as an ion, and in the form of salts, - possibly ion-proteids, - where the metal can dissociate as an ion.

What is true for the $\mathrm{K}$ may also be true for the $\mathrm{Mg}$, but it can scarcely be so for the $\mathrm{Zn}$ in Raulin's solution, although, curiously enough, it is not so much less important for Aspergillus than K. Raulin found that if he allowed spores to develop on the above-mentioned solution, which contained all fourteen constituents, except $\mathrm{K}$, the crop was only one twenty-fifth of the dry weight of that which he got when he added $\mathrm{K}$. When the trace of $\mathrm{Zn}$ contained in that solution was omitted, the dry weight of the crop was only one tenth of that which he obtained when $\mathrm{Zn}$ was added. Raulin has made similar determinations for all the constituents of his nutritive solution. The figure following each substance in the table below expresses how many times greater the dry weight of the crop was with the addition of the substance than without it.

\begin{tabular}{|c|c|c|c|c|c|c|c|c|c|c|}
\hline $\mathrm{NH}_{4}$ & $\cdot$ & & • & 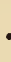 & • & & $\bullet$ & $\bullet$ & $\bullet$ & \\
\hline $\mathrm{PO}_{4}$ & • & 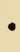 & • & 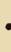 & $\bullet$ & $\bullet$ & • & $\bullet$ & • & • \\
\hline $\mathrm{Mg}$ & • & $\bullet$ & $\cdot$ & 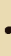 & & - & $\bullet$ & $\bullet$ & • & $\bullet$ \\
\hline $\mathrm{K}$ & $\cdot$ & $\bullet$ & $\bullet$ & • & . & • & $\bullet$ & $\bullet$ & - & $\bullet$ \\
\hline $\mathrm{SO}_{4}$ & • & • & $\bullet$ & . & . & • & • & $\bullet$ & • & $\bullet$ \\
\hline $\mathrm{Zn}$ & • & • & • & . & 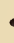 & • & • & . & • & 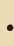 \\
\hline $\mathrm{Fe}$ & • & • & • & • & • & • & • & $\bullet$ & 。 & • \\
\hline $\mathrm{SiO}_{3}$ & • & . & . & & & 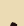 & & & . & . \\
\hline
\end{tabular}

It was to be expected that the omission of $\mathrm{NH}_{4}$ from the solution would reduce the crop considerably (to $\frac{1}{15} \overline{3}$ of its weight), inasmuch as it 
furnishes the material for the manufacture of the proteins. The $\mathrm{PO}_{4}$ is needed for the nucleins, and it is probable that the $\mathrm{Mg}$ is necessary for the building up of definite important compounds; but the $\mathrm{Zn}$ is no part of any compound of the plant. It is therefore obvious that the nutritive solution for a plant not only contains substances which are of importance for the building up of its living matter, but also substances which do not enter into these compounds and are yet of importance. I am inclined to believe that the explanation of the latter facts takes us back to the antagonistic salt effects discussed in the previous lecture.

If we compare the nutritive solutions for animals with those of plants, we find in general that $\mathrm{PO}_{4^{-}}, \mathrm{NH}_{4^{-}}, \mathrm{NO}_{3}$-ions, which are of such importance for plants, are either of no importance for animals, or are directly poisonous, e.g. the $\mathrm{NH}_{4}$-ions. Inasmuch as the animals get all their proteins and carbohydrates directly or indirectly from plants, it is to be expected that they do not depend upon the $\mathrm{CO}_{2}$ of the air or the $\mathrm{NH}_{4}, \mathrm{NO}_{3}$, or $\mathrm{PO}_{4}$ of the soil. We meet, however, with another striking difference between animals and plants, which was not to be expected a priori; namely, the fact that $\mathrm{Na}$, which appears neither in Knop's solution for Phanerogams nor in Raulin's solution, is one of the most, if not the most, important constituent of a nutritive solution for animals. Next in importance for animals is $\mathrm{Ca}$, which does not appear in Raulin's solution, although it seems to be important for phanerogamic plants.

We have already seen that the majority of marine animals, e.g. marine Gammarus, can only live in solutions which contain certain salts, $\mathrm{NaCl}, \mathrm{CaCl}_{2}, \mathrm{KCl}$, and $\mathrm{MgCl}_{2}$ in definite proportions. The lack of $\mathrm{Mg}$ is not so fatal as the lack of one of the other three metals. One anion is sufficient; namely, $\mathrm{Cl}$. Without $\mathrm{Na}, \mathrm{K}$, or $\mathrm{Ca}$ the animal lives at the utmost but a couple of hours, as a rule a much shorter time; while in a mixture of $\mathrm{NaCl}, \mathrm{KCl}$, and $\mathrm{CaCl}_{2}$ it may live as long as two days, and still longer upon the addition of $\mathrm{MgCl}_{2}$.

Similar results were obtained in experiments on the substances which Tubularians need for regeneration and growth. These $\mathrm{Hy}$ droids can only live in a solution which contains $\mathrm{NaCl}, \mathrm{KCl}, \mathrm{CaCl}_{2}$, and $\mathrm{MgCl}_{2}$. If one of these salts is lacking, no polyp can be regenerated. In order to allow the polyp to grow, a substance must be added which keeps the reaction of the solution neutral; namely, $\mathrm{NaHCO}_{3} * *$

The conditions for the development of the eggs of the sea urchin,

* Loeb, Pfüger's Archiv, Vol. Ior, p. 340, I904. 
Strongylocentrotus purpuratus, are similar.* $\mathrm{NaCl}, \mathrm{KCl}$, and $\mathrm{CaCl}_{2}$ are necessary; as without one of these salts no segmentation is possible. For the complete development $\mathrm{Mg}$ and $\mathrm{SO}_{4}$ are also required, but these latter two constituents do not possess the same degree of importance as $\mathrm{Ca}, \mathrm{Na}$, or $\mathrm{K}$. In addition, a substance is needed which keeps the solution neutral, e.g. $\mathrm{NaHCO}_{3}$. Other constituents of the sea water, such as $\mathrm{PO}_{4}, \mathrm{Fe}$, are not required. This latter statement disagrees with the conclusions of Herbst. $\dagger$

The same is true for Medusæ: they will keep alive in solutions of $\mathrm{NaCl}, \mathrm{KCl}, \mathrm{CaCl}_{2}, \mathrm{MgCl}_{2}$, in the proportion and concentration in which these solutions occur in the sea water. In addition, a substance is required which keeps the sea water neutral, e.g. $\mathrm{NaHCO}_{3}$. I think these examples may suffice as the proof of the fact that for marine animals $\mathrm{NaCl}$ and $\mathrm{CaCl}_{2}$ and $\mathrm{KCl}$ are essential for the maintenance of life. It is questionable whether the substances which growing animals require for the manufacture of living matter are taken from the surrounding solution. Were this the case, only traces of any of these salts should be sufficient, while in reality the proportion of $\mathrm{Na}$, $\mathrm{K}$, and $\mathrm{Ca}$ can vary only within certain limits in the solution.

The tissues of marine animals seem to require a solution of the same character. Dr. Rogers has, at my suggestion, determined in which solution the heart of a marine crab beats longest. He found that sea water is an excellent "nutritive" solution for the heart, and that the same is true for a van't Hoff solution; namely, a solution of roo molecules $\mathrm{NaCl}, 2.2 \mathrm{KCl}, 2 \mathrm{CaCl}_{2}, 7.8 \mathrm{MgCl}_{2}, 3.8 \mathrm{MgSO}_{4}$. To this should be added a trace of $\mathrm{NaHCO}_{3}$. The action of sea water becomes better if a little $\mathrm{CaCl}_{2}$ is added, possibly on account of a slight antagonistic effect between $\mathrm{Ca}$ and $\mathrm{Mg}$.

It is remarkable that the tissues of fresh-water and land animals, e.g. the frog, the tortoise, and apparently the mammals, live longest in a solution which has the same constitution as the sea water, and differs from the latter only in its concentration. The optimal concentration of the solutions for frogs and land animals is about that of a $\frac{m}{8}$ solution of $\mathrm{NaCl}$. In order to keep the isolated heart of cold-blooded animals alive, Ringer has recommended the following solution:- $\ddagger$

* Loeb, Pfiuger's Archiv, Vol. I03, p. 503, I904.

† Herbst, Archiv für Entwickelungsmechanik, Vol. 5, p. 649, I897, and numerous other papers on the same subject.

Herbst did not recognize the antagonistic effects of salts, and so concluded that if the elimination of one of the constituents of the sea water was injurious, this proved the necessity of the omitted substance for the animal. The above-mentioned observations on Fundulus show in my opinion the fallacy of this conclusion.

‡ Quoted after Rusch, Pfï̈ger's Archiv, Vol. 73, p. 535, 1898 . 


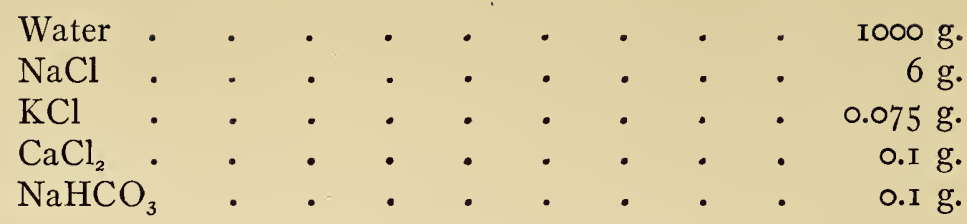

Rusch has applied this solution with success for the isolated heart of warm-blooded animals, with the difference only that he added $8 \mathrm{~g}$. instead of $6 \mathrm{~g}$. of $\mathrm{NaCl}$ to $1000 \mathrm{~g}$. of water.

Locke* recommends the following solution for the isolated heart of the rabbit:-

\begin{tabular}{|c|c|c|c|c|c|c|c|c|c|}
\hline Water & • & • & • & . & • & . & - & - & $1000 \mathrm{~g}$ \\
\hline $\mathrm{NaCl}$ & • & • & • & • & - & • & • & - & 9.10 \\
\hline $\mathrm{KCl}$ & • & - & • & 。 & • & . & • & - & 0.2 \\
\hline $\mathrm{CaCl}_{2}$ & $\bullet$ & $\bullet$ & $\bullet$ & • & • & . & 。 & - & 0.2 \\
\hline $\mathrm{NaHCO}_{3}$ & • & $\cdot$ & • & . & . & • & . & $\cdot$ & O.I \\
\hline
\end{tabular}

The solution is said to be more effective if a little dextrose is added, e.g. I g.

Otherwise Locke's solution differs from Ringer's by a somewhat higher amount of $\mathrm{KCl}$ and $\mathrm{CaCl}_{2}$. His figures for these latter salts are approximately those which Abderhalden found for the concentration of these salts in the serum of rabbits; namely, 0.024 per cent $\mathrm{CaCl}_{2}$ and 0.042 per cent $\mathrm{KCl} . \dagger$

If we express the percentage solutions of Ringer, Locke, or Abderhalden, in the values of grammolecular solutions, we find that it is approximately 100 molecules $\mathrm{NaCl}$ to 2 molecules of $\mathrm{CaCl}_{2}$. This is practically the proportion in which these salts exist in the sea water, and in which marine animals live longest. This proportion may vary a little for marine animals, and the same is true for the solutions in which the tissues of animals live best, as a comparison of the figures of Ringer and Locke shows.

An observation mentioned already in a former lecture shows conclusively that the mixture of $100 \mathrm{NaCl}, 2 \mathrm{KCl}$, and $2 \mathrm{CaCl}_{2}$ cannot be considered as a nutritive solution for animals, but must play a different rôle. Fundulus lives just as well in distilled water as in sea water. This fact proves that these animals do not depend for their nutrition

* Locke, Centralblatt für Physiologie, Vol. 14, p. 670, 1901.

+ The fact that Locke also mentions sugar as one of the necessary constituents of his solution indicates that he considers the other constituents also as nutritive material. This would, however, be wrong. From my own experiments I do not think that the addition of sugar is of any value. 
and development upon the salts dissolved in the sea water. If the young fish, however, are put into a pure solution of $\mathrm{NaCl}$ of the concentration in which this salt is contained in the sea water $\left(\frac{m}{2}\right)$, the animal dies in less than twelve hours. If $\mathrm{CaCl}_{2}$ is added, the animal does not live more than twenty-four hours. If it is desired to keep animals alive permanently, - my experiments lasted for ten days, - not only $2 \mathrm{CaCl}_{2}$ but also $2 \mathrm{KCl}$ must be added to $100 \mathrm{NaCl}$. This is exactly the solution which is generally considered as a nutritive solution for animals.*

I believe that these facts show that we must discriminate between nutritive and protective solutions. Ringer's solution, as well as the sea water, are primarily protective and not nutritive solutions. What is meant by this becomes clear if we remember what was said concerning the antagonistic effects of salt. A $\frac{m}{2}$ solution of $\mathrm{NaCl}$, as well as a $\frac{m}{64}$ solution of $\mathrm{ZnSO}_{4}$, alone are each poisonous for the eggs of Fundulus. If mixed, the solution becomes considerably less poisonous. It is probable that these two salts if together in solution materially diminish their rate of diffusion into the tissues. It follows from these experiments that the rôle of the $\mathrm{Ca}$ and $\mathrm{Mg}$ in the sea water, as well as in a Ringer's solution, consists partly in antagonizing the effects which would be produced by the $\mathrm{NaCl}$ were it alone in solution. The experiments with Fundulus suggest that in this case the presence of the $\mathrm{Ca}$ and $\mathrm{Mg}$ in the sea water diminishes the rapidity of diffusion of the $\mathrm{NaCl}$ into the tissues. It is possible that the $\mathrm{Zn}$ acts in some protective way in the case of Raulin's solution, although in regard to this it is not possible to make a definite statement.

But there remains the other fact that $\mathrm{K}$ is also needed. The life of Gammarus and many other marine animals is not essentially prolonged by the addition of $\mathrm{CaCl}_{2}$ or $\mathrm{MgCl}_{2}$ or both to the $\mathrm{NaCl}$ solution, but is materially prolonged by the addition of $\mathrm{CaCl}_{2}$ and $\mathrm{KCl}$ to the $\mathrm{NaCl}$ solutions. Besides we cannot, in general, substitute any other bivalent metal (with the exception of $\mathrm{Sr}$ ) for $\mathrm{Ca}$; nor can we substitute any other univalent cations for $\mathrm{Na}$ and $\mathrm{K}$. This indicates that the metals $\mathrm{Na}, \mathrm{Ca}, \mathrm{K}$, and $\mathrm{Mg}$ play a rôle in life phenomena other than that of serving for the synthesis of living matter, and also other than that of merely regulating the velocity of diffusion. We have already alluded to the possibility of their necessity for phenomena of secretion. We are inclined to believe that what is generally called irritability and contractility is due to the influence of these ions. 


\section{Concerning a Theory of Irritability and the Rôle of Na, $\mathrm{K}$, AND CA FOR ANIMAL Life}

In 1899 I outlined a general theory of irritability which may be briefly summarized in the following sentences which I quote from a former paper: "The salts, or electrolytes in general, do not exist in living tissues as such exclusively, but are partly in combination with proteids (or fatty acids). The salts or electrolytes do not enter into this combination as a whole, but through their ions. The great importance of these ion-proteid compounds (or soaps) lies in the fact that, by the substitution of one ion for another, the physical properties of the proteid compounds change (e.g. their surface tension, their power to absorb water, or their viscosity or state of matter). We thus possess in these ion-proteid or soap compounds essential constituents of living matter, which can be modified at desire, and hence enable us to vary and control the life phenomena themselves."*

Life phenomena, and especially irritability, depend "on the presence in the tissues of a number of various metal proteids, or soaps ( $\mathrm{Na}$, $\mathrm{Ca}, \mathrm{K}$, and $\mathrm{Mg}$ ), in definite proportions."

I first applied this conception to a phenomenon which had hitherto been observed only occasionally; namely, rhythmical contraction of the muscles of the skeleton. $\dagger$ I found that such rhythmical contractions occur only in solutions of electrolytes, i.e. in compounds which are capable of ionization. In solutions of nonconductors (urea, various sugars, and glycerine), these rhythmical contractions are entirely or practically impossible. Only in certain, not in all, salt solutions are such rhythmical contractions possible. All the solutions of Na-salts are able to produce them, but in a 0.7 per cent $\mathrm{NaCl}$ solution, contractions begin later, and are less powerful, than in an equimolecular $\mathrm{NaBr}$ solution. The experiments on the rhythmical contractions of the muscles of the skeleton led to some other data concerning the effects of those salts. Solutions of Na-salts produce rhythmical contractions only if the muscle cells contain $\mathrm{Ca}$-ions in sufficient numbers. As soon as there is a lack of $\mathrm{Ca}$-ions in the tissues, the $\mathrm{Na}$-ions are no longer able to cause rhythmical contractions. On the other hand, if we add Ca-salts in sufficient quantity to the $\mathrm{NaCl}$ solution, it will no longer cause rhythmical contraction in a fresh muscle of the frog. It there-

* Loeb, Am. Jour. Physiology, Vol. 3, p. 337, 1900.

† Loeb, Festschrift für Professor Fick, Würzburg, i899.

The idea of the general existence of such ion-proteid compounds was developed independently by Pauli and myself in I899. Loeb, Pfïger's Archiv, Vol. 75, p. 303, I 899 ; and Festschrift für Fick, 1899; and W. Pauli, Wiener akademischer Anzeiger, October 12, 1899; and Ueber physikalisch-chemische Methoden und Probleme in der Medizin, Wien, 1900. 
fore looks as if the presence of a certain quantity of $\mathrm{Na}$-ions caused contractions; but if the quantity of the Na-ions becomes too great in proportion to the $\mathrm{Ca}$-ions, the muscle loses its irritability. On the other hand, if there are too many $\mathrm{Ca}$-ions present, the rhythmical contractions become also impossible. The quotient of the concentration of the Na-ions over the concentration of the Ca-ions, $\frac{\mathrm{C}_{\mathrm{Na}}}{\mathrm{C}_{\mathrm{Ca}}}$, becomes therefore of importance for phenomena of irritability. We shall see later that $\mathrm{Mg}$ acts very much like $\mathrm{Ca}$ in this respect.

It is hardly necessary to mention that this suggested the possibility that muscular contraction, in general, is due to a substitution of $\mathrm{Na}$ for $\mathrm{Ca}$, or vice versa, in certain compounds (proteins or soaps) in the muscle. Every substance or agency will act as a stimulant which brings about such a change of the metals in these compounds in the muscle.

It may be added that all the salts of univalent metals act like the Na-salts, inasmuch as they cause rhythmical contractions when the muscle is put into them. All these salts, however, have secondary effects which usually prevent the contraction from lasting as long as in $\mathrm{NaCl}$. In $\mathrm{KCl}$ the muscle gives only a few twitches when thrown into the solution, and then stops. In $\mathrm{LiCl}$ the twitches may last over a day. As of the salts with a univalent metal, only the Na- and K-salts occur in the muscle, only the substitution of one of these salts need be considered for the theory of irritability.

Not only Ca- but also Sr- and Mg-salts are capable of antagonizing the stimulating effects of a pure $\mathrm{NaCl}$ solution when added to the same. As I stated six years ago, we owe it to the $\mathrm{Ca}$ - and $\mathrm{Mg}$-salts in our blood that our skeletal muscles do not contract rhythmically like our heart.

We may now give a provisional answer to the question why it is that the Na-salts, which are unnecessary in the nutritive solution of a plant, become of so great importance for the life of an animal. If our hypothesis be correct, the answer should be that all the muscular contractions are due to a substitution of $\mathrm{Na}$-(or $\mathrm{K}$ ) for $\mathrm{Ca}$ - or $\mathrm{Mg}$-ions, or vice versa. In the plant, which has no muscles, there is no need for any $\mathrm{NaCl}$. Likewise we can understand why $\mathrm{CaCl}_{2}$ plays a lesser rôle in plants than in animals, as Raulin's investigations indicate.

In an $\frac{n}{8}$ solution of $\mathrm{NaCl}$ it requires, as a rule, a long time - an hour or more - before the contractions begin at ordinary room temperature; while in a more concentrated solution the contractions begin more rapidly. I concluded from this that a $\mathrm{NaCl}$ solution produces 
this effect only through the diffusion of $\mathrm{NaCl}$ into the muscle. As soon as the concentration of the $\mathrm{NaCl}$ or the $\mathrm{Na}$-ions in the muscle has reached a certain value, the muscle fiber will begin to contract. Normally the quotient $\frac{\mathrm{C}_{\mathrm{Na}}}{\mathrm{C}_{\mathrm{Ca}}}$ in the muscle is too small to permit such contractions. The addition of a slight amount of $\mathrm{NaHO}$ accelerates the process, possibly by accelerating the diffusion of the salt into the muscle.*

The fact that $\mathrm{CaCl}_{2}$ inhibits the rhythmical contractions which are produced by the $\mathrm{NaCl}$, suggested experiments on the effects of salts which precipitate $\mathrm{Ca}$ or diminish the concentration of free $\mathrm{Ca}$-ions through the formation of salts with a low degree of dissociation. It was found that such salts, e.g. sodium-oxalate,-fluoride, -citrate, and -tartrate, act much more powerfully than $\mathrm{NaCl}$ or sodium-acetate or -succinate. If such salts be applied to the nerve they produce before the twitchings begin a condition of increased irritability, comparable to the catelectrotonic condition caused by the constant current at the region of the cathode. $\dagger$

The addition of a slight amount of acid to a $\frac{n}{8} \mathrm{NaCl}$ solution shortens the latent period for the beginning of the rhythmical contractions. We shall see later on that the acid acts possibly like the above-mentioned salts; namely, by liberating the calcium from certain organic combinations in the muscle or nerve. Inasmuch as $\mathrm{CO}_{2}$ is produced in the muscle itself, this relation is of importance.

These facts suggested the idea that the process of contraction is caused by an exchange of $\mathrm{Na}$ or $\mathrm{K}$ for $\mathrm{Ca}$ or $\mathrm{Mg}$, or vice versa, in certain compounds in the muscle (or nerve). This change must be accompanied by a change in some physical property of the compound, e.g. the surface tension, the state of aggregation, viscosity, absorbing.power for water, etc. The change in such a physical property may determine or facilitate the process of contraction.

I applied the facts found in the muscle to the study of rhythmical contractions in a more favorable object; namely, the swimming bell of the Medusa. The jellyfish is comparable to a free-swimming heart which beats rhythmically, with this difference, however, that the jellyfish does not beat incessantly, like the heart, but intermittently, with long pauses between series of contractions. It is known that the central nervous system of the Hydromedusa is situated in a ring near the edge of the Medusa. Romanes had already observed that if the

* Loeb, Festschrift für Fick, Würzburg, I 899. 1902.

$\dagger$ Loeb, Am. Jour. Physiology, Vol. 5, p. 362, 1901. Pfiuger's Archiv, Vol. 91, p. 248, 
edge of a Hydromedusa be cut off from the center, the former continues to beat while the latter stops beating. This fact was utilized as an argument to prove that the contractions in a Medusa originate normally from the nerves in the margin. This may be so, but it seemed to me that the center of a Medusa (deprived of its nerve ring) might also be able to beat if it were not prevented from so doing by the constitution of the sea water. I found, indeed, that the isolated center of Gonionemus, a Hydromedusa, common at Woods Hole, is able to beat rhythmically in a pure solution of $\mathrm{NaCl} *$ The center beats in such a solution very rapidly, and the more rapidly the higher, within certain limits, the concentration of the $\mathrm{NaCl}$ solution. The addition of a small quantity of $\mathrm{CaCl}_{2}$ or $\mathrm{MgCl}_{2}$ retards or inhibits the contractions caused in the $\mathrm{NaCl}$ solution. If a salt which precipitates $\mathrm{Ca}$ or diminishes the concentration of its ions is added in excess to sea water (e.g. sodium oxalate, fluoride, citrate), the center can be caused to beat in sea water also.

It is thus obvious that the case of the center of the Medusa seems very analogous to that of the muscle. Just as the latter is prevented from twitching in the blood on account of the presence of $\mathrm{CaCl}_{2}$ and $\mathrm{MgCl}_{2}$, so the isolated center of Gonionemus is prevented from beating in sea water on account of the presence of $\mathrm{CaCl}_{2}$ and $\mathrm{MgCl}_{2}$.

After these data had been obtained I asked Dr. Lingle to determine whether similar laws hold for the heartbeat. It was known that if the sinus venosus of a frog's heart be severed from the heart, the former goes on beating as before; while the rest of the heart, especially the isolated ventricle, stops beating in blood. This observation is comparable to the one made by Romanes on jellyfish; and we may carry the analogy a step farther, by comparing the center of the Medusa to the ventricle; the edge to the sinus venosus of a frog's heart. Lingle worked on the heart of a tortoise. $t \mathrm{He}$ found that the ventricle is only able to beat after it has been put for about half an hour into a pure solution of $\mathrm{NaCl}$. When the ventricle remains permanently in the sodium chloride solution, the heartbeats will stop after a certain time, as Lingle believes, on account of the diffusion of too much $\mathrm{NaCl}$ into the heart muscle. If the strip of the ventricle is put into a moist chamber after the beats are once started in a $\mathrm{NaCl}$ solution, they may continue for a number of days, until the process of putrefaction puts an end to the contraction. No other substance can take the place of $\mathrm{Na}$. Li, which acted so well in the case of the isolated frog's muscle, can be only partially substituted for $\mathrm{N} \lambda \mathrm{Cl}$. One of the most remarkable

* Loeb, Am. Jour. Physiology, Vol. 3, p. 383, 1900.

† D. J. Lingle, Am. Jour. Physiology, Vol. 4, p. 265, I900; Vol. 8, p. 75, 1902. 
facts which Dr. Lingle found is that even the heart stimulants, such as caffeine, cannot cause the strip to beat, except in the presence of $\mathrm{NaCl}$. These experiments give the impression that the ventricle of the tortoise does not beat in the blood, because of the fact that the $\mathrm{NaCl}$ in the blood is prevented from entering into the heart cells or from acting upon them through the presence of another salt; namely, $\mathrm{CaCl}_{2}$, or $\mathrm{MgCl}_{2}$, or both.

These experiments show that in order to start the heartbeat, a pure $\mathrm{NaCl}$ solution, or a pure solution of an Na-salt, is required; but if the heart remains permanently in a pure $\mathrm{NaCl}$ solution, it stops beating. The pure solution of $\mathrm{NaCl}$ acts like a poison. If, however, a small amount of $\mathrm{CaCl}_{2}$ be added to the $\mathrm{NaCl}$ solution after the heartbeats have once started, the beats can go on for a long time. They can also continue in serum after they are once started in a pure $\mathrm{NaCl}$ solution. The addition of $\mathrm{Ca}$ therefore acts antagonistically to the injurious action of the pure $\mathrm{NaCl}$ solution. $\mathrm{Ca}$ cannot start rhythmical contractions in the ventricle, but it is necessary to sustain the rhythmical action once started by $\mathrm{NaCl}$. It is possible again that the pure $\mathrm{NaCl}$ solution becomes toxic through the fact that in such a solution too many $\mathrm{Na}$-ions take the place of $\mathrm{Ca}$, in the ion-colloids, and that this is prevented by the presence of a trace of $\mathrm{Ca}$. It is possible that the $\mathrm{Ca}$ prevents or retards the diffusion of $\mathrm{Na}$ into the muscle. In a pure $\mathrm{NaCl}$ solution, however, the rhythmical action of the heart strip can also be sustained for a long time without the addition of $\mathrm{Ca}$, if pure $\mathrm{O}$ is allowed to bubble through the $\mathrm{NaCl}$ solution, or if a trace of $\mathrm{H}_{2} \mathrm{O}_{2}$ is added to the solution. I consider these observations of the greatest importance, inasmuch as they show that the processes of oxidation going on in the muscle give the latter equal protection against the $\mathrm{NaCl}$ poisoning, just as the addition of $\mathrm{CaCl}_{2}$ to the $\mathrm{NaCl}$ solution. Could it be possible that the increase in oxidations leads to the setting free of $\mathrm{Ca}$ inside the muscle, and that the $\mathrm{Ca}$ acts in this case?

When I entered upon the investigation of the effect of salts on the rhythmical contractions of the muscle, I had in mind the solution of the problem of electrical stimulation. Previous experiments on the effects of the galvanic current had led me to the idea that the polar effects of the current are due to the ions which are blocked in their progress by the semipermeable membranes in these organs; and my idea was that experiments with salts would show which ions are responsible for the effects of a galvanic current. If the hypothesis that ions are responsible for the stimulating effects of a current were correct, it was to be expected that in solutions of nonconductors no twitchings would occur. One of the first facts that I ascertained was that this idea was 
generally correct. In solutions of dextrose, cane sugar, milk sugar, and glycerine, no twitchings of the common muscles occurred, no matter how concentrated the solution. In solutions of urea the same was true, in general, but occasionally transitory contractions were observed. In alcohol I also observed occasionally a slight twitching, but it is possible that in these latter cases the twitchings were caused by an indirect effect of urea and alcohol upon reactions or changes inside the muscle fibers. On the whole, I am under the impression that the muscle cannot be, or only exceptionally, and to a slight extent, caused to contract by solutions of nonconductors. I found that the same is true for the rhythmical contractions of the center of the jellyfish (Gonionemus). Dr. Lingle tried the same experiments on the strips from the ventricle of the tortoise, with the same result. In pure solutions of dextrose, cane sugar, and glycerine, no beats originated, even if the strip remained in these solutions for a day; but when the ventricle was afterward put into a pure $\mathrm{NaCl}$ solution the contractions began, showing that these solutions had only prevented the contractions without permanently injuring the heart. Lingle also determined what the minimum concentration of $\mathrm{NaCl}$ was that was able to start heartbeats. He found that in a mixture of 98 c.c. $\frac{n}{4}$ cane sugar +2 c.c. $\frac{n}{8} \mathrm{NaCl}$, or 96 c.c. $\frac{n}{4}$ cane sugar +4 c.c. $\frac{n}{8} \mathrm{NaCl}$, no beats started; while with 90 c.c. $\frac{n}{4}$ cane sugar + ro c.c. $\frac{n}{8} \mathrm{NaCl}$ beats could
be produced.

All these experiments seemed to support or, at least, not to contradict the idea set forth in my first paper on this subject, that the rhythmical contractions depend upon the exchange of $\mathrm{Na}$ (or $\mathrm{K}$ ) and $\mathrm{Ca}$ (or $\mathrm{Mg}$ ) in certain compounds, possibly proteids or soaps, in the muscle. Such an exchange might alter the physical properties, e.g. the surface tension, or viscosity, etc., of the substance; and a sudden change in one of the properties might result in a change of form such as underlies contraction. I figured to myself that the change starting rhythmical contractions was a sudden change in surface tension, e.g. a phenomenon of spreading, and gave expression to this possibility in my book on Brain Physiology. A series of new observations confirms me in the idea that we are dealing here with phenomena which must occur at the surface of the elements.

In I90 I I described a form of irritability in the muscle which, to my knowledge, had never been noticed before, and which is produced by such salts as precipitate $\mathrm{Ca}$ or diminish the concentration of free $\mathrm{Ca}$-ions, such as citrates, oxalates, fluorides, carbonates, phosphates, etc., and 
especially the sodium salts of these acids.* The experiment is as follows: If the gastrocnemius of a frog is put into a $\frac{m}{8}$ solution of sodium citrate and left there for two or three minutes, it will go into powerful tetanic contractions or rather cramplike clonic contractions when taken out of the solution; while these contractions stop at once when the muscle is put back immediately. This can be repeated at desire, the muscle always going into contractions when exposed to the air, and relaxing again when put back into the solution. Zoethout found that this reaction can be produced quicker and with greater certainty when a slight amount of a $\mathrm{K}$-salt is added to the solution. I believe that the $\mathrm{K}$ antagonizes the tendency to rhythmical contractions which the muscle possesses in a sodium-citrate solution. It seems to be necessary that

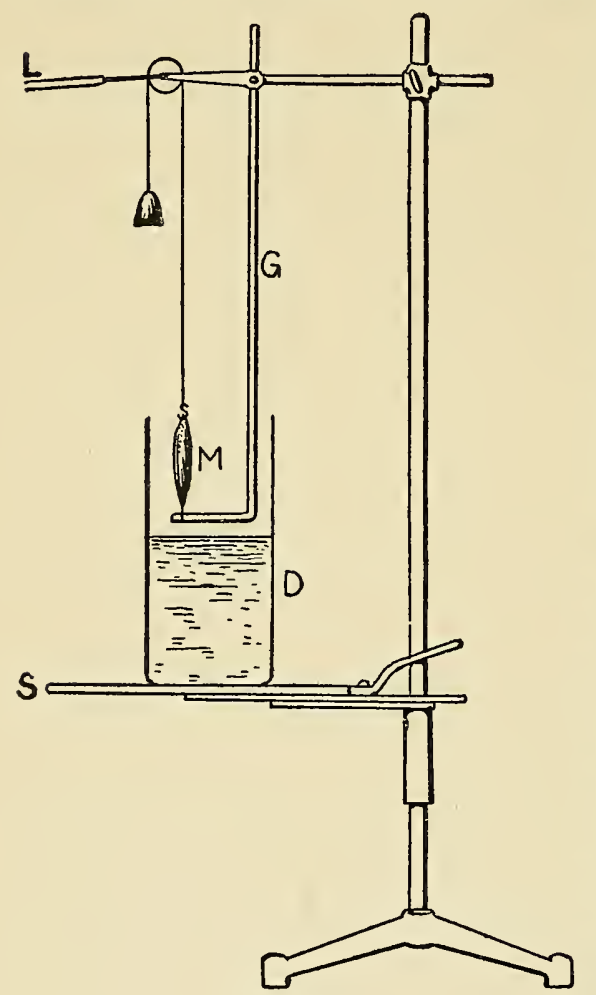

FIG. 15. this tendency to rhythmical contractions be overcome in order to obtain the phenomenon which we are now discussing, and which I called in a preliminary way the contact reaction of muscle, inasmuch as it can be produced by changing the nature of the medium which surrounds the muscle. The apparatus used for the demonstration of this experiment is shown in Fig. I5.

When only part of the muscle is lifted out of the citrate solution, only those fibers go into tonic contraction which are in contact with the air; while those fibers which remain in the solution do not contract. The reaction, therefore, is a purely local one in each individual muscle cell. This reaction not only occurs when the muscle is brought from the solution into contact with air, but also when it is brought into contact with $\mathrm{CO}_{2}$, oil, toluol, sugar, or glycerine solutions. All these solutions are nonconductors, and 
I at first believed that I was dealing here only with a break shock caused by the muscle's own current; but this was contradicted by various facts: first, that only those individual fibers contracted which were lifted out of the solution, while the others remained relaxed; second, that the latent period for the contraction after the muscle has left the solution is too long; namely, as much as a second or more. The most convincing proofs against such an assumption are, however, the following facts. The irritability of the muscle for the contact reaction does not reach its maximum at once, but only after a certain time. When the sensitiveness of the muscle has reached its height, a glycerine or a sugar solution can be substituted for the citrate solution. Whenever the muscle is at that time taken out from the glycerine or sugar solution and brought into contact with the air, the contraction occurs; while it ceases when the muscle is put back into the sugar solution. After a short time, however, the muscle loses its contact irritability in the sugar or glycerine solution. These experiments, however, certainly prove that the contact reaction is not a break shock caused by the resting current of the muscle itself when it is lifted out of the citrate solution.

It is a very interesting and theoretically important fact that the muscle loses this peculiar form of irritability very soon when it remains in contact with air, oil, sugar solution, glycerine, or salt solutions, different from those that produce this specific irritability. In $\mathrm{LiCl}$ or $\mathrm{NaCl}$ solutions the contact irritability is lost as fast, if not faster, than in a sugar or glycerine solution. We can reëstablish the irritability, however, by putting the muscle back into the sodium citrate solution for some time. This fact, together with those mentioned before, suggests the following as the most probable explanation of the peculiar phenomena of contraction with which we are dealing in this case. The solutions which produce the contact irritability possess anions which are liable to form insoluble calcium compounds. Whatever the effects of these anions may be, the fact that in less than a minute the contact effects are noticeable, indicates that only the surface layer of the muscle, or the surface layer of each individual fiber, is altered. It is impossible for the anions to migrate deeper into the muscle in so short a time. In the surface layer of the muscle or the individual fibers, we have therefore temporarily a diminution of Ca-ions. We have then a muscle whose surface layer differs from that of an ordinary excised muscle. If this layer is once established, the muscle contracts at any change from the citrate, carbonate, fluoride, etc., solutions to air, $\mathrm{CO}_{2}$, oil, $2 n$ sugar solution, glycerine, chloroform, or toluol. If the muscle be left in these media, or put into a $\mathrm{NaCl}$ or a $\mathrm{CaCl}_{2}$ solution, it loses this contact 
irritability. This loss of contact irritability of the muscle in air, oil, etc., may be due to the migration of Ca-ions from the interior of the fiber or muscle to the surface, thus reëstablishing approximately the original normal surface condition. If we then put the muscle back for a short time into a sodium citrate or sodium fluoride, etc., solution, a diminution of $\mathrm{Ca}$-ions will again occur in the surface layers, and the contact irritability will be reëstablished. As we should expect, the length of time that the muscle remains in the solution is as important as the concentration of the solution. If we dip a muscle for a few seconds only into a sodium citrate solution ( $\mathrm{I}-\mathrm{g}$. molecule in Io 1.) the contact irritability cannot be produced, as there is not time for a large enough number of citrate-ions to enter the muscle.

Dr. Zoethout carried these investigations still farther. He found that if a muscle be put into a pure $\frac{n}{8}$ solution of any potassium salt, e.g. $\mathrm{KCl}, \mathrm{KNO}_{3}, \mathrm{KI}, \mathrm{K}_{2} \mathrm{SO}_{4}, \mathrm{~K}$-oxalate, etc., the tone of a muscle increases, i.e. the muscle shortens while it is in the solution. If, however, the muscle is put into a pure $\frac{m}{8} \mathrm{CaCl}_{2}$ or $\mathrm{NaCl}$ solution, it again relaxes.* The minimum concentration of $\mathrm{KCl}$ for bringing about this increase in tone of the gastrocnemius of a frog was I c.c. $\frac{m}{8} \mathrm{KCl}+9$ c.c. $\mathrm{H}_{2} \mathrm{O}$ or $\frac{m}{8}$ glycerine. If, however, a potassium salt was chosen whose anion is liable to decalcify the muscle, the minimum concentration could be less. Thus $\frac{1}{2}$ c.c. $\frac{m}{8} \mathrm{~K}$-citrate $+9 \frac{1}{2}$ c.c. $\mathrm{H}_{2} \mathrm{O}$ was already effective. Zoethout interprets this as showing that the Ca-ions of the muscle itself are liable to antagonize the shortening action of the $\mathrm{K}$-ions. This interpretation he supported by a number of experiments. "It occurred to me that since potassium increases the tone of the muscle and calcium inhibits this action of the potassium, it might be possible that the precipitation of the calcium salts causes contact irritability, becauses it destroys the normal equilibrium between these two salts in the muscle." "Upon testing this view we found it to be correct. The contact reaction produced by sodium citrate is increased if we previously, or simultaneously, introduce K-ions into the muscle." $\dagger$ Zoethout's conclusions are as follows: "If the calcium salts in the muscle are decreased, the efficiency of the $\mathrm{K}$-ions to increase the tone of the muscle is increased. If the $\mathrm{K}$-ions in the muscle are increased, the efficiency of such salts as Na-oxalate and $\mathrm{Na}$-citrate to cause contact irritability is increased.

* Zoethout, Am. Jour. Physiology, Vol. 7, p. 199, 1902.

† Zoethout, Am. Jour. Physiology, Vol. 7, p. 320, 1902. 
The contact irritability depends (as Loeb suggested) on the disturbance of the normal ratio of salts in the muscle. Perhaps it is the disturbed ratio between the potassium and calcium salts which makes the contact reaction possible." Of course the experiment of Zoethout does not explain why the contact reaction only occurs when the muscle is taken out of the citrate solution.

I am inclined to believe that not only the $\mathrm{K}$ but also the Na-salts are concerned in this reaction; but it is certain that Zoethout's observations establish the fact that the antagonism between $\mathrm{K}$ and $\mathrm{Ca}$-salts is to be considered in the theory of animal irritability and stimulation. The statement contained in my older publications, namely, that possibly the substitution of $\mathrm{Na}$ for $\mathrm{Ca}$, or vice versa, caused the twitching of the muscle must be modified so as to include also the substitution of $\mathrm{K}$ for $\mathrm{Ca}$, or vice versa. Perhaps it may be said that the substitution of any univalent cation for $\mathrm{Ca}$ in the muscle, or vice versa, causes a twitching. As of the univalent metals, however, only $\mathrm{Na}$ and $\mathrm{K}$ occur in the tissues, they are the principal ones to be considered. It seems from these observations and others, all of which cannot be considered in this short sketch, as if indeed the substitution of $\mathrm{Na}$ or $\mathrm{K}$ for Ca-salts, or vice versa, is the essential feature of the twitching or of muscular stimulation. It would be of the utmost importance to determine which of the two possible changes was the real cause. We know that in general a substitution of $\mathrm{Ca}$ for $\mathrm{K}$ or $\mathrm{Na}$ in colloids favors the formation of more solid or insoluble compounds, e.g. in the case of soaps. In the case of the coagulation of blood or milk, it is also obvious that $\mathrm{Ca}$ in moderate quantities favors coagulation.

Ringer had already observed that barium salts have a stimulating effect upon muscle, and I have been able to confirm this observation. A pure solution of any soluble barium salts gives rise to powerful rhythmical contractions of the muscle; and the threshold for this stimulation is much lower for $\mathrm{Ba}$ than for the corresponding $\mathrm{Na}$-salts. In a $\mathrm{NaCl}$ solution the contractions last longer than in $\mathrm{BaCl}_{2}$ solution, on account of the greater toxicity of the $\mathrm{BaCl}_{2}$. I expected from this that a pure solution of $\mathrm{CaCl}_{2}$ or $\mathrm{SrCl}_{2}$ might act similarly to $\mathrm{BaCl}_{2}$, but this does not seem to be the case for the muscle. Two years ago, however, I found some new facts concerning the influence of salts upon rhythmical contractions of the center of a Californian jellyfish, Polyorchis, which meet this expectation.* If the margin containing the central nervous system of this Medusa be cut off from the center of the swimming bell, the center no longer contracts spontaneously in sea water; nor if it be put into a pure $\mathrm{NaCl}$ solution of about the concentration of the 
sea water do contractions begin. It differs in this regard very markedly from Gonionemus, whose center begins to beat at once in a pure $\mathrm{NaCl}$ solution. After a certain time, however, generally a number of hours, rhythmical contractions will begin in the isolated center of Polyorchis in a pure $\mathrm{NaCl}$ solution, and may last with long interruptions for two or three days. When they have ceased in a pure $\mathrm{NaCl}$ solution, a few single contractions can at any time be produced by touching the subumbrella with a drop of a solution of a potassium salt; but the addition of a potassium salt to the $\mathrm{NaCl}$ solution, although it promptly calls forth a single contraction or a short series of contractions, does not maintain the rhythm.

A sure means of producing rhythmical contractions of the isolated center of Polyorchis at once in a pure $\mathrm{NaCl}$ solution is the addition of a certain amount of a salt which precipitates $\mathrm{Ca}$, or diminishes the concentration of the Ca-ions, e.g. Na-citrate, -tartrate, -oxalate, etc. I generally used the citrate as it seems to be the least harmful. If Io c.c. of a $m$ sodium citrate solution be added to a IoO c.c. $\frac{3}{8} n \mathrm{NaCl}$ solution, rhythmical contractions of the isolated center begin usually at once, and may last an hour or more. A second means of calling forth rhythmical contractions in a pure solution of $\mathrm{NaCl}$ at once is the addition of a trace of an acid, e.g. $\mathrm{HCl} . \mathrm{CO}_{2}$ acts in the same way, and I have wondered whether this acid which is formed regularly in the body does not thus play an important rôle in rhythmical contractions in general. The addition of acids may even cause the center to beat in sea water. About $\mathrm{I} .5$ to 2 c.c $\frac{n}{\mathrm{IO}} \mathrm{HCl}$ to $\mathrm{IOO}$ c.c. of sea water is required for this purpose. Alkalis have the opposite effect. The action of the acid may be the same as that of the oxalate and citrate; namely, to set free $\mathrm{Ca}$, which is in organic combinations in the cells, or at the surface of the cells, and make thus a substitution of $\mathrm{Na}$ or $\mathrm{K}$ for $\mathrm{Ca}$, or vice versa, in these organic compounds, possible. It may be mentioned here that the oxalates, citrates, and similar salts, and the acids, are believed to play such a rôle in the process of the coagulation of milk.* One of the promptest means of producing rhythmical contractions in the isolated center of Polyorchis is putting it into a pure solution of $\mathrm{CaCl}_{2}, \mathrm{BaCl}_{2}$, or $\mathrm{SrCl}_{2}$. Instead of dissolving the $\mathrm{CaCl}_{2}$ in distilled water, it may be dissolved in a $\frac{3}{8} m$ or $\frac{m}{2}$ sugar solution in order to have a solution which is more nearly isosmotic with sea water. If an isolated center is put into a solution of ro c.c. $\frac{3}{8} m \mathrm{CaCl}_{2}+5$ o c.c. $\frac{3}{8} m$ cane sugar I904.

* A. S. Loevenhart, Hoppe-Seyler's Zeitschr. für physiologische Chemie, Vol. 4I, p. 177, 
or into ro c.c. $\frac{3}{8} m \mathrm{CaCl}_{2}+5$ o c.c. distilled water, the center usually begins to beat rhythmically. The rhythmical contractions may last for three hours or more. Such rhythmical contractions can even be caused in a center which has been washed and kept for three hours in a pure solution of cane sugar, to make sure that the sea water at the surface of the muscle cells has been entirely removed. In this case, however, the contractions do not last as long, inasmuch as a solution of cane sugar as well as a pure $\mathrm{CaCl}_{2}$ solution are injurious to the muscle.

$\mathrm{BaCl}_{2}$ is much more effective than $\mathrm{CaCl}_{2}$, as it requires a much lower concentration of $\mathrm{BaCl}_{2}$ than of $\mathrm{CaCl}_{2}$ to produce rhythmical contractions in an isolated center of Polyorchis. Even in a solution of $\frac{1}{2}$ c.c. $\frac{5}{8} \mathrm{~m}$ $\mathrm{BaCl}_{2}+5 \circ$ c.c. $\frac{3}{8} m$ cane sugar, rhythmical contractions were produced which lasted about nine minutes. $\mathrm{SrCl}_{2}$ is much less toxic than $\mathrm{BaCl}_{2}$ and it acts more like $\mathrm{CaCl}_{2}$.

If it be true that the exchange of $\mathrm{Ca}$ for $\mathrm{Na}$ or $\mathrm{K}$, or vice versa, in certain organic combinations be the cause of these rhythmical contractions, we are apparently confronted with conflicting facts; namely, that $\mathrm{Ca}$-salts, as well as salts which precipitate $\mathrm{Ca}$, produce rhythmical contractions; but the facts are no more in conflict in this case than in the similar case of the coagulation of milk, where both a previous treatment of the milk with decalcifying salts or acid, as well as the addition of a soluble calcium salt, favor coagulation. In this case the probable explanation, according to Loevenhart, is that a soluble calcium salt is necessary for the coagulation. This calcium salt may be added from without, or may be obtained from the milk itself, by freeing it from a combination in which it is held there. The same may be true for the rhythmical contractions in the center of Polyorchis. In order that a contraction may occur, the formation of a certain calcium compound (soap or a calcium proteid?) is required. This condition may be satisfied by the diffusion of calcium into the cells from without, or by calcium being freed from certain other compounds within the muscle cells themselves (by acid, certain salts, like the oxalates or citrates or, as we shall see later, by the action of enzymes). The process of contraction is due to the substitution of $\mathrm{Na}$ or $\mathrm{K}$ for the $\mathrm{Ca}$, or vice versa. $\mathrm{Ba}$ and $\mathrm{Sr}$ act like $\mathrm{Ca}$.

Why is it that the isolated center of Polyorchis does not contract rhythmically in normal sea water? If $\mathrm{CaCl}_{2}$ acts as a stimulus, it is not probable that it is the $\mathrm{CaCl}_{2}$ of the sea water which inhibits its contraction. It might be possible that the action of the $\mathrm{CaCl}_{2}$ in the sea water is antagonized by the $\mathrm{NaCl}$. There seems to be indeed a certain antagonism, inasmuch as it is easier to produce rhythmical contractions in a pure solution of $\mathrm{CaCl}_{2}$ or in a solution of $\mathrm{CaCl}_{2}$ in cane 
sugar, than in a mixture of $\mathrm{CaCl}_{2}$ and $\mathrm{NaCl}$ solutions; $*$ but the antagonism is not complete, and $\mathrm{I}$ have actually obtained contractions in a mixture of $\mathrm{NaCl}+\mathrm{CaCl}_{2}$ in a center of Polyorchis. It can be shown that the $\mathrm{Mg}$-salts contained in the sea water inhibit the muscular contractions. If we start rhythmical contractions in a mixture of 50 c.c. $\frac{3}{8} m \mathrm{NaCl}+$ Io c.c. $m \mathrm{Na}$-citrate, and then put the center into a pure $\mathrm{NaCl}$ solution, or a solution of 50 c.c. $\mathrm{NaCl}+\mathrm{I}$ or 2 c.c. $\mathrm{CaCl}_{2}$, the center continues to contract. If, however, the center be put into a solution of 50 c.c. $\frac{3}{8} m$ $\mathrm{NaCl}+5$ c.c. $\frac{3}{8} m \mathrm{MgCl}_{2}$ the contractions are inhibited. I believe that it is generally more due to the $\mathrm{MgCl}_{2}$ than to the $\mathrm{CaCl}_{2}$ that an isolated center of a Medusa does not beat in normal sea water.

The facts thus far described give no clear answer to the question whether the substitution of $\mathrm{NaCl}$ or $\mathrm{KCl}$ for $\mathrm{CaCl}_{2}$ or the reverse process causes the contraction. Possibly the following observation may throw light on this problem: If an isolated center is put into 50 c.c. $\frac{3}{8} m$ cane sugar + Io c.c. $\frac{3}{8} m \mathrm{CaCl}_{2}$ contractions will begin, which continue when the center is put into 50 c.c. $\frac{3}{8} m$ cane sugar + Io c.c. $m$ sodium citrate; but if the center is put from the latter into the former solution, it stops beating at least for some time. Various modifications of this experiment give similar results: they seem to speak in favor of the idea that the substitution of $\mathrm{Na}$ or $\mathrm{K}$ for $\mathrm{Ca}$ causes a contraction; but the evidence is by no means unequivocal.

The question may be asked how it happens that in a pure solution of $\mathrm{NaCl}$ the beats do not start at once, but only after a number of hours. Is it necessary that $\mathrm{NaCl}$ enter the cells of the Medusa, and that this process requires time? Were this the reason, we should expect that within certain limits an increase in the concentration of the $\mathrm{NaCl}$ solution should accelerate the beginning of the contractions. I have not been able to find that this is true. The contractions began about equally late in a $\frac{3}{8} m$ and a $\frac{4}{8}, \frac{5}{8}$, or $\frac{6}{8} m \mathrm{NaCl}$ solution. I am more inclined to believe that the $\mathrm{Ca}$ must enter into an appropriate combination in the muscles, and, for that purpose, must be freed from another combination which is responsible for the delay in the beginning of the spontaneous contractions of the center of Polyorchis in a pure $\mathrm{NaCl}$ solution. The beats of the center begin in a pure $\mathrm{NaCl}$ solution when the muscle cells of the center have had time to free an abundant amount of calcium from an organic combination contained in them. This might be done by a hydrolytic enzyme directly or indirectly, in the latter case through the influence of an acid, e.g. $\mathrm{CO}_{2}$, in the muscle cells. This supposition has its analogue in the action of rennet in the

* It is possible that this antagonism is due to the fact that the $\mathrm{NaCl}$ and $\mathrm{CaCl}_{2}$ retard each other's diffusion into the cells. 
coagulation of milk, where this enzyme seems solely concerned in rendering available $\mathrm{Ca}$, which naturally is held in organic combination in the milk in such a form as to be of no use for the process of coagulation.*

A word may be said in regard to the difference in the behavior of the isolated center of Gonionemus and Polyorchis toward a pure solution of $\mathrm{NaCl}$. The former begins to beat in such a solution almost instantly, the other as a rule only after a long interval. The difference may consist simply in the fact that the cells of Gonionemus have from the start enough $\mathrm{Ca}$ in an available form, while this is not the case in Polyorchis. In the case of the former, the beats can begin immediately in a pure $\mathrm{NaCl}$ solution, while in the latter this is not possible.

The question may now be asked, What keeps the normal heart beat or the normal contractions of the jellyfish going? I believe the conditions are the same as those discussed in muscles, the strips of ventricle, or the center of the Medusa, with this difference only, that the salts or ions, which according to our hypothesis are needed for that purpose, are all supplied from within. I am inclined to believe that the constant chemical changes, such as oxidations, or the production of $\mathrm{CO}_{2}$, or other processes, lead also to an effect which in the isolated center can be brought about by certain salts, such as citrates or oxalates; namely, the setting free of $\mathrm{Ca}$ so that it may form dissociable colloidal compounds and be then either replaced by $\mathrm{Na}$ or $\mathrm{K}$, or vice versa. It is possible that the $\mathrm{CO}_{2}$ formed in the muscle may aid in this process.

The margin of a jellyfish which contains the central nervous system contracts for a time at least, rhythmically in any solution, and certainly in solutions of $\mathrm{NaCl}, \mathrm{KCl}$, and $\mathrm{CaCl}_{2}$. I was surprised to find that the addition of $\mathrm{MgCl}_{2}$ to any of these solutions makes the contractions of the margin more normal, as I believe, in an indirect way. For successful rhythmical contractions it is necessary that a real relaxation follows the contraction. I noticed that the edge of a Polyorchis has a tendency to remain permanently contracted in a mixture of $100 \mathrm{NaCl}, 2 \mathrm{KCl}, 2 \mathrm{CaCl}_{2}$, and this tendency finally interfered with the contractions. This effect is due to the Ca. I found, however, that upon the addition of $\mathrm{MgCl}_{2}$ this tendency to a continued contraction lessened and the Medusa showed a more normal type of contractions.

If it be true that the process of stimulation consists in an exchange of $\mathrm{Na}$ - and $\mathrm{K}$-ions for $\mathrm{Ca}$-ions (or Mg-ions?), or vice versa, in the tissues, and that normal irritability depends upon the presence of these ions in definite proportion in the tissues, it is to be expected that a change in these proportions would alter the irritability and give the tissues properties which they do not possess normally. I have already mentioned 
such an instance in the case of contact irritability which the muscle assumes when put into a solution of a decalcifying salt. As an example of abnormal sensitiveness on the part of sensory nerve endings, I may mention an observation on the nerve endings of the skin of a decapitated frog. If such a frog be suspended vertically over a dish containing dilute acid or alkali, so that the feet come in contact with the acid, they will be withdrawn. If, however, the feet be dipped into a dish of pure water, this will not occur; but if the feet of a frog are put for half a minute or a minute into a solution of $\mathrm{AlCl}_{3}$ or Na-citrate, and are then put back into pure water, the feet are withdrawn immediately, in a most violent way,* which might suggest to an anthropomorphically inclined observer the idea that the contact with water caused the decapitated frog the most excruciating pain. This experiment is the more surprising as the contact with the sodium-citrate or aluminium-chloride solution does not as a rule cause such a reaction. This hypersensitiveness of the skin can be done away with by putting the feet subsequently into a normal or $2 n$ solution of cane sugar. Urea acts similarly, but not so well. I consider it possible that a number of cases of abnormal sensibility, such as accompany certain neuroses, may have their basis in a change in the proportion of metal proteids or soaplike compounds in a tissue.

As far as the action of salts on motor nerves is concerned, I have made only the observation mentioned above, that those sodium salts whose ions are liable to form insoluble $\mathrm{Ca}$ compounds are liable to cause an increased irritability in a motor nerve. Mathews $\dagger$ has made a long series of investigations on the concentration at which the various salts produce rhythmical contractions when applied to a motor nerve. His results practically coincide with the statements made in regard to the muscles; his interpretation, however, is different. From the fact that lithium or potassium citrate causes the muscle to contract in a rather low concentration when applied to the motor nerve, he concludes that it is the anion which stimulates. I consider it more probable that the citrate in this case acts on the $\mathrm{Ca}$ in the nerve in the way mentioned above, and that this causes the stimulation. The formation of the Cacitrate is the essential feature, and this will occur no matter whether the citrate is introduced into the muscle in the form of the sodium or lithium salt. The nerve, however, differs from the muscle in that the former can be stimulated through the loss of water, which is not possible in the case of the muscle. It makes no difference whether the nerve loses water through evaporation, or whether the water is withdrawn from the muscle by a hypertonic solution. According to Mathews, cane sugar and

* Loeb, Pfüger's Archiv, Vol. 91, p. 248, I902.

$\dagger$ A. P. Mathews, Am. Jour. Physiology', Vol. 2, p. 455, 1904. 
urea will bring about this effect in a $\frac{m}{2}$ solution, while for $\mathrm{KCl}$ this concentration lies at $\frac{m}{4}$ or $\frac{m}{5}$. Considering the dissociation of the latter solution, these values do not differ very widely.

I had noticed in my experiments that those salts which produce the abnormal or increased irritability in muscles or nerves are identical with those which are commonly used as purgatives. The action of the purgative salts has been explained by Schmiedeberg and Cushny in this way, that these salts inhibit the absorption of liquid from the intestine, and the excess of fluid in the intestine causes the purgative effect. It seemed to me that the increase in irritability caused by these salts in the muscles and nerves of the intestine must suffice to favor an increase in the peristaltic motions of the intestine, and that this must cause the purgative effect. If this were correct, cathartics should be just as effective if given subcutaneously or intravenously as if given per os; and moreover, it should be possible to stop these effects by giving calcium salts. MacCallum* investigated this point and found indeed that barium salts or citrates, sulphates, fluorides, etc., have cathartic effects if injected under the skin or in the blood vessels. The quickest peristaltic effects could be produced by applying $\frac{m}{8}$ solutions of these salts to the peritoneal surface of the intestine. Application of a solution of $\mathrm{CaCl}_{2}$ or $\mathrm{MgCl}_{2}$ inhibited these effects. MacCallum found, in addition, that the watery character of the stools in this case is due to an active secretion of fluid into the intestine (and not as had been assumed to a retention of fluid in the intestine). When he isolated an empty loop of the small intestine in a rabbit, it was filled in a short time with a clear liquid, after a series of drops of a sodium-citrate or barium-chloride solution had been applied to the peritoneal surface of the intestine. It was thus possible to obtain in a short time 20 c.c. or more of a perfectly clear fluid from the small intestine of a small rabbit. This secretion of liquid into the intestine could also be inhibited by $\mathrm{CaCl}_{2}$ or $\mathrm{MgCl}_{2}$.

MacCallum $†$ showed also that the secretion of other glands can be accelerated by the addition of the above-mentioned salts, and can be transitorily retarded by the addition of Ca-salts. The same salts, e.g. $\mathrm{BaCl}_{2}$ or $\mathrm{Na}$-citrate, which accelerate the secretion of fluid into the intestine also accelerate the secretion through the kidneys, and this acceleration can be counteracted by solutions of $\mathrm{CaCl}_{2}$. We have

* J. B. MacCallum, University of California Publications, Physiology, Vol. I, p. 4, I903; pp. II 5 and 125, 1904. Am. Jour. Physiology, Vol. X, p. IOI, 1903; and p. 259, 1904. Pfiuger's Archiv, Vol. 104, I904.

$\dagger$ MacCallum, University of California Publications, Physiology, Vol, I, p. 81, 1903. 
already pointed out that these facts may aid us in obtaining a theory of secretion, i.e. an understanding of the additional forces besides osmotic pressure which must be at work in the process of secretion.

It is obvious from all these observations that the salts, especially the $\mathrm{Na}$-, $\mathrm{K}$-, and $\mathrm{Ca}$-salts, play a dominating rôle in the regulation of those life phenomena which fall generally under the head of irritability or stimulation and inhibition. To give a further idea of how far-reaching the influence of salts in this direction is, I may mention the following fact: Bock and Hoffmann * found, and other authors confirmed the fäct, that solutions of sodium salts, e.g. $\mathrm{NaCl}, \mathrm{NaBr}$, etc., when injected into the blood, cause glycosuria in a rabbit. It seemed to me that in this case, too, the accelerating effect of citrates and the inhibiting effect of Ca might be found. I asked Dr. M. H. Fischer, who was then a member of the laboratory, to investigate this question. He found that it is necessary in this case to infuse a $\mathrm{NaCl}$ solution of a higher concentration than $\frac{n}{8}$. The higher the concentration the quicker, according to Fischer, the glycosuria ensues. $\dagger$ Fischer found, also, that the citrates, etc., act more powerfully than $\mathrm{NaCl}$, and that $\mathrm{CaCl}_{2}$ was, to a certain extent, able to counteract this effect of $\mathrm{NaCl}$. These observations support the idea of Pflüger $\ddagger$ that this is a case of nervous glycosuria produced through the influence of the salts upon certain nervous elements in the medulla oblongata. It is possible that through this influence the concentration of sugar in the blood is raised transitorily, while the $\mathrm{CaCl}_{2}$ has the opposite effect. MacCallum $\$$ has made the interesting observation that in this case sugar is secreted not only through the kidney but also into the intestine.

If we finally summarize the results of these observations, we come to the conclusion that all those phenomena which depend on the action of muscles, nerves, or glands seem to be influenced to a large extent by the salts, and that especially changes in the proportion of $\mathrm{Na}$ or $\mathrm{K}$ to the Ca-ions in the tissues seem to affect their properties and their actions. The idea to which we have given preference, namely, that the substitution of $\mathrm{Na}$ or $\mathrm{K}$ for $\mathrm{Ca}$, or vice versa, in certain organic compounds gives rise to a contraction, may possibly have to be modified in detail, and undoubtedly many new facts will be required and found before we are ready for a final theory; but I am inclined to believe that the main structure will remain such as intimated in my papers in 1899

* Bock und Hoffmann, Reichert und Du Bois-Reymond's Archiv, p. 550, 1871 . 1904.

$\dagger$ Fischer, University of California Publications, Physiology, Vol. 1, p. 77, 1903; p. 87,

$\ddagger$ Pfïger's Archiv, Vol. 96, p. 313, 1903.

$\S$ MacCallum, University of California Publications, Physiology, Vol. 1, p. 125, 1904. 
and I900; namely, that the normal qualities, especially the normal irritability, of animal tissues depend upon the presence in these tissues of $\mathrm{Na}-, \mathrm{K}-, \mathrm{Ca}-$, and $\mathrm{Mg}$-ions in the right proportion; that these ions are at least partly in combination with colloids (proteids or higher fatty acids or possibly carbohydrates), and that any sudden change in the relative proportions of these ion lipoids or ion proteids or ion carbohydrates alters the properties of the tissues and gives rise to an activity or an inhibition of the activity, according to the sense in which the change takes place. Finally, I believe that the natural rhythmical processes such as heartbeat, respiration, etc., are due to a substitution of certain metal ions for others, these substitutions being caused by the enzymatic processes going on continually, and by which, among others, metal ions are freed from certain combinations, and rendered available for others, as seems to be the case in the action of rennet in the coagulation of milk. We certainly understand by this hypothesis why the combination of the Na-, K-, Ca-, and possibly Mg-salts is so important for life phenomena, especially those of animals.

\section{The Reaction of Living Matter and the Rôle of Bicar- bonates for the Preservation of Life}

Not only the life of the aquatic animals but the life of every cell is passed in a solution of electrolytes. It had generally been assumed that the liquids in the animal tissues, as well as the sea water, had an alkaline reaction, while the liquids of the tissues of plants had an acid reaction. This assumption was founded upon the titration method. Physical chemistry altered the conception of alkalinity, and measured it by the concentration of the free hydroxyl-ions. Höber* was the first to make use of the methods required to determine the concentration of the hydroxyl-ions in the blood, and found with the aid of gas batteries that the blood was slightly alkaline. His method was defective in a detail, and later Friedenthal, $\uparrow$ Fränckel, $\ddagger$ Farkas, and Höber himself showed that the concentration of the hydroxyl-ions in the blood is not higher than in distilled water. Cottrell and I found the same for sea water. $\S$ Friedenthal showed also that the liquids of the tissues of animals and plants are practically neutral. We therefore may draw the conclusion that life phenomena occur in a neutral liquid. The formation of $\mathrm{CO}_{2}$ is one of the most general processes in living tissues. Besides, other acids (e.g. lactic acid in the muscle) are formed in metabo-

* Höber, Pfï̈ger's Archiv, Vol. 81, p. 535, 1900.

† Friedenthal, Zeitsch. für allgemeine Physiologie, Vol, I, p. 56, 1902.

\$ Fränckel, Pfiiger's Archiv, Vol. 96, p. 601, 1903.

$\S$ Loeb, Pfüger's Archiv, Vol. 99, p. 637, 1903; and Vol. Io I, p. 340, 1904. 
lism. Respiration eliminates the $\mathrm{CO}_{2}$ in part, but there would be danger that every organism would finally perish through its own production of acid were these acids not constantly neutralized. This is partly done by the carbonates of the blood. The proteids of the blood are also capable of neutralizing a considerable amount of acid by combining with it,* and I believe this rôle of the proteids in the blood should not be overlooked. The fact can be demonstrated in a striking manner by putting a frog's muscle into roo c.c. of ox blood, to which ro c.c $\frac{n}{\text { IO }}$ $\mathrm{HCl}$ or IO c.c. $\frac{n}{\mathrm{IO}} \mathrm{NaHO}$ have been added. The muscle does not absorb water in such a solution, and remains alive for several days. If the muscle be put into an isotonic solution of $100 \mathrm{NaCl}, 2 \mathrm{CaCl}_{2}, 2 \mathrm{KCL}$, to which the same amounts of acid or alkali are added, the muscle absorbs considerable quantities of water and dies rapidly. A third means of keeping the reaction of the liquids of the tissues neutral is probably the compensatory production of bases in the body, possibly induced by the acids.

It is easy to show that marine animals are able to develop and grow only in such solutions as are capable of neutralizing the acids which might be formed. If the polyp be cut off from stems of Tubularia crocea, new polyps are formed in about two days if the temperature is about $20^{\circ} \mathrm{C}$. As soon as the polyp is formed, growth begins. If a solution be prepared of 100 molecules $\mathrm{NaCl}, 2$ molecules $\mathrm{KCl}, 2$ molecules $\mathrm{CaCl}_{2}$, 7.8 molecules $\mathrm{MgCl}_{2}, 3.8$ molecules $\mathrm{MgSO}_{4}$, isotonic with sea water, the formation of polyps occurs more slowly than in sea water, and growth is slight. If, however, to such a solution be added from 0.5 to I c.c. $\frac{m}{8} \mathrm{NaHCO}_{3}$ or O.I c.c. $\frac{m}{8} \mathrm{Na}_{2} \mathrm{CO}_{3}$ or 0.2 to I.o c.c. of a $\frac{n}{\text { Io }}$ solution of $\mathrm{NaHO}$, regeneration and growth occur with normal velocity. $\dagger$ These three substances have the property in common that they are able to neutralize acids, and I am inclined to ascribe it to this peculiarity that they are capable of accelerating growth in Tubularians. It harmonizes with this view that $\mathrm{NaHCO}_{3}$ acts better than NaHO. If, however, a trace of acid instead of alkali is added to the original solution, growth is still more retarded. The addition of o.I to o.I 5 c.c. $\frac{n}{\text { IO }} \mathrm{HCl}$ solution to Ioo c.c. of the above-mentioned solution suffices to suppress growth entirely; this corresponds to a concentration of $\mathrm{HCl}$ of $\frac{n}{6000}$ to

* Bugarszky und Liebermann, Pfïger's Archiv, Vol. 72, p. 51, 1898. Spiro und Pemsel, Zeitsch. für physiol. Chemie, Vol. 26, p. 233, 1898.

† Loeb, Pflüger's Archiv, Vol. 101, p. 340, I904. 
$\frac{n}{10000}$. Similar conditions exist for the development of the eggs of a sea urchin, Arbacia. I found that in neutral solutions of $\mathrm{NaCl}, \mathrm{KCl}$, $\mathrm{CaCl}_{2}, \mathrm{MgCl}_{2}, \mathrm{MgSO}_{4}$, the eggs of Arbacia can reach the pluteus stage, but that no normal skeletons are formed. If, however, $\mathrm{NaHCO}_{3}$ is added, normal skeletons are formed. Similar results were previously obtained by Herbst, and in this case also the $\mathrm{NaHCO}_{3}$ serves for the neutralization of an acid. Experiments in Strongylocentrotus purpuratus were still more surprising in this respect.* When these eggs were put immediately after fertilization into a van't Hoff solution (IOO $\mathrm{NaCl}$, $2 \mathrm{KCl}, 2 \mathrm{CaCl}_{2}, 7.8 \mathrm{MgCl}_{2}, 3.8 \mathrm{MgSO}_{4}$ ), only few eggs went beyond the two-cell stage, and only very few reached the pluteus stage. If, however, to 100 c.c. of such a solution 0.5 to I.O c.c. $\frac{3}{8} m \mathrm{NaHCO}_{3}$ were added, almost all the eggs went into the pluteus stage. In such a solution the development also occurred just as fast as in normal sea water.

The addition of o.I c.c. $\frac{5}{8} m \mathrm{Na}_{2} \mathrm{CO}_{3}$ solution caused also some eggs to reach the pluteus stage. These plutei, however, did not live as long as when the bicarbonate was added. When 0.2 to $0.4 \frac{n}{\text { IO }} \mathrm{NaHO}$ was added to roo c.c. of the van't Hoff solution, the majority developed, but no skeletons were formed. We must, however, take into consideration the fact that in such solutions, as I found, $\mathrm{NaHO}$ is neutralized in a few hours or in less than a day by the $\mathrm{CO}_{2}$ of the air and the $\mathrm{CO}_{2}$ formed by the eggs, while the formation of a skeleton occurs only after from forty-eight to seventy-two hours. The addition of 0.8 c.c. of a $\frac{m}{6}$ $\mathrm{Na}_{2} \mathrm{HPO}_{4}$ solution acted similarly to the addition of $\mathrm{NaHO}$.

I think these examples may suffice to show the importance of a regulator which is capable of keeping the solution in which marine animals live neutral. The same is true for the liquids in which tissues live; this point was investigated by Rogers in experiments on the heart of the crab. Here, also, the addition of bicarbonate made a great difference. This is also, as I believe, the explanation of the fact that Ringer's solution is improved through the addition of a trace of $\mathrm{NaHCO}_{3}$. Gaule $\dagger$ was the first to point out the necessity of neutralizing the acid formed in the heart if we wish to make it beat in an artificial solution. In freshwater animals, Wolfgang Ostwald made the interesting observation that, if Gammarus be put into a salt solution of a comparatively high osmotic pressure, life could be prolonged considerably by adding $\mathrm{NaHCO}_{3}$ to the solution. He was able to show that without the addition of the

* Loeb, Pfï̈ger's Archiv, Vol, I03, p. 503, I904.

† Gaulẹ, Du Bois-Reymond's Archiv, p. 291, 1878. 
bicarbonate, the hypertonic solution was rendered acid by the animals.*

During some of the above-mentioned experiments Osterhout and I found that marine algæ under the influence of light make the sea water slightly alkaline, while in the dark they do not act in this way. They produce also this alkalinity under the influence of light in a solution of $\mathrm{NaCl}, \mathrm{KCl}, \mathrm{CaCl}_{2}$, which shows that the act of assimilation is accompanied by the excretion of a base. It is possible that this is one of the means by which the reaction of the ocean is kept neutral in spite of the animal life. It is also possible that this is one of the reasons why animals keep better in a well-lighted aquarium if green plants are added.

Acids as well as alkalis act as poisons in comparatively low concentrations. The toxic concentration for acids is generally much smaller than for bases; the toxic effects are not altogether in proportion to the concentration of the $\mathrm{H}$ - or $\mathrm{HO}$ - ions. Organic acids as a rule are more toxic than should be expected from their degree of dissociation. A very weak base like $\mathrm{NH}_{4} \mathrm{OH}$ is for Gammarus (possibly for many organisms) more toxic than $\mathrm{NaHO}$, while tetramethylammonium hydroxide is less toxic. $\dagger$ This indicates that in the case of ammonia the $\mathrm{NH}_{3}$ is responsible for the toxic effects, and not the $\mathrm{HO}$ - ion. This is supported by the fact that $\mathrm{NH}_{4} \mathrm{Cl}$ is more toxic for animals than $\mathrm{NaCl}$, and almost as, if not slightly more toxic than $\mathrm{KCl}$. By way of digression I may remark that, contrary to a possibility I had considered for some time, I have reached the conclusion that the toxic effects of electrolytes are determined by chemical reactions and equilibrium conditions, and not by the electric charges of the ions.

\section{Electrical Stimulation}

In plants, electrical stimulation plays no rôle, and the same may be said to be true for those phenomena in the life of animals which they share with plants, e.g. cell division. From all we know cell division cannot be called forth or controlled by the galvanic current; but the galvanic current is an excellent stimulant for the functions of those tissues which may be considered characteristic of animals alone; namely, muscles and nerves. It is perhaps more than a mere accident that in this respect the efficiency of $\mathrm{Na}$ - or $\mathrm{K}$ - and $\mathrm{Ca}$-salts and the electrical current coincide.

We have seen in the third lecture that the solid parts of living tissue consist of colloids which are nonconductors, while the liquids are col-

* Wolfgang Ostwald, Pfïger's Archiv, Vol. 106, p. 568, 1905.

+ Not yet published. 
loidal solutions which contain also salts. It is obvious that such a system can act only as a liquid conductor in which the current is carried by the dissociated ions or such colloidal particles as possess an electric charge. The concentration of the colloidal particles is very small compared with that of the electrolytes in solution, so that for the conduction the latter are mainly or practically exclusively responsible.

When a constant current is sent through a nerve-muscle preparation or through a muscle, two kinds of effects are to be considered: the one effect shows itself only at a rapid change in the intensity of the current, and consists in a twitching of the muscle. The second effect shows itself throughout the whole duration of the current, and consists in an increase of irritability at the cathode and a decrease at the anode. It can be shown that the twitching originates on the making of the current at the cathode and on the breaking at the anode. The two effects of a current are therefore different at the two poles.

When a current goes through a liquid conductor its work consists, first, in the pulling of the ions through the liquid to the electrodes, and second, in the withdrawal of the charges from the ions and the transformation of the latter into uncharged atoms at the electrodes. The question arises as to which of the two effects of the current the physiological actions are due: to the increase of the concentrations of ions at the electrodes, or to the withdrawal of their charges. I believe that this question can be decided for the twitchings in favor of the idea that the twitchings are due solely to the increase in the concentration of the ions at one pole, and not to the loss of the charge of the ions.

It had been known for a long time that the galvanic current can only cause a twitching in the muscle, when it goes lengthwise through its nerve; while its effect diminishes or becomes zero when it travels crosswise through the nerve. I have shown that the same is true when the nerves are stimu-

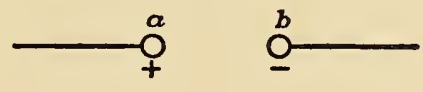
lated by induction.* Let $a$ and $b$ (Fig. I6) be the electrodes of a Toepler-Holtz machine, and $c d$ the nerve of a

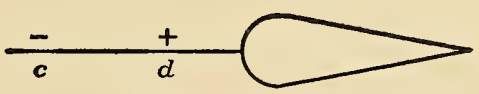

FIG. I6. nerve-muscle preparation of a frog; the preparation is placed on an insulated-glass plate. If $c d$ is parallel to the spark discharge and at not too great a distance from it, the muscle twitches every time a spark passes between $a$ and $b$. If, however, this nerve is put at right angles to the spark discharge and symmetrical to the two electrodes, but equally near or even a little nearer to it than before (Fig. I7), no twitch-

* Loeb, Pfüger's Archiv, Vol. 67, p. 483, 1897; and Vol. 69, p. 99, 1897. 
ing or a much weaker one occurs when a spark is produced. The same effect can be produced when a Rumkorff induction apparatus is used in place of a Toepler-Holtz machine.

The explanation of the experiment is as follows: let us assume that at a given moment the electrode $a$ (Fig. I6) be charged positively

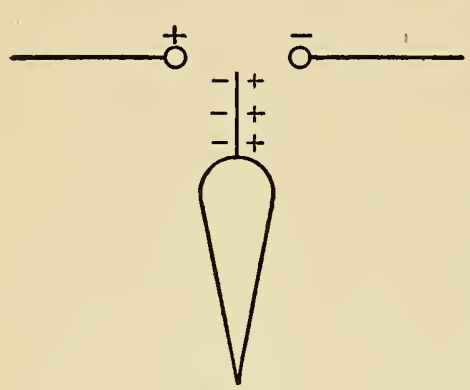

FIG. 17. and $b$ negatively; in this case the nerve will possess at $c$ a negative, at $d$ a positive charge. As soon as the spark passes, the charges in the nerve will disappear also; a current will go lengthwise through the nerve, and a twitching will result. If, however, the nerve is placed at right angles to the spark discharge and symmetrical in regard to the two electrodes (Fig. I7), the current must go crosswise through the nerve, and no effect or only a minimal effect ensues. In this experiment no electrical charges are withdrawn from the ions, and the only effect of the current exists in a change in the concentration of the ions at various places in the nerve. Since, however, in this case of stimulation of the nerve by induction, the effect is the same as in the case of a direct application of the electrodes to the nerve, we must draw the conclusion that in the latter case also the change of concentration is sufficient for the physiological effect, and that the withdrawal of the charge from the ion cannot be the cause.

Nernst has tested the idea that the electrical current only stimulates the nerve by bringing about changes in the concentration of ions at various places in the nerves.* It had been known for some time that the interrupted current is an excellent medium for stimulating nerves or muscles, and it was also generally known or accepted that alternating currents produce only weak effects when the number of alternations becomes very high. Quantitive determinations had also shown that the minimum intensity of an alternating current which is required to bring about tetanus, increases with the number of alternations. These facts Nernst used as a starting point to test the idea that the current acts only by changing the concentration of ions at the place of stimulation. "According to our present knowledge, the galvanic current cannot produce in a tissue, i.e. a purely electrolytic conductor, any other effects than displacements of ions, i.e. changes of concentration; we therefore conclude that the latter must be the cause of the physiological effects. In the case of an alternating current, changes

\footnotetext{
* Nernst, Nachrichten der Gesellschaft der Wissenschaften zu Göttingen, p. 104, 1899.
} 
of concentration occur whose sense changes with the direction of the current. When their average reaches a definite value, the physiological effect becomes noticeable and the threshold is reached.

"It is possible to calculate the average changes of concentration without making excessively specific assumptions. We know that in tissues the composition of the watery solution which acts as the electrolytic conductor is not everywhere the same, and especially that it is different inside and outside the cells. Semipermeable membranes prevent the equalization by diffusion and only at such membranes can changes in the concentration be produced by the current. In the interior of a homogenous solution, the current cannot produce such an effect, as in each instance just as many ions migrate into such an element of volume as leave it. At the semipermeable walls, changes of concentration must occur, inasmuch as the current carries salts to such a membrane which blocks their further motion. Such salts as are able to pass through the membrane undertake the conduction of the current through the membrane. The seat of the electrical stimulation must therefore be at the latter.

"If a current of the density I carries the quantity $v$ of salt to the membranc, a migration of the salt away from the membrane must occur through diffusion. The average change of concentration at the membrane depends therefore upon the antagonistic effects of the current and diffusion." * Nernst developed the equations for this process (according to a method by Warburg), which show that the intensity of an alternating current, which is just sufficient to produce a stimulating effect, must increase in proportion to the square root of the number of alternations in the second. Nernst tested this theory experimentally in coöperation with Von Zeynek and Barratt, and found it true for alternations from 100 to 2000 . This proves that the experimental data agree with the assumption that the electrical stimulation is due to a change in the concentration of ions in the living tissues. Such changes occur wherever the progress of ions is blocked, and this may be at the limit of each individual surface film of protoplasm. In some cases it may be at the surface of the protoplasmic layer of a cell, in other cases, such blocks may occur inside a single cell.

Nernst's experiments were concerned only with the physiological effects of alternating currents, and he does not discuss the effects of constant currents. While a constant current is passing through a nerve or muscle, the latter generally remains at rest. As long as the current continues to pass through, new ions must be carried to the poles. It is difficult to understand why this should not result in any motor effect; here is a gap which needs to be filled.

* Nernst und Barratt, Zeitsch. fïr Electrochemie, Vol. 10, p. 664, I904. 
It is of the greatest importance that the stimulation at the making of a current occurs at the cathode, as this indicates that an increase in the concentration of the cations is responsible for this result. On account of the fact that the migration velocity of the potassium ions is greater than that of the other cations in the muscle, it might appear as though the latter were responsible for the stimulating effect at the cathode at the making of the current.* If the current is broken, the stimulation occurs at the anode. It has been suggested by Grützner that the effect of the breaking of a current is in reality due to a current of polarization which, of course, has the opposite direction from the polarizing current. In this case, too, the stimulating effect at the anode at the breaking of a current is due to an increase in the concentration of the cations.

While a constant current is passing through a nerve, a region of increased irritability exists around the cathode. I pointed out four years ago that such a condition can be produced in the nerve by treating it with a salt which precipitates or diminishes the concentration of the calcium ions, e.g. sodium-oxalate, -citrate, -fluoride, -carbonate, etc. It is not impossible that a substitution of $\mathrm{K}$ for $\mathrm{Ca}$, or vice versa, in ion-colloids actually occurs at the cathode, while a constant current flows through the nerve. At the anode we must expect, and we find, a decreased irritability. Until quite recently the phenomena of catelectrotonus and anelectrotonus, and perhaps the effects of the current in general, were explained on the basis of antagonistic physiological processes being aroused by the current, one being called assimilation, the other dissimilation. As it is impossible to connect an adequately definite chemical idea with these terms, it is useless to discuss this view. It is obvious that those who used these terms did so under the impression of the since refuted notion that a metallic conduction occurs in living tissues, and that therefore a current can directly break up chemical compounds in the nerve or muscle; while we now know that the dissociation exists before the current starts. Moreover, the above-mentioned experiments on the effects of induction on the nerve show that even without any charges being withdrawn from the nerve, and without any secondary chemical effects, the stimulation occurs. This shows that the secondary chemical reactions at the poles, due to the transformation of the ions into atoms, have nothing to do with the stimulating effects of the current. I believe that for these reasons it is advisable to discontinue the assertion that the current causes dissimilation at the one and assimilation at the opposite pole of a cell.

It seems to be a general law that wherever the constant current * I expressed this possibility in my lectures five years ago. 
has any effect whatever, the stimulation occurs at the cathode. As far as Infusorians are concerned, it is generally stated that the stimulation occurs at the anode; but this statement is nevertheless wrong, as Dr. Bancroft has recently shown.* If a constant current goes through a Paramacium, the effect is that the position of the cilia on the side of the cathode is altered, while on the side of the anode the cilia retain their normal position, provided the current is not too strong. The abnormal position of the cilia on the side of the cathode consists in their free end pointing toward the oral end of the Paramacium. It can be shown that this is the position of the cilia which is produced by any kind of stimulus, mechanical or chemical. Budgett and I have shown that if a Paramcecium be put into $\frac{m}{\mathrm{I} 6}$ solution of $\mathrm{NaCl}$ (or any salt), the Infusorian moves backward. This is due to the fact that the salt causes a change in the position of the cilia, the latter pointing with their free end forward instead of backward. If a constant current is sent through a Paramecium, this change in the position of the cilia occurs at the cathode end, while at the anode end no such change occurs. It is therefore obvious that if we speak of the stimulating effect of a constant current upon an Infusorian, we should state that this stimulation occurs at the cathode side of the Infusorian. The opposite statement is due to an observation made by Kühne; namely, that Actinospharium, a Rhizopod, when subjected for some time to a constant current, begins to disintegrate on the anode side. $\dagger$ This effect he called a stimulation, or even tetanus. Maxwell and I, however, pointed out long ago that this is merely a play on words, inasmuch as these phenomena of disintegration (cytolysis ?) observed by Kühne are causẽd by electrolysis and are not necessarily connected with the stimulating effect of the current. This is corroborated by observations made by Budgett and myself. $\ddagger$

Not only muscular contractions but phenomena of secretion can also be produced by a current. When a current is sent through a trough filled with water which contains an Amblystoma, a secretion of whitish mucus appears on the skin wherever the outside of the latter is struck by the current curves emanating from the anode (Figs. I8 and I9). \& Here we have also apparently an anode effect of the current. This effect depends partly, at least, upon a stimulation of the central nervous system, and we do not know whether the stimulation is anodic or cathodic. It may be that the influence of the central

\footnotetext{
* F. W. Bancroft, Pfï̈ger's Archiv, Vol, 107, p. 535, 1905.

† Kühne, Untersuchungen über das Protoplasma und die Contractilität, Leipzig, I 864.

$\ddagger$ Loeb und Budgett, Pfinger's Archiv, Vol. 65, p. 518, 1879.

$\$$ Loeb, Pfïger's Archiv, Vol. 65, p. 308, 896.
} 
nervous system consists only in causing a contraction of muscular or
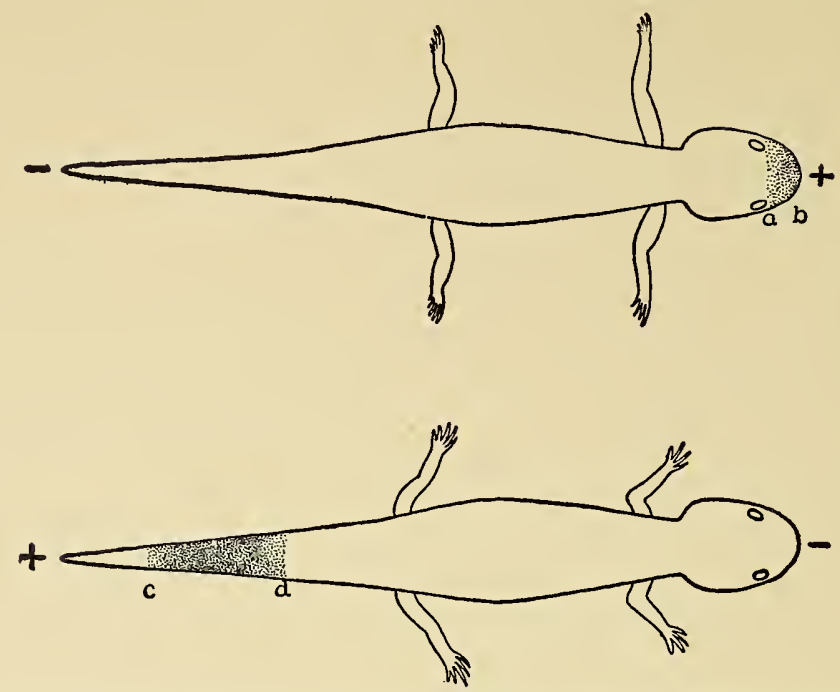

FIG. 18. - The secretion of mucus on the skin of Amblystoma under the influence of a constant current. The animals were kept in a trough of water through which a current passed. The current lines were straight and parallel with the longitudinal axis of the animal. The black dots indicate the spots where the secretion of mucus appeared. The drawing shows that the glands secrete at the anode side of the animal where the current lines cut its surface.

contractile elements which result in the contents of the mucous glands being squeezed out. The secretion is partly, however, a direct effect of

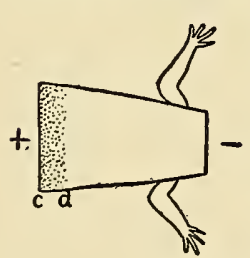
the current on the skin, and results finally in the disintegration of the latter. In this case we may be dealing with an electrolytic effect due to secondary chemical reactions. Budgett and I found that these anodic effects of the current on Infusorians and Amblystoma can be imitated by applying $\mathrm{NaHO}$ to these organisms. Whatever the cause of the

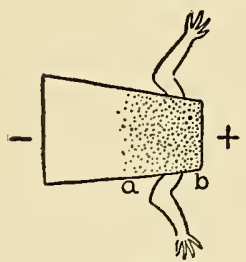

FIG. I9.-The same experiment as in Fig. I8 carried out with pieces of Amblystoma. 
supports the stand with the nerve to bring about a twitching of the muscle. If we may be guided by physical analogies, - which however, are not absolutely reliable, - this mechanical stimulation might be compared with the effect which a mechanical agitation has, under certain conditions, upon an oil drop on the surface of a $\mathrm{Na}_{2} \mathrm{CO}_{3}$ solution. In this case it may lead to a dissolution of a solid soap film on the surface, or to an alteration of the surface, by bringing new particles of both liquid media in contact.. Thus phenomena of spreading may be provoked by a slight mechanical agitation. Mechanical stimulation is much more effective in nerves than in muscles.

As a rule, heat is also mentioned as a stimulant though nobody uses this form of energy for this purpose. The term "stimulation by heat" is a misleading phrase, as we shall see presently.

It appears from the foregoing that by the word "stimulation" we mean a process which is unknown to us, which, however, seems to consist after the data given in this lecture in the substitution of $\mathrm{Na}$ - or $\mathrm{K}$ ions for $\mathrm{Ca}$, or vice versa, in some colloidal (proteid or lipoid) compound of the muscle or nerve, whereby some physical qualities of the colloidal substances are changed. 


\section{LECTURE VI}

\section{THE EFFECTS OF HEAT AND RADIANT ENERGY UPON LIVING MATTER}

\section{EfFEcts of HeAt}

In discussing the effects of heat or temperature upon life phenomena, we meet with the difficulty that heat influences living matter in two ways; namely, chemically and physically. In chemical regard the temperature influences the reaction velocity most powerfully, and in physical regard it influences the viscosity of the liquids of the cell (colloidal solutions) and their state of matter (coagulation, gelation). In studying the influence of temperature upon life phenomena we must keep these two effects apart.

There is an upper temperature limit at which all organisms can be killed; it is generally assumed that in this case death is due to the fact that certain proteids are coagulated by heat, and this process is not reversible. Setchell has ascertained that in hot springs whose temperature is $43^{\circ} \mathrm{C}$., or above, no animals or green algæ are found.* In hot springs whose temperature is above $43^{\circ}$ he found only the Cyanophycea, whose structure is more closely related to that of the bacteria than to that of the algæ, inasmuch as they have neither definitely differentiated nuclei nor chromophores. The highest temperature at which Cyanophycea occurred was $63^{\circ} \mathrm{C}$. Not all the Cyanophycea were able to stand temperatures above $43^{\circ} \mathrm{C}$., but only a few species. The other Cyanophycee are found at a temperature below $40^{\circ} \mathrm{C}$., and were no more able to stand higher temperatures than the real algæ or animals. The Cyanophycece of the hot springs were as a rule killed by a temperature of $73^{\circ}$. From this we must conclude that they contain proteids whose coagulation temperature lies above that of animals and green plants, and may be as high as $73^{\circ}$. Among the fungi many forms can resist a temperature above $43^{\circ}$ or $45^{\circ}$; the spores can generally stand a higher temperature than the vegetative organs. Duclaux found that certain bacilli (Tyrothrix)

* W. A. Setchell, Science, N. S., Vol. 27, p. 934, 1903. 
found in cheese are killed in one minute at a temperature of from $80^{\circ}$ to $90^{\circ}$; while for the spores of the same bacillus a temperature of from $105^{\circ}$ to $120^{\circ}$ was required.*

Duclaux has called attention to a fact which is of importance for the investigation of the upper temperature limit for the life of organisms. According to this author it is erroneous to speak of a definite temperature as a fatal one, instead we must speak of a deadly temperature zone. This is due to the fact that the length of time which an organism is exposed to a higher temperature is of importance. Duclaux quotes as an example a series of experiments by Christen on the spores of the bacilli of the soil and of hay. The spores were exposed to a stream of steam and the time determined which was required at the various temperatures to kill the spores.

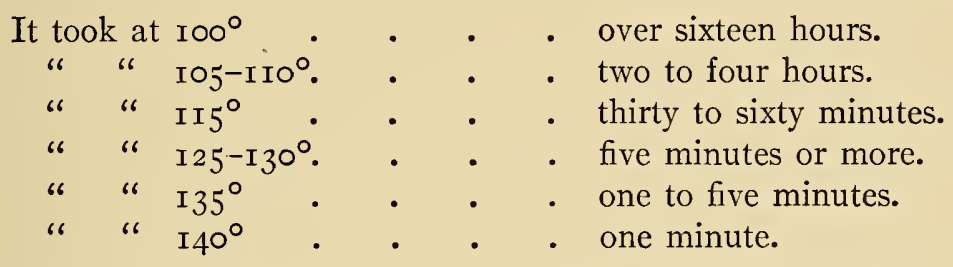

In warm-blooded animals $45^{\circ}$ is generally considered a temperature at which death occurs in a few minutes; but a temperature of $44^{\circ}$, $43^{\circ}$, or $42^{\circ}$ is also to be considered fatal with this difference only, that it takes a longer time to bring about death. This fact is to be considered in the treatment of fever.

It is generally held that death in these cases is due to an irreversible heat coagulation of proteids. According to Duclaux, it can be directly observed in microörganisms that in the fatal temperature zone the normally homogeneous, or finely granulated, protoplasm is filled with thick, irregularly arranged bodies, and this is the optical expression of coagulation. The fact that the upper temperature limit differs so widely in different forms is explained by Duclaux through differences in the coagulation temperature of the various proteids. It is, e.g. known that the coagulation temperature varies with the amount of water of the colloid. According to Cramer, the mycelium of Penicillium contains 87.6 water to I2.4 dry matter, while the spores have 38.9 water and 6I.I dry substance. This may explain why the mycelium is killed at a lower temperature than the spores. According to Chevreul, with an increase in the amount of water, the coagulation temperature of albuminoids decreases. The reaction of the proto-

* Duculax, Traité de microbiologie, Vol. I, p. 280, 1898. 
plasm influences the temperature of coagulation, inasmuch as it is lower when the reaction is acid, higher when the reaction is alkaline. The experiments of Pauli show also a marked influence of salts upon the temperature of coagulation of colloids.

The process of heat coagulation of colloids is also a function of time. If the exposure to high temperature is not sufficiently long, only part of the colloid coagulates; in this case an organism may again recover. We gain from these experiments a further confirmation of the idea expressed in an earlier lecture, that the process of coagulation or gelation may not be a purely physical process, but the outcome of a chemical reaction.

When we analyze the effects of heat upon life below the upper fatal temperature zone, we must first realize that the velocity of chemical reactions is raised to two or more times its original amount, whenever the temperature advances $10^{\circ} \mathrm{C}$. (van't Hoff and Arrhenius). This holds good for the reactions in living organisms as well as for nonliving, as may be seen from the following table concerning the influence of temperature upon the $\mathrm{CO}_{2}$ production by seeds of lupines: $100 \mathrm{gr}$. of seeds produced in one hour according to Clausen,* the following number of milligrams of $\mathrm{CO}_{2}:-$

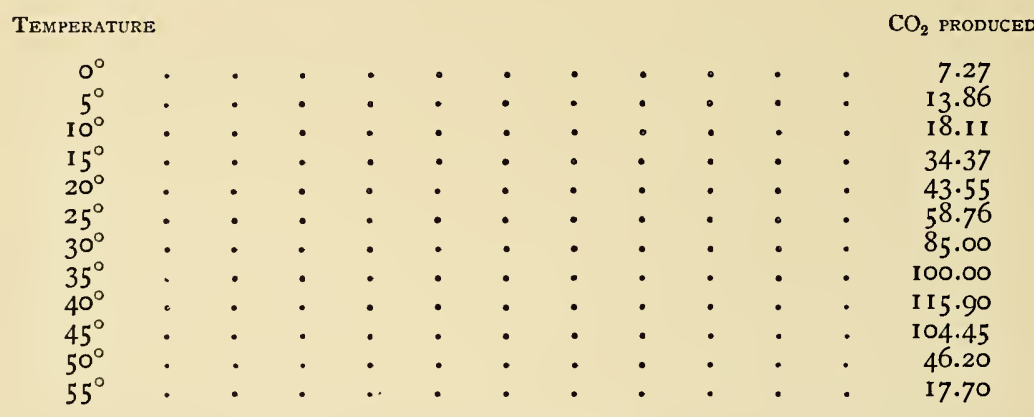

We see that below the temperature of $40^{\circ}$ the amount of $\mathrm{CO}_{2}$ is approximately doubled for every rise of $10^{\circ}$ in temperature. Above this temperature, however, the amount of $\mathrm{CO}_{2}$ diminishes rapidly with any further increase of the temperature. This is very generally observed in enzymatic processes, and may be due to the fact that the enzyme itself undergoes hydrolysis, which of course follows the temperature law of van't Hoff and Arrhenius; $\dagger$ or it may be that the enzyme undergoes heat coagulation (or a process of clumping), by which

* Quoted after Cohen, Lectures on Physical Chemistry for Physicians and Biologists, New York, 1902.

† Tammane, Zeitsch. für physikal Chemie, Vol. 18, p. 426, 1895. 
the reaction area between enzyme and fermentable substance is diminished. The question arises, Can we show that certain life phenomena are a direct function of a reaction velocity? In my book on the Comparative Physiology of the Brain, I expressed the idea that the rhythmical contractions of the jellyfish, of the heart, and perhaps in general, are a function of enzymatic processes. It seemed to me that this idea could be put to a test, since in case it were true, the rate of heartbeats should vary with the temperature, according to the figures found by Arrhenius for the influence of temperature, upon reaction velocity, i.e. we should find that with a rise of temperature of $10^{\circ} \mathrm{C}$. the rate of heartbeats should at least double. At my request Mr. Snyder undertook experiments in this direction on strips of the ventricle of the tortoise heart. He found, indeed, that inside the temperature range of from $5^{\circ}$ to $30^{\circ} \mathrm{C}$., the number of heartbeats is about doubled for every rise of temperature of $10^{\circ} \mathrm{C}$. The strips of the ventricle were kept in a moist chamber, which was submerged in a water bath of constant temperature. The contractions of the strips were recorded in the usual way. I will give as an example the records of six experiments.* The hearts of six terrapins were put into moist chambers, and the latter were kept at a constant temperature for two hours and forty minutes. Two strips were kept at a temperature of $10^{\circ} \mathrm{C}$., two at $20^{\circ}$ and two at $30^{\circ}$. The average number of heartbeats was determined for every five or ten minutes. The left vertical column of the following table gives the time in minutes, the other vertical columns gives the average number of heartbeats for each heart at that time.

\begin{tabular}{|c|c|c|c|c|c|c|}
\hline \multirow{2}{*}{$\begin{array}{c}\text { Time } \\
\text { Minutes }\end{array}$} & \multicolumn{2}{|c|}{$T=10^{\circ}$} & \multicolumn{2}{|c|}{$T=20^{\circ}$} & \multicolumn{2}{|c|}{$T=30^{\circ}$} \\
\hline & Heart I & HEART 2 & HEART 3 & HEART 4 & HEART 5 & HEART 6 \\
\hline 5 & 9.5 & 9.5 & 21.5 & 21 & 48 & 48 \\
\hline IO & 7 & 9 & $2 I$ & 24 & 48 & 44 \\
\hline I 5 & 6.7 & 8.7 & 19 & I8 & 48 & 40 \\
\hline 20 & 7 & 8.2 & I9 & 16.5 & $4 I$ & \\
\hline 30 & 7 & 7 & 16 & I4 & & \\
\hline 40 & 6.5 & 7.9 & 15.5 & 15.5 & & \\
\hline 50 & 6.5 & 7.9 & I 3.5 & 16 & & \\
\hline 60 & 6.2 & $7 \cdot 4$ & I3 & I 5 & & \\
\hline 80 & 6.2 & 6.8 & I I & I 4.5 & & \\
\hline 100 & 6.5 & 7.1 & IO & IO & & \\
\hline I 20 & 6.4 & 6.6 & 8 & IO & & \\
\hline 140 & 6.5 & 6 & 8 & 9 & & \\
\hline 160 & 6.5 & 5.9 & 7.6 & 9 & & \\
\hline
\end{tabular}

Other experiments gave similar results. The experiments show that the influence of temperature upon the rate of contractions in different

* C. D. Snyder, University of California Publications, Physiology, Vol. 2, p. 125, 1905. 
hearts is practically the same, and that a rise of $10^{\circ} \mathrm{C}$. increases the rate to a little more than twice the original figures. It was found that temperatures above $25^{\circ} \mathrm{C}$. injure the heart rather soon, and for this reason the rate of contraction was regular at a temperature of $30^{\circ} \mathrm{C}$. for the first fifteen or twenty minutes only.

These experiments show that the heartbeat is caused by chemical processes which go on constantly. O. Hertwig* has made experiments on the influence of temperature upon the time required for the development of the eggs of the frog. He compared the time required to reach three successive stages in the development at the temperatures of $6^{\circ}, 10^{\circ}, 15^{\circ}, 20^{\circ}$, and $24^{\circ}$. The temperatures were not kept perfectly constant. From Hertwig's results E. Cohen calculated $\dagger$ that the influence of temperature followed the law of van't Hoff and Arrhenius.

When the temperature of the protoplasm becomes sufficiently low, e.g. approximately $0^{\circ} \mathrm{C}$., the velocity of the chemical reactions becomes so small that the manifestations of life cease. Cold-blooded animals can at any time be revived from this condition of latent life by raising their temperature. The lack of water acts similarly to a low temperature. This is the reason why seeds can be kept alive so long. Lack of water may reduce the reaction velocity of the hydrolytic processes in seeds at ordinary temperature so considerably that it may become practically zero.

The question may be raised whether lowering of the temperature can ever kill an organism, or whether there exists a low temperature limit for life phenomena. From our viewpoint the criterion for death is the nonreversibility of the changes brought about by the agency in question. We must therefore ask, Does lowering of temperature bring about irreversible changes in the protoplasm, as does a raising of the temperature? The answer seems to be that for many cold-blooded animals there is no lower temperature limit in the sense of our definition, and if death occurs at a low temperature, it is due to secondary and entirely accidental effects connected with the freezing of the water in the cells. It is known that the formation of ice crystals in the cells may mechanically injure and kill them. This seems to be the case in the freezing of plants. Another accidental irreversible change is connected with the thawing of animals that have been frozen. It seems to be certain that a frog after being frozen cannot be brought back to life again if the temperature is raised suddenly, while it may live if allowed to thaw slowly. Barring these two secondary and mechani-

* O. Hertwig, Archiv für Mikroskop. Anatomie und Entwickelungsgeschichte, Vol. 51, p. 319,1898 .

t E. Cohen, loc. cit. 
cal complications, the lowering of temperature does not seem to bring about irreversible changes in the condition of protoplasm, which are incompatible with life. This seems to be in harmony with the fact that living matter contains no colloidal solutions which are transformed into irreversible gels by cooling. Gelations which are brought about by cooling seem to be, in general, reversible processes, e.g. the gelation of gelatine.

Experiments made recently by Pictet and others show that various cold-blooded animals and bacteria may be cooled to very low temperatures without being killed. Many, possibly most, warm-blooded animals seem, however, to behave differently. If their blood is cooled for some time to a temperature of $15^{\circ} \mathrm{C}$. or below, they cannot again recover. If this fact which is generally stated is correct, it shows that in the warm-blooded animals a reversible, fatal change occurs at such a lowering of their temperature, although we have not the slightest conception which substance or variable is responsible for this result. It is interesting that, according to Setchell, the Cyanophycea of the hot springs also die when suddenly brought into water whose temperature is below $40^{\circ}$. It is possible that we are dealing in this case also with some secondary effect connected with the lowering of temperature.

The variables thus far mentioned do not yet exhaust the range of possibilities in which temperature influences life phenomena. The coefficient of partition of one substance between two others may vary with the temperature. This is the case, e.g. for the coefficient of partition of chloralhydrate between oil and water. This coefficient increases with the temperature, which means that with an increasing temperature more chloralhydrate will leave the watery liquids of the body and go into the tissues which are rich in fat, e.g. nervous elements. In consequence of this fact a frog which is poisoned with chloralhydrate at room temperature may become normal again upon cooling, as chloralhydrate must in this case go from the nervous elements into the watery liquids of the body. The following fact belongs possibly in the same category. It is known that decapitated frogs show an increase in irritability when kept for some time on ice. If the reaction velocity were decisive for the reflex irritability, it should be expected that, with an increase in temperature, the irritability would increase. Could it be possible that in this case the coefficient of partition of some toxic or inhibiting substance formed in the body varies in the same sense with the temperature, as in the case of chloralhydrate? If this were the case the fact might become intelligible that with decrease in temperature the reflex irritability is increased. 
There are, however, a number of biological effects of temperature for which we cannot yet indicate the physical or chemical variable. It is generally known that in many hibernating northern chrysalids the velocity of metamorphosis is increased if the chrysalids are exposed for some time to a temperature of $0^{\circ}$. This fact is possibly related to the experience, that treatment with ether can hasten the development of buds and plants. An equally puzzling effect of heat is the influence a low temperature has upon the production of wings in A phides. As long as the temperature is high and the moisture sufficient, plant lice are wingless; but if the temperature be lowered, wings begin to grow. In this case the lowering of temperature favors the growing of an organ, an effect which is rather paradoxical in view of the fact that the phenomena of development seem to be plainly a function of the reaction velocity of underlying chemical processes.

The late Dr. Greeley* showed that a certain group of Infusorians, Monas, can at any time be caused to form spores by exposing them for a short time to a low and afterward to a higher temperature. Forms of irritability can also be varied through the influence of temperature. I have shown that positively heliotropic Copepods can be made negatively heliotropic by raising the temperature, and negatively heliotropic Copepods can be made positively heliotropic by lowering the temperature. This will be more fully discussed in the next lecture. In passing I may mention that certain changes - seasonal variations can be brought about by changes in temperature. $\dagger$

\section{General Effects of Radiant Energy upon Living Matter}

The electromagnetic theory of light has led to the idea that there must exist besides the already known ether waves other waves on both sides of the scale. Hertz discovered the method by which we can experiment with ether waves of several centimeters or more with the same certainty as was before possible with the shorter waves, which are able to produce sensations of heat or light. The question had to be put whether or not Hertzian waves had any physiological effect. I made eight years ago an extended series of investigations on this subject, and the first experiments seemed to speak in favor of the idea that the Hertzian waves have effects upon the nerves; but I was able to show by a closer analysis that these apparent effects of these waves were not due to the oscillatory character of the discharge, and that the same results could be brought about by nonoscillatory discharges. $\ddagger$

* A. W. Greeley, Biological Bulletin, Vol. 3, p. 165, 1902.

† Wolfgang Ostwald, Zeitsch. fïr Entwickelungsmechanik, Vol. I8, p. 415, 1904.

† Loeb, Pfüger's Archiv, Vol. 67, p. 483, 1897; and Vol. 69, p. 99, 1897. 
If we wish to study the physiological effects of ether waves, we may therefore confine ourselves to the waves of shorter length. Among these waves those are especially interesting for us whose length is $0.8 \mu$ and less, inasmuch as these waves affect our retina, and produce those chemical effects in green plants which make assimilation in these plants possible.

Among the various known effects of these waves two are of importance for us; namely, the photochemical effect and the radiation pressure. The latter seems to be of great importance as far as cosmical phenomena are concerned, as Arrhenius has shown; but I do not believe that they play any rôle in life phenomena, as Rádl seems to assume,* who believes they are responsible for the heliotropic effects of light. This view is, as I believe, contradicted by the fact that radiation pressure is independent of the wave length, while the heliotropic effects are eminently a function of the wave length. This latter influences, however, the photochemical effects, and for this reason it seems advisable to consider the possibility that the biological effects of light are indirectly chemical effects. It seems that every chemical reaction which is influenced by ether waves at all can be influenced only by waves of a definite, limited period. As in this case radiating energy is transformed into chemical energy, the light waves can have no effect unless they are absorbed. We find indeed that in all cases only such light waves produce a chemical or biological action as are absorbed; but the reverse statement, that wherever in an organism an absorption of light occurs (e.g. in pigment spots) a biological effect must be produced, is not correct.

In order to give an idea of the possible chemical effects of light, a few instances may be quoted. Ultraviolet rays cause the formation of ozone from the oxygen of the air, as can be beautifully demonstrated with the aid of the Heraeus mercury quartz lamp. According to Vogel, violet rays cause the oxidation of guaiacum and give it a blue color, while red rays reduce it and make it appear yellow. The oxidizing and reducing effects of light seem to be of special physiological importance. Thus Duclaux attributes the well-known sterilizing effect of light upon bacterial cultures partly, at least, to the formation of acids which are produced by the light in the nutritive medium. He has shown that fats are oxidized and hydrolized under the influence of light, and that the acid thus formed acts antiseptically. According to the same author, sugars are oxidized in an alkaline medium by light. Hydrogenperoxide is also found among the products formed under the influence of light in culture media.

* Rádl, Untersuchungen über den Phototropismus der Thiere, Leipzig, 1903. 
It is perhaps of special biological significance that the oxidation of many dysoxidizable substances occurs more rapidly in the light than in the dark. Schönbein and recently Jorissen have shown that aldehydes are oxidized more rapidly in the light than in the dark; the same is true for oil of turpentine. According to Richardson and Forteg, amylalcohol is oxidized quicker in light than in the dark. Bodländer is inclined to attribute these effects of light to a dissociation of oxygen; his assumption is based upon the electromagnetic theory of light.*

It is a common biological conception that the occurrence of pigment in animals or plants bears a close relation to biological effects of light; we may perhaps for this reason quote an observation which bears on this problem. The observation was made by H. W. Vogel. $\dagger$ The silver salts and especially the bromide of silver of common negatives are preëminently sensitive for rays between blue and ultraviolet. If, however, eosin or cyanin is added in traces, the maximum of the photographic effect moves toward the side of the longer waves in the spectrum.

After this preliminary orientation we shall discuss briefly the biological effects of light. The most important biological rôle of light lies in the assimilatory activity of green plants. The transformation of the $\mathrm{CO}_{2}$ of the air into sugar (and starch) in the green plant occurs only under the influence of light. This assimilation occurs in chlorophyll granules (or on their surface) inside the cells of green plants (or certain animals). All attempts thus far made to separate a substance from the chlorophyll which is able to form sugar from the $\mathrm{CO}_{2}$ of the air have failed. $\$$ Narcotics like ether and chloroform which inhibit the motor activities of the cell also inhibit the chlorophyll action. (This indicates also that the narcotics have another action than a mere physical one, as Overton assumes.) Yet it is not unlikely that in respect to chlorophyll, a similar experience will be made to the one made in regard to zymase; namely, that mere technical difficulties at present prevent the isolation of the assimilating catalyzer in the chlorophyll granules from the living cell.

The chemical side of the process of assimilation is unknown. Baeyer suggested that from $\mathrm{H}_{2} \mathrm{CO}_{3}$ at first formaldehyde, $\mathrm{HCOH}$, is formed which by polymerization yields $\mathrm{C}_{6} \mathrm{H}_{\mathrm{r}_{2}} \mathrm{O}_{6}$. Hoppe-Seyler $\S$ expressed the idea that chlorophyll undergoes first a combination with $\mathrm{H}_{2} \mathrm{CO}_{3}$

* Bodländer, Ueber langrame Verbrennung. (Ahrens' Sammlung chemischer und chemisch-technischer Vorträge), Stuttgart, I 899.

$\dagger$ I quote after Ostwald's Grundriss der allgem. Chemie.

$\ddagger$ R. O. Herzog, Hoppe-Seyler's Zeitsch. fiur physiol. Chemie, Vol. 35, p. 459, 1902.

$\S$ Hoppe-Seyler, Physiologische (hemie, 1876 . 
which, under the influence of light, falls apart in such a way as to yield chlorophyll (or the catalyzer contained therein), $\mathrm{O}_{2}$, and a third product, the latter being sugar or a substance from which sugar may be formed. It is obvious that Hoppe-Seyler's idea represents that conception of the action of the catalyzer which is more and more supported by the facts.

The different parts of the spectrum do not accelerate the process of assimilation equally well; chlorophyll absorbs the rays between $B$ and $C$ of the spectrum, and also the rays beyond $F$. Engelmann has shown by a very ingenious method that the rays between $B$ and $C$ cause the most vigorous assimilation, that the effectiveness of the rays between $D$ and $E$ is a minimum, and that a second maximum exists beyond $F *$ Those rays are therefore the most effective for the process of assimilation which are most vigorously absorbed by the chlorophyll.

It is as yet uncertain whether the light influences directly any other synthetic processes than those which lead to the formation of sugars and starch. $\dagger$ The lack of light must make itself felt in an indirect way in any process in the plant for which the formation of carbohydrates is a prerequisite, e.g. the formation of proteins.

The life of animals does not depend so directly upon the presence of light. This is evidenced by the fact that animal life occurs in caves. Life at the bottom of the ocean also occurs practically in the dark, inasmuch as the light furnished by phosphorescence is only slight. It has occasionally been stated that eggs of animals develop better or quicker in the light than in the dark; but a closer analysis of such statements has shown invariably, thus far, that they are due to an experimental error. Some authors managed by faulty methods to exclude the air also with the light, and others did not exclude or consider the influence of microörganisms in their experiments. Driesch's experiments have failed to show any influence of light upon the development of eggs; and my own experiments in that direction have also thus far yielded only negative results. The fact that the eggs of mammals develop in the uterus, shows sufficiently that eggs can develop in the dark.

In years of experimenting I have found only one form of animals in which diffused daylight has an influence upon the formation of organs; namely, Eudendrium, a hydroid. $\ddagger$ When stems of Eudendrium are

* Engelmann, Pfüger's Archiv, Vol. 27, p. 485, 1882 ; and Vol. 38, p. $386,1886$.

$\dagger$ As fungi can form proteids in the dark when a carbohydrate is contained in the culture medium, it seems at least possible that light is not directly required for the formation of proteids in green plants.

I Loeb, Pfüger's Archiv, Vol. 63, p. 273, 1895. 
brought from the ocean to the aquarium, the old polyps die in a few days. If the aquarium is exposed to sufficiently strong light, new polyps are formed, while this formation does not occur in weak light or the dark. It seems, however, as if the formation of stolons could occur also in the dark. The different parts of the visible spectrum are not equally effective. Behind screens of red glass the formation of polyps was less favorable than behind screens of blue glass, even if the degree of brightness of both kinds of glass seemed to be the same. 


\section{LECTURE VII}

\section{HELIOTROPISM}

\section{i. The Heliotropism of Sessile Organisms}

MACHINES which are constructed artificially are arranged in such a manner that the energy which they require is provided by the hand of man. Through the blind play of the forces of nature durable machines can be created only if their supply of energy is regulated automatically. As an example of that type of machine we may mention the waterfall. The waterfall is a machine which transforms distance energy into kinetic energy and heat, and the permanency of this machine is guaranteed by the physical conditions that determine the continued flow of water to the cataract. The green plants represent another type of such machines; namely, machines which, among others, transform radiating energy into chemical energy. The permanency of this kind of machines is guaranteed by the presence of an automatic arrangement in such plants, whereby their stems grow toward the light. The automatic turning of the stems of many plants toward the light is called heliotropism. We shall go a little deeper into the analysis of these phenomena, inasmuch as heliotropism and similar phenomena give, to a large extent, an insight into the mechanism of automatic selfpreservation of organisms.

The stems of many plants in the open grow vertically upward, while the same stems when raised in a room which receives light from only one side grow toward the window. Roots which contribute toward the maintenance of the plant by absorbing the necessary salts from the soil show very frequently (though not always) the opposite behavior. Whien exposed to light they bend and grow away from the source of light. This behavior is determined only by rays of a certain wave length of the visible spectrum and possibly by some ultraviolet rays. The dark heat rays have no such effects.

We do not yet know with the same degree of certainty, as in the case of the process of assimilation, the relative heliotropic efficiency of each part of the spectrum; but from experiments with colored screens it appears that the more refractive green, blue, and violet rays of the 
spectrum are more effective heliotropically than the less refractive red and yellow rays. There exists thus apparently a division of labor, the longer light waves accelerating assimilation, the shorter waves accelerating heliotropism. This can be demonstrated with the aid of screens, inasmuch as behind red screens the plants assimilate well, while they do not bend or bend only slowly, toward the source of light; while behind a blue screen they bend actively toward the light, their assimilation being diminished.

We call organisms which bend or grow toward the source of light positively heliotropic or phototropic, and those that bend or grow away from it negatively heliotropic.

As far as the mechanism of the heliotropic bending is concerned, we must remember that in most cases it occurs most effectually in the tips of branches or roots. As this region is also the growing region, botanists frequently state that the process of heliotropic bending is a function of growth. This, however, is certainly not true for grasses, in which the bending occurs in the nodes which are flexible, while in the less flexible internodes no bending occurs. It seems therefore as though the phenomena of growth were not essential in the heliotropic reaction, and that the reason that the tips react better to light than the older parts is perhaps due in part to the fact that the latter are not so soft and flexible.

How can light bring about heliotropic curvatures? Let us suppose that light strikes a plant on one side only, or more strongly on one side than on the opposite side, and that it be absorbed in the superficial layers of tissue of that side. In this case we assume that on that side certain chemical reactions occur with greater velocity than on the opposite side. What these reactions are is unknown; we may think provisionally of oxidations. This change in the velocity of chemical reactions either produces a tendency of the soft elements on that side to contract a little more than on the opposite side, or creates otherwise a greater resistance to those forces which have a tendency to elongate or stretch the plant, e.g. hydrostatic pressure inside the cells, or imbibition of certain tissue elements. The outcome will be that one side of the stem will be stretched more than the opposite side, and this will bring about a curvature of the stem. Where the latter is soft at the tip, the bending will occur only, or chiefly, in that region; and as the degree of softness decreases rapidly from the tip downward, the result will be that the tip will bend toward the source of light. This result may possibly be aided by a greater photosensitiveness of the extreme tip of the stem, although I am not aware that this is an established fact. 
Through the process of bending, both sides of the stem come under the influence of light, and this fact determines the extent of the bending. As soon as the tip of the stem is bent to such an extent as to expose the symmetrical sides or elements of the stem equally to the light, the bending must cease; and the tip of the stem must continue to grow in this direction. The reason for this is obviously the fact that if the symmetrical elements of the tip are struck by the ray of light at the same angle, the photochemical effects in symmetrical elements must be the same, and the tendency to contract or the resistance to elongation must be the same on both sides. In this case the tip or rather its axis of symmetry will continue to grow in the direction of the rays of light. It is, of course, taken for granted in this discussion, that the plant is exposed to only one source of light. What has thus far been said refers to positively heliotropic organs, e.g. stems, which bend toward the source of light if illuminated from one side only. The same reasoning applies also to negatively heliotropic organs, e.g. roots, with the difference only, that in the latter case the photochemical effects result in a relaxation or a decreased resistance to the stretching forces on that side of the organ where the light strikes. It appears as if there might exist a chemical or physical difference between stem and root; it might be possible that while the light accelerates oxidation in one organ it accelerates reduction in the organ with opposite heliotropism. It might also be possible that the chemical effects of light are the same in the stem and the root of a plant, but that the colloids in the root are affected by these substances in the opposite sense from those of the stem. We have no data which enable us to test these suggestions.

Wortmann * has made sections through the tips of stems and roots which were exposed to light from one side only. He found that the cells on that side of the stem which was directed toward the light possess denser protoplasm than the cells on the opposite side; in roots it was the reverse. Wortmann concluded from this that the protoplasm itself is heliotropic in the stem and that it creeps toward the illuminated side, while in the root the reverse process takes place. Botanists have raised the objection that a creeping of the protoplasm from cell to cell could not occur so rapidly on account of the great resistance offered to such a process. I wonder whether the changes which Wortmann observed are not of a character similar to those observed by Darwin in the basal cells of the tentacles of Drosera, an insectivorous plant, which he designated as aggregation. $\dagger$ In the unstimulated condition these cells are filled with a homogeneous watery liquid of a pur-

* Wortmann, Botanische Zeitung, I887.

$\dagger$ Darwin, Insectivorous Plants. 
plish color. The walls are lined with a layer of colorless circulating protoplasm. If, however, the cells are investigated after a prolonged stimulation of the glands of the plant, the basal cells of the tentacle no longer contain a homogeneous liquid, but solid masses of various shape which have the purplish color and are surrounded with an almost colorless liquid. These changes do not necessarily depend upon the bending of the tentacles, but only upon the stimulation of the glands. This process of aggregation (which may be a gelation) is reversible, and after a period of rest the original appearance of the protoplasm is reëstablished. By way of digression we may mention that Darwin observed that the process of aggregation traveled from the stimulated gland to the contracting tentacle, and that what he observed here directly may occur invisibly in the stimulated nerve fiber. It is possible that in the positively heliotropic organs a process of aggregation occurs in the cell on the side of the light, while in negatively heliotropic organs the reverse occurs on the light side; and this may be the explanation of Wortmann's observations. On the side where the protoplasm becomes denser (or undergoes aggregation?) the cellulose walls become subsequently thicker than on the opposite side.

The same phenomena of heliotropism which we find in plants we find also in sessile animals; and the identity of the heliotropic reactions in these two groups of organisms is so complete that it would be at any time possible to demonstrate the phenomena and laws of plant heliotropism in such animals, and vice versa. One of the best animal forms in which to show this identity is Eudendrium, a hydroid. As stated in the preceding lecture, the polyps of this hydroid soon fall off when it is brought from the ocean into the aquarium; but in a few days new polyps are formed, and as soon as this occurs the little stems in the region below the polyp bend toward the source of light, when illuminated from one side only (see Figs. 20 and $2 \mathrm{I}$ ). The region in which this curvature occurs is situated immediately below the polyps, and it happens that in this region also the main growth of the stem occurs. The bending of the polyp or the tip of a branch continues until the symmetrical points of the stem are struck by light at the same angle. If there is only one source of light this occurs when the axis of symmetry falls into the direction of the rays of light. As soon as this happens the stem continues to grow in the direction of the rays of light.

In Eudendrium just as in plants the more refractive blue rays are more effective than the red rays; behind a red screen the heliotropic curvatures in Eudendrium do not occur at all, or only slowly, while behind a blue screen they occur as rapidly as in mixed daylight.

In Eudendrium we are able to convince ourselves that the region 
behind the polyp in which the heliotropic curvatures occur possesses contractility, and the forces underlying protoplasmic contraction are responsible for the heliotropic curvature. The heliotropic curvature consists here in the stem undergoing a stronger contraction or shortening on the more strongly illuminated side of the polyp than on the opposite side. When the aquarium is turned by an angle of $180^{\circ}$ soon
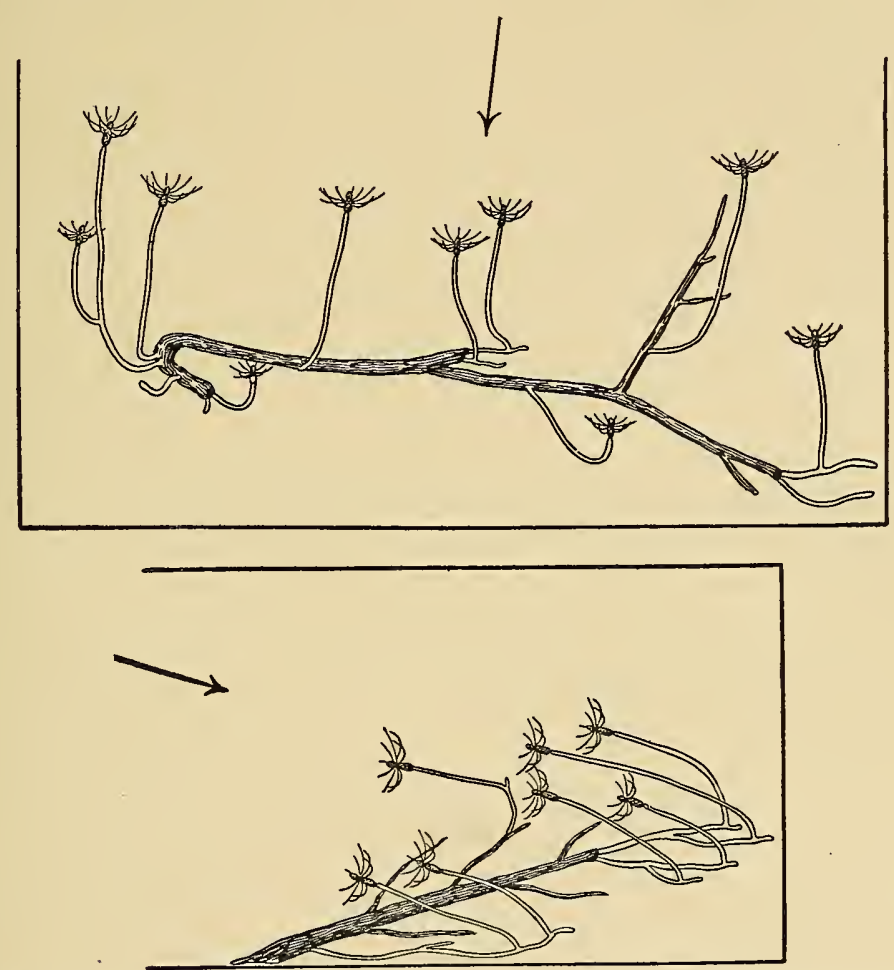

FIGs. 20, 2I. - Positive heliotropism of the polyps of Eudendrium. The new polyp-bearing stems all grow in the direction of the rays of light which is indicated by an arrow in each figure. (From nature.)

after the curvature occurs, the stem turns and bends in the opposite direction.* Sachs mentions that in the stems of plants also the heliotropic curvature can be again reversed, provided the experimenter does not wait until the bent region of the stem has become too hard. The heliotropic curvature in Eudendrium is therefore a phenomenon of contractility and not a phenomenon of growth, although growth may accidentally occur at the same time.

* These observations were made in 1895 at Woods Hole, and were mentioned briefly in Pfïger's Archiv, Vol. 63, p. 273, I 895. 
We find heliotropic curvatures in animals where there can be no doubt that the curvature is due solely to a process of contraction, and not to a process of growth. Spirographis Spallanzani is a marine Annelid from $10 \mathrm{~cm}$. to $20 \mathrm{~cm}$. long, which lives in a rather rigid yet flexible tube. The latter is formed by a secretion from glands at the surface of the animal. The tube is attached by the animal with its lower end to some solid body, while the other end projects into the water. The worm lives in the tube and only the gills, which are arranged in a spiral at the head end of the worm, project from the tube. The gills, however, are quickly retracted, and the worm withdraws into the tube when touched or if a shadow is cast upon it.

When such tubes with their inhabitants are put into an aquarium which receives light from one side only, it requires, as a rule, a day or more until the foot end of the tube is again attached to the bottom of the aquarium. As soon as this occurs, the anterior end of the tube is

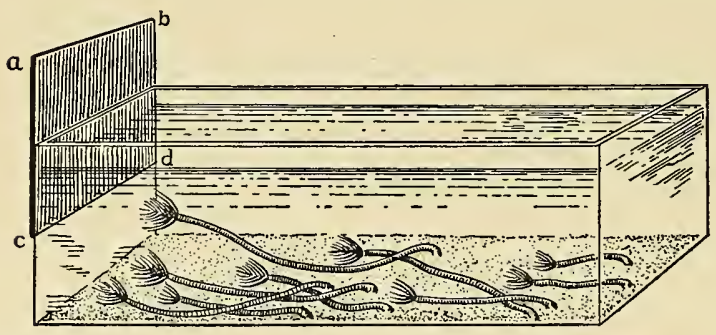

FIG. 22. - Positive heliotropism of Spirographis Spallanzani. (From nature.) raised by the worm until the axis of symmetry of the gills falls into the direction of the rays of light which enter through the window into the aquarium (Fig. 22)* When the animal has once reached this position it retains it as long as

the position of the aquarium and the direction of the rays of light remain unchanged. If, however, at any time the aquarium is turned $180^{\circ}$ so that the light falls in from the opposite direction, the animal bends its tube during the next twenty-four or forty-eight hours in such a way that the axis of symmetry of its circle of gills is again in the direction of the rays of light (see Fig. 23). When the light strikes the aquarium from above, the animals assume an erect position, like the positively heliotropic stems of plants when they grow in the open.

In these phenomena the mechanical properties of the tube play a rôle. When the animal is taken out of the bent tube, the latter retains its form. How does this permanent change of form of the tube come about? In my opinion through new layers being secreted on the inside. The youngest layers of the secretion are more elastic than the old layers, and, moreover, have at first a powerful tendency to shorten. 
If such a secretion occurs on one side of the tube only, or more so than on the opposite side, the former must become shorter than the latter, and the result must be a curvature of the tube, that side becoming concave where the new secretion has occurred.

On this assumption, which is based on many observations, the process of heliotropic curvature is in this case as follows: when the light strikes the circle of gills from one side only, in these elements certain chemical reactions occur more quickly, or to a larger extent, than on the opposite side. This results in corresponding alterations of the sensory nerve endings, the sensory nerves, and

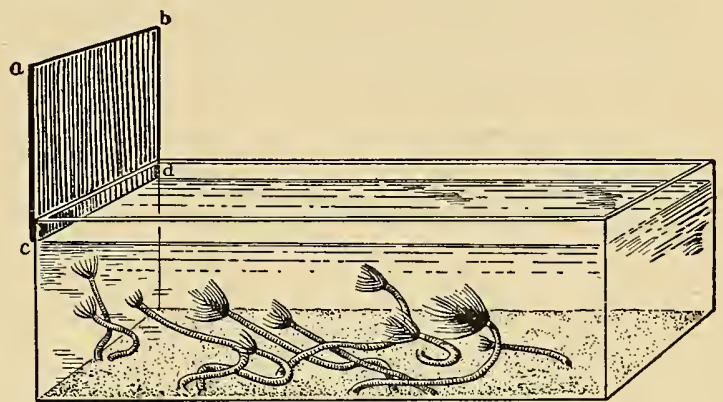

FIG. 23. the corresponding motor nerves, and their muscles. The sense of these changes is such as to throw the muscles connected with the nerves of the gills on the light side into a more powerful tonic or static contraction than the muscles on the opposite side of the body. The consequence is a bending of the circle of tentacles, or the head, toward the source of light, which will continue until the axis of symmetry of the circle of tentacles falls into the direction of the rays of light. When this happens, symmetrical tentacles are struck at the same angle (or in other words with equal intensity) by the rays of light, and therefore the tone (state of contraction) of the antagonistic muscles is the same. The result is that the circle of tentacles becomes fixed in this position. The bending of the head produces an increased pressure and friction of the animal against that side of the tube which is directed toward the light, and this pressure and friction lead to an increased secretion and the formation of a new layer inside the tube.

Observations on another marine worm which lives in a stony tube, Serpula uncinata (Fig. 24), add an interesting detail.* These worms occur in colonies of thousands whose tubes are in close contact. The tubes of this form differ from those of Spirographis in that they are made of calcium salts (probably carbonates), and are inflexible. Nevertheless, these worms are positively heliotropic, like Spirographis, and in the ocean all the tubes of a colony are straight and parallel, and 
directed upwards. If such a colony is put horizontally into an aquarium which receives its light from above in the direction of the arrow $c d$, Fig. 24, it will be observed that very soon the heads of the worms are

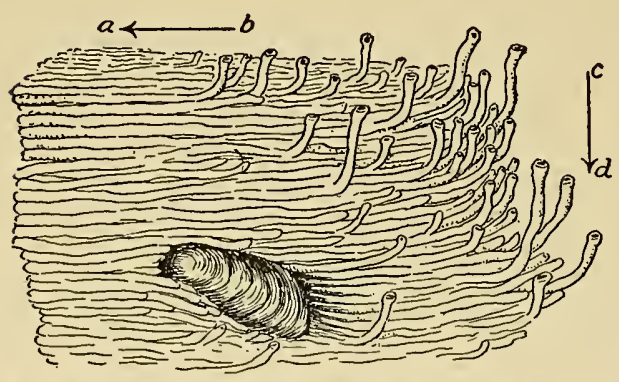

FIG. 24. - Positive heliotropism of Serpula uncinata. The light had originally struck the animal in the direction of the arrow $a b$, and their tubes were parallel with the direction of the rays. When the light fell in the direction $c d$ the tubes began to grow at right angles to their former direction. Partly diagrammatic. turned upward so that the axis of symmetry is in the direction of the rays of light. Very soon the tubes begin to grow in front through the deposition of new lime salts (which are secreted by glands). But the direction of this growth is now at right angles to the longitudinal axis of the old tubes. This again shows that the primary effect of the light in the heliotropic reactions is the bending of the tip, or head, of the animal through protoplasmic or muscular contraction. The bending of the tube or growth are secondary phenomena which follow the former. I believe that the phenomena of heliotropism of sessile animals and plants are essentially alike. The presence of nerves in animals is no reason for denying this identity, especially since some botanists, e.g. Hildebrandt, claim that tissues which functionally resemble nerves also exist in plants.

\section{Heliotropism of Free-moving Animals}

We have seen that the essential feature of the heliotropic reaction consists in the fact that the light automatically puts the plant or the animal (Eudendrium, Spirographis) into such a position that the axis of symmetry of the body, or organ, falls into the direction of the rays of light. In the case of positively heliotropic organs, the tip, or head, is directed toward the source of light, while it is the reverse in the case of negatively heliotropic organs. If we imagine that such a positively heliotropic organ, e.g. the polyp of Eudendrium, or a worm, like Spirographis, be endowed with the power of spontaneous locomotion, and if for some internal reasons the animal were compelled to be constantly in motion (as is the case with many pelagic larvæ), we should notice that these animals had no choice left in regard to the direction of their motion. The light would turn them automatically until their axis of symmetry was in the direction of the rays of light, and the animal could 
then move only in this direction. If the positively heliotropic polyp of Eudendrium could be transformed into a free-swimming animal, it would be compelled to swim automatically toward the source of light.

It had been known since man began to use artificial light that certain animals, especially insects, show a tendency to fly or creep to the flame. The explanation generally given of this phenomenon was anthropomorphic; it was assumed that the animals fly into the flame because they are fond of light, or that they are driven by curiosity, or that they are afraid of the dark. It seemed to me that we had no right to see in this tendency of animals to fly into flame the expression of an emotion, but that this might be a purely mechanical or compulsory effect of the light, identical with the heliotropic curvature observed in plants. I believed that the essential effect of the light upon these animals might consist in a compulsory automatic turning of the head toward the source of light, corresponding to the turning of the head, or the tip, of a plant stem toward the light; and that the process of moving toward the source of light was only a secondary phenomenon. It seemed to me also that if the stem of the plant could suddenly acquire the power of locomotion, it would act exactly like the animals which fly into the flame.*

I have since been able to prove directly that this deduction is correct. Eudendrium furnishes us the opportunity of observing the same organism in rapid succession as a free-moving and as a sessile organism. In an early stage of development the larvæ of Eudendrium are ciliated pelagic organisms which swim actively. When these larvæ are in an aquarium which receives its light from one side only, they swim at once toward that side and remain there as long as the direction of the rays of light remains unchanged. If the aquarium is turned, they also turn at once, and swim toward the lighted side of the aquarium. This condition does not last long, for the larva soon attaches itself, or rather adheres, to a solid body, and immediately afterward a polyp grows out from the end opposite that which is attached to the solid body. As soon as the polyp grows out, it undergoes a positively heliotropic curvature, as described above, provided that the light continues to fail into the aquarium from one side only. It is thus possible to see the same individual behave in twenty-four hours, first, like an insect that is attracted by the light, and then like a heliotropic plant. I mentioned before that the heliotropic curvature of the stem of Eudendrium occurs much more rapidly behind a blue than behind a red screen, if

* The first paper on the identification of the flying of animals into the light with the heliotropic curvatures of plants appeared in January, 1888. Sitzungsberichte der Wïrzburger med. physik. Gesellsch., I888. The same number contained also a preliminary notice on the identity of geotropism in animals and plants. 
it occurs in the latter case at all. I have found that the ciliated larvæ of Eudendrium swim rapidly toward the source of light behind a blue screen, while they react quite slowly, or not at all, behind a red screen.*

We will now show that the same ideas also hold for forms which, like the insects, possess a central nervous system. $\dagger$ We may choose for this purpose animals like the caterpillars of Porthesia chrysorrhea, or the winged Aphides. When the young caterpillars of Porthesia, which hibernate in a nest, are brought during winter into a warm room, they leave the nest. If a large number of these larvæ are put into a test-tube which is placed upon a table with its longitudinal axis at right angles to the plane of the window, all the caterpillars move toward the window side of the tube, where they remain. If the test-tube be turned carefully by an angle of $180^{\circ}$ in a horizontal plane, the animals will go back at once to the window side, and the quicker, the stronger the intensity of the light. They react in this way, whether the source of light is sunlight, diffused daylight, or lamplight. The representatives of the anthropomorphic viewpoint would say that the animals go to the source of light because it is brighter at the window side of the test-tube than at the room side. It can, however, be shown that in this case the animal has no choice, but that its head is turned mechanically toward the light by the latter, and that it is compelled to move in this position. The proof of the correctness of the mechanical, automatic, or heliotropic view lies in the fact that the animals also move toward the source of light, even if in so doing they must pass from the light into the shade. The experiment can be made in the following simple manner: Let, through the upper half of a window (ww, Fig. 25), direct sunlight $S$ fall upon a table, through the lower half, the diffused daylight $(D)$. A test-tube $a c$ is placed on the table in such a way that its long axis is at right angles with the plane of the window; and one half $a b$ is in the direct

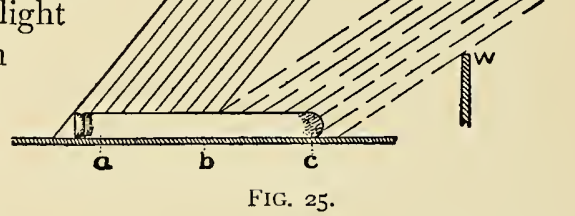
sunlight, the other half in the shade. If at the beginning of the experiment the animals are in the direct sunlight at $a$, they promptly

* These observations on the larvæ of Eudendrium were made in I895 at Woods Hole, but have not been published heretofore.

$\dagger$ Loeb, Der Heliotropismus der Thiere und seine Uebereinstimmung mit dem Heliotropismus der Pfanzen, Würzburg, I 889. Reprinted in Studies in General Physiology, Vol. I, Chicago, 1905. 
move toward the window, gathering at the window end $c$ of the tube, although by so doing they go from the sunshine into the shade. This shows that the effect of light consists in turning the head of the animal, and subsequently its whole body, toward the source of light, so that the symmetrical points of the photosensitive surface of the body - in this case the eyes - are struck by the rays at the same angle. The animals will remain at the window side of the tube at $c$ (Fig. 25). The experiment disproves the anthropomorphic idea that the animals go to the brightest spot in space.

It can also easily be shown that in these animals, just as in plants, the more refrangible blue rays are more effective than the red rays, and that the latter act like weak light. Let us suppose that a test-tube containing the animals be placed on a table near the window (ww, Fig. 26), through which diffused light $D$ enters; and that one half of the test-tube, namely, that near the window, be covered with blue glass $a b$. At the beginning of an experiment the animals are gathered at the room end of the test-tube. They behave as if the test-tube were entirely uncovered, and move toward the window side of the test-tube, where they remain. The same experiment may be repeated, only with the difference, that the window side $a b$ of the test-tube is covered with red instead of blue glass. The animals now creep in the direction of the window to that point in front of $a$ where the light, filtered by the red glass, begins to strike them. Here they gather, migrat-

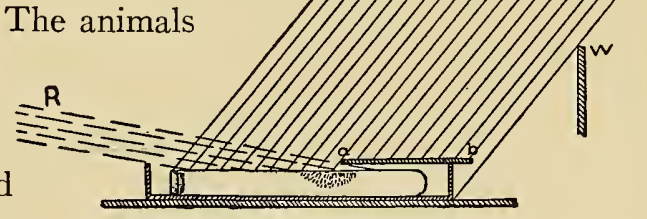

FIG. 26 . ing constantly in a narrow circle at the limit between red and diffused light. The explanation of the latter experiment is as follows: As long as the animals are at the room end of the test-tube, they are struck simultaneously by the diffused daylight $D$ which falls through the window, and by the weak light $R$ which is reflected from the walls of the room. Under these circumstances the animals are forced to turn their heads toward the stronger source of light, namely, the window, and consequently move toward it. As soon as they reach the point where the light from the window has to pass through the red glass, before striking them, the light reflected from the walls of the room, which contains the effective blue rays, is heliotropically more effective than the light from the window, which has lost most of its heliotropi- 
cally effective rays. Consequently the heads of the animals are turned automatically toward the room side of the test-tube, just as would be the case with the tip of a positively heliotropic stem under similar circumstances. They move toward the room side, but cannot go far, because, as soon as the unfiltered light from the window again strikes them, the latter being stronger, the head is now turned automatically toward the window again, and they move toward the latter until they get under the red glass; and now the whole process repeats itself. It thus happens that the animals gather in front of $a$ at the limit between the uncovered part of the test-tube and the red glass, where they keep on moving in a narrow circle. Similar results are obtained if an opaque body is substituted for the red glass.

If the whole test-tube be covered with red glass, the animals still show a slight tendency to move toward the window side of the tube; but their motions are no longer in a straight line as before, but more irregular. They finally, however, gather at the window side of the tube; but it requires much more time before they gather there than if the test-tube is covered with blue glass. Red light acts upon these animals like weak light; this can be shown directly by experiments with daylight towards sunset, or in a comparatively dark room.

It seems, therefore, that these phenomena are indeed the same as those in positively heliotropic sessile animals and plants; and we may designate such animals whose heads are turned automatically toward the light, when the light strikes them from one side, as positively heliotropic. It should be observed that the essential feature in these reactions is the compulsory turning of the head by the light, which leaves the animal no choice, making all the caterpillars of Porthesia or all the plant lice of the same culture behave exactly alike, just as in the case of a magnet all the pieces of iron are compelled to behave alike. This compulsory character of heliotropic reactions seems to have been overlooked by those anthropomorphic opponents of the theory of animal heliotropism, who offer the objection that we can turn toward the window voluntarily. This objection is about as absurd as if we should argue against the existence of magnetism because we can turn and move toward a magnet without being made of iron.

We not only find animals whose heads bend or turn toward the light, which consequently must move toward the source of light, if they move at all, but also animals whose heads bend or turn away from the source of light. We call such animals negatively heliotropic. Such negatively heliotropic animals are, e.g. Gammarus pulex, a freshwater Crustacean, the larvæ of the house fly, when fully grown and ready to go into the pupa stage, the larvæ of Limulus in a certain stage, 
Copepods and other animals, under certain conditions, as we shall see later. For the negatively heliotropic animals the rule holds also, that the blue rays are more effective for heliotropic reactions than the red rays. It is easy to show that these animals move away from the source of light in the direction of the rays of light. The fact can be demonstrated nicely in the case of the fully grown larvæ of the fly, by compelling them to move on a table on which strong light, e.g. direct sunlight, falls. If a shadow is thrown on the table by means of a pencil, it will be found that the larvæ move parallel with the shadow, away from the source of light. It can also be readily demonstrated that these animals are not, as the anthropomorphists would probably state, afraid of the light, or fond of darkness, but they are purely negatively heliotropic, which means that the head is bent or turned away automatically by the light from the source of light, exactly like the tip of a negatively heliotropic root. This can be shown by putting the larvæ on a table which has been placed near the window in such a position that the half of the table which is nearer the window is struck by diffused daylight, the other half by the direct sunlight. If the animals, at the beginning of the experiment, are at the window side of the table in the shade, their heads, under the influence of the light, will be mechanically bent away from the window, and all the animals will begin to move in the direction of the rays of light. They go from the shade into the sunlight. I have modified this experiment by putting the larvæ in long glass tubes, one end of which lay in the shade near the window, the other in direct sunlight. The animals went from the shade on the room side of the tube into the end which was in the direct sunlight; here they remained permanently, notwithstanding the fact that they soon died from the effect of the sunlight (or the heat?). When the animal is struck by light on one side only, those muscles which turn the head away from the source of light contract more strongly than their antagonists; the consequence is a bending of the head away from the light. As soon as the symmetrical points of the photosensitive surface of the animals are struck by the light at the same angle, the tension of the photosensitive surface becomes equal; hence the animals remain in this orientation. If they move, their locomotions will therefore occur in the direction of the rays of light, and away from the source of light.

We mentioned before that the laws of heliotropic curvature in plants can be successfully demonstrated in animals. We may add that the heliotropic motions of animals to and from the light can be demonstrated in free-moving plants. Under certain conditions, which are not yet completely analyzed, the cells of algæ are transformed into smaller 
cells, which are provided with cilia, and move out from the algæ. Strassburger showed that these swarm spores may be heliotropic and move in the direction of the rays of light to or away from the source of light. The blue rays are more effective in this case than the red rays.

\section{The Control of the Precision and Sense of Heliotropic Reactions in Animals}

When a large number of animals are tested for heliotropic reactions, we find that there are two problems to be solved: the first, to account for the variations in the degree of heliotropic sensitiveness; the second, to account for the variation in the sense of heliotropism. As far as the first factor is concerned, we find animals that are not heliotropic at all, animals that show a slight degree of heliotropism, and others that are so pronounced in their heliotropism, that their motions, and indirectly their whole existence, is only a function of light. As far as the sense of heliotropism is concerned, we find positively and negatively heliotropic animals. What causes these differences? We started with the assumption that the heliotropic reactions are caused by a chemical effect of light; in all such reactions time plays a rôle. We assume, furthermore, that if light strikes the two sides of a symmetrical organism with unequal intensity, the velocity or the character of the chemical reactions in the photosensitive elements of both sides of the body is different; that in consequence of this difference the muscles, or contractile elements, on one side of the organism are in a higher state of tension than their antagonists. The consequence is a curvature or a bending of the head. With this assumption it becomes at once obvious what is responsible for the variation in the intensity of heliotropism. Let us consider for the time being only positively heliotropic animals. Some of these, e.g. winged plant lice or the caterpillars of Porthesia (immediately after leaving the nest), may be called most intensely positively heliotropic, inasmuch as they move toward the source of light in as straight a line as their structural imperfections permit. If they deviate from the direction of the rays of light for only a short time, possibly less than a second, the difference in the tension of the muscles on both sides of the body becomes so great that it suffices to turn their heads automatically again toward the source of light. If one side of the body alone be exposed to the light for only a fraction of a second, the light causes such a difference in the chemical substances formed on both sides of the body that the threshold for the difference in the tone of the muscles is exceeded, and the bending of the head must occur. If, however, the light does not increase the reaction velocity as much 
or if the mass of photosensitive substances is less, it will require a longer one-sided exposure of the animal before the threshold for creating a difference in the tension of the muscles on both sides of the body is reached. Such animals will also move toward the source of light, but they do not move so directly in the direction of the rays of light as the strongly heliotropic forms, but much more irregularly. Finally, if the light does not accelerate the reaction velocity in the animal at all, or if the proper photosensitive substances are not present, or the proper products are not formed in the photochemical reaction, the animal will not appear in the slightest degree heliotropic.

The correctness of this view can, I believe, be demonstrated, by exposing animals which in strong light are intensely positively heliotropic to weak light. If in the strong light they move in as straight a line toward the source of light as the imperfections of their locomotions permit, a low intensity of light can be found where they still go toward the source of light, but where their progressive motion follows the direction of the rays of light much less accurately. In the weaker light the acceleration of the photochemical reactions is less than in strong light, hence the time during which an animal can deviate from the direction of the rays, exposing only one side of its body to the source of light, becomes longer. The same result can be obtained by putting these animals behind a red screen. This explains, also, the influence of temperature upon the precision with which the heliotropic animals follow the direction of the rays of light. Within certain limits the precision with which such animals move in the direction of the rays increases with the temperature.

If it be true that the immediate effect of the light in causing the heliotropic reactions is of a chemical nature, we should expect that it must be possible by the use of chemicals to control the precision and sense of the heliotropic reactions. I have recently found facts * which prove the correctness of this supposition. It may be of importance that these chemicals are such as may be formed by the organism itself. The experiments were made on fresh-water Crustaceans, Gammarus pulex, Daphnia, and Cyclops. If Gammarus are left to themselves, they may be found in any part of the aquarium clinging to solid bodies; but if they are disturbed by transferring them from one vessel to another, or by merely stirring the water in the vessel in which they are, they become, transitorily at least, negatively heliotropic. It is possible, however, to make them at once intensely positively heliotropic, by adding certain chemicals to the water, e.g. esters. If the negatively heliotropic Gammarus are in a glass jar containing 50 c.c. of tap water, they become

* Loeb, University of California Publications, Physiology, Vol. 2, p. I, I904. 
positively heliotropic if $\mathrm{I}$ or 2 c.c. of a grammolecular solution of an ester, e.g. ethylacetate, is added. Ethylbutyrate and methylacetate act similarly, only they seem to be more toxic. The transformation is rapid but not instantaneous, and by giving smaller doses of ethylacetate the latent period may be prolonged.

A second means of making them positively heliotropic is through the addition of acids. If, instead of an ester, I to 2 c.c. of $\frac{n}{\text { IO }}$ solution of an acid, e.g. hydrochloric, oxalic, or acetic acid, is added, the animals also become positively heliotropic. It seems to me of importance that $\mathrm{CO}_{2}$ is especially active in this respect. If $\mathrm{CO}_{2}$ is allowed to bubble through the vessel in which the Gammarus are, or if from 5 to ro c.c. of soda water (or even beer!) is added to $5 \circ$ c.c. of water, they become also positively heliotropic. Boracic acid seems to be ineffective.

Of other substances which act in a similar way, alcohol, paraldehyde, ammonium salts, and to a slight extent $\mathrm{K}$-salts, may be mentioned. But much higher concentrations of these substances are needed than of the acids or esters. The positive heliotropism which is produced in this way is only transitory.

In a colony of Cyclops some individuals, as a rule, are outspokenly positively heliotropic, others are rather indifferent to light, and a few may gather at the room side of a glass dish. If, however, I to 2 c.c. of $\frac{n}{\mathrm{IO}} \mathrm{HCl}$, or another not too weak acid is added, or $\mathrm{CO}_{2}$ is admitted, the animals all gather in a narrow region at the window side of the vessel. If the water is rendered weakly alkaline, they become less outspokenly positively or even, in part at least, negatively heliotropic. I have not been able to obtain this latter effect of alkalies in Gammarus. We see, therefore, that acid, especially $\mathrm{CO}_{2}$, not only makes negatively heliotropic Cyclops positively heliotropic, but increases the intensity of the positive heliotropism in those that were already positive at the beginning of the experiment.

In Daphnia it can be shown that when they are only weakly positively heliotropic, e.g. in weak light, the addition of acid in the abovementioned concentration makes them intensely positively heliotropic.

I may perhaps call attention to the fact that acids, especially $\mathrm{CO}_{2}$, are formed in organisms; that, moreover, esters are formed in the stems of many plants. It may be that these substances play a rôle in the production and variation of heliotropism in plants and animals.

In my first publications on animal heliotropism I had already mentioned the fact that chemical changes in certain animals apparently 
produce also changes in the degree and sense of heliotropism. I had found that the caterpillars of Porthesia chrysorrhoea are outspokenly heliotropic only as long as they are not fed. After having begun to eat, their heliotropic sensitiveness diminishes or disappears completely; and in later stages of their growth and development their heliotropism becomes very weak, even if they are caused to starve again. In ants the intensity and the sense of heliotropism seem to be connected with the development of their sexual products. At the time of sexual maturity the males and females are markedly heliotropic;* while in the workers not a trace of heliotropism is demonstrable.

Many animals change the sense of heliotropism during their development. The larvæ of Limulus polyphemus are positively heliotropic immediately after hatching, while they become negatively heliotropic in later stages. The larvæ of the common house fly are negatively heliotropic at the end of their larval period, while this reaction neither exists in the earlier stages nor in the imago stage. It is not impossible that in all these cases the real cause for the changes in the sense and intensity of heliotropism is to be found in chemical changes which accompany sexual maturity or larval development. Larvæ of Polygordius (a marine Annelid) are, when caught, negatively heliotropic; in about two hours, however, they become positively heliotropic. I found that they could be made positively heliotropic at any time by cooling the sea water to about $7^{\circ} \mathrm{C}$., or below. It was also possible to make positively heliotropic larvæ negatively heliotropic by raising the temperature of the water. Larvæ which were positively heliotropic at $24^{\circ}$ were rendered negatively heliotropic by raising the temperature to $29^{\circ} \mathrm{C}$. Larvæ which were positively heliotropic at room temperature became much more positively heliotropic when the temperature was lowered; while those which were already negative at room temperature remained so when the temperature was raised. $\dagger$ It was possible to make the same larvæ in succession negative or positive at desire; it was only necessary not to raise the temperature too suddenly above $25^{\circ}$, as this apparently injured the animals. The immediate effect of temperature in this case was possibly a chemical one.

Results similar to those obtained by changing the temperature could be obtained by changes in the concentration of the sea water. When Polygordius was suddenly put into sea water diluted with fresh water, those that were positively heliotropic before became negatively heliotropic, while those that were already negative continued so. It

* Kellogg has observed that bees also become outspokenly positively heliotropic at the time of their nuptial flight, Science, 1904.

$\dagger$ Loeb, Pfïger's Archiv, Vol. 53, p. 81, I 893. 
sufficed for this purpose to add from 30 to 60 c.c. of fresh water to roo c.c. of sea water. If, however, the concentration of the sea water was raised through the addition of $\mathrm{I}$ gr. $\mathrm{NaCl}$, or the equivalent amount of some other salt, or of sugar, the animals became positively heliotropic. Loss of water on the part of the animal acted therefore like cooling, and an increase in the amount of water like raising the temperature.

I made similar observations concerning the changes in the sense of heliotropism in Copepods.

In some forms light itself seems to play a rôle in the sense of heliotropism. The Nauplii of Balanus are positively heliotropic upon leaving the egg, but they soon become negatively heliotropic. Groom and I found that when the larvæ were kept in a dark room which was illuminated by a gas flame, they remained positively heliotropic toward the flame. In strong light they soon became negatively heliotropic, and, as a rule, the quicker the stronger the light.* These experiments were made at Naples. Experiments which I made on Nauplii of Balanus in Berkeley showed that the reaction of these latter toward light differs somewhat from those found at Naples, and is much more complicated.

While in all these cases one would naturally suspect that chemical influences determine the sense and precision of heliotropic reactions of animals, the same is not so obvious in the following cases. Miss Towle found that Cypridopsis, an Ostracode, is at times negatively, at other times positively, heliotropic. The artificial transformation of positively heliotropic specimens into negatively heliotropic was not possible. It was, however, possible to make negatively heliotropic specimens positively heliotropic by mechanical agitation. $\dagger$ S. J. Holmes observed that terrestrial Amphipods are positively heliotropic, while the Amphipods living in the water are negatively heliotropic. This led him to try whether or not terrestrial Amphipods would become negatively heliotropic when thrown into water. He found, indeed, that one of these terrestrial Amphipods, Orchestia, when thrown into the water, becomes rapidly negatively heliotropic. In sea water these animals remain permanently negatively heliotropic, while in fresh water they become positively heliotropic again before they die. $t$

I have often wondered whether there are any differences in the behavior of negatively and positively heliotropic animals aside from their behavior toward light. When larvæ of Polygordius were kept in a vertical test-tube in a dark room, it often happened that one lot of these

* Groom and Loeb, Biologisches Centralblatt, Vol. 10, p. I69, I890.

† E. W. Towle, Am. Jour. Physiology, Vol. 3, p. 345, 1900.

†. J. Holmes, Am. Jour. Physiology, Vol. 5, p. 21 I, I901. 
animals collected at the top, another at the bottom of the tube. When these two groups were separated in two different vessels and exposed to the light, it was found that those animals that had collected at the bottom of the tube in the dark room were invariably negatively heliotropic, while the others were positively heliotropic. The reverse was also true; namely, that if positively and negatively heliotropic larvæ of Polygordius were put into vertical tubes in the dark, the positively heliotropic specimens invariably gathered at the top, the others at the bottom of the tube. In Limulus larvæ I noticed that when positively heliotropic they swam at the surface of the dish, while in the negatively heliotropic state they crept at the bottom. It is, however, questionable how far this observation can be generalized. In the Nauplii of Balamus I have noticed that negatively heliotropic larvæ swim with the same velocity toward the room side as positively heliotropic animals move in the opposite direction.

Heliotropism, and especially positive heliotropism, is extremely common among animals, particularly pelagic animals. I have found pelagic larvæ of fish which reacted in just as machinelike a manner to light as caterpillars or Crustaceans; but in adult fish, and particularly in higher vertebrates, typical heliotropic reactions can no longer be demonstrated. It rarely happens that animals endowed with the mechanisms of associative memory react in such a machinelike manner to the elementary forces of nature as the heliotropic animals which we have discussed.

Heliotropism plays a wide rôle in determining the behavior of animals, and there are animals whose life becomes at certain periods of their existence, at least, a function of light. Since I have treated the bearing of heliotropism upon the theory of animal instincts in another place* it need not be repeated here.

\section{The Reaction of Animals to Sudden Changes in the Inten- SITY OF Light}

One source of endless misunderstandings and waste of time among scientists results from the indiscriminate application of one principle to all those cases̀ which by accident have one feature in common with the cases covered by the principle, but differ in almost every other regard. We have already mentioned the absurdity of the idea that every kind of turning to the light should be a case of heliotropism. Heliotropism covers only those cases where the turning to the light is com-

* Loeb, Comparative Physiology of the Brain and Comparative Psychology, G. P. Putnam's Sons. 
pulsory and irresistible, and is brought about automatically or mechanically by the light itself. On the other hand, there are compulsory and mechanical reactions to light which are not cases of heliotropism; namely, the reaction to sudden changes in the intensity of light. When the Serpula stretch out their gills, they instantly withdraw them if an opaque body passes between the animal and the source of light. Spirographis behaves similarly. Instead of casting a shadow upon the animal, the same reaction may be produced by suddenly closing the shutters of the windows. It is thus evident that we are dealing here with the effect of a sudden decrease in the intensity of light comparable to the twitching of a muscle upon the breaking or sudden decrease in the intensity of a current. It should be noticed, however, that I never succeeded in bringing about the sudden contraction of Serpula or Spirographis by a sudden increase in the intensity of light.

There are other forms which react as well upon a sudden increase as upon a sudden decrease in the intensity of light, e.g. fresh-water Planarians and earthworms. In these forms a sudden increase in the intensity of light causes restlessness, while the reverse change causes the animals to come to rest. This may lead to the gathering of the animals in such parts of the vessel as represent relative minima in the intensity of illumination. When such an animal comes from a bright spot to a darker spot, it comes to rest ("falls asleep"). In consequence of this fact such a relative minimum must act like a trap in which the animals are caught. The consequence is that the number of animals collecting in such a place must always increase, inasmuch as any animal which gets to such a spot by chance must remain there because its motions cease.

The fact that we are dealing here with the gathering of animals caused by light might easily mislead an investigator to mistake these reactions for negative heliotropism. It was a long time before I realized myself that I was dealing here with an effect of light which was specifically different from heliotropism. In the latter case the results are a function of the constant intensity, in the former a function of the quotient of the change of intensity over time. It is, however, easy to demonstrate the difference between the two kinds of gathering, experimentally. If negatively heliotropic animals be put into a cylindrical glass jar, and it be placed near a source of light, the animals move in the direction of the rays gathering at the negative end of the jar ( $b$, Fig. 27). If fresh-water Planarians are put into such a circular glass dish, they show very little or no tendency to move in the direction of the rays of light, creeping along in an irregular manner and gathering not at the negative or positive side of the jar, but on both sides, $c$ and $d$ (Fig. 27), 
where, on account of the refraction of light, the intensity is a relative minimum.*

The fact can be demonstrated still differently: if one part of the aquarium is covered with an opaque body, these organisms gradually gather under the covered part, where they come to rest. If the cover is suddenly removed, they begin to become restless and creep about. In heliotropism we deal with an automatic orientation of the animal by light, which compels all the animals to move in the same direction. In animals like earthworms or Planarians this orienting effect of light is very slight, and the animals may or do move in every direction.

Of course, it is possible that sensitiveness to sudden changes in the intensity of light exists also in a heliotropic animal. Serpula uncinata
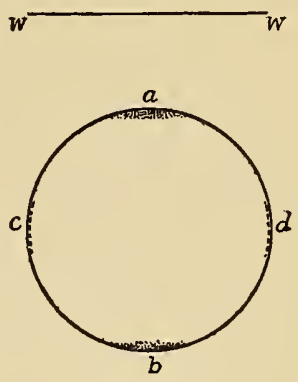

FIG. 27. is positively heliotropic, and yet contracts rapidly when the intensity of the light is suddenly decreased. In Planarians the sensitiveness to changes in intensity prevails, while, according to G. H. Parker, they show a slight degree of negative heliotropism.

* Loeb, Pfïger's Archiv, Vol. 53, p. 81, 1893. 


\section{LECTURE VIII}

\section{FURTHER FACTS CONCERNING TROPISMS AND RELATED PHENOMENA}

\section{General Theory of Tropisms *}

IN the preceding lecture and in my former writings I had given a theory of tropisms which may be considered as an application of Faraday's conception of lines of force. We may conceive space as being traversed by various kinds of lines of force, some of which are present permanently, and in the same direction, e.g. lines of gravitation; while others may be present or absent, and may vary their direction, e.g. light rays, or electrical lines of force, etc. The bodies of living organisms possess as a rule a symmetrical structure, not only morphologically but also chemically, or dynamically. By this I mean that symmetrical points at the surface of the body of an organism possess practically the same chenical substances qualitatively as well as quantitatively, and hence the velocity and kind of chemical reactions must be the same for such symmetrical points. Asymmetrical points of the organism, however, possess a different chemical structure, and hence the velocity and kind of reaction does not need to be, and probably generally is not, the same.

It is presumed, and is in all probability true, that those forms of energy which influence orientation or the direction of the motion of an organism, do so because they alter the velocity or the character of the reaction.

On account of the symmetrical structure the organisms are oriented automatically in any field of force which affects their chemical reactions neither too little nor too much, in such a way, that symmetrical points of the surface of the body are struck by the current curves at the same angle. In this case each element of the surface receives the same number of current curves.

The way in which this automatic orientation of the organism is brought about has already been mentioned in a preceding lecture. If

* Cf. Loeb, Pfïger's Archiv, Vol. 64, p. 439, I897. 
the current curves of radiating energy, e.g. light rays, strike an animal on one side only, or on one side more strongly than on the symmetrical side, the velocity or the kind of chemical reactions in the symmetrical photosensitive points of both sides of the body will be different. The consequence will be in a positively heliotropic animal a stronger tension or tendency to contract in the muscles connected with the photosensitive points of the one side of the body than in those connected with the opposite side. It seems that in animals the region at the oral pole is, as a rule, more sensitive than the rest of the body. Consequently the tension of the muscles determining the position of the head or oral pole is more intensely affected by differences in the intensity of light than that of the muscles of the rest of the body. The head is consequently bent until its symmetrical photosensitive points are again struck at the same angle by the rays of light. The tension of the symmetrical muscles of the head then again becomes equal, and the head must remain in this position unless other forces disturb its orientation. The rest of the body follows the orientation of the head, a point which is more fully discussed in my book on Brain Physiology.

Aside from the data given in the previous lecture on this subject, two more facts support this view. The one-sided section or destruction of certain parts of the brain causes a diminution in tone in the muscles which turn the body toward one side. The consequence is that animals in which such an operation has been performed, no longer, or only with difficulty, are able to move in a straight line, moving instead constantly in a circle or spiral.* We speak in such cases of forced movements. The same condition which is brought about in a more permanent way by certain one-sided lesions of the brain can be produced transitorily by a one-sided illumination of the photosensitive surface of a highly heliotropic animal, with this difference only, that the very difference in the tension of the muscles and the forced movement resulting therefrom leads to a remedy of the evil by bringing the symmetrical points of the animal back into a position where they are struck at the same angle by the lines of force.

The second fact in support of this conception is that when the photosensitive elements on one side of the body are eliminated, the animal is compelled to move in a circle. S. J. Holmes $\dagger$ and Parker $\ddagger$ have indeed found that such is the case. I will quote Parker's observation on the subject. His experiments were made on a butterfly (Vanessa

* Loeb, Comparative Physiology of the Brain, p. I50.

† S. J. Holmes, Am. Jour. Physiology, Vol. 5, p. 21 I, I90I.

$\ddagger$ G. H. Parker, The Phototropism of the Mourning-cloak Butterfly (Vanessa Antiopa), Mark Anniversary Volume, 1903. 
antiopa). "Since the head is the portion stimulated by light, it is natural to suspect that the eyes are the particular parts concerned. Loeb has pointed out that the orientation of an organism in light is dependent upon the equal stimulation of symmetrical points on its body. Should the eyes be the parts stimulated, any interference with one of these ought to result in a disturbance of the direction of the butterfly's locomotion. Thus if the cornea of one eye were blackened, the insect in locomotion, being positively phototropic, ought to move as though that eye were in shade; namely, in a circle, with the unaffected eye toward the center. Specimens prepared by blacking the cornea of one eye showed the expected response. When the right eye was covered, the insects crept or flew in a circle, with the left side invariably toward the center; and the reverse took place when the other eye alone was blackened. These circus movements agree with those observed by Holmes in other positively phototropic Arthropods." These data explain why in a field of force which affects the chemical processes in an animal neither too little nor too much, the animal is turned automatically until symmetrical points of its surface are struck equally by the lines of force. As soon as this occurs the animals must keep this orientation, and therefore have no further choice in the direction of their motions.

Whether the oral pole is turned toward the source of the lines of force or away from it, depends upon whether the energy which streams along the lines of force alters the chemical reactions in such a way as to increase the tone of the muscles (or the contractile protoplasm) connected with the stimulated elements, or to decrease it.

The light rays are not the only lines of force which bring about an automatic orientation of animals; the galvanic current curves act as lines of force, and we speak in that case of galvanotropic orientation, or galvanotropism. A number of plants and animals are oriented automatically by the lines of gravitation emanating from the center of the earth, and are compelled to put their axes or planes of symmetry into a vertical direction (geotropism). While in these cases the current curves are very marked, the same cannot be said in regard to the lines of force in a field of diffusion. The lines of diffusion determined by the particles emanating from a center of diffusion should be straight lines, but in reality currents of air or liquids cause disturbances of these ideal lines. It thus happens that in the case of chemotropism we can at the best expect only an approximate orientation.

There are some other tropismlike reactions of animals and plants which we shall discuss here, although they do not strictly belong in this chapter; namely, stereotropism and rheotropism. 


\section{Galvanotropism}

When animals are exposed to a galvanic current, compulsory reactions may occur which agree with the compulsory reactions produced by light, with the difference that we have to substitute the current curves for the light rays. When parallel current curves strike a symmetrical organ or organism sidewise, the contractile elements, e.g. muscles, on one side of the organ, or organism, undergo a higher degree of tension than on the other side; the outcome is a bending or turning of the organ or animal until its axis, or plane of symmetry, is in the direction of the current curves. As soon as this occurs, the symmetrical elements of the surface of the body are struck at the same angle by the current curves and the kind and acceleration of chemical reaction is the same on both sides of the organism; consequently the symmetrical muscle elements show the same state of contraction. But the fact that the current curves penetrate throughout the whole animal causes often complications which prevent an ideal orientation such as we observe in the case of light.

A most striking case of galvanotropism was found recently by Bancroft* in Polyorchis penicillata, a Medusa. "The method of experimentation consisted in cutting the Medusa in various ways, and placing the pieces in a trough of sea water through which the galvanic current was conducted with non-polarizable electrodes. The current strength varied from 25 to $200 \delta$. The responses were usually distinct with $25 \delta$, but became more decided as the current was increased.

"If a meridional strip (Fig. 28) passing from the edge on one side through the center of the bell to the other edge be prepared and the current passed through transversely, tentacles and manubrium turn and point toward the cathode (Fig. 28). A reversal of the current initiates a turning of these organs in the opposite direction, which is usually completed in a few seconds. This can be repeated many times and the tentacles continue to respond after hours of activity. The manubrium, however, tires sooner and fails to respond. If the strip is placed

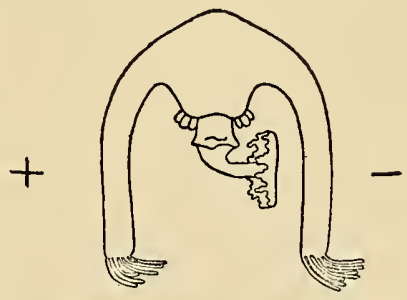

Fig. 28.-AFTER BANCROFT. with its subumbrella surface upward and extended in a straight line parallel to the current lines (Fig. 29), the making of the current causes the tentacles at the anode end to turn through an angle of

* F. W. Bancroft, Jour. Exper. Zool., Vol. I, p. 289, 1904. 
$180^{\circ}$ and point toward the cathode. The tentacles at the cathode end become more crowded together, reminding one of the tip of a moistened paint brush, and also point more directly toward the cathode. The experiment may be varied in still other ways by cutting smaller or larger pieces from the edge of the swimming bell, but the response

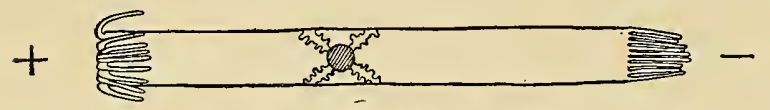

FIG. 29.-AFTER BANCROFT. is always the same. The tentacles, wherever possible, and to a less extent the manubrium, bend so

as to point toward the cathode. The response depends in no way upon the connection of these organs with the swimming bell, muscles, or nerve ring, for it is obtained equally well with isolated tentacles and pieces of tentacles. Isolated tentacles when placed transversely to the current lines curve so as to assume a more or less complete $\mathrm{U}$-shape, with their concave side toward the cathode. When placed parallel to the current, the tentacles do not curve" (Fig. 30). The latter observation shows very nicely the fact that the whole reaction is due merely to an increase in the tension of the muscles on the cathode side of the organ.

We are dealing here with the galvanotropic reactions of sessile organs where the whole reaction is merely a galvanotropic curvature. Wherever the current affects the locomotive organs of a freeswimming animal, besides the galvanotropic orientation of the animal, a swimming either toward the cathode or anode must occur. As an example, the reaction of an Infusorian, Paramacium, may be quoted. Verworn observed that Paramacium, when put into a trough through which a galvanic current passes, is oriented in such a way as to put its oral pole

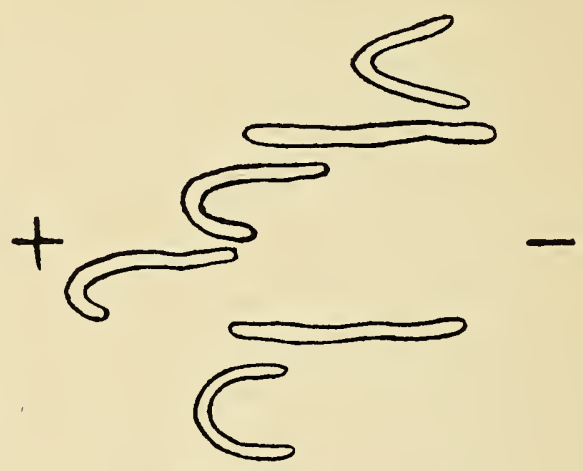

FIG. 3O.-AFTER BANCROFT. toward the cathode. It swims in this orientation toward the cathode.* The mechanism of this reaction was discovered by Ludloff. $\dagger$ The locomotion of Paramecium is brought about by cilia. As a rule, these cilia are directed backward ( $A$, Fig. $3 \mathrm{I}$ ), and therefore their

* Verworn, Pfïger's Archiv, Vol. 45, p. I ; and Vol. 46, p. 267, I889.

† Ludloff, Pfiuger's Archiv, Vol. 59, p. 525, 1895. 
powerful stroke being directed backward, the animal is pushed forward. Ludloff found that if a Paramecium is struck sidewise by the current, the position of the cilia on the cathode side is reversed; namely, they are now turned forward (Fig. 3I, B); while on the anode side of the animal they remain practically unaltered. Instead of striking symmetrically on both sides of the animal, the cilia on the cathode side strike forward powerfully, those on

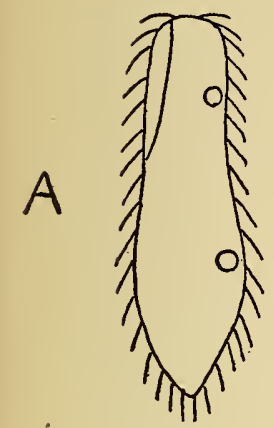
the anode side backward. The animal is thus under the influence of a couple of forces which turn its oral pole toward the cathode side. As soon as it is in this condition the symmetrical cilia are struck equally by the current curves, and they must assume a symmetrical position. Such is, indeed, the case. They are now pointed forward at the oral end, at the aboral end backward ( $B$, Fig. $3 \mathrm{I}$ ). As long as the current is not too strong, the oral region where the cilia point forward is rather small, and therefore the cilia which are pointed backward prevail, and the organism moves forward toward the cathode. That the motion of the organism to the cathode is exclusively due to the position of the cilia, and not to a stimulating effect
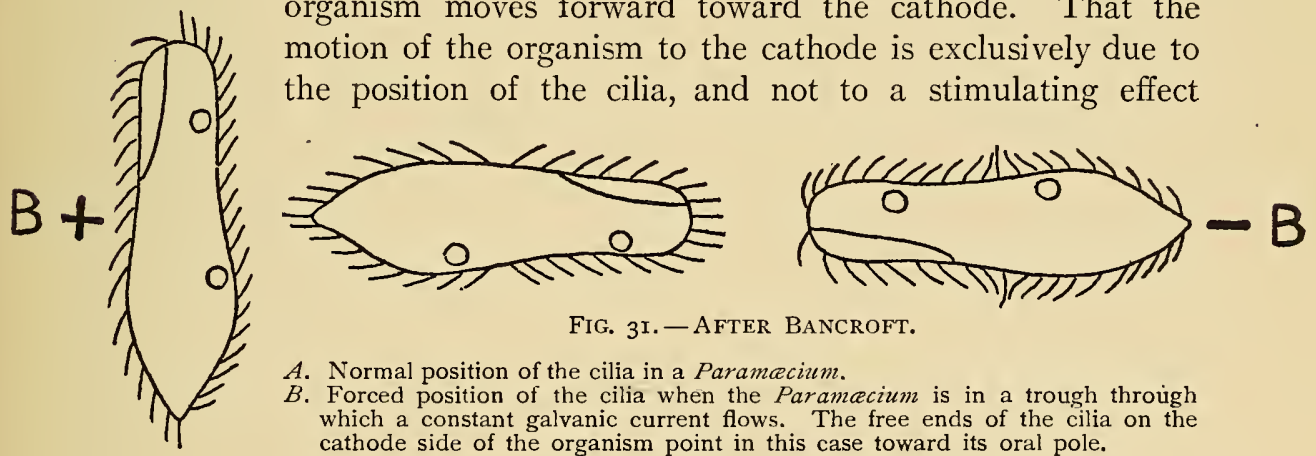

FIG. $3^{\text {T. }}$ - AfTER BANCROFT.

A. Normal position of the cilia in a Paramecium.

$B$. Forced position of the cilia when the Paramacium is in a trough through which a constant galvanic current flows. The free ends of the cilia on the cathode side of the organism point in this case toward its oral pole.

of the current at the anode, as Verworn had assumed, follows from observations made by Budgett and myself.* We found that in certain solutions, e.g. 0.8 per cent $\mathrm{NaCl}$ solution, the Paramacia show a tendency to swim backward. When exposed to a galvanic current in such a solution, they show a tendency to go to the anode. The explanation is that in such an organism the cilia are pointed forward under the influence of the solution. Bancroft found that when the current goes crosswise through such a Paramacium, the cilia on the cathode side continue to point forward while those on the anode side assume their natural position, pointing backward. The animal is thus turned with its oral pole toward the cathode. As soon as this 
occurs the cilia on both sides of the body, with the exception of a small number on the anode side, point forward, and the animal is therefore pushed backward to the anode.

Maxwell and I have investigated a little more carefully the reactions of a Crustacean, Palcmonetes, to a constant current.* When these animals are put into a trough through which a current passes (whose intensity is neither too weak nor too strong), all the animals move gradually toward the anode. The Crustacean can swim forward or backward and can walk forward, sidewise, or backward. The effect of the current does not in this case consist in a compulsory orientation of the organism, but merely in a compulsory change in the relative position of the legs, or swimmerets. The result is always such as to facilitate the motion to the anode, and to render more difficult the locomotion to the cathode. "Palamonetes uses the third, fourth, and fifth pairs of legs for its locomotion. The third pair pulls in the forward movement, and the fifth pair pushes. The fourth pair generally acts like the fifth, and requires no further attention. If a current be sent through the animal longitudinally, from head to tail, and the strength be increased gradually, a change soon takes place in the position of the legs. In the third pair the tension of the flexors predominates, in the fifth the tension of the extensors. The animal can thus move easily with the pulling of the third and the pushing of the fifth pairs of legs, that is to say, the current changes the tension of the muscles in such a way that the forward motion is rendered easy, the backward difficult. Hence it can easily go toward the anode, but only with difficulty toward the cathode. If a current be sent through the animal in the opposite direction, namely, from tail to head, the third pair of legs is extended, the fifth pair bent; that is, the third pair can push, and the fifth pair pull. The animal will thus go backward easily and forward with difficulty. When Palamonetes swims forward, the swimming appendages, among which the tail fin must be counted, push backward forcibly and forward gently; in swimming backward the opposite occurs. If the current be sent through Palcemonetes in the direction from head to tail, the swimming appendages and the tail also are stretched backward, or dorsad, to their fullest extent. This proves that the tension of the muscles that move those organs backward is greater than that of their antagonists. The shrimp can thus swim forward toward the anode easily under the influence of such a current, but backward only with difficulty. If the current passes through in the opposite direction, from tail to head, the tail and the ventral appendages are turned forward. The tension and the

* Loeb and Maxwell, Pfüger's Archiv, Vol. 63, 1896. 
development of energy now predominate in those muscles which move the swimming appendages forward. In this way the animal can swim backward easily, while it is difficult or impossible for it to swim forward.

"Palamonetes can also walk sidewise. This movement is produced by the pulling of the legs on the side toward which the animal is moving (contraction of the flexors), while the legs of the other side push (contraction of the extensors). If a current be sent transversely, say from right to left, through the animal, the legs of the right side assume the flexor position, those of the left side the extensor position. The transverse current assists the animal in moving toward the right, toward the anode, and prevents it from moving toward the left, toward the cathode." *

The, galvanotropic reactions were first discovered in vertebrates. Purkinje noticed that if a galvanic current is sent through the brain of a human being, sensations of motion and dizziness are produced. Brenner recognized the polar character of this effect, and found that if a current of sufficient intensity is sent laterally through the head, the person falls toward the anode side upon making the current, toward the cathode side, upon breaking the current. Mach noticed that if a current is sent sidewise through fishes, the animals have a tendency to roll toward the anode side. $\dagger$

The introduction of the term "galvanotropism" into physiology dates from J. Müller-Hettlingen, who found in Hermann's laboratory that if the seedlings of Vicia faba are exposed to a constant current, the tips of the roots bend toward the cathode. $t$ Hermann soon afterward made similar experiments on the larvæ of frogs. He found that these animals, when put into a trough through which a current goes, are turned into the direction of the current curves, putting their heads toward the anode. $\$$ I must, however, admit that I never succeeded in repeating this experiment on tadpoles.

Blasius and Schweizer $\|$ found that a large number of animals, when put into a trough with water through which a constant current goes, have a tendency to go to the anode. They assume that the current acting upon the central nervous system causes sensations of pain when it goes in the ascending direction through the animal; while it calms the animal when it goes in the opposite direction (from head to tail).

* Quoted from Loeb, Comparative Physiologv of the Brain and Comparative Psychology, New York, 1900.

† Mach, Grundlinien der Lehre von den Bewegungsempfindungen, Leipzig, I875.

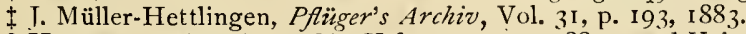

$\$$ Hermann, Pfïger's Archiv, Vol. 37, p. 457, i885; and Vol. 39, p. 414, I886.

ii Blasius und Schweizer, Pflïger's Archiv, Vol. 53, p. 493, I893. 
The animals according to these authors choose the position which occasions the least pain; namely, with their heads toward the anode. This assumption is contradicted by the above-mentioned experiences on the effects of the galvanic current on the brain of human beings, which show that the tendency to fall toward one side is not produced, and not even accompanied, by any sensation of pain. Moreover, the above-mentioned observation on the effects of the current on the tentacles of Polyorchis, the reactions of Paramacium, and the observations on Palcmonetes, show that these reactions find their adequate explanation in the direct effects of the current upon the organs or nervous mechanism of locomotion; that there is no room left for the smuggling in of hypothetical pain sensations between the current and its effect upon the mechanism of locomotion. I have repeatedly pointed out that it is superfluous, and often in direct contradiction to the facts, to assume the existence of human sensations in lower animals, and to put these hypothetical sensations as a necessary link between the external stimulus and its motor effect. It is easy to see what led Blasius and Schweizer to their assumption. If we send a current through a trough in which are found specimens of a Salamander, Amblystoma, the attitude of the animal changes considerably, according to the direction in which the current goes. When the current goes from tail to head, the animal assumes an opisthotonic position, with its mouth open. It is evidently this condition, together with a certain restlessness, which caused Blasius and Schweizer to assume that the ascending current excites the animal painfully. If we, however, look at the condition of the animal when the current goes from head to tail, we see that in this case the animal is also in a forced position; namely, with its head downward and its back convex. The right expression of the facts is, it seems to me, that the descending as well as the ascending current change the tension of certain muscles; but while the latter causes the contraction of the extensors of the vertebral column and of correlated muscles, the former causes the contraction of the flexors. The assumption of the pain sensation as the necessary link in the one case and not in the other is quite arbitrary and unnecessary. It is probable that in animals possessing a central nervous system, the galvanotropic reactions are brought about chiefly by the action of the current upon the central nervous system. Since the galvanic current influences not only the superficial layers of an organism like the light, but penetrates through the whole body, the cases of ideal galvanotropic orientation are not so common as those of heliotropic orientation. 


\section{Geotropism}

It is well known that even in the dark the tips of the main roots of many plants show a tendency to grow vertically downward, while the tips of the main stem show the opposite tendency. If such plants are put into a position other than vertical, the tip bends until the vertical lines strike symmetrical points at the same angle. In such cases we call the roots positively, the stems negatively, geotropic. Knight has shown by putting plants on a rotating disk that these effects are due to gravitation. In a centrifugal machine the tips of the root grow toward the periphery, the stems toward the center of the disk. In grasses the curvature occurs in the nodes, while in other forms it occurs in the growing region near the tip of the root or the stem.

While chemistry furnishes sufficient data for the assumption of photochemical effects in organisms, we do not know of any direct effect of gravitation upon chemical reactions. Eight years ago I pointed out that such an effect might occur in this way; namely, that in the cells, or in certain cells, of geotropic organs, nonmiscible substances (e.g. solids and liquids) might exist, and that by the change in the position of the organ a change in the relative position of these phases might be brought about.* This change in position might be connected with an acceleration of the reactions on the one side, and the reverse effect on the opposite side of the organ. I was led to such an assumption by the observations made on the resting muscle in a stretched and normal condition. If the excised muscle of a frog is stretched passively by a weight, it produces more lactic acid than in the unstretched condition. $\dagger$ I am inclined to attribute this effect of the stretching merely to a change in the form of the muscle. It might be possible that the stretching increases the surface of certain (the anisotropic?) elements in the muscle, whereby the area of contact (with the isotropic substance?) and therefore the reaction velocity might be increased. Something similar might happen in geotropic organs, when they are put into a hori-

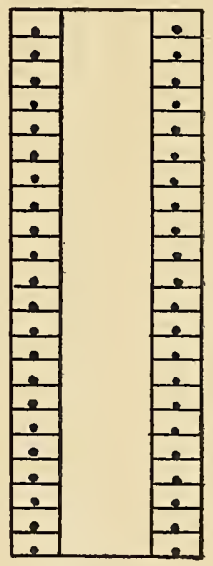

FIG. 32. zontal position. Suppose that in the normal (upright) condition of the stem certain solid or viscous substances (e.g. nuclei) of a higher specific gravity than the other constituents of the cell lie at the base of 
each cell of the tip of the stem (Fig. 32). If, however, the stem is put into a horizontal position, these heavier particles will go to the peripheral side of the cells on the lower half of the tip and to the central side of the cells on the upper half of the tip (Fig. 33). This difference in the

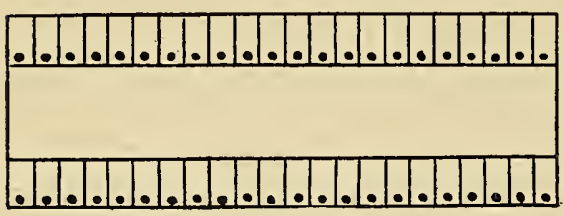

FIG. 33 . position of these solid particles may determine differences in the reaction velocity of the chemical processes in both groups of cells. In the cells on the upper side the heavier elements are in more direct contact with the substances diffusing into the cells from the pith, while in the cells on the under side the reverse is true. These assumptions are purely speculative, serving only as an illustration of the statement that a change in the position of an organ might influence the reaction velocity on the upper and lower sides of the organ differently. In consequence of such an influence, a curvature like that in heliotropic reactions might be produced.

Czapek has found chemical differences between the tips of roots which were put into a horizontal position and those left in their normal vertical position. In the extreme tips of the positively geotropic roots of Lupinus albus the amount of homogentisinic acid increased about I 5 per cent in about half an hour when put into a horizontal position. At the same time, a retardation in the blueing of tincture of guaiacum was noticeable, which he considered the effect of the formation of an antioxidase.* It is, however, questionable, whether these chemical changes are responsible for the geotropic curvature. In order to prove this it would be necessary to show a chemical difference in the lower and upper sides of a root or stem which had been put or brought into a horizontal condition. Czapek, however, states that he could not find any difference between the upper and lower sides.

Animals also show geotropic phenomena.† Antennularia, a $\mathrm{Hy}$ droid, behaves toward gravitation like a geotropic plant, and it would be possible to demonstrate the principle of geotropic curvatures in this animal. When the stem of Antennularia antennina, which normally grows vertically upward, is put into an oblique position in the aquarium, the tip bends until it is again in a vertical position, and then continues to grow in this direction vertically upward. The roots are not quite so straight as the main stem, and although they have a tendency

* Czapek, Ber. der deutsch. bot. Gesell., Vol. 20, p. 464, 1902. He obtained similar results in a case of light effects; ibid., Vol. 21, p. 243, 1903.

† Loeb, Sitzungsber. der physik. med. Gesellsch., Würzburg, Tanuary, 1888; and Pfïger's Archiv, Vol. 49, p. 175, 1891. 
to grow down vertically, the geotropic reaction is not so precise as in the stem. The latter is negatively, the former, positively, geotropic. In free-moving animals, geotropism is not so rare; Cucumaria cucumis, a Holothurian, possesses five rows of feet with which it can creep on vertical surfaces. If the animal be put on a vertical glass plate, it will creep vertically upward. When the plate is turned very slowly around a horizontal axis, the animal remains quiet during the rotation, but as soon as the plate is fixed, the Cucumaria again creeps vertically upward. This occurs also in the dark room. We will call such animals that are compelled to creep vertically upward, negatively geotropic.

Many marine animals and many insects show this reaction. If free-swimming aquatic animals which show a tendency to gather at the top or the bottom of a vessel are used for experimentation, the experimenter must be careful not to mistake the passive sinking or rising of such forms for geotropic reaction. Ostwald has called attention to the fact that with increasing temperature the internal friction of the water diminishes rapidly, which necessitates that organisms which float at the surface at a lower temperature must either sink down at a higher temperature, or are unable to work upward, on account of the diminished internal friction of the water. In addition, the resistance due to the shape of the animal plays a rôle in these phenomena.*

The attempt which many animals make to keep the axes of their eyes as nearly as possible in their normal position in space when the body is put into an abnormal position, is a common reaction which seems to be determined by gravitation. In Crustaceans the eyestalks form a small angle with the horizontal plane when the animal is in its normal position. When turned on one side, however, so that the right side is directly downward, the eyes no longer keep their symmetrical position in regard to the plane of symmetry of the animal, but the right eye is raised, the left lowered. $\dagger$ It looks as if the eyes had a tendency to keep their former normal position in space; just as the root or stem of a geotropic plant tries to keep its orientation toward the center of the earth. This reaction of the eyes also exists in vertebrates, and can be nicely demonstrated in fishes, lizards, birds, or rabbits. In frogs the eyes do.not show the so-called compensatory motions, but the head as a whole tries to keep its normal orientation toward the horizon, when the body of the animal is put into an abnormal position. These reactions exist universally, but in such forms as possess a powerful associative memory the reaction is liable to be interfered with.

* Wolfgang Ostwald, Zoologische Jahrbücher, Vol. 18, p. 1, I903.

† Clark, Jour. of Physiology, Vol. 19, p. 327, 1896. E. P. Lyon, Am. Jour. Physiology, Vol. 3, p. 86, 1899 . 
Knight's experiment can be made in these forms. When they are put on a rotating disk and turned in a horizontal plane, the eyes are displaced during the rotation in the plane of the rotation, but in the opposite direction.

In this case again a source of error has to be guarded against; namely, the influence of the retinal image. The tendency to keep the eyes and the head in the normal position to the horizontal when the body is turned, may be determined by the influence of the visual impressions. The apparent motion of the objects on the retina when the animal turns may cause a motion of the eye and head in the opposite direction. This suspicion is the more justified as in some insects these compensatory motions cease when the eyes are blackened.* Lyon has, however, shown that in sharks and flounders these compensatory motions are not diminished when the optic nerves are cut. In these forms at least we seem to deal with really geotropic reactions.

The next question must be, In which organs are these geotropic reactions produced? The answer might be simple enough were this field not in a hopeless state of confusion through the hypothesis concerning the functions of the semicircular canals. Flourens had stated that the sectioning of one of the semicircular canals causes the eyes and head of the animal to move in the direction of the plane of the canal. Goltz showed that destruction of the inner ear leads to disturbances "of the maintenance of the equilibrium of the animal." This term, "equilibrium," is not clear unless it be supplemented by the statement "with reference to the horizon or to the center of the earth." Goltz advanced the now famous hypothesis that semicircular canals are an organ where the equilibrium of the head, and indirectly of the whole animal, is regulated. If the head is bent, according to Goltz, the flow of the lymph in the canals causes a stimulation of the nerve endings in the ampullæ of these canals, and this calls forth a reflex motion, by which the head is put back into its normal position. Mach showed that physical reasons prevented a flow of lymph such as Goltz's hypothesis demanded; but that the pressure of the lymph against the nerve endings in the ampullæ, caused by changes in the position of the head, might suffice to bring about the effects which Goltz's hypothesis demanded. He showed, moreover, that this hypothesis also demanded that any stimulation of one of three ampullæ only called forth a motion of the eyes and head in the direction of the canal, and no other. While this hypothesis at first met with general opposition, it was later accepted, and it has, among others, received some support from my own laboratory. Nevertheless, the hypothesis is wrong. Lyon has shown

* E. P. Lyon, loc. cit. Rádl, Der Phototropismus der Thiere, Leipzig, I903. 
conclusively in my laboratory that the stimulation of the horizontal canals in sharks and flounders calls forth motions of the eyes in the plane of the canal, as the hypothesis demands, but that the two other canals, or their ampullæ, are either nonsensitive to stimulation, or give no motion of the eyes or the head in the plane of the stimulated canal. I will confess that I did not at first credit Lyon's statements, but I have convinced myself that he is unquestionably right. It seems that all the authors who had stated that stimulation of one of the semicircular canals caused motions of the eyes or head in the plane of the canal, based their statements only on the effects of the stimulation of one of the three canals; namely, the horizontal. The negative or questionable results they obtained in the case of the two vertical canals they did not dare to accept in the face of the strikingly clear results the horizontal canal yielded.* Suggestion does not play a rôle in ordinary matters only, but occasionally also in science.

It is, however, possible that the compensatory motions and reactions are after all produced in the inner ear, although the semicircular canals have little or nothing to do with it. This follows from the fact that when the auditory nerve in a shark is cut, all the compensatory motions cease. $t$ It may be that the otoliths in the inner ear are responsible for this effect. Mach $\ddagger$ was the first to point out this possibility, and Delage $\S$ made a number of experiments which seemed to speak in favor of this view. The most striking experiment was made by Kreidl on Palcmon. The otolith organs of this Crustacean are found in the basal part of the small antennæ. Palcemon loses its otoliths during the process of moulting, and after moulting it repairs the loss by putting small granules of sand into the ear. Kreidl kept such Crustaceans in vessels which were free from sand, but which contained instead very finely powdered iron. After moulting the animals put this iron powder into their ears. It was possible to test in such animals the otolithhypothesis of the geotropic reaction. The otolith rests on cells in which the sense nerves end. They are therefore supposed to press upon the nerve endings. When the animal is laid on one side, the otolith, instead of pressing, will pull at the cell, and this causes a change in the nerve endings which results in a righting motion (compensatory motion) of the eyes, or, if possible, of the whole body. If this view were correct, it should be expected that a magnet could produce effects similar to

* It is much easier to ascertain motions of the eyeball from right to left or vice versa than up and down. This is due to the fact that we estimate the motion from the displacement of the sclerotic. In the upward and downward motions, however, the sclerotic is, as a rule, not visible.

† Loeb, Pfiüger's Archiv, Vol. 49, p. I79, I891 ; and Vol. 5o, p. 66, r891.

$\ddagger$ Mach, Grundlinien der Lehre von den Bewegungsempfindungen, Leipzig, 1875 .

$\S$ Delage, Archiv. de Zoologie expérimentale, Vol. 5, 1887. 
gravitation, when the otoliths were of iron. If, e.g., the magnet were approached from the right side of the animal, the iron otolith would be pulled toward the right, and this should result in a reflex turning of the animal upon its left side. Kreidl found indeed that this occurred.* Kreidl's experiments were repeated and confirmed by Prentiss.

Delage, Kreidl, and Lyon all agree that the "maintenance of equilibrium" or more correctly speaking the geotropic reactions of the animal do not entirely disappear when the small antennæ are cut off. This proves that another organ contributes to these reactions, namely, the eyes. Removal of the eyes and the antennæ does away with the compensatory motions.

While it is thus probable that the otoliths have something to do with the reactions of the animal, it does not seem as if this were generally the case. The flounder possesses a single large otolith in each ear, which can easily be extracted without injury to the ear. Lyon found that if the otoliths were removed, the geotropic reactions and "maintenance of equilibrium" were not disturbed.

This field requires further investigation, and I should not be surprised if it were found that the really geotropic reactions of animals were determined in certain cells of the inner ear, or in certain cells of the brain, while otoliths may or may not act in an accessory way. It would, however, be a mere anthropomorphism to assume otolith organs inside the cells (as some botanists now begin to do for plants). Inside of the cells of geotropically sensitive organs gravitation may probably act through an influence upon the reaction velocity of certain chemical processes, as set forth at the beginning of this chapter.

\section{Chemotropism and Related Phenomena}

Theoretically we may assume that if substances diffuse in air or in water, the particles move in a straight line away from the center of diffusion. If they strike an organism whose surface is affected by the diffusing substances on one side only, the contractile protoplasm, or the muscles, turning the tip or the head or the whole organism toward that side, are thrown into a different state of contraction from their antagonists. The consequence is a turning or bending of the tip or the head until symmetrical points of the chemically sensitive surface of the body are struck by the lines of diffusion (or the diffusing particles) at the same angle. As soon as this occurs the contractile elements on both sides of the organ, or organism, are in an equal I893.

* Kreidl, Sitzungsber. der Wiener Akademie der Wissensch., Vol. 102, Abth. 3, p. I49, 
state of contraction, and the animal will bend or move in the direction of the lines of diffusion. There is practically, however, this difficulty; namely, that the lines of diffusion are generally disturbed by currents due to changes and variations in temperature, and instead of the straight lines of force we have in this case often irregular and changing ones. This makes it a priori hopeless to expect that in the case of chemotropism the organisms move in as straight a line as in that of heliotropism, geotropism, and certain cases of galvanotropism. In the majority of cases we are also dealing with a response to sudden changes in the nature and concentration of the substances contained in the medium.

Engelmann was probably the first to call attention to this type of phenomena. He found that certain bacteria and Infusorians gather around a source of oxygen.* In this case it was evidently a response to changes in the concentration of the oxygen, the organisms coming to rest where the tension of oxygen was a relative maximum. Pfeffer first compared these phenomena with those of other tropisms in his classical paper "Oriented Locomotor Motions produced by Chemical Stimuli." $\dagger$ He showed that the zoöspermix of ferns, mosses, and other plants move toward points from which certain substances diffuse into the water in which these organisms are. Pfeffer found that such effects are produced upon spermatozoa of ferns by malic acid and its salts, and upon those of mosses by cane-sugar solutions. The biological importance of this observation lies in the fact that malic acid is comparatively common in plants, and the presence of this acid in the archegonia of the ferns possibly contributes toward bringing the sperm to the egg. From the normal archegonium no malic acid diffuses, but those ready to be impregnated let part of their contents diffuse. The appearance of Pfeffer's paper aroused in many the hope that it might be shown that the animal egg, too, attracted the spermatozoa in some such chemotropic or chemotactic way; but all the experiments thus far made in this direction by J. Dewitz, Buller, and others - I have made quite a few experiments myself on this subject - have without exception shown that such is not the case in the eggs thus far tried. There does not seem to exist an attraction of the spermatozoa on the part of the egg, but the meeting of spermatozoa and the egg is left to chance, except that automatic tropismlike mechanisms exist, whereby the ripe males gather near the ripe females and the sperm is shed in the neighborhood of the egg. Pfeffer's method consisted in introducing a solution of the chemical substance to be tested, e.g. malic acid, into

\footnotetext{
* Engelmann, Pfïger's Archiv, Vol. 25, p. 285, I88I; Vol. 26. p. 537, 1881 ; and Vol. 29, p. 387, I 882 .

+ Pfeffer, Unters. aus dem bot. Institut in Tübingen, Vol. I, p. 363, I881-1885.
} 
a capillary tube which was sealed at one end, and then putting the tube with the open end into the water which contained the spermatozoa. "When the liquid in the tube contains only o.or per cent malic acid, the spermatozoa (of ferns) very soon move toward the opening of the capillary tube. At the same time many spermatozoa move into the capillary tube and within from five to ten minutes many hundreds of spermatozoa may accumulate in the tube. The malic acid acts as well in the form of a free acid as in the form of salts, and that it is a specific stimulant may be seen from the fact that in the same time probably not a single spermatozoön enters a capillary tube containing pure water or a solution of other substances." Massart and Bordet used this method of Pfeffer's on leucocytes.* It had been known for a long time that in inflamed tissues the number of leucocytes increases, and it was generally admitted that at least part of the supernumerous leucocytes migrate there from the capillaries. In order to answer the question as to what causes this migration, Massart and Bordet put capillary tubes containing cultures of bacteria, especially staphylococcus pyog. aureus into the abdominal cavity of the frog. After twentyfour hours the authors found leucocytes in large numbers in the tube. If a sterile culture medium was introduced, no leucocytes migrated into it. This seems to indicate that substances produced by the bacteria determine the direction in which the leucocytes move.

To give a more distinct picture of these phenomena I may mention a few of the observations made by Garrey $\dagger$ on this subject. A small square trough contained the organisms - in this case Chilomonas, an Infusorian. At one side a small capillary tube was inserted, into which the solution of the substance was put whose efficiency was to be tested. At the beginning of the experiment the organisms were equally distributed all over the square space. When very dilute $\mathrm{HCl}$ was put into the capillary tube, a clear circular area entirely free of organisms was soon formed around the opening of the tube. The organisms recede from the $\mathrm{HCl}$, diffusing into the trough, and thus indicate very nicely the rapidity and extent of diffusion. This clear area increases until the $\mathrm{HCl}$ has diffused to the end of the square space, when the organisms are again distributed equally. In this case we are probably not dealing with a real tropism, but with a reaction to sudden changes in the intensity of the stimulus. When the organisms go from neutral water to sufficiently acidulated water, they are repelled. According to Jennings, they swim first backward and then toward one side, a

* Massart and Bordet, Soc. Roy. des Sciences méd. et nat. de Bruxelles, 3 Févr., 1890. Reviewed Physiol. Centralblatt, Vol. 4, p. 332, I89I.

† Garrey, Am. Jour. Phvsiology, Vol. 3, p. 291, I90o. 
reaction which is quite common among Infusorians, and to which Jennings has given a special name, motor reflex or motor reaction.*

Garrey found that the phenomenon described above can be produced by many inorganic acids, provided their concentration is $\frac{\mathrm{I}}{\mathrm{I} 500} n$ or above. Alkalis bring about the same effect at a somewhat higher concentration; namely, $\frac{\mathrm{I}}{500} n$. Salt solutions require a still higher concentration, e.g. $\mathrm{NaCl}$, and $\mathrm{LiCl}$ require a minimum concentration of about $\frac{n}{30}$, and $\mathrm{KCl}$ about $\frac{n}{50} \cdot \mathrm{MgCl}_{2}, \mathrm{CaCl}_{2}, \mathrm{SrCl}_{2}$, and $\mathrm{BaCl}_{2}$ acted at a lower concentration; namely, $\frac{m}{100}$ to $\frac{m}{200}$. $\mathrm{ZnSO}_{4}, \mathrm{ZnCl}_{2}, \mathrm{CuSO}_{4}$, and $\mathrm{AgNO}_{3}$ were effective in a concentration of $\frac{m}{1000}$ to $\frac{m}{2000}$.

The immense biological rôle of these reactions is known to every one who has worked with insects. The finding of food, the depositing of eggs, and the meeting of the two sexes for the process of pairing are determined to a large extent by diffusing substances. I may relate the following observation $\dagger$ which certainly has been made often enough before. A female butterfly was put into a small, closed wooden box which was suspended from the middle of the ceiling of a room whose windows were open. At first no other butterfly of the species to which the female belonged was visible, but during the next half hour three male butterflies of the same kind approached the house, stopped at the window, then flew into the room, and settled on the wooden box through the openings of which they tried to enter. This effect could have been produced only by an emanation from the female butterfly. As an example of how emanations direct the motions of females that are ready to deposit their eggs, the fact may be cited that certain volatile substances emanating from meat "attract" the female fly. If fat and meat of the same animal are put side by side on the window sill, the female fly will light on the meat, where she deposits her egg, but not on the fat. This tropismlike reaction guarantees the perpetuation of the race, inasmuch as the larvæ feed and develop on meat, but not on fat.

\section{Stereotropism (Thigmotropism)}

Certain animals are compelled to put their bodies as much as possible into contact with solid bodies, while other organisms show the

* Jennings, Am. Jour. Physiology, Vol. 2, p. 374, I 899 ; and numerous subsequent papers by the same author.

+ Loeb, Animal Heliotropism and its Identity with the Heliotropism of Plants, Würzburg, I 889 . 
reverse behavior. The former organisms I designated as positively, the latter as negatively, stereotropic.

The first discovery in this direction was made by J. Dewitz,* who found that the spermatozoa of the cockroach (Periplaneta orientalis) are "attracted by surfaces." "If small pieces of glass or some cther object are placed between a slide and a cover-glass so that there is a space between cover glass and slide, and if this space be filled with a $\mathrm{NaCl}$ solution containing the spermatozoa, the latter gather only at the cover glass and the slide. In the rest of the liquid no spermatozoa are found. If a glass bead be put into such a liquid containing spermatozoa, the latter in no case leave the surface of the bead, although they are constantly in motion." Dewitz recognized that this reaction was of the greatest importance for the entrance of the spermatozoa into the egg of the cockroach. This egg possesses a micropyle, and only here can the spermatozoa enter the egg. When the egg is laid it passes the duct of the seminal receptacle, where the female carries the sperm it receives in the act of pairing. The egg then comes in contact with the sperm, some of which is possibly pressed out of the receptacle reflexly by the passing of the egg. When once on the surface of the egg, the spermatozoa can no more leave it, but must move on its surface incessantly. In this way one spermatozoon finally reaches the micropyle and gets into the egg. The impregnation of the egg is therefore in this case a function of the stereotropism of the spermatozoa.

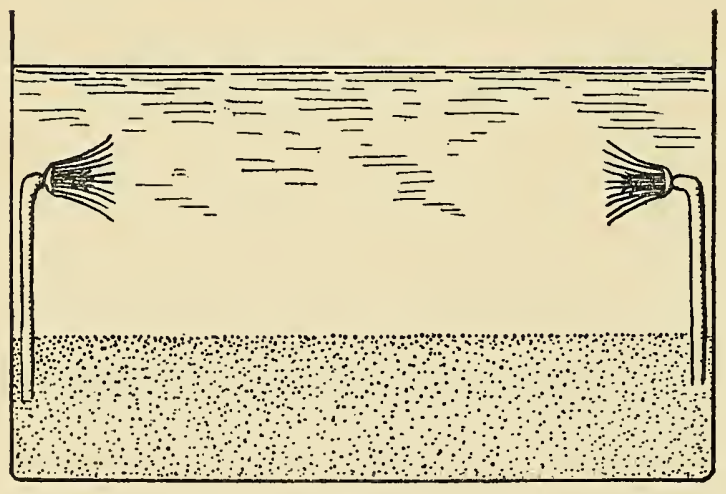

FIG. 34 .

Although stereotropism is no real tropism, inasmuch as in this case lines of force do not exist, there exist stereotropic curvatures. When the stems of Tubularia are fixed in an aquarium in such a way that the polyp touches the wall of the aquarium (Fig. 34), the polyp begins to bend away from the wall until at right angles with it, and then continues to grow in this direction. The stolon, however, sticks to the glass wall, possibly by the secretion of a sticky substance.

* J. Dewitz, Pflïger's Archiv, Vol. 37, p. 219, 1885; and Vol. 38, p. 358, 1886. 
It had been known that a number of animals hide in crevices. This phenomenon was generally ascribed to a supposed timidity or photophobia of these animals, which were believed in this way to protect themselves from their enemies. I showed that in this case the animals are forced to bring their bodies as much as possible in contact with solid bodies. Amphipyra is an outspokenly positively heliotropic butterfly which has a tendency to creep into crevices. If a number of these animals are kept in a box and a plate of glass is put on the bottom of the box so that it rests upon pieces of glass just high enough to allow the Amphipyra to creep under the glass plate, all of the butterflies will be found after a time collected under the plate. This happens as well when they are in the dark as when the plate of glass is exposed to full sunlight. As long as they cannot creep into crevices they run around restlessly, while they become quiet as soon as their bodies come in contact on all sides with other solid bodies.

The crevices thus act like a trap where such animals are gradually caught until metabolic changes (need of food) again make them restless, and compel them to move about.*

A similar form of irritability exists in ants. When sexually mature ants are kept in boxes containing pieces of folded paper or cloth, all of these animals will be found after some time in the folds, even if the box is absolutely dark. This form of reaction leads to the foundation of a nest, inasmuch as the female, after pairing, creeps into a crevice, where it lays its eggs.

This form of irritability is also found in worms. If, e.g., earthworms are kept in a glass vessel with a horizontal bottom and vertical walls, they collect and crawl in the angle between the vertical and horizontal side. Experiments which S. S. Maxwell made on Nereis, a marine Annelid, show how great the force is which keeps such animals in contact with solid bodies. These animals burrow in the sand. If they are kept in a porcelain dish, into which a number of glass tubes have been put which are just large enough to allow a Nereis to enter, it will be found that in about twenty-four hours each tube will contain a Nereis. The animals cannot even be induced to leave the tube if the latter is exposed to direct sunlight, which kills them, although by crawling out they might save their lives. $\dagger$ There are other forms which avoid contact with solid bodies as persistently as the animals thus far mentioned seek it. This form of irritability, negative stereotropism, is found in many swimming forms, e.g. the nauplii of Balanus. 
Positive stereotropism is apparently that form of irritability which next to chemotropism is most instrumental in bringing about the union of the two sexes. The holding of the female by the male during copulation is evidently in many forms purely a form of stereotropism. In frogs such contact irritability develops during the spawning season, on the ventral side of the chest. At that time the contact of the ventral side of the chest with any solid body causes a reflex closing of the arms of the male frog around the solid body. The embrace becomes lasting, however, only in case the embraced object is a female frog. In this case, obviously, other stimuli contribute toward making the embrace lasting. What the nature of these stimuli is, is not yet known.* Holmes has called attention to the fact that the embrace of the female Gammarus by the male is a similar case of stereotropism. $\dagger$ These reactions can even be demonstrated in the decapitated frog.

\section{Concluding Remarks concerning Tropismlike Reactions}

It is obvious that the tropisms furnish the understanding for many purposeful instinctive reactions, and that what is generally called an instinct is often nothing more than a compulsory turning and moving of an organism in a given direction. I have carried out such an analysis of animal instincts in another book, and therefore do not wish to enter upon this subject here. I believe, indeed, that the tropisms and tropismlike reactions will one day form the main contents of a scientific psychology of lower forms. The tropisms, however, and tropismlike compulsory reactions also play a rôle in the mutual arrangements of organs and tissues. The first case of this kind mentioned was the observation that the tigerlike coloration of the yolk sac of the Fundulus embryo is due to a creeping of the chromatophores upon the blood vessels. At first the chromatophores and blood vessels are formed without any definite relation to each other, but by and by every chromatophore creeps on the capillary, enveloping it completely. $f$ I am not able to state whether this is a case of chemotropism caused by the oxygen in the capillary tubes, or a case of stereotropism. Driesch $\S$ suggested later that the migration of the mesenchyme cells to those spaces in the gastrula of the sea urchin where the skeleton is to be formed, might be due to a tropism. Herbst $\|$ has pointed out the possibility of a wide application of the tropisms in ontogenetic processes.

* Goltz, Beiträge zur Lehre von den Nervencentren des Frosches, Berlin, I 869.

+ S. J. Holmes, Biological Bulletin, Vol. 5, p. 288, 1903.

‡ Loeb, Pfï̈ger's Archiv, Vol. 54, p. 525, 1893; and Jour. of Morphology, Vol. 8, p. 16r, 1893 .

i| Herbst, Ueher die Bedeutung der Reizphysiologie fïr die causale Auffassung der Ontogenese, Biologisches Centralblatt, Bd. I4 and Bd. I5, 1894 and 1895 . 
The more fertile a principle is, the more we can afford to be conservative in applying it. It is obvious that certain reactions have been called tropisms which have nothing to do with them; possibly Roux's cytotropism belongs to this group. Roux has observed motion of the cleavage cells of the germ of the frog's egg to and from each other; he has called these cases cytotropism. Driesch has pointed out that these are phenomena which are caused purely by capillary forces between the eggs. If this be correct, as it seems to be, and if we are not dealing in this case with a reaction of living matter to an outside stimulus, we are not dealing with a tropism; for by the latter we mean distinctly a class of compulsory reactions of the organism to outside stimuli; but not the passive motions of bodies caused by capillary forces. That these bodies consist of living protoplasm does not influence this discrimination.

Another warning to be careful in applying this principle was shown by recent investigations of E. P. Lyon.* It is a well-known fact that many fishes put their bodies into the direction of a current of water, and try to swim against the current. It was commonly supposed that this orientation was caused by the streaming of the water, possibly its friction against the sides of the body. Lyon has shown that this behavior is an optical reflex caused by the apparent motion of the object while the animal is moved passively by the stream. When he inclosed the fish in glass jars and dragged these jars through the water, the fish inside the jars oriented themselves in the direction opposite to that in which the jar was moved. There is no objection to calling this a tropic reaction, but it is certain that it should no longer be called rheotropism.

Attention should also be called to the fact that while the tropisms form in many cases the mechanism by which the preservation of the individual and the species is brought about, there are many cases of tropism which are of no use to the species; the whole field of galvanotropism is an example of this. Galvanotropism is purely a laboratory phenomenon; outside of the laboratory no animal ever comes into a situation which might call forth a galvanotropic reaction; yet galvanotropism is not uncommon among animals. Among the positively heliotropic animals, we find forms which are never exposed to the light, e.g. the caterpillar of the willowborer, or Cuma Rathkii, a Crustacean which lives in the mud at Kiel. I pointed out sixteen years ago that these cases speak against the assumption that the tropisms could have been acquired by the way of natural selection, $\dagger$ and Morgan has recently taken the same ground ; $\ddagger$ but I do not wish to enter upon a criticism of

* E. P. Lyon, Am. Jour. Physiology, Vol. 12, 149, 1904.

+ Loeb, Der Heliotropismus der Thiere, 1889.

$\ddagger$ T. H. Morgan, Adaptation and Evolution, New York, 1904. 
the principle of natural selection, which has certainly been a factor in the elimination of forms, although it played no rôle in producing any qualities or irritabilities. The fact that cases of tropism occur even where they are of no use, shows how the play of the blind forces of nature can result in purposeful mechanisms. There is only one way by which such purposeful mechanisms can originate in nature; namely, by the existence in excess of the elements that must meet in order to bring them about. In green plants and in some animals the positive heliotropism is useful; yet there exists probably an endless number of heliotropic animals for which their heliotropism is about as useless as is galvanotropism. The prerequisites for heliotropism are a symmetrical body form, which seems to be present in almost all organisms-although some asymmetries exist - and the presence of photosensitive substances, which is not quite so common, but certainly not infrequent. Some of the regular substances found in protoplasm seem to turn readily into a photosensitive form. As the two conditions mentioned above are quite common, the laws of probability make it necessary that in a certain number of cases both conditions will be fulfilled, and then we may expect heliotropic actions. If it now occurs that in an organism the turning to the light helps it to find its food, as is the case with certain caterpillars, e.g. Porthesia chrysorrhcea, or the stems of green plants whose starch is manufactured by light, we have a "purposeful mechanism." Again, according to the laws of probability, the number of animals in which the three groups of conditions meet is much smaller than where only two meet. The tropisms thus furnish an insight into the origin of purposeful reactions by the blind forces of nature. 


\section{LECTURE IX}

\section{FERTILIZATION}

\section{The Specific Character of the Fertilizing Power of the SPERMATOZOÖN}

IT is comparatively easy for the physicist to give to his data the form of a mathematical law, inasmuch as the independent variables are mostly in evidence, and all that remains to be done is to find the formula which expresses the relation between the variable and the function. In biology the independent variable is generally unknown, and the main energy of the investigator must be devoted to discovering this variable. The history of the problem of fertilization is extremely instructive in this regard. Although the fact that many animals, e.g. fishes, birds, etc., develop from an egg has been known as long as man has observed, it was not until 1827 that von Baer discovered the mammalian egg; and although Leuwenhoek, or a pupil of his, discovered the existence of spermatozoa in the sperm as early as 1677 , it was not until I843 that the fact was really established that generally the development of the egg is caused by the entrance of a spermatozoön.

As far as we know at present the entrance of a spermatozoön into the egg has two kinds of effects which must be kept apart: the first, namely, the starting of the process of development, the developmental effect; the second, the transmission of the paternal qualities to the new organism, the hereditary effect. We shall first discuss the developmental effects of the spermatozoön upon the egg, raising the question whether this effect of the spermatozoön is specific or general; that is to say, whether a spermatozoön can cause only the development of an egg of the same species or of any egg. It is well known that animals belonging to the same family, e.g. various kinds of dogs, the horse and the donkey, can be successfully crossed. In fishes, also, it has long been known that various types of hybrids can be easily obtained. Spallanzani and other observers were never able to obtain hybrid larvæ among the Batrachians. Pflüger, however, found that the first segmentations can be produced in the eggs of Rana fusca by the sperm of a salamander 
(Triton alpestris). When the eggs of the toad (Bufo vulgaris) are fertilized with the sperm of Rana fusca, they develop beyond the morula stage.* Born hybridized various kinds of toads. $\dagger$

It is rather remarkable that all these experiments seemed to indicate that the fertilizing power of a spermatozoön is quite specific, and that it does not go beyond the closely related forms. It was of considerable interest to find out whether the stimulating power of a spermatozoön might not be extended to more distant species. Nobody had succeeded in fertilizing the eggs of the sea urchin with the sperm of the starfish, and I had myself vainly tried to accomplish this result until it occurred to me that by altering the constitution of the sea water this result might be accomplished. The sea water has normally a practically neutral reaction. If, however, just enough $\mathrm{NaHO}$ or $\mathrm{Na}_{2} \mathrm{CO}_{3}$ is added to make its reaction faintly alkaline, the eggs of the sea urchin, Strongylocentrotus purpuratus, can be fertilized by the sperm of every starfish which has thus far been tried, and by that of Ophiurians. $t$ It suffices for this purpose to add I to 2 c.c. $\frac{n}{\text { Io }} \mathrm{NaHO}$ to Ioo c.c. of sea water. The relative number of sea-urchin eggs that can be fertilized in this way by the sperm of starfish or brittle star varies for various forms. With the sperm of Asterias ochracea, Asterias capitata, and an Ophiurian, as many as 50 per cent of the eggs could be fertilized, while with the sperm of the twenty ray starfish (Pycnopodia spuria) only 5 per cent, and with the sperm of Asterina only I per cent. In normal sea water only exceptionally an egg of Strongylocentrotus is fertilized by the sperm of Asterias; and in this case the fertilization occurs very late, - from twelve to thirty-six hours after the sperm has been added. The sperm of Pycnopodia and Asterina was never able to cause a fertilization of the sea urchin's egg in normal sea water.

It seems that the increase in the alkalinity of the sea water increases only the fertilizing power of the spermatozoön, and not that of the egg. When the sperm of starfish is introduced into alkaline sea water in which there are eggs of Strongylocentrotus, it takes from five to eight minutes before the fertilization membrane - which indicates the entrance of a spermatozoön into the egg - is formed. After a short time, which varies with the concentration of the $\mathrm{HO}$-ions in the sea water, the sperm loses its fertilizing power, and the spermatozoa agglutinate with each other. The eggs, however, do not lose their power of being fertilized by remaining in this abnormal solution. If the spermatozoa of the star-

* Pfïger's Archiv, Vol. 29, p. 48, 1882.

† Born, ibid., Vol. 32, p. 453, 1883 .

$\ddagger$ Loeb, University of California Publications, Vol. I, pp. I, 39, 85. Pflüger's Archiv, Vol. 99, pp. 323, 637; Vol. 104, p. 325, 1904. 
fish are brought from the alkaline sea water into normal sea water which contains the eggs of the sea urchin, none or only a few eggs are fertilized, showing that only in the alkaline sea water does the sperm of the starfish possess the qualities necessary for the fertilization of the egg of the sea urchin.

It is not so easy to decide which change must occur in the sperm of the starfish in order to enable it to fertilize the egg of the sea urchin. It is certain that the addition of alkali increases the energy of the motions of the spermatozoa of the starfish, but it is also certain that the addition of bicarbonate to sea water brings about an equal or a still more powerful increase in the energy of the motions of the spermatozoa of the starfish without increasing their power of fertilizing the eggs of the sea urchin. At present it is generally assumed that all that is necessary for the entrance of the spermatozoön into the egg is the ciliary motion of the spermatozoön which brings it in contact with the egg, and that the entrance of the spermatozoön into the protoplasm of the egg is due to the energy of its ciliary motion. I consider it possible on the basis of these observations that the ciliary motion of the spermatozoön is required only to bring spermatozoön and egg protoplasm into close contact, and that the entrance of the spermatozoön into the interior of the egg protoplasm is due to surface tension forces. It is not impossible that the conditions for this process depend upon the surface tension between spermatozoön and sea water becoming greater than the sum of surface tensions between sea water and egg, and spermatozoön and egg. In this case the egg protoplasm must spread at the limit between spermatozoön and sea water. The spermatozoön is thus introduced into the interior of the egg. These ideas are supported by the fact that the spermatozoön of the starfish fertilizes the eggs of its own species in normal sea water, and that the process is not aided by making the sea water alkaline.

It is also hardly necessary to mention the fact that the eggs of Strongylocentrotus purpuratus can be best fertilized in neutral sea water, not in alkaline sea water. It is a surprising fact that in the alkaline sea water in which the fertilization of the sea urchin's egg by starfish sperm succeeds best, the fertilization of the same egg by sperm of their own species is rendered difficult or impossible. This may be due to the fact that the motility of the spermatozoa of the sea urchin is diminished by the alkaline sea water.

I have tried to fertilize the eggs of the sea urchin with the sperm of Annelids and Mollusks, but thus far without success. It therefore looks as if the fertilizing power of a spermatozoön were to some extent at least specific. It is also possible, however, that if our idea concerning 
the rôle of surface tension for the entrance of the spermatozoön is correct, these restrictions to the fertilizing power of the spermatozoön are only apparent, and that we have only to find modifications of the natural media, which allow the spermatozoön to enter the eggs of foreign species.

As a rule only one spermatozoön enters an egg: as soon as this has entered no further spermatozoön can enter. This is also true for fragments of an egg. First, O. and R. Hertwig and later Boveri, Delage, and many other authors showed that a piece of an unfertilized egg can be fertilized by a spermatozoön. Janssens has recently observed that if a piece of protoplasm be cut off from a fertilized egg, this can no longer be fertilized. It is not impossible that the entrance of a spermatozoön alters the surface tension of the protoplasm of the egg, making it thus impossible for another spermatozoön to enter.

The egg of a starfish is, as a rule, not yet ripe, i.e. capable of being entered by a spermatozoön immediately after it is taken from the ovary. It has to lie for about two hours in sea water before it is ready for fertilization. During this time the polar bodies are thrown out. Delage has shown that if a piece of protoplasm be cut off from an egg of a starfish (Asterias glacialis) before it is ripe, it cannot be fertilized by a spermatozoön, but that this can be done when the piece of protoplasm is cut off from the egg after the egg has gone through the process of maturation.*

It is generally stated that the pollen of a hermaphroditic plant cannot fertilize the egg cells of the same individual. Castle found that similar though less pronounced conditions exist in a hermaphroditic Ascidian; namely, Ciona intestinalis. The eggs of a Ciona can, as a rule, not be fertilized with the sperm of the same individual, while they can be fertilized with the sperm of another individual. This immunity of the eggs against sperm of the same individual is not without exception. In some cases Castle found that 5 , Io, or even 50 per cent of the eggs of an individual could be fertilized with sperm of the same individual. Morgan confirmed Castle's observations, and found that if the eggs are put for about ten minutes in a 2 per cent ether solution in sea water, in a number of (but not in all) cases the number of fertilized eggs shows a slight increase. $\dagger$

\section{Artificial Parthenogenesis and the Theory of Fertilization}

It is hardly necessary to state that at all times authors have been ready to explain the fertilizing or developmental action of the sper-

* Delage, Archiv. de Zool. expérimentale, Vol. 7, pp. 383, 5 II.

† Morgan, Jour. of Exper. Zoöl., Vol. I, p. I35, I904. 
matozoön. One such explanation states that the spermatozoön imparts a peculiar mode of motion to the egg, leaving it to science to find out what this mysterious motion is. Other authors say that the egg is comparable to a watch which cannot go unless a spermatozoön enters, leaving it to science to find out the wheels and the spring in the egg, and the relation of the spermatozoön to this mechanism. Others again say that the spermatozoön exercises a stimulus, forgetting, however, to tell us what is the nature of the stimulus. The list of such explanations might be continued, but they all show the same characteristic; namely, that an explanation by phrases or words is offered where an explanation by facts is wanted. Instead of devoting any time to this kind of metaphysics, we shall consider some of the facts of parthenogenesis.

The oldest and best-known case of parthenogenesis is that of plant lice (Aphides). When the temperature and moisture are sufficiently high, the Aphides reproduce themselves parthenogenetically. Males do not exist under such circumstances. This condition can be maintained for years, possibly indefinitely. Similar cases of parthenogenesis seem to occur in Daphnia. A remarkable case of parthenogenetic development occurs among bees (and possibly among social wasps), where, according to Dzierzon, the male bees originate from unfertilized eggs, while the female (queens and workers) originate from fertilized eggs. The queen pairs only once and the sperm is carried in a receptacle. When an egg passes the duct without any sperm coming from the duct, it remains unfertilized. Dzierzon found that old queens lay only eggs from which male bees develop, and the examination of the receptacle showed that in such cases the receptacle was free from sperm. It was, moreover, observed that the workers, whose rudimentary sexual organs exclude copulation, occasionally lay eggs from which, however, only male bees originate. The observations of Dzierzon were confirmed and enlarged upon by Siebold, Leuckart and very recently by Petrunkewitsch.

In such cases of parthenogenesis the development of the egg is not called forth by a spermatozoön, but by another, at present, unknown condition. More recently the fact has been established that eggs, which naturally develop only when a spermatozoön enters, can be caused to develop artificially by certain physical and chemical means. In I886 Tichomiroff published the fact that the unfertilized eggs of silkworm, Bombyx mori, can be caused to develop by rubbing them gently with a brush, or by putting them for a short time into concentrated sulphuric acid. Siebold had already mentioned, and Nussbaum confirmed his observation, that a small number of such eggs develop without these 
means.* The publication of Tichomiroff caused Dewitz to make similar experiments on the eggs of frogs, and he believed that he found that treatment of these eggs with corrosive sublimate caused them to segment. $\dagger$ Roux, however, showed that Dewitz's conclusion was based upon an error, inasmuch as the eggs did not segment, but underwent coagulation, which gave the surface of the egg occasionally the appearance of having segmented.

A Russian author, Kulagin, made the statement that he put fish eggs into diphtheria antitoxine and saw a segmentation; but inasmuch as he published but this one statement on the subject, it is hard to tell whether or not sources of error were sufficiently avoided.

In $\mathrm{I} 887$, O. and R. Hertwig published their well-known experiments on the effects of various poisons on the segmentation of the eggs of Echinoderms. During these experiments, R. Hertwig made the observation that if eggs are transitorily treated with a 0.1 per cent solution of sulphate of strychnia, and are then put back into sea water, these eggs show karyokinetic figures, and occasionally segment. This observation was repeatedly discussed by him in subsequent papers. $t$ Hertwig raised the question whether other media might not have similar effects. Mead found in Woods Hole, that if a little $\mathrm{KCl}$ is added to sea water, the eggs of Chatoptorus, a marine Annelid, throw out their polar bodies, a process which in this form is normally only produced by the entrance of a spermatozoön into the egg. $\mathrm{NaCl}$ has no such effect. Morgan tried the effect of the addition of $\mathrm{NaCl}$ and other salts to sea water on unfertilized eggs of sea urchins, in order to test some statements made by myself and Norman concerning the effects of these salts on fertilized eggs. He found that unfertilized eggs form artificial astrospheres in such solutions, $\|$ and afterward $\mathbb{1}$ made the important observation that if these eggs are put back into normal sea water, they may begin to segment. He states, however, that "the result is a mass of extremely minute granules or pieces. These pieces never acquire cilia and do not produce any form that resembles any stage of the normal embryo. Later the masses disintegrate" (p. 454). The pathological cases of tumors, or galls show also that cell division and growth may be produced which do not lead to the formation of an embryo.

I was led to try experiments on artificial parthenogenesis in order

* M. Nussbaum, Archiv für mikrosk. Anat., Vol. 53, p. 444, 1899.

† J. Dewitz, Biol. Centrallilatt, Vol. 7, p. 93, I887.

I R. Hertwig, Ueber Befruchtung und Conjugation, Verhandl. der deutsch. zoolog. Gesellsch., 1892; and Sitzungsber. der Gesellsch. für Morphologie und Physiologie, in München, I895; and Festschrift für Gegenbauer, Vol. 2, p. 23, 1896.

$\S$ A. D. Mead, Lectures Delivered at Woods Hole, Boston, I 898 .

|| T. H. Morgan, Archiv für Entwickelungsmechanik, Vol. 3, p. 339, 1896.

IT T. H. Morgan, Archiv für Entwickelungsmechanik, Vol. 8, p. 448, 1899. 
to test the idea of the rôle of ion-proteids in the mechanism of living matter. If it were true that the salts played the rôle which I was inclined to ascribe to them, it might also be possible to cause with their aid the normal development of eggs. The experiments did not sustain this idea as I had expected, but I succeeded in producing plutei from the unfertilized egg of the sea urchin by exposing the eggs for about two hours to sea water whose concentration had been raised by about 40 per cent to 50 per cent. It was immaterial which substance was used to raise ine concentration of the sea water, except for the fact that no substances could be used which injured the eggs too much. The best effects can be produced by raising the concentration of the sea water through the addition of $\mathrm{NaCl}$ *

When unfertilized eggs are put into hypertonic sea water, they lose water and shrink. When put back into normal sea water, they absorb water again. We must therefore raise the question as to which of these two conditions causes the egg to develop, the loss of water when the egg is put into the concentrated sea water, or the taking up of water when it is put back into normal sea water. It can be shown that the former is the cause. If we increase the concentration of the sea water less than 40 per cent, if $e . g$. we add 7 c.c. of a $2 \frac{1}{2} m$ solution of $\mathrm{NaCl}$ to 93 c.c. of sea water, some of the unfertilized eggs of Arbacia will develop into swimming blastulæ, even if left permanently in the hypertonic sea water. I have recently repeated this experiment with the eggs of Strongylocentrotus. If the eggs of this sea urchin were left in a mixture of roo c.c. sea water +5 c.c. $2 \frac{1}{2} n \mathrm{NaCl}$ solution, after about six hours segmentation began, and after one or two days swimming larva began to appear. These larvæ, however, did not develop into gastrulæ or plutei, probably on account of the abnormal condition of the sea water. In this case only a loss, but no taking up, of water occurred. When the unfertilized eggs of the sea urchin are put permanently or transitorily into sea water which is diluted with distilled water, no development is produced.

But although the osmotic method led to the development of larvæ from the egg, it differed in a number of points in its effects from the process of fertilization by spermatozoa. In the first place, the eggs fertilized with sperm form a characteristic membrane as soon as the spermatozoön has entered, while the unfertilized eggs treated with hypertonic sea water develop without the formation of a membrane. Second, the rate of development is considerably faster in the fertilized egg than in the egg caused to develop parthenogenetically. Third, the larvæ originating from fertilized eggs rise to the surface of the water as soon as they begin

* Loeb, Am. Jour. Physiology, Vol. 3, p. 135, r899; Vol. 3, p. 434, 1900; Vol. 4, p. 178, I900; and Science, Vol. 2, p. 612, April, 1900. 
to swim, while those originating by the above-mentioned osmotic process swim at the bottom of the dish. Fourth, the number of larvæ developing from fertilized eggs is, as a rule, practically Ioo per cent, while in the case of artificial parthenogenesis a much smaller percentage of the eggs develop into swimming larvæ. In the case of Arbacia, I often succeeded in causing more than 20 per cent of the unfertilized eggs to develop, but in the case of Strongylocentrotus - the form of the sea urchin common at Pacific Grove - I was rarely able to obtain even as high a percentage of developing eggs. Often enough only a fraction of I per cent of the eggs yielded swimming larvæ by the osmotic method of artificial parthenogenesis.

In thinking over the possible cause of this difference between the development of the egg fertilized by sperm and of the egg caused to develop by osmotic influences, it occurred to me that the spermatozoön might carry into the egg not one, but several, substances or conditions, each of which was responsible for only a part of the specific features of sexual fertilization; and that in order to completely imitate the action of the spermatozoön it might be necessary to combine two methods of artificial parthenogenesis, each of which alone imitated the process of sexual fertilization only partially. This latter idea proved correct far beyond my expectations.*

I found that if the eggs of Strongylocentrotus purpuratus are put into 50 c.c. sea water to which 3 c.c. $\frac{n}{\text { Io }}$ of a fatty acid, e.g. formic, acetic, propionic, butyric or valerianic acid, are added, and are left in this water for from one half to one and one half minutes, they form a membrane when put back into normal sea water. The eggs go through the internal changes characteristic of nuclear division, but they rarely segment. In about six hours they begin to disintegrate, and after twentyfour hours scarcely an egg is left alive. If the eggs are left in the acidulated sea water, they neither form a membrane nor segment. If the eggs which have formed a membrane are put for from twenty-five to fifty minutes into sea water whose concentration has been raised by adding $\mathrm{I}_{5}$ c.c. $2 \frac{1}{2} n \mathrm{NaCl}$ solution to roo c.c. of sea water, the results are surprising. Instead of a fraction of a per cent of the eggs developing, I had it in my power to cause 90 to roo per cent of the eggs to develop. All the eggs formed a membrane which is characteristic of the egg fertilized with sperm. The rate of segmentation was practically the same as that of the eggs of the same female fertilized with sperm. A large percentage of the blastulæ originating from this combination of methods lcoked perfectly normal, and rose to the surface of the sea

* Loeb, University of California Publications, Physiology, Vol. I, pp. 83, 89, I I3, 1904. 
water. Their further development into gastrulæ and plutei occurred with the same velocity as that of the control eggs, which had been fertilized by sperm; and the larvæ showed an equal degree of vitality. It is an easy matter to produce and collect an unlimited number of plutei from the eggs treated with this method.

When the eggs are taken out too early from the acidulated sea water, they form no membrane, and the same is true when they remain too long in the acidulated sea water. If eggs that have been treated with a fatty acid without forming a membrane are submitted to the hypertonic sea water for from twenty-five to fifty minutes, they will not develop into larvæ, and not even segment. It is therefore obvious that the membrane formation and not the treatment with acid is responsible for these effects. This is corroborated by some further observations.

$\mathrm{O}$. and R. Hertwig discovered that if sea water is saturated with chloroform - only traces of which are soluble in water - the unfertilized eggs of the sea urchin form a membrane when put into this chloroform sea water.* Herbst found that benzol, toluol and creosote act similarly. $\dagger$ It seemed to me that possibly hydrocarbons in general might act in this way, and as a test I used amylene. It indeed called forth the membrane formation. This method of calling forth a membrane formation by hydrocarbons has a serious drawback, inasmuch as the eggs show a tendency to undergo cytolysis, and are killed. By the speedy transportation of the eggs into normal sea water some may be saved.

It seemed of interest to ascertain whether it made any difference for the parthenogenetic development which substance was used for the production of the membrane. When the eggs were taken immediately after the formation of the membrane from the sea water containing benzol, not all the eggs that had formed a membrane underwent cytolysis. When these eggs were subsequently treated in the way described above with hypertonic sea water, they segmented, and some of them developed into plutei. As long as the formation of a membrane is induced by a substance which does not injure the egg too much, the subsequent short exposure to hypertonic sea water may lead to the formation of an embryo. In regard to their vitality, and possibly their structure, the embryos may possibly differ according to the substance which is used for the production of the membrane. This, however, must be determined by further experiments.

It agrees further with the idea that the membrane formation and not

* O. and R. Hertwig, Untersuchungen zur Morphologie und Physiologie der Zelle, Heft 5, Jena, 1887 .

$\dagger$ Herbst, Biologisches Centralblatt, Vol. 13, p. I4, 1893; and Mittheilungen aus d. Zool. Station Neapel, Vol. 16, p. 445, 1904. 
the acid effect is essential in these experiments, that not all the acids can be used in these experiments. $\mathrm{HNO}_{3}, \mathrm{HCl}, \mathrm{H}_{2} \mathrm{SO}_{4}$ and dibasic or tribasic organic acids such as oxalic or citric, etc., could not be used, while $\mathrm{CO}_{2}$ called forth the membrane formation.

The order in which the two agencies are employed is not a matter of indifference. When the eggs are first exposed to the above-mentioned hypertonic sea water for about twenty to fifty minutes and then submitted to a process which calls forth the membrane formation (e.g. to the treatment with fatty acid), the eggs form a membrane, but will not develop into larvæ. As a rule, they disintegrate within twenty-four hours, and behave in every way as if they had been treated with the acid alone. If one wishes to treat them with hypertonic sea water first, they must remain in this solution for about from one and one half to two hours. If after this time the membrane formation is called forth, almost all the eggs develop, and a number of the larvæ rise to the surface. This method also gives good results.

If in eggs the membrane formation is called forth first, and if they are subsequently exposed to the above-mentioned hypertonic sea water for more than fifty minutes, either no egg develops or the development is very abnormal.

All the facts mentioned in this and the previous communications indicate that the process of membrane formation is an essential and not a secondary phenomenon in this method of artificial parthenogenesis.

Five years ago I ventured the suggestion that the process of membrane formation is a process of coagulation. It is, however, obvious that the membrane formation in these experiments cannot be attributed to an acid coagulation, as in this case the membrane formation should occur while the eggs are in the acid, and not after they are taken out. Moreover, the fact that only certain acids act in this way also excludes such an opinion. These facts suggested the possibility that the fatty acids did not produce the membrane formation through the $\mathrm{H}$-ion, but by the anion or the undissociated molecule, and that, moreover, the $\mathrm{H}$-ion directly antagonized the membrane formation. This idea was tested and found correct. If a fatty acid is added to benzol sea water, the eggs are no longer able to form a membrane while they are in this mixture, though they form a membrane while they are in benzol sea water which is free from fatty acid. From a closer observation of the process of membrane formation I am inclined to believe that it is due to a process of secretion, i.e. the squeezing out under pressure of a liquid from the interior of the egg.* I am

\footnotetext{
* Loeb, Pfïger's Archiv, Vol. 103, p. 257, I904.
} 
no more able to state the nature of the forces which underlie secretion in this than in any other case.

These experiments show that it is possible to completely imitate by physicochemical means the effect of the spermatozoön upon the sea, urchin egg. It is also obvious that this method is somewhat complicated and specific, and that it cannot be well covered by the phrase that the method consists in a "stimulation," for the word "stimulation" does not - as far as I know - mean that we have to treat an organ first for one half minute with 50 c.c. of sea water +3 c.c. $\frac{n}{\text { Io }}$ butyric acid and then for from twenty-five to fifty minutes with a mixture of roo c.c. of sea water $+\mathrm{I} 4$ c.c. $2 \frac{1}{2} n \mathrm{NaCl}$ solution. Moreover, these quantitative data vary slightly for different species of sea urchins, e.g. Strongylocentrotus purpuratus and franciscanus.

Yet some authors have maintained that any kind of stimulus, or various chemical substances, might produce artificial parthenogenesis in the egg of the sea urchin. These statements are based partly on misunderstandings and partly on errors. In a former paper I stated that it makes no difference how the osmotic pressure of the sea water is raised, whether by sugar, by urea, or by salts; if the pressure is only sufficiently high, the parthenogenetic development of the sea urchin's egg will occur. Morgan makes use of this fact to attempt to show that inasmuch as sugar as well as salts cause the development, various stimuli can produce the development. He overlooks the fact that in this case the sugar or salt does not act chemically, but solely osmotically by withdrawing water from the egg, and that for this effect it is immaterial what the chemical character of the dissolved substance is. Other authors have been misled by mistaking parasitic larvæ found in their cultures for the larvæ of sea urchins. Ariola has maintained that the eggs of sea urchins develop normally parthenogenetically at Naples. I may state that neither the unfertilized eggs of Arbacia nor those of Strongylocentrotus of the Atlantic or the Pacific coast of America ever develop, and that the same has been found for the eggs of the sea urchins at Naples by all competent workers. Ariola has given a description and drawings of the larvæ he found which he considered as normally parthenogenetic, larvæ of sea urchins, and I believe that they were probably larvæ of some mollusk; they were certainly not the larvæ of the sea urchin. I mention this fact simply to show that unless an author actually observes the origin of a larva from the egg, he may fall into serious error. Viguier maintains that the sea urchins in Algiers are naturally parthenogenetic. I should place more confidence in this author's statements were they written in a more dispassionate, scien- 
tific tone, and if his precautions against sources of error were more adequate. Still, it is not impossible that some physical or chemical condition accidentally present in Algiers may bring about effects similar to the extraction of water from the eggs of these animals in this country.

Since it is possible to fertilize the egg of the sea urchin and that of the starfish by the spermatozoa of the latter species, it seemed also possible that the fertilization of the starfish's egg might be caused by the same substances which cause the fertilization of the egg of the sea urchin. I have made experiments on the egg of a form of Asterina which is common in the bay of Monterey.* This egg forms a membrane upon the entrance of a spermatozoön. I found that as in the case of the sea-urchin egg, the egg of Asterina forms a membrane after having been treated with a fatty acid. The only difference is that the egg of Asterina requires more acid for this result than the egg of Strongylocentrotus. When the eggs of Asterina had been put for about one and one half to two minutes into a mixture of 50 c.c. sea water +5 c.c. $\frac{n}{\text { Io }}$ acetic or butyric acid, they formed a membrane when put back into normal sea water. When they were put into 50 c.c. sea water + I c.c. benzol or amylene, they formed a membrane while they were in this mixture.

Eggs in which this membrane formation had been called forth were able to develop into normal larvæ, and the development of such eggs resembled in rapidity and the form of the larva completely that produced by sperm.

The egg of the starfish is, as a rule, not mature when it leaves the ovary. It possesses a large nucleus, and the process of maturation consists in the nucleus being dissolved in the protoplasm of the egg and the polar bodies being thrown out. As long as the large nucleus is visible in the egg it cannot be fertilized by a spermatozoön, nor can its development be called forth by a treatment with one of the fatty acids or with one of the hydrocarbons, like benzol or amylene. Not until the nucleus has become dissolved in the protoplasm can a spermatozoön fertilize the egg, and at about the same time it becomes possible to produce artificially a membrane formation and development.

There is a noticeable difference in the method by which the starfish egg can be caused to develop and the method which is necessary in the case of the sea-urchin egg. For the tormer the process of artificial membrane formation is sufficient, while the sea-urchin egg has, in addition, to be submitted for a short time to the action of hypertonic sea water. This difference is rendered a little more comprehensible by the fact that

* Loeb, University of California Publications, Physiology, Vol. 2, p. 147, 1905. 
a small percentage of the eggs of the starfish are able to develop without any external cause or agency being applied. The number of these eggs varies in the eggs of different individuals, but is, as a rule, very small, e.g. a fraction of I per cent. The rate of segmentation in these "naturally" parthenogenetic eggs is slower than the rate of development of the eggs fertilized by sperm, and the blastula begins to swim considerably later than the blastulæ coming from fertilized eggs or from eggs in which a membrane had been produced artificially. Moreover, the blastulæ of the spontaneously developing eggs differ somewhat in appearance from the blastulæ coming from the two latter.

Neilson and I found that the number of eggs which develop without a membrane formation can be increased by treating the eggs transitorily with acidulated sea water. Delage* simultaneously obtained the same result by treating the eggs of Asterias with $\mathrm{CO}_{2}$; I am inclined to believe that the $\mathrm{CO}_{2}$ acts as an acid, although Delage is not willing to admit this.

The fact that the unfertilized eggs of the starfish may develop without any external cause has often been overlooked, and this has led some authors again to state that any "stimulus" may cause the development of this egg. Acids, indeed, increase the number of eggs which will develop; the same is possibly true for mechanical agitation, as A. P. Mathews has observed. $\dagger \mathrm{He}$ is inclined to believe that in this case the mechanical agitation is the direct cause of development (by producing coagulation). It is, however, necessary to state that the taking up and dropping of eggs with a pipette suffices. In eggs of Amphitrite, an Annelid, I have convinced myself that the number of eggs which develop does not bear any relation to the extent of the mechanical agitation. I consider it possible that some secondary factor connected with the agitation, such as the diffusion of gases into or from the egg, e.g. $\mathrm{CO}_{2}$, may be the real factor involved in this case.

The experiments thus far mentioned indicate that the process of membrane formation, or some process underlying this, is of importance for the complete physicochemical imitation of the developmental influence of the spermatozoön. The question arises, What is the nature of this process? It seems to me from my observations on Echinoderms that the essential feature of this process is the squeezing out under pressure or the secretion of a fluid from the protoplasm of the egg. As a mechanical effect, the surface film of the egg is lifted and separated from the protoplasm by a liquid secreted by the egg. When the secretion of this liquid occurs very slowly, the lifting up of the sur-

* Delage, Archiv, de Zool. expérimentale, Vol. 10, p. 213.

$\dagger$ A. P. Mathews, Am. Jour. Physiology, Vol. 6, p. 142, rgor. 
face film will not occur; only when the secretion of the liquid is rapid enough will the secretion result in the membrane formation. According to this view, the secretion of a liquid from the egg is the essential feature, while the membrane formation itself is possibly only a secondary, mechanical effect of the sudden secretion. If this be true, the essential feature in fertilization in Echinoderms is not the membrane formation itself, but the secretion of a liquid from the interior of the egg. This conception is corroborated by an observation I made several years ago. I found that the unfertilized eggs of a sea urchin could be kept alive in sterilized sea water for a week, or possibly more. When sperm was added to such eggs, they developed, but without the formation of membranes. It is quite possible that a process of secretion may be produced in every egg through the entrance of a spermatozoön, while the actual separation of the surface film of the egg from the protoplasm is only a secondary mechanical consequence of this secretion, which may or may not occur.

Since I have only recently recognized the importance of the process of membrane formation for the complete physicochemical imitation of the developmental effect of the spermatozoön, I have not yet found time to see whether it holds good only for Echinoderms. An observation recently made by Professor Lefevre on artificial parthenogenesis in a marine worm, seems to indicate that the artificial membrane formation, or rather the process underlying it, is of more general importance. Lefevre found that about 50 per cent of the eggs of Thalassema develop into normal larvæ, after having been exposed to sea water (to which a little acid had been added) for a few minutes. After they were taken out of the acidulated sea water, they formed a membrane and developed. The case seems to be similar to that of Asterina. The development of the eggs seemed to be normal, and the vitality of the larvæ seemed to be the same as that of the larvæ originating from fertilized eggs. I, as well as others, had, before Lefevre's observations, produced artificial parthenogenesis in the eggs of worms, but without artificial membrane formation. In all these cases the larvæ had always a diminished vitality, and the development was often different from that of the egg fertilized by sperm. I had found that the unfertilized eggs of Chetopterus, a marine Annelid, can be caused to develop into swimming larvæ* with certainty by adding a small but definite amount of a soluble potassium salt; but the vitality of these eggs was considerably less than that of the larvæ originating from fertilized eggs. I may also add - although this does not belong to our problem - that I noticed that the eggs of Chatopterus, which had been caused to develop parthenogenetically by $\mathrm{KCl}$, reached the trochophore stage and began to swim about seem-

* Loeb, Am. Jour. Physiology, Vol. 4, p. 423, r 90 r. 
ingly without segmenting. Frank Lillie* afterward examined such eggs histologically and convinced himself indeed that such is the case. Bullot $\uparrow$ produced a much more normal type of development in the unfertilized eggs of another Annelid, Ophelia, by submitting these eggs for about two hours to hypertonic sea water. In this case the segmentation was normal and the larvæ formed were also normal, but they only lived two days. It will therefore be of interest to find out whether in Chetopterus the same means which in Echinoderms lead to a membrane formation are able to induce a parthenogenetic development which resembles in all its features the development caused by a spermatozoön.

Kostanecki $\ddagger$ found that by a treatment with hypertonic sea water, the unfertilized eggs of a Mollusk (Mactra) could be caused to undergo the first segmentations; and I found afterward $\$$ that this method led in other Mollusks (Lottia, Acmea) to the production of swimming larvæ. I have recently tried my new method on the eggs of Lottia gigantea. It seems that the combination of the treatment with fatty acid and hypertonic sea water gives better results than the osmotic treatment alone. Some attempts have been made to cause the eggs of vertebrates to develop parthenogenetically. Bataillon\| has shown that the unfertilized eggs of the frog and of Petromyzon can be caused to segment as far as the morula stage by putting them for some time into a salt solution of a certain concentration, whereby they lose water.

It was natural to try whether or not substances can be extracted from the spermatozoön which cause the unfertilized egg to develop. Piéri made the statement that this could be done, but he evidently worked with sea water contaminated by spermatozoa. After the appearance of my first paper, H. Winkler made experiments with the extract of spermatozoa of sea urchins which, according to his description, caused the eggs of the same species to go through the first stages of segmentation; $\mathbb{T}$ no larvæ, however, developed from these eggs. These experiments were repeated by Gies, who tried to ascertain whether or not an enzyme could be obtained from the spermatozoön which caused the unfertilized egg to develop; but the results were absolutely negative. Not a trace of segmentation could be produced in eggs treated with such extracts. These results contradict the conclusions of Winkler.** I am inclined to believe that Winkler worked with sea water whose concen-

* F. Lillie, Archiv für Entwickelungsmechanik, Vol. 14, p. 477, 1902.

$\dagger$ Bullot, Archiv fiir Entwickelungsmechanik, Vol. I8, p. 16I, I904.

$\ddagger$ Kostanecki, Bulle. Académie de Sciences, Krakau, Igoz.

§ Loeb, University of California Publications, Physiology, Vol. I, p. 7, 1903.

I| Bataillon, Archiv für Entwickelungsmechanik, Vol. 18, 1904.

T Hans Winkler, Nachrichten der Gesellsch. der Wissenschaften zu Göttingen, p. 87, 1900.

** Gies, Am. Jour. Physiology, Vol. 5, p. 53, I90I. 
tration had been slightly raised, or which had been rendered slightly alkaline through evaporation. In either case results such as he produced may be observed.

Max Cremer also obtained absolutely negative results when he tried to cause the development of fish eggs with extracts obtained from the sperm of the same species with the Buchner press.

We may finally raise the question whether we can form, on the basis of the facts mentioned, any idea as to how the spermatozoön causes the egg to develop. From the facts stated in our fourth lecture in regard to cell division it is obvious that the essential effect of the spermatozoön consists in the transformation of part of the protoplasmic or reserve material in the egg into the specific nuclein or chromatin substance of the nucleus. In each nuclear division one half of the mass of each original chromosome goes into the nucleus of each of the two resulting cells. But during the resting period which elapses until these nuclei are ready to divide again, each chromosome grows to its original size again, and then a new division occurs. It is quite possible that the oxygen which is required for the process of cell division is needed for the synthesis of nuclein or chromatin substance. The fact that the rate of development is influenced by temperature in much the same way as are chemical reactions supports the idea given above that the essential feature of fertilization consists in the starting or the acceleration of a chemical reaction which is going on steadily in the egg.

It was natural to think first of the possibility that the spermatozoön carries a positive catalyzer into the egg, and thus accelerates the abovementioned synthetical process, which might also occur in the unfertilized egg but too slowly to lead to any development. It occurred to me that if this idea were correct the unfertilized eggs of the sea urchin might segment in normal sea water if they only could be kept alive for a sufficient length of time. In order to test this idea I took out the ovaries with bacteriological precautions and kept the eggs alive in sterile sea water for a week. Not an egg segmented, but when sperm was added, segmentation occurred promptly. This observation did certainly not support my idea of the spermatozoön carrying a positive catalyzer into the egg. It then occurred to me that a rise in temperature should act like a spermatozoön, since a rise in temperature should accelerate the velocity of chemical reactions. While a rise in temperature promptly accelerates the development after the egg is fertilized, or caused to develop by physicochemical methods, I have thus far not been able to start development in this way.

It then occurred to me that a superposition of two methods of fer- 
tilization should lead to an acceleration of a process of development, if it were true that the nature of fertilization consisted in a positive catalysis. I combined fertilization by sperm, osmotic fertilization, and the new method of fertilization in all possible ways in the egg of Strongylocentrotus without, however, being able to accelerate the process of development; on the contrary, as a rule, the process of development was markedly retarded. The idea that the spermatozoön carries a positive catalyzer into the egg has, therefore, thus far not received any support.

A second possibility which was to be considered was that the spermatozoön removes from the egg somehow a negative catalyzer or a condition whose presence in the egg prevents the development of the latter. If this were the case, we could readily understand why a rise in temperature which accelerates the development in the fertilized egg cannot - as far as my present knowledge goes - start the process of development in the unfertilized egg. We can, moreover, well understand why a process of secretion which seems to underlie the membrane formation may be of such great importance for the process of development. Finally, we may be able to understand a fact which I have observed in the eggs of starfish, and which has not yet been mentioned. When the eggs of Asterina or Asterias are allowed to ripen, they will die within a few hours unless they develop either spontaneously or through the influence of sperm or some of the above-mentioned agencies.* The disintegration which leads to the death of the nondeveloping egg is obviously due to an oxidation, since $I$ found that the same eggs when kept in the absence of oxygen will not disintegrate. We know that oxygen is an absolute prerequisite for the development of the fertilized egg. The fact that oxygen is a poison for the mature but nondeveloping egg shows that altogether different chemical processes must occur in the unfertilized, nondeveloping and the developing egg of the starfish. The process of fertilization seems, therefore, to consist in the elimination or alteration of a chemical condition in the egg, and that this alteration makes the processes of synthesis of nuclein material from the protoplasm possible.

In my first experiments on artificial parthenogenesis I was inclined to believe that the immediate effect of the methods employed consisted in a modification of the condition of the colloids in the egg. This view is contradicted by my recent experiments. When the process of artificial membrane formation is produced in the egg of a sea urchin, the egg does not show the changes leading to a cell division, e.g. the formation of astrospheres, until after one or two hours. But even this does not

* Loeb, Pfüger's Archiv, Vol. 93, p. 59, I902. University of California Publications, Physiology, Vol. 2, p. 147, 1905. 
lead to the development of the egg unless the egg has been submitted for twenty minutes to the hypertonic sea water. It is therefore obvious that the process of astrosphere formation or similar alterations cannot be the direct effect of the act of fertilization and, moreover, it cannot be the essential feature of it. I am inclined to believe that the direct and essential effect of the spermatozoön and the methods of artificial parthenogenesis is the starting of a definite chemical process, and that the formation of astrospheres is only a secondary effect of this.

It is in harmony with this idea that the process of segmentation in the case of artificial parthenogenesis is entirely regular, and does not differ from that of fertilized eggs, provided that the right concentration and time of exposure are selected.

I have not entered into a discussion of the cytological changes which are noticeable in an egg in which artificial parthenogenesis has been produced, and refer the reader to a masterly paper* by E. B. Wilson on this subject.

* E. B. Wilson, Archiv für Entzvickelungsmechanik, Vol. I2, p. 552, I90I. 


\section{LECTURE $\mathrm{X}$}

\section{HEREDITY}

\section{The Hereditary Effects of the Spermatozoön and EgG}

IN addition to the developmental effects, the spermatozoön has a hereditary effect, inasmuch as it transmits the paternal qualities to the offspring. The experiments on artificial parthenogenesis or chemical fertilization suggest the possibility that the developmental and the hereditary agencies in the spermatozoön are connected with different substances. O. Hertwig twenty years ago defined the process of fertilization as the fusion of two nuclei; namely, the egg nucleus and the sperm nucleus. While this fusion is apparently of importance for the hereditary effects, one fails to see how a fusion of two nuclei must cause an egg to develop. The experiments on artificial parthenogenesis indicate clearly enough that the development of the egg can be caused without even the presence of a sperm nucleus. On the other hand, the experiments on merogony show that a fragment of egg protoplasm which has no nucleus can develop when fertilized by a spermatozoön. Delage made extensive experiments in which he cut pieces of protoplasm from the egg of Echinoderms, Annelids, and Mollusks.* These pieces developed when a spermatozoön entered into them. In this case fertilization occurred without a fusion of nuclei, as there was no egg nucleus present.

It is a very striking fact that for the first stages of development the hereditary influences of the spermatozoön and the egg are by no means equal. It seems that for these first stages the influence of the egg by far exceeds that of the spermatozoön. It may almost be said that the first stages of the embryo are exclusively or almost exclusively determined by the egg, and not by the spermatozoön. This is best illustrated if we hybridize forms whose first stages of development differ radically from each other, e.g. sea urchin and starfish. The pure larvæ of both forms go through a blastula and gastrula stage, but then their development becomes strikingly different, inasmuch as the sea urchin larva develops into a pluteus with a skeleton, while the starfish larva

* Delage, Archives de Zoologie expérimentale, Vol. 7, p. 383, 1899. 
forms no skeleton. If the egg of a sea urchin is fertilized by the sperm of a starfish, those larvæ that live long enough develop invariably into a pluteus.* It would be interesting to ascertain whether the hybrid larvæ produced from a starfish egg by the fertilization with a sea urchin spermatozoön ever form a pluteus larva. These data also indicate that the statement that fertilization consists in the fusion of two nuclei does not cover all the facts.

As far as the adult is concerned, it seems that, as a rule, spermatozoön and egg have an equal share in the transmission of the hereditary qualities. Mendel states that in the case of the hybridization of two species of peas, $a$ and $b$, the results were the same, whether the pollen came from the species $a$ and the egg from the species $b$, or vice versa. We shall see later on that the early embryo is to a certain extent predetermined in the protoplasm of the egg. This makes it natural that these early stages should depend upon the egg, and not upon the spermatozoön. As far as the adult is concerned, the protoplasm has to be formed by the taking up of food, and the chemical as well as the subsequent physical changes which the material undergoes will be under the influence of the catalytic agencies of both the egg and the spermatozoön.

We do not know which circumstances in the sexual cells determine the hereditary effects, although one would naturally think first of definite chemical compounds as the bearers of hereditary qualities. The greater part of the spermatozoön, namely, the head, consists of a salt whose acid is nucleinic acid, whose base in some fishes and starfish is protamine, in other forms histones, which latter, however, are closely related to the protamines. In order to decide whether the nucleins or the histones or the protamines are of importance for the hereditary qualities, it would be necessary to decide whether the nuclei of the eggs of one form contain always the same base as that found in the sperm of the same species. This should be expected from the fact that the hereditary influence of egg and sperm is equal in the adult offspring, at least. It seems that the base is not always identical in the egg and spermatozoön of the same species, and this seems to indicate that the nucleic acid is of more importance for heredity than protamines and histones. Aside from the nuclein we find albumin and globulin, especially in the tail, and in the latter also lecithin, cholesterin, and fat. Miescher believed that in the head of the spermatozoön an iron compound exists. It is impossible to draw any far-reaching inference concerning the nature of the substances which transmit hereditary qualities from these meager data.

The fact that the spermatozoön contributes just as much to the trans- 
mission of hereditary qualities in the adult as the egg, although the mass of the latter is, as a rule, many times larger than that of the spermatozoön, makes it certain that only a small fraction of the contents of the egg has anything to do with this transmission of hereditary qualities. Since the head seems to be the more important part of the spermatozoön for the process of heredity, and this head is a homologue of the egg nucleus, Boveri expressed the idea that the nucleus, and not the protoplasm, is the really significant part of the egg in matters of heredity. In order to test this idea he undertook a very ingenious experiment; namely, the fertilization of an enucleated fragment of the egg of one species of the sea urchin by the sperm of another species. If his view were correct, such a hybridization should produce a larva with purely paternal characteristics, as the egg only furnished the protoplasm which was not expected to influence the hereditary qualities. The execution of this experiment is extremely difficult. Boveri is inclined to believe that, according to the experiments carried out so far, the fertilization of enucleated fragments of eggs of Spharechinus by the sperm of Echinus yields plutei of a pure type of Echinus, although he does not consider the question as definitely settled.* I am inclined to believe that in the early stages the paternal influence would, at the best, be very slight.

The egg protoplasm contains more or less reserve material which is only gradually transformed into the characteristic compounds of the embryo. It is therefore obvious enough that at first the embryo must show effects of this relation. When the protoplasm of the egg possesses a striking pigment, the larva will possess the same for some time at least; if such an egg is hybridized with the sperm of a form whose egg is unpigmented, the larva will, of course, possess a "maternal" quality which is due solely to the protoplasm (Driesch). In the eggs of birds the incubation period depends ceteris paribus upon the mass of yolk. When a species with a long incubation period is crossed with one of a short incubation period, the egg, and not the sperm, determines the incubation period, as Whitman observed in pigeons. It is obvious, then, that during the first stages of development an influence of the protoplasm upon heredity may make itself felt, which will disappear as soon as the protoplasm of the egg has been transformed into the tissues of the embryo. It does not seem to me that a discussion as to the relative influence of protoplasm and nucleus upon heredity will prove very fertile, but that it is necessary to transfer this problem as soon as possible from the field of histology to that of chemistry or physical chemistry. This view is supported by investigations concerning the toxic effects of blood of one form upon not too closely related forms.

* Boveri, Archiv für Entwickelungsmechanik, Vol. 2, p. 394, I896. 
Until about thirty years ago the idea was held generally that a transfusion of the blood of an animal into the veins of a human being was permissible or advisable in the case of severe loss of blood. We know to-day that in such cases physiological salt solutions or human blood must be injected, and that the blood of animals is generally toxic. This important discovery was made by Landois,* who showed that blood of a foreign species generally destroys the red corpuscles of the animal into which it is infused. He investigated systematically the destructive force of foreign blood upon the red corpuscles of various animals, and made the remarkable discovery that there exists a striking relation between this effect and the blood relationship of animals. I will quote the summary of this part of his investigation: "My results include a point which is of importance for the systematic order of animals; namely, that those animals which are closest to each other in regard to their anatomical qualities also possess the most homogeneous blood, inasmuch as a transfusion of blood between two closely related animals brings about the least rapid destruction of the foreign blood. The transfusion thus offers us a means of determining in questionable cases the relationship of animals. A transfusion of blood is possible between varieties of the same species; the blood of species that are very close to each other shows hemolysis only very gradually, and the animals withstand large quantities of foreign blood; the more distant, however, animals are, the more violent the effects of the foreign blood become" (p. 289). The hemolysis consists in the red blood corpuscles becoming permeable for the hemoglobin they contain, which begins to diffuse out. The red blood corpuscles become in consequence pale (ghosts or shadows). It is obvious that this diffusion of the hemoglobin is rendered possible through some chemical alteration of the blood corpuscle. The experiments of Landois prove that the blood of closely related species is chemically and physicochemically more nearly identical than the blood of more distant forms. More recently the observations of Landois were taken up by Friedenthal, $\uparrow$ Gruenbaum, and Nuttall. $\ddagger$ These experimenters were able to avail themselves of Bordet's precipitation method. Bordet had found that after serum of a foreign species has repeatedly been injected into a rabbit, a precipitation will occur when blood of that foreign species and the blood of this rabbit are mixed. Moreover, the same reaction occurs when blood from an animal related to the one whose serum had been injected is mixed with the blood of the rabbit. Friedenthal and Nuttall used this reaction to find out the

* Landois, Die Transfusion des Blutes, Leipzig, 1875 .

$\dagger$ Friedenthal, Engelmann's Archiv, p. 494, I901 ; and Berliner klinisch-therapeuptische Wochenschrift, 1904.

¥ G. Nuttall, Blood Immunity and Blood Relationship, Cambridge, 1904. 
blood relationship of animals. Nuttall found among others that if dog's serum was injected into a rabbit, the serum of this rabbit afterward gave a precipitation with the blood of eight various canides, but with the blood of no other group of animals! These experiments may also explain why the bastards between the sea urchin and starfish show a much greater mortality than the pure breed. In my experiments the hybrids between starfish and sea urchin died in large numbers after they reached the blastula or gastrula stage.* It seems as if the spermatozoön of the starfish, in addition to a developmental substance, also carries something else into the sea urchin's egg which poisons the latter. It remains for further experiments to decide how far the physicochemical incompatibility of heterogeneous species which Landois and his successors discovered, restricts heterogeneous hybridization. It is, however, already obvious enough that ultimately the problem of hybridization and heredity must be transferred from the morphological to the chemical or physicochemical field.

We may now continue the discussion of the problem of heredity. The man whose work marks with that of Landois the beginning of a real theory of heredity had a fate similar to that of Landois. Gregor Mendel was a teacher of physics in Graz, and evidently the writings of Darwin induced him to investigate the laws of heredity; but he went at the problem in a spirit so entirely different from that of the biologists, and at the same time in a way which was so superior, that his discoveries were entirely overlooked for over thirty years, until De Vries discovered the same facts, and also discovered accidentally Mendel's paper. At almost the same time Correns and Tschermak also called attention to Mendel's work. Mendel $\dagger$ carried on experiments on the hybridization of varieties of peas which he selected so that they differed in only one characteristic. It was his intention to find out what became of that discriminating or critical characteristic in the offspring. He found that the children of such parents - the first generation of hybrids - did not occupy an intermediate position between the two parents in regard to the discriminating characteristic, but were all pure breeds, inasmuch as the discriminating characteristic of one parent was transmitted to all of the children, while the characteristic of the other parent was apparently not transmitted. The discriminating characteristic of the peas used by Mendel for his experiments were, e.g., the difference in the shape of the ripe seeds, whether they were spherical or angular. When he crossed two forms of peas which were identical in every respect, except

* Loeb, loc. cit.

† Gregor Mendel. Versuche über Pfanzenhybride. Ostwald, Klassiker der Naturwissenschaften, Vol, r2r. De Vries, Die Mrutationstheorie, Leipzig, 1901. 
that the shape of one parent was angular that of the other round, all the children or hybrids of the first generation had round seeds. It was immaterial whether the female or the male was of the round seed variety. If we now assume, as we must, that there is also a corresponding difference in the sexual cells of the round seed variety and the angular seed variety, we must assume that in the mixing of the two the determinants of the round shape of the seed dominated, while the determinants for the angular shape of the seeds were prevented from manifesting themselves.

In another set of experiments Mendel crossed two varieties which were alike in every respect except the coloration of the albumin of the seed (endosperm). In one variety this possessed a pale yellow color, in the other it was green. The children of two such parents possessed only yellow endosperm.

In a third case the discriminating characteristic between the two parents was the color of the shell of the seed: one was white, the other gray or grayish brown. The former also had white blossoms, the latter violet blossoms. The children all had seeds with gray shells and violet blossoms.

It is therefore obvious that in these cases one characteristic dominated, and Mendel called this the dominating characteristic, while the other, which was suppressed in the first generation of children, he called the recessive characteristic. Thus the spherical shape of the seed is a dominating, the angular shape a recessive, characteristic.

The first generation of hybrids was therefore in regard to the discriminating characteristic not distinguishable from the pure breed of the one parent, which possessed the dominating characteristic; yet it was different in one respect, namely, its sexual cells. The child of two parents, the one of which possessed angular, the other spherical seeds, possessed two kinds of sexual cells in about equal number; namely, one half being cells possessing the determinant for the dominant, the other possessing the determinant for the recessive, characteristic. This follows from the results of Mendel's experiments when he crossed the hybrids of the first generation among themselves. In this case there was no uniform offspring, but the two distinct types, one with the recessive and one with the dominating characteristic, now reappeared. Only a fraction of the hybrids of the second generation had the dominant characteristic, the rest had the recessive characteristic. When the number of the individuals used for experimentation was sufficiently large, there existed always a definite ratio between the two kinds of offspring: the number of hybrids with the recessive characteristic was always one third of those with the dominating characteristic. This is exactly what 
we should expect if the hybrids of the first generation possessed two kinds of sexual products in equal numbers; namely, those of the paternal and those of the maternal species or variety. If a large number of individuals of this kind be crossed, according to the law of probability, in one fourth of the cases an egg cell with the determinant for the recessive characteristic and a pollen cell of the same type would meet. This would result in pure offspring with the recessive characteristic. In one fourth of the cases egg cells with the determinant of the dominating characteristic would meet with the pollen of the same type, and the result would be pure offspring with the dominant characteristic. In one fourth of the cases an egg cell with the determinant for the dominant characteristic would be met by pollen cells with the determinant for the recessive characteristic, and this would give rise to individuals with the dominant characteristic; in the last fourth of the cases an egg cell with the determinant for the recessive characteristic would be met by pollen with the determinant for the dominant characteristic, and this again would give offspring with the dominant characteristic. In this way three fourths of the total offspring in the second generation would have the appearance of the species or variety with the dominant, and one fourth of the total offspring would have the appearance of the species with the recessive, characteristic; both kinds would therefore be in the numerical relation of one to three, as stated.

Through many cultures, Mendel has shown that his conclusions are correct. Thus, e.g., his theory demanded that if the last-mentioned experiment be continued, and the individuals of the first-mentioned fourth of the offspring, namely, the ones that have reverted to the recessive character, be bred among themselves, only pure breeds with recessive character should be produced. The experiments proved that this is entirely correct.

Mendel raised also the question as to what would happen if varieties of peas which differ in regard to two or more characteristics should be hybridized. In this case, the hybrids of the first, as well as of the later, generations behaved as if a specific hereditary substance existed for each characteristic, and as if these substances did not irfluence each other. For each one of the discriminating characteristics, the same laws hold which existed where the varietics differed only in regard to one characteristic.

The epoch-making importance of Mendel's work lies in the fact that he, for the first time, gave not a hypothesis but a theory of heredity, which made it possible to predict the results of hybridizations numerically. His work forms the basis for all further work in this field which is of equal theoretical and practical importance. 
The observations of Mendel have since been confirmed and enlarged upon. Not only botanists like De Vries, who independently rediscovered Mendel's laws, but also zoölogists like Bateson and his pupils, Cuénot, Castle, Guyer, and many others, have added to this field.

Mendel's laws do not, however, include all the cases of hybridization. De Vries has investigated this field in a masterful way, and has shown that there are at least two types of hybridizations: one in which, as in Mendel's cases, a separation of the discriminating characteristics occurs again in the offspring, and another in which constant races are at once produced. This type of hybridization is the one which proves especially useful to plant breeders in their attempts to produce new varieties. De Vries believes that the latter type of hybrids is produced when the sexual cells of one parent have a determinant for which there is no corresponding determinant in the sexual cells of the other parent.

The objection might be raised that such a theory of chemical determinants in the sex cells as the cause of heredity might find difficulty in explaining the heredity of instincts; I believe that the contrary is the case. In a paper on "Egg Structure and the Heredity of Instincts" * I have pointed out that the hereditary character of the instincts demands a chemical rather than a morphological theory of heredity. Many instincts are obviously the outcome of tropisms. For the transmission of an instinct based on heliotropism, all that is required is the presence in the sexual cells of photosensitive material, or of a substance from which such material can be formed.

The current morphological and cytological literature contains many attempts at explaining the phenomena of heredity on a purely morphological or cytological basis. There is no objection to this, as long as we realize that the morphological structurcs can only play a rôle through their physical and chemical properties.

\section{The Determination of Sex and the Secondary Sexual Characters}

Several years ago an embryologist published the hypothesis that sex could be determined by submitting the mother to a certain diet. Delage pointed out that this idea was contradicted by the fact that in about 30 per cent of the cases twins have different sex, which would be impossible if the diet of the mother determined the sex of the offspring. There is, however, one condition under which twins have invariably the same sex; namely, when they come from the same egg. We have seen in a former lecture that from one egg twins can arise; namely, 
when the contents of the egg are cut in two during the early periods of development, e.g. when the first two cleavage spheres become separated from each other. In the case of mammalian or human twins, we possess a criterion for the fact whether they come from one or two eggs in the condition of the egg membranes. Twins coming from different eggs have as a rule separate chorions. This follows from the development of the chorion. In all cases where twins have a common chorion they have also identical sex. This indicates that the sex of the embryos was determined before the germ was split into two parts, and as this must occur in the earliest stages of development, it follows that the sex of an embryo is definitely determined very early; how early can only be guessed at in mammalians, but in certain lower forms it can be shown that the sex is already preëstablished in the egg before the egg is even fertilized.

A striking example for this assertion was discovered by Korschelt in Dinophilus apatris, a worm of the group of Turbellarians. As Korschelt's paper is not accessible to me, I quote the observation after Lenhossék.* Dinophilus lays two kinds of eggs, the one large and opaque, the other small and transparent. The eggs are fertilized inside the body of the female, and are afterward deposited in the sea water. Korschelt separated the two types of eggs, and found that the large opaque eggs give rise to females, the small transparent eggs to males. If this observation is correct, there can be no doubt left that in this case sex is already determined in the egg before the egg is fertilized.

Facts of a somewhat analogous character seem to exist in a number of forms such as plant lice, Cladocera and Rotifers. The Aphides are viviparous as long as the temperature is not too low and the plant is not drying out. Under such conditions they give rise to offspring of one sex only, namely, females. These reproduce females parthenogenetically which possess no receptacle. When the plant dries out, or the temperature becomes low, in addition to females, males are also produced. The females which originate at this time possess a receptacle, and hence can pair. After pairing they are not viviparous, but lay fertilized eggs, the so-called winter eggs. From such eggs parthenogenetic females invariably arise, and now the cycle may be repeated. It is obvious that at least the sex.of the winter egg is determined as soon as it is formed. The same is probably true also for the sex of the embryo which proceeds from the summer eggs. In Cladocera conditions are not very different. From the winter egg females invariably arise, and these give rise parthenogenetically to females until, under conditions which have not been sufficiently investigated, males and females are formed,

* Lenhossék, Das Problem der geschlechtsbestimmenden Ursachen, Jena, 1903. 
which copulate. As in Aphides, only a definite type of eggs, the socalled winter eggs, require fertilization, and from the fertilized eggs a female originates in every case. In Rotifers also the winter eggs are said to require fertilization and give rise to females.

We have already mentioned the fact that in bees the unfertilized eggs give rise almost, or quite exclusively to males, while females can only (or perhaps mainly) arise from fertilized eggs. This seems to indicate that the entrance of a spermatozoön may give the egg a female character, while without it, it has a male character. Lenhossék believes it is possible that in bees, as perhaps in most animals, two kinds of eggs exist, one for each sex ; that for some reason the male egg is not fertilized when it is laid, while the female is fertilized. It is, however, difficult to harmonize with such a view the fact that old queens, whose supply of sperm in the receptacle is exhausted, and virgin queens lay only male eggs.

Among certain insects, e.g. the Hemiptera and Orthoptera, two kinds of spermatozoa have been found, but one kind of eggs. These two kinds of spermatozoa differ in regard to a single chromosome, which is found only in one half of the spermatozoa, while it is lacking in the other; or which is larger in one half of the spermatozoa than in the other half.

The first one to recognize the existence of two kinds of spermatozoa was Henking, who stated that in Pyrrhocoris (a Hemipteron) one half of the spermatozoa of each male possessed a nucleolus while the other half did not. Montgomery afterwards showed that Henking's nucleolus was an accessory chromosome. To McClung* of the University of Kansas belongs the credit of having first recognized the importance of this fact for the problem of sex determination. $\mathrm{He}$ observed an accessory chromosome in one half of the spermatozoa of two forms of Orthoptera, Brachystola and Hippiscus, and traced their history. His conclusion may be quoted in full: "A most significant fact, and one upon which almost all investigators are united in opinion, is that the element is apportioned to but one half of the spermatozoa. Assuming it to be true that the chromatin is the important part of the cell in the matter of heredity, then it follows that we have two kinds of spermatozoa that differ from each other in a vital matter. We expect, therefore, to find in the offspring two sorts of individuals in approximately equal numbers, under normal conditions, that exhibit marked differences in structure. A careful consideration will suggest that nothing but sexual characters thus divides the members of a species

* C. E. McClung. The Accessory Chromosome-Sex Determinant? Biological Bulletin, Vol. 3, p. 43, I9O2. 
into two well-defined groups, and we are logically forced to the conclusion that the peculiar chromosome has some bearing upon the arrangement.

"I must here also point out a fact that does not seem to have the recognition it deserves; viz. that if there is a cross division of the chromosomes in the maturation mitoses, there must be two kinds of spermatozoa regardless of the presence of the accessory chromosome. It is thus possible that even in the absence of any specialized element a preponderant maleness would attach to one half of the spermatozoa, due to the "qualitative division of the tetrads" "*

McClung was inclined to believe that that half of the spermatozoa which contains the accessory chromosome gives rise to male offspring, while the other half gives rise to female offspring.

E. B. Wilson $\dagger$ has recently investigated the chromosomes of the sex cells in a number of Hemiptera, and ascertained that the occurrence of two kinds of spermatozoa is a constant phenomenon in this group. While in some forms the two kinds differ by an accessory chromosome occurring in one half of the spermatozoa of a male, in other forms they differ in regard to the size of one of their chromosomes. In the latter forms this specific "idiochromosome" is large in one half of the spermatozoa of a male and small in the other half of the spermatozoa. While McClung assumed that the accessory chromosome is a determinant for the male sex, Wilson shows that it is more probable that it gives rise to the female offspring.

If we sum up all these data concerning determination of sex, we therefore come to the conclusion that sex is, in all probability, already predetermined in the sex cells. In some forms, e.g. Aphides and other parthenogenetic forms, sex can unquestionably be determined by the eggs alone, and consequently we must assume here the existence of two kinds of eggs. In other organisms, like the Hemiptera and Orthoptera, we have two kinds of spermatozoa and apparently one kind of eggs, and in these cases it is the spermatozoön which determines the sex. There exists apparently a third type of forms, e.g. bees, ants and social wasps, in which both eggs and spermatozoa share in the determination of sex, inasmuch as the eggs alone determine the male, while the spermatozoön determines the female sex; if both are united, the influence of the spermatozoön predominates. If this is correct in this group of animals, only one kind of eggs and only one kind of spermatozoa will be found.t

* McClung, loc. cit.

† E. B. Wilson, Science, N. S. Vol. 22, p. 500, 1905.

† It follows from these data that the female egg, or spermatozoön, predetermines also a different group of instincts from the male egg. Morphologically as well as in regard 
A good deal of mysticism arose from the fact that the number of young males and females is so approximately equal in many forms, e.g. in the human race. The fact, discovered by McClung, that through the process of chromosome division two kinds of sex cells must be formed in equal numbers in the male of Hemiptera and Orthoptera removes this source of mysticism.

The fact that all attempts to influence the sex of a developing embryo have thus far failed, harmonizes with the data given above. Born and others maintained that it was possible to influence the sex of tadpoles or frogs, or of the larvæ of flies, by the food on which the larvæ were fed. These statements have proved to be untenable.

Maupas and Nussbaum have tried to determine sex, not by any influence upon the developing embryo directly, but upon its offspring. They experimented on a Rotifer, Hydatina senta. Nussbaum states that the mode of nutrition of the female embryo after it leaves the egg determines whether it will later give rise to large female eggs, or to small eggs for both sexes. Maupas had stated that the temperature determines the sex; but Nussbaum disagrees with him, believing that temperature has no direct effect upon the determination of sex.*

The two sexes differ also in regard to the so-called secondary sexual characters, e.g. the shape of the antennæ in male and female butterflies, etc. The question now arises, Are these secondary characters already predetermined in the egg, or are they secondarily determined by the maturing or mature sexual glands? If the former were the case, the castration of the larvæ before sexual maturity is reached should not prevent the development of the secondary sexual characteristics. Oudemans extirpated the sexual glands in caterpillars of Ocneria dispar, yet the butterfly showed all the secondary sexual characters. Professor Kellogg told me that he found that the castration of the young caterpillars of the silkworms has no effect upon the formation of the secondary sexual characters. These observations also agree with the idea that the secondary sexual characters are predetermined in the egg, and some of them possibly at as early a stage as the primary sexual characters.

The idea that the sexual glands determine, e.g. by internal secretion,

to instincts, man and woman represent different species, and inasmuch as for a normal and happy life the instincts must act as a guide, it would seem erroneous to attempt to make life for both sexes absolutely identical. It would be equally preposterous, however, to insist that, for this reason, man and woman should not have equal rights. The traditional barriers to the rights of women are based, not on physiological grounds, but on the survival of the savage's idea, who made woman his slave. The adjustment of the sphere of action of woman should be left to her own instincts and judgment, and not to the dictation of lawyers and politicians.

* For further information, see Herbst, Formative Reize in der thierischen Ontogenese, Leipzig, I90I. 
the formation of all the secondary sexual characters, is also refuted by the following observations. There are cases of hermaphroditism known in which the one side of the body contained a testicle, the other an ovary. In hermaphroditic insects of this kind, it has been observed that the secondary sexual characters differed also on the two sides, the side with the ovary having a female, the other side a male antenna. This would be impossible if a substance produced by the sexual glands, and circulating in the blood, were the cause of the secondary sexual characters. If, however, the primary as well as certain secondary characters are already preformed in the egg, it might be well possible that an egg was already female on one side and male on the other side.

Crampton grafted the heads of one sex upon the bodies of the other sex in pupæ of butterflies, in trying to find out whether the sexual glands could influence the secondary sexual characters on the head, but this was not the case. There are then certain secondary sexual characters which seem to be determined before the sexual glands reach the mature stage. Certain secondary sexual characters, of course, such as develop at the period of sexual maturity, are determined by the development of the sexual glands and fail to appear when these glands are removed before the time of sexual maturity.

\section{Egg Structure and Heredity}

The form of the body as well as the instincts of the animal are transmitted through the sexual cells. We are forced to assume that the egg or the spermatozoön must possess a structure of a degree of complexity equal to that of the adult, or that the development occurs in a manner which renders such an assumption unnecessary. It is hardly necessary to mention that we must choose the latter alternative.

If we examine the living egg of a sea urchin or a starfish, we find that its contents are chiefly liquid. If such eggs are exposed to a slight one-sided pressure, e.g. under the cover glass, the surface film or membrane bursts, and the liquid contents can be seen streaming slowly into the surrounding sea water. In this liquid minute granules are noticeable, which may be solid, but the main mass of the egg is liquid. The nucleus is surrounded by a solid film. It is possible or probable that the chromosomes are, in a certain phase of cell division, solid, or possess a high degree of viscosity. This follows from the fact that the form of each individual chromosome remains constant through all cell divisions. It is obvious that a mass which is to a large extent liquid cannot possess a structure of such a degree of complexity as the adult starfish or sea urchin. Moreover, we can observe directly 
that the solid constituents of the body, e.g. the skeleton, are formed later on, and that its form can, of course, be only indirectly predetermined in the egg.

We are therefore forced to conclude that for the transmission of the hereditary qualities no complicated or morphological structure is required in the sexual cells. This harmonizes with the idea already gathered from the preceding parts of this lecture, that chemical conditions are the bearers of hereditary qualities in the egg, for the instincts as well as the form of the body.

Driesch has shown that when a single cell of the two- or four-cell stage in the development of the egg in the sea urchin is isolated, this cell not only develops into a pluteus, but the mode of development is not essentially different from that of the intact egg.* It would be merely a play on words to speak in such a case of regeneration. The development in the early stages consists in successive divisions of each cell and the creeping of each of these cells to the surface, so that finally the mass of cells thus formed is a sphere with cells at the surface, while a space in the center remains free from cells and is filled with a liquid. The cells at the surface of this hollow sphere then form cilia at their external surface, and in this stage the larva, which now begins to swim through the motion of the cilia, is called a blastula. The next stage in the development is the growing in at one spot of the blastula, of a group of cells, into the hollow space of the sphere; and the cells thus growing in, form finally an inner lining of the cells of the blastula. This process is called the gastrulation, inasmuch as this inner lining is the beginning of the alimentary tract of the larva. At this stage the larva is called the gastrula. Later on large cells are formed, the mesenchyme cells, which creep to certain places in the gastrula, giving rise to the skeleton, probably through the secretion of $\mathrm{CaCO}_{3}$, or of a substance that leads to the formation of $\mathrm{CaCO}_{3}$. According to Driesch, the process of development of a pluteus from an isolated cell of a two- or fourcell stage of the sea urchin's egg occurs in practically the same way, as in the case of the development of an intact egg; except that the larva developing from a single cell of the two- or four-cell stage is smaller than the normal larva, having only one half or one fourth the mass of the latter. There may be also slight differences in the development, owing, as I believe, to a kind of hysteresis, inasmuch as the side of the cell which was in contact with the other cells of the egg before the blastomeres were separated, acts possibly a little differently from the other sides. These experiments of Driesch are of great importance, inas-

* For the extensive literature on this subject, see E. B. Wilson's book, The Cell, New York, 1900 ; or T. H. Morgan's book on Regeneration, New York, 1900. 
much as they show how twins, triplets, and quadruplets can originate from one egg. The lack of any complicated structure in the unsegmented egg is, I believe, evidenced very strikingly in the following observation. I have mentioned in a former lecture that if the egg of a sea urchin (Arbacia) is put into diluted sea water (equal parts of sea water and distilled water), many eggs will burst, and part of the protoplasm will flow out, without necessarily being separated from the rest of the egg. In this case the normally spherical egg is transformed into a double sphere or a dumb-bell-shaped mass (Figs. 35 and 36 ). This mass may give rise to a single embryo, or to "Siamese twins," and whether the one or the other occurs depends upon the width of the piece

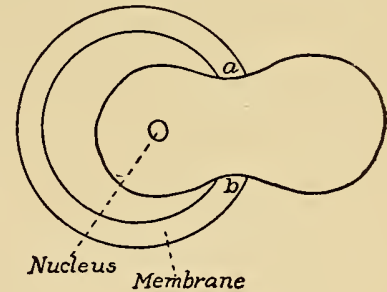

FiG. 35 . $a b$ (see Figs. 35 and 36 ) that connects the two spheres.* If this piece is very narrow, as in Fig. 36 , twin blastulæ will originate from such an egg; if it is wide, as in Fig. 35,

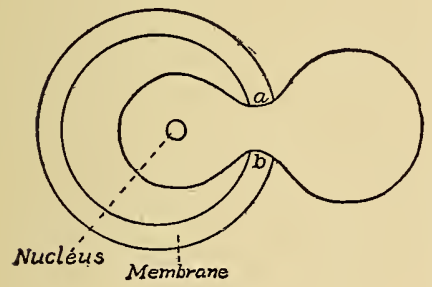

F1G. 36. only a single embryo will develop from it. Why this should be so can be readily recognized. We have already stated that the cells have a tendency to creep to the periphery of the egg, thus leaving an empty space in the center which becomes the blastula cavity. When the connecting piece is very narrow, it will be filled with cells, and the two segmentation cavities can and will remain separate, and two blastulæ will be formed (Fig. 37). If, however, the piece $a b$ is wide (Fig. 38), an open space will be left in this connecting piece, by which the two blastula cavities communicate, and in this case only one blastula cavity, and hence only one embryo will be formed. The distorted dumb-bell-shaped blastula soon becomes spherical (through the secretion under pressure of liquid into the interior), and a normal larva results. These facts prove that as far as the

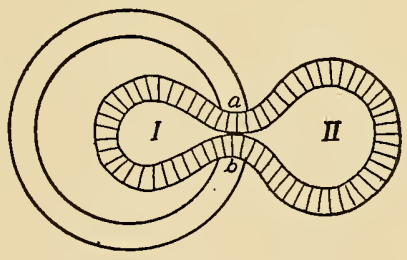

FIG. 37 . formation of the blastula is concerned there is no preformed structure of any high degree of complication present in the egg; and this is still more true for the later embryonic formations, which follow the blastula stage.

* Loeb, Archiv für Entwickelungsmechanik, Vol. 8, p. 363, 1899. 
In these deformed eggs the distribution of the nuclear material during cell division is entirely different from that which normally occurs; yet normal embryos result. Driesch has shown the same in a different way; namely, by submitting the developing eggs to pressure. In eggs thus flattened, the planes of segmentation differ from those of the normal egg, yet normal embryos are formed. These observations exclude the idea that the distribution of the nuclear material through the egg is of importance for the form of the embryo.

Driesch succeeded in causing fertilized sea urchins' eggs to fuse in a number of cases. Such a fusion of the masses of two fertilized eggs

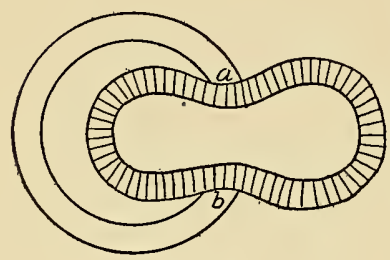

FIG. $3^{8}$. into one, resulted in the formation of a single giant embryo (pluteus).* Such a result would be inconceivable did the egg possess a structure of such a degree of complexity as the adult animal. Zur Strassen $\dagger$ had already before Driesch's experiments made the observation that the eggs of a parasitic worm, Ascaris, occasionally give rise to giant embryos through the fact that two eggs fuse and that their combined masses now give rise to but one organism. If the egg possessed a complicated structure, the fusion of the masses of two eggs could no more give rise to a single individual of gigantic dimensions than two individual adult animals could be transformed into one by fusing their masses. I have also observed that with the proper chemical treatment the eggs of the starfish and of Chcetopterus can be caused to fuse; that from two or more such eggs a single giant embryo may result. $f$

Boveri and Driesch assume the existence of a certain simple structure in the unfertilized egg of the sea urchin. According to Boveri, the egg protoplasm consists of three layers occupying different parts of the egg (see Fig. 6, p. 3I). These three masses can still be recognized in the first four cleavage cells, but in the eight-cell stage cells arise which no longer contain all three layers. It is possible that only such isolated cells can give rise to a single embryo, as contain all three layers. This may account for the fact that an isolated blastomere of the four-cell stage can still develop into a normal embryo, while the same is no longer true for the isolated cell of the eight-cell stage. $\$$ As far as the possible origin of the differentiation observed by Boveri is concerned, I have noticed in an Ophiurian that the immature eggs

* Driesch, Archiv für Entwickelungsmechanik, Vol. 10, p. 4rr, 1900.

$\dagger$ Zur Strassen, Archiv für Entwickelungsmechanik, Vol. 7, 1898.

$\ddagger$ Loeb, Am. Jour. Physiology, Vol. 4s p. 423, rgor.

$\S$ See Lecture 2 . 
are attached like berries on one side to a tissue which is ramified like the branches of a tree. That side which is attached to the tissue is free from pigment, while the other part is pigmented. I consider it quite possible that the difference in structure observed by Boveri in the egg of the sea urchin, as stated above, is of a purely physical character; namely, that it consists in the fact that different phases are represented in the egg. Two liquids separated by a layer of a more viscous substance might give rise to a differentiation, as noticed by Boveri. If two eggs fuse, the complete union of the corresponding layers in both eggs must be possible, in order to produce single embryos, as would be the case if the contents of two vessels were mixed, each of which contained oil and water.

That the organs which originate later in the larva, e.g. the skeleton, are not preformed in the egg from the beginning is obvious, and requires no further discussion.

The idea that any structure which may exist in the undivided egg is of the simplest physical kind is also corroborated by the observations made by Chun, Driesch, Morgan,* and Fischel, $\uparrow$ on the eggs of Ctenophores. The Ctenophores possess a simple bell-shaped body, the outside of which contains eight ribs or rows of cilia in symmetrical distribution. The above-named authors found that if the first two cleavage cells of the Ctenophore's egg are isolated, a Ctenophore originates from each cell; that such a Ctenophore, however, possesses only four ribs. Fischel found that if the egg of a Ctenophore is cut into several pieces, and each piece gives rise to an embryo, the total number of ribs possessed by these larvæ never exceeds eight. The body of a Ctenophore consists mainly of a jelly, or gel, and, in all probability, this gel already exists in the egg, and determines its shape and the symmetry relations of the future embryo, inasmuch as the ribs arrange themselves symmetrically on its surface. It is obvious that the degree of preformed structure in this case need not exceed the symmetry relations due to simple physical conditions. The difference between the Ctenophore's egg and the sea urchin's egg deserves some special mention. An isolated blastomere of the two-cell stage of the sea urchin's egg gives rise to a whole embryo, while an isolated blastomere of the same stage in a Ctenophore's egg gives rise to but a half embryo, as far as the ribs are concerned. This difference is probably due to a difference in the viscosity of the contents of the two eggs, the fluid contents of the sea urchin's egg assuming a spherical shape again after isolation; while the blastomere of the egg of a Ctenophore, being

* Driesch und Morgan, Archiv fïr Entwickelungsmechanik, Vol. 2, I895.

† Fischel, Archiv für Entwickelungsmechanik, Vol. 6, I897. 
more viscous and jellylike, keeps the hemispherical shape, even after its isolation. If this idea is correct, it ought to be much more difficult to produce a giant embryo by the fusion of the contents of two eggs, in Ctenophores than in sea urchins, inasmuch as their fusion would be more difficult on account of the jellylike consistency of the main mass of the embryo.

It seems that in the egg of Mollusks, also, the simple symmetry relations of the body are already preformed. It is well known that there are shells of snails which turn to the right while others turn in the opposite direction. The shells of Lymnaus turn to the right, those of Planorbis to the left. It had been observed that the eggs of rightwound snails do not segment in a symmetrical, but in a spiral, order. Crampton and Kofoid discovered independently of each other that in left-handed snails an asymmetrical spiral segmentation occurs also, but the direction of the spiral is the reverse of that in the segmentation of the right-handed snails.* The asymmetry of the body in snails is therefore already preformed in the egg. The conditions which determine such an asymmetry may be of a very simple character. $\dagger$

From the facts we have thus far discussed it is obvious that in eggs whose contents possess a high degree of fluidity not much beyond the simplest symmetry relations can be preformed. A higher degree of preformation is only possible where liquid and solid constituents are contained in different parts of the egg.

E. B. Wilson + has recently found a still more marked differentiation in the eggs of some Annelids and Mollusks than the cases thus far discussed. Wilson isolated the first two blastomeres of the egg of Lanice, an Annelid. These two blastomeres are somewhat different in size; from the larger one of the first two blastomeres, the segmented trunk of the worm originates. Wilson found that "when either cell of the two-cell stage is destroyed, the remaining cell segments as if it still formed a part of an entire embryo. The later development of the two cells differs in an essential respect, and in accordance with what we should expect from a study of the normal development. The posterior cell develops into a segmented larva with a prototroch, an asymmetrical pre-trochal or head region, and a nearly typical metameric seta-bearing trunk region, the active movements of which show that the muscles are normally developed. The pre-trochal or head region bears an apical organ, but is more or less asymmetrical, and, in every case observed, but a single eye was present, whereas the normal larva

* Crampton, New York Academy of Sciences, 1894; Kofoid, Proceedings of the Am. Academy of Arts and Sciences, Vol. 29, 1894.

+ Conklin, Anatomischer Anzeiger, Vol. 23, p. 577, 1903.

‡. B. Wilson, Science, Vol. 20, p. 748, I904; and Jour. Exper. Zoöl., Vol. I. 
hass two symmetrically placed eyes. The development of the anterior cell contrasts sharply with that of the posterior. This embryo likewise produces a prototroch and a pre-trochal region, with an apical organ, but produces no post-trochal region, develops no trunk or setæ, and does not become metameric. Except for the presence of an apical organ, these anterior embryos are similar in their general features to the corresponding ones obtained in Dentalium. None of the individuals observed developed a definite eye, though one of them bore a somewhat vague pigment spot.

"This result shows that from the beginning of development the material for the trunk region is mainly localized in the posterior cell; and, furthermore, that this material is essential for the development of the metameric structure. The development of this animal is, therefore, to this extent, at least, a mosaic work from the first cleavage onward - a result that is exactly parallel to that which I earlier reached in Dentalium, where I was able to show that the posterior cell contains the material for the mesoblast, the foot, and the shell; while the anterior cell lacks this material. I did not succeed in determining whether, as in Dentalium, this early localization in Lanice preëxists in the unsegmented egg. The fact that the larva from the posterior cell develops but a single eye, suggests the possibility that each of the first two cells may be already specified for the formation of one eye; but this interpretation remains doubtful from the fact that the larva from the anterior cell did not, in the five or six cases observed, produce any eye."

It should, however, be pointed out that the posterior cell, which in the whole egg only seems to form the segmented trunk of the animal, forms a head if isolated, although the latter in the cases thus far observed was not symmetrical. We do not wish to enter further into this field of experimental embryology, and we refer the reader, in addition to the papers mentioned here, to those published by Chabry, Conklin, Driesch, O. Hertwig, Morgan, Pflüger, Roux, Schultze, Whitman, Wilson, and many others. It was our intention in this connection only to show that the first structures in the egg do not seem to be beyond the reach of purely physicochemical data. On the other hand, these data corroborate still further the statement that the early forms of the embryo are determined by the egg, and in no way depend upon the spermatozoön. It has occasionally been suggested that it might be possible to produce an organism from a spermatozoön alone, if the latter were only transplanted into a nutritive medium. This could only be true if the culture medium used possessed also the typical structure of the egg, which is not very likely.

Boveri and others have shown that often very early in the develop- 
ment, part of the substance of the egg is laid aside as the germ from which the sexual glands develop. While the rest of the egg is transformed into the various organs of the body, this part remains what it is; namely, embryonic matter. This embryonic matter begins to grow at a certain stage in the development. Miescher* has investigated this phenomenon somewhat in the case of the salmon. The salmon leave the ocean and migrate into rivers to spawn. When they begin to go into the rivers their testicles and ovaries possess little weight, while their muscles are powerfully developed. At this time the testicle is only $\frac{1}{1000}$ to $\frac{1}{700}$ of the weight of the whole animal, while a few months later it is 5 per cent of the body weight. In the female fish the relative weight of the sexual glands is still more considerable. According to Miescher, the salmon do not take up any food while they are in the fresh water. The source of material from which the sexual glands are built up must therefore be in the animal. Possibly through an increase in hydrolytic processes this material gets into the blood and is retained by the sexual glands. Miescher found that the muscles apparently furnished the material from which the glands are built up. The male and female animals behave somewhat differently in regard to the utilization of the material furnished by the muscles. In the sexual gland of the males the protein taken up from the blood is partly hydrolyzed, and the products, according to Miescher,--protamin, guanin, sarkin, - collect in the spermatozoa. In the ovaries this hydrolysis does not occur, and the protein of the blood is utilized for the building up of the eggs whose mass is considerably larger than that of the spermatozoa. The hydrolysis of the muscles is due, according to Miescher, to lack of oxygen, caused in his opinion by the diminution in the rapidity of the circulation of the blood through the muscles at the time of the growth of the sexual glands.

* Miescher, Histochemische und physiologische Arbeiten, Leipzig, 1897. 


\section{LECTURE XI}

\section{ON THE DYNAMICS OF REGENERATIVE PROCESSES}

\section{SAChs's Hypothesis of the Formation of Organs}

THE investigation of the physicochemical conditions for the formation of organs in the egg meets with the difficulty that the germ is too small for a thorough experimental analysis of the processes which occur there. It seems to me that it will be easier to use for such an analysis another series of morphogenetic processes; ramely, regeneration. In many plants and animals when an organ is cut off, a new organ is formed which is identical with the lost organ. The only scientific hypothesis of morphogenesis which we thus far possess, - namely, that of Sachs,* - starts with the processes of regeneration.

Sachs takes it for granted that the variety in the form of organs is determined by a corresponding variety in their chemical constitution. As an illustration of the relation between chemical constitution and the formation of organs, he uses his experiences with the influence of light upon the origin of blossoms. If plants, e.g. Tropeolum majus, are put into the dark in spring, their flowering buds which are already formed are not able to develop. In the dark the assimilating power of the green plant is inhibited, and Sachs concluded that the specific substances which are required for the formation of the blossoms cannot be formed by the leaves in the dark. In the light, however, these substances are formed in the leaves, and are carried by the sap from the leaves to the nearest flowering buds. Growth was not restricted in the dark, as was shown by. the formation of large (etiolized) shoots in the dark by the same plants. From this fact Sachs concluded that if only the quantity, and not the quality of the material circulating in the sap determined the nature of organs, the Tropcolum should have formed flowers; for the mass of the shoots formed in the dark was a multiple of the mass of material required for the production of flowers.

* Sachs, Stoff und Form der Pfanzenorgane. Gesammelte Abhandlungen über Pfanzenphysiologie, Vol. 2, p. I I59, Leipzig, I 892. The reader will find a rather complete survey of the literature on Regeneration in Morgan's book on this subject (T. H. Morgan, Regeneration, New York, I90I). 
If the tip of the stem alone is put into the dark, while the leaves are exposed to the light, the tip forms blossoms. Therefore Sachs concluded that in the light the leaves form substances which are of specific importance for the formation of flowers. He found in support of this view that bulbs of tulips, hyacinths, iris, and crocus, if they are caused to grow in the dark during the spring, produce normal blossoms. In these plants the material and the specific substances necessary for the formation of their flowers were stored up during the preceding year. Sachs generalized this conclusion: Not the quantity of material alone but also the quality is decisive for the formation of organs. There are as many specific substances in a plant as there are different organs. It is obvious that this idea is in full harmony with the experiments of Mendel and De Vries on heredity, inasmuch as this theory ultimately forces us to assume specific substances as the determinants for the hereditary qualities.

To make Sachs's hypothesis as clear as possible, we will quote the following passage: "We may imagine the process (of organization) as being in a way comparable to the successive processes in a chemical factory, where from the original raw material chemical compounds of the greatest variety are formed in succession until the final product is obtained chemically pure, possibly in an extremely small quantity. Although our analyses seem to indicate apparently always the same protoplasm, starch, sugar, fat, we must realize that these substances may themselves differ,* or that traces of other substances may force them to solidify in different organic forms. To give one example, it seems that the formation of flowers and seeds depends upon a storing up of phosphates in these organs, that the plant cannot form flowers and seeds until there is a comparative excess of phosphates compared with the other ashes in the saps. ... An excess of phosphates may force a beet to produce flowers in the first instead of the second year." Sachs applied the same idea to the problem of regeneration. If we cut a piece from the branch of a willow tree, it will under the proper conditions, form roots near the basal and shoots near the apical end. Sachs raises the question as to how it happens that the cutting off of a piece causes the formation of organs in places where it would never occur without this operation or other disturbing conditions. The question is answered by Sachs in harmony with his above-mentioned hypothesis. Duhamel had assumed the existence of two currents of sap in the plant, one ascending, the other descending; the latter carrying root-forming, the former stem-forming, material. Sachs imagines that "as long as a green plant with an upright stem is nourished and 
growing, the specific formative substances of the root flow from the assimilating leaves to the root at the lower end of the stem; while the shoot-forming substances flow from the leaves upward to the apices of the twigs. If a piece be cut out from the stem or the root, the cut surfaces form an obstruction where these substances now gather." In such a piece the root-forming substances will therefore gather at the basal end of the twig, and cause here the formation of roots; and the shoot-forming substances will collect at the apical end where they favor the formation of shoots. Sachs's hypothesis finds a beautiful confirmation in the phenomena of regeneration in leaves. The leaves are the factories in which the carbohydrates, and perhaps all the specific substances in the sense of Sachs, are formed. The dissolved substances flow from the leaves to the base, and from here to the stem. If pieces be cut from a leaf, e.g. in a Begonia, shoots as well as roots are formed at the basal end of the leaf where the substances flow. Goebel has added a great many beautiful observations on regeneration in plants which support Sachs's conclusion.

The observations of pathologists on compensatory hypertrophia support also in my opinion the idea of Sachs.* If, e.g., one kidney is removed, the other increases in mass. The same seems to hold also for other glandular organs. Pathologists assume that this is due to the greater work now done by the remaining gland. If the hypothesis of Sachs is applicable here, it is possible that certain substances which caused the growth of these glands circulate only in limited quantities in the blood. If a gland be removed on one side of the body, these substances will all flow through the remaining organ which will, therefore, begin to grow.

\section{Heteromorphosis and Regeneration in Tubularia}

The only way which seems to lead directly to any information concerning the dynamics of regeneration lies in our finding means to substitute at desire one organ for another. The results thus obtained no longer rest upon surmises, but allow us to determine the variables of which the process of regeneration. is a function. Sixteen years ago I undertook to bring about such substitutions of one organ for another at desire. I succeeded in a number of hydroids and an ascidian, and called the process heteromorphosis $\dagger$ to discriminate between this phenomenon and the substitution of an organ by an identical one

* Loeb, Untersuchungen zur physiologischen Morphologie der Tiere, Würzburg, 1890 and 1891. (Translated in Studies in General Physiology, Chicago, 1905.)

† Loeb, loc. cit. 
regeneration). Since then heteromorphoses have been obtained in a number of animals.

Tubularia mesembryanthemum of the Mediterranean and Tubularia crocea of the Pacific Ocean are hydroids which consist of an undivided stem (ss, Fig. 39) from 2 to $6 \mathrm{~cm}$. long, which has a polyp ( $p$, Fig. 39) at the oral, a stolon or foot $w$ at the aboral end. If a piece $a b$ (Fig. 40) is cut from the stem of a Tubularian, according to the observations of Allman, a polyp forms at the oral end $a$, a stolon at the aboral end $b$. Allman therefore called this animal "polarized," thereby signifying that each element of the stem of the animal possesses a different oral and aboral side. I undertook to bring about a heteromorphosis in this animal, and succeeded in finding a method by which without fail at the aboral cut end $b$ of a piece of the stem a polyp can be produced. This method consisted in putting the piece $a b$ with its oral end $a$ into the sand, while the aboral end $b$ was surrounded by water on all sides. In this case a polyp FIG. 39 . instead of a stolon was invariabiy formed at the aboral end $b$. The
oral end which is in the sand does not regenerate, presumably on account of the lack of oxygen. When both ends of a piece $a b$ cut from the stem of a Tubularian are surrounded by sea water, the oral end $a$ invariably forms a polyp. The aboral end $b$ may form a stolon or a polyp. In Tubularia crocea I observed that under such conditions the aboral ends form polyps in about 90 per cent of the cases, and stolons in about Io per cent. In this case $9 \circ$ per cent of animals were obtained with a head at either end (see Fig. 4r).

There was, however, a marked difference in the velocity of regeneration of the two polyps. The polyp at the oral end forms without exception more quickly than the polyp at the aboral end. The difference in time may vary from two days to two weeks; the difference apparently being less at a high than at a low temperature. Even if the piece of

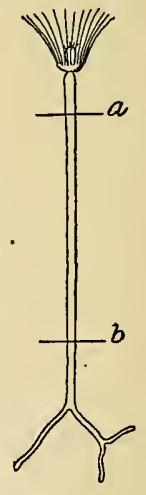

FIG. 40. the stem forms a head at either end an intimation of the old polarity still exists, inasmuch as the oral pole is formed earlier than the aboral pole.*

In the following year I was able to show that the formation of the polyp at the aboral end could be accelerated by suppressing the formation of the polyp at the oral end. The mode of procedure of demonstrating this fact was as follows: Pieces $a b$ (Fig. 40) were cut from a 
number of Tubularian stems; one half of these pieces were put vertically, but reversed, i.e. with the oral end $a$ in the sand, in order to suppress the formation of polyps at this end. The other half of the pieces were also put vertically and reversed into the same aquarium, but in such a way that both cut ends $a$ and $b$ were surrounded by sea water. These latter pieces formed polyps at the oral end $a$ after three or four days, while it took nine days for them to form polyps at the other end. The stems, however, whose oral ends were put into the sand, where consequently the formation of polyps at the oral end was suppressed, formed polyps at the aboral end within three or four days. Hence, the suppression of the formation of the polyp at the oral end accelerated con-

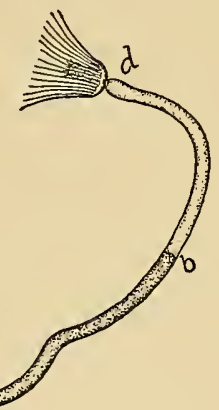
siderably* the formation of the polyp at the aboral end.

The next question was, How can the suppression of the polyp at the oral end accelerate the formation of the polyp at the aboral end? The following experiments were intended to answer this question.

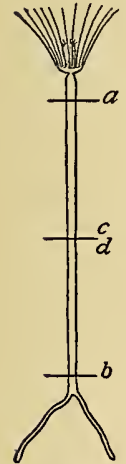
Pieces $a b$ (see Fig. 42) were cut from a number of stems, and each of these pieces was cut in two between $c$ and $d$. If all four cut ends were surrounded by sea water, polyps were first formed at the oral end of each half; namely, at $a$ and $d$, where the polyp formation occurred simultaneously. Considerably later the polyps were formed at the aboral ends $c$ and $b$, and here also the polyp formation occurred simultaneously. It therefore appears as if the polarity in this case were due to a condition of the nature of a current $(e . g$. of liquid), by which certain substances were carried through the stem in the direction from the aboral to the oral end. The deposition of certain substances by the current at the anterior end retards the formation of the polyp at the opposite FIG. 42 . end. The idea that a current is the decisive variable in this case could in the middle. If this is done, the polarity is done away with and a polyp is formed simultaneously at both ends. $\dagger$ The same experiment

* Loeb, loc. cit., II, 1891 .

† Loeb, Pfiüger's Archiv, Vol. 102, p. 152, 1904. 
was made from a different point of view independently by Godlewski.* Through the ligature the current which carries away substances from the aboral end is inhibited, and hence the cause for the polarity is removed.

When I first made these experiments the hypothesis of Sachs seemed to suggest that in the excised piece of a stem not enough specific polypforming material was present to allow the simultaneous forming of two polyps, but the experiments already mentioned exclude this idea. It is further excluded by the observations made by Miss Bickford, who found that even if a stem be cut into a number of small pieces, each oral end of such a piece forms a polyp. Hence it is not a question of lack of material but only a lack of free cut ends, which block the flow of sap, if only one polyp is formed in a piece cut from the stem of a Tubularian. It is therefore apparently the process of streaming itself which may take something away from the aboral end, which is responsible for the fact that a stolon is formed here, or if a polyp be formed that its formation is delayed.

As far as the method of regeneration is concerned, Miss Bickford has found that it does not consist in the growth of a new polyp from the old material, but in a direct transformation of the

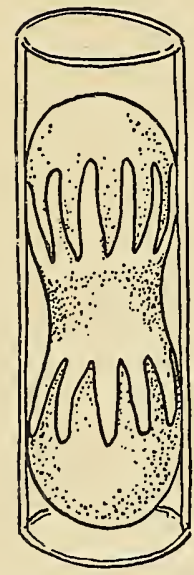

FIG. 43.-AFTER MISS BICKFORD.

Beginning of the formation of two polyps inside a piece from a stem of Tubularia. material of the stem into a new polyp. Miss Bickford observed this directly under the microscope in small pieces from the stem of a Tubularian, which were not even of the size of a normal polyp. In such cases the whole mass of the piece was transformed into a polyp. $\dagger$ In the case of the smallest pieces the result was still more striking. At each free end of the small piece of the stem tentacles and a proboscis were formed (Figs. 43 and 44), but inasmuch as there was no material left for the formation of a stem in addition to two polyps, or not even for two entire polyps, a kind of Janus head was formed, two faces or probosces of a polyp looking in opposite directions. No new outgrowth occurred, but the old tissues arranged themselves into a new shape, forming a polyp, while before they had formed part of the stem. The most remarkable fact was the transformation of certain cells of the entoderm into secretory cells of the stomach.

It is not yet possible to tell exhaustively which forces have to do with this transformation. The stem is surrounded by a chitinous layer. I have never observed the formation

* Godlewski, Archiv für Entwickelungsmechanik, Vol. I8, p. I I I, 1904.

† Elizabeth E. Bickford, Jour. of Morphology, Vol. 9, p. 4I 7, I894. 
of a polyp inside of the intact stem, but only where the cells inside the chitinous layer come in contact with the sea water. The mere interruption of the continuity of a stem does not seem to suffice, as I have never seen the formation of a polyp at the point where the stem was ligatured. It is possible that the lack of oxygen is responsible for the fact that no polyp can be formed except at a free end of a stem, since the chitinous surface of the stem is very little permeable for oxygen.

A second condition is the closing of the body cavity after the cut is made and the establishment of a circulation. The body of the Tubularian hydroid is a long, hollow cylinder, and the hollow space in the center of a Tubularian is divided by a septum into two chambers which communicate at the ends ( $a$ and $b$, Fig. 45). In this space a circulation of the liquid is maintained by the ciliary motion of the endothelial cells in such a way as to make the flow of liquid ascending on one side and descending on the opposite side. This stream carries red and yellowish pigment granules which are apparently formed by the cells of the en-

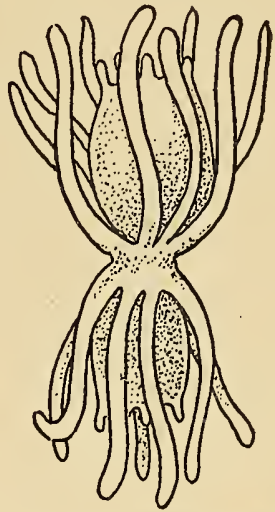

FIG. 44.-AFTER MISS BICKFORD.

The same specimen a littie later, after the formation of the polyps was completed. The chitinous tube was removed. dothelium. The analogy with similar cases suggests the possibility that these pigments are respiratory pigments, serving a purpose similar to, e.g., the red blood corpuscles in our body. If we now cut

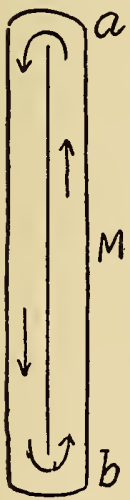

FIG. 45.

out a piece from the stem of the hydroid, the opening at either end closes in an hour (more or less according to the temperature) by the cells of the cut end spreading out over the opening concentrically.* According to my observations, no piece of a hydroid can regenerate unless this circulation is established. This may be due to the fact that the circulation serves as a, means of supplying oxygen, and a liberal supply of oxygen seems to be an absolute prerequisite for all phenomena of regeneration and growth. Any piece of a Tubularian, however, which can establish a circulation can form a polyp. Thus, when a stem is split lengthwise, the cellular masses may become disconnected into several pieces. Each such piece may form a polyp at both ends.

When we ligature a stem in the middle, the circulation will be interrupted, inasmuch as at a place where the ligature is made the septum 
is not perforated. Very soon, however, after the ligaturing, a perforation at the septum on either side of the ligature occurs, and the circulation is again established. One might think that the current just described was responsible for the phenomena of polarity in Tubularians, inasmuch as this current carried away certain material from the aboral pole. The direct observation supports this idea to some extent. As I pointed out fifteen years ago, the place where a new polyp will be formed is always recognizable some time before the actual regeneration occurs, by the collecting of the red or yellow pigment granules in greater density at that spot. It agrees with this statement that if a piece be cut out from the stem of a Tubularian and suspended in sea water, the red pigment always collects first in great masses at the oral end, where the polyp is formed first, and only later at the other end. In my earlier writings on heteromorphosis I pointed out that this seems to be in harmony with Sachs's idea, inasmuch as it indicates a migration and collection of definite substances at the end of a regenerating piece as the cause of the formation of a new organ. Morgan and Miss Stevens raised the objection that after the formation of the polyp the remnants of these red granules are thrown out by the polyp: This seems to me in no way to speak against the possibility that the red granules contribute some substances necessary to the formation of the polyp. As is well known, the red blood corpuscles perish regularly in the body, and their products of decomposition form constituents of the bile. Yet nobody would think of using this fact as an argument against the importance of the red blood corpuscles or the bile. I am inclined to believe that Morgan and Miss Stevens underestimate the fact which Sachs tried to emphasize, that chemical processes underlie the phenomena of regeneration.

But I am far from believing that the circulation current is the only factor in the transport of substances through the Tubularian. It is possible that in Tubularia we are dealing also with a current of sap through specific tissue, as is found in plants. Setchell has made it probable that in Laminaria regeneration always starts from that tissue which conducts the nutritive material. It may be that there exists a flow of material from cell to cell in the entoderm or ectoderm of the Tubularia or both, and that this flow occurs naturally from the aboral to the oral end, but that it is reversed in the aboral piece of the stem when a ligature is made in the stem. Even if the fact that the pigment granules are carried away from the rest of the stem and are gathered at the oral end be responsible for the polarity, it remains to be explained what keeps the granules rather at that than at the opposite end. These details still have to be worked out, but I believe that we may 
consider it as established experimentally that the conditions which determine the morphological polarity are due to something of the nature of a current inside of the Tubularian. The mysterious morphological polarity is thus reduced to a polarity which can be expressed in physical or physicochemical terms. We see that this result differs in one point from Sachs's hypothesis. The latter includes the effect of specific substances, while this condition does not appear in the results of our experiments. It is, however, hardly necessary to state that our experiments by no means exclude this possibility. I have discussed the case of regeneration in Tubularians at some length, not only because it is well known to me through my own experiments, but also because on account of its simplicity, it lends itself better to a reduction of dynamically unintelligible morphological data to the more rationally expressible physical or physicochemical conditions.

Osterhout and I tried to test the effects of a ligature on plants, especially on willow twigs. As we have already stated, a piece cut out from a willow twig forms roots first at the basal and shoots at the apical end. The process of regeneration in this case differs in several essential features from that in Tubularians. The formation of the new organs occurs in the willow twig not at the cut end but at the anlage of the roots and shoots, both of which exist here normally. All that the operation does in this case is to cause the anlage of roots which would never have developed now to grow out into roots. The reader should realize that the anlage of the roots which begin to grow in consequence of the cutting off of the twig is not injured by the operation and is often far removed from the wound. The idea that this anlage grows out because the sap which would otherwise flow downwards is now blocked by the cut, and becomes available for the anlage of the roots, looks very plausible in the light of the actual facts. As part of the sap flow can be suppressed by a tight ligature around the rind of a stem, Osterhout and I tried the experiment of ligaturing a number of willow twigs in the middle. The result was that a ligature caused the root anlage above it and the shoots below it to develop, which without the ligature would not have developed. In the case of the willow, we are also dealing with a flow of material through conductive tissue, i.e. tissue through which nutritive material is conducted.

\section{Regeneration in an Actinian (Cerianthus membranaceus)}

The phenomena of regeneration in Cerianthus can be easily understood from the experiments on Tubularians, if we imagine the body wall of Cerianthus to consist of a series of longitudinal elements which 
run parallel with the axis of symmetry of the animal from the tentacles to the foot. The number of these elements may be supposed to correspond to the number of the outer row of tentacles of the normal animal. Each such element behaves like a Tubu-

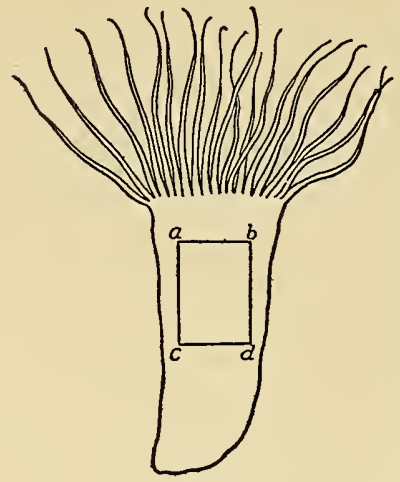

FIG. 46 . larian, with this difference, however, that the elements in Cerianthus are more strongly polarized than Tubularia. No heteromorphosis has thus far been produced in these elements in Cerianthus, and each one is able to form a tentacle at its oral pole only. This fact can be nicely illustrated in the following way: if a square or oblong piece ( $a b c d$, Fig. 46 ) be cut from the body wall of a Cerianthus in such a way that one side, ac, of the oblong is parallel to the longitudinal axis of the animal, tentacles will grow on one of the four sides only; namely, on the side $a b *$ The three other free edges are not able to produce tentacles. If an incision be made in the body wall of a Cerianthus, tentacles will grow on the lower edge of the incision (Fig. 47).

I have recently tried whether or not by tying a ligature round the middle of a piece of an Actinian this polarity could not be suppressed. But the experiments did not succeed, inasmuch as the cells compressed by the ligature died, and through bacterial action were liquefied so that the pieces in front and behind the ligature fell apart. It is therefore impossible to decide whether or not a condition of the nature of a current or a flow of substances in a certain direction through these elements is responsible for this polarity, though I consider this probable. I found, however, that one condition is necessary for the growth and regeneration of tentacles which also plays a rôle in the corresponding phenomena in plants; namely, turgidity. The tentacles of Cerianthus are hollow cylinders closed at the tip, and by liquid being pressed into them they can be stretched and appear turgid. If, however, an incision is made in the body,

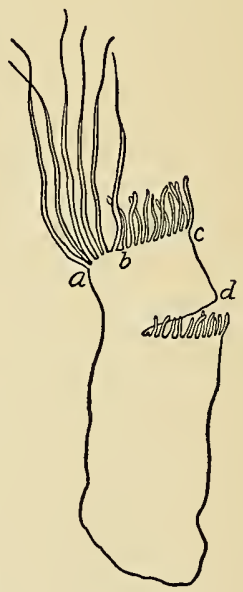

FIG. 47. the tentacles above the incision can no longer be stretched out (Fig. 47). I have found that the turgid condition of the tentacles is neces- 
sary for their growth. In one experiment the oral disk of a Cerianthus was cut off ; very soon new tentacles began to grow at the top, and after having reached a certain size, an incision was made in the animal at $d$, Fig. 47. The tentacles above the incision between $b$ and $c$, Fig. 47 , collapsed in consequence and ceased to grow, while growth of the others between $a$ and $b$ continued. On the lower edge of the incision new tentacles began to grow.

Child* has elucidated to some extent these phenomena of turgidity. Every tentacle is a hollow cylinder, and this cylinder continues downward where it communicates with the body cavity. When liquid is pressed into the tube from the body cavity, the tentacles are stretched; but if the liquid leaves the tube, the tentacles relax also. If an incision is made below a tentacle into the wall of the body of a Cerianthus, no more liquid can be pressed into that tentacle, and it relaxes. Child confirmed my observation, that regeneration of the tentacles in Cerianthus is no longer possible when they relax. He added a number of pretty demonstrations of the necessity of the turgidity of the tentacles for regeneration. He found, for instance, that if an incision is made into the foot of a Cerianthus and the edges of the wound are prevented from healing together the tentacles lose their turgidity and are no longer able to grow. He found, also, that the tentacles degenerate under such conditions.

It is unknown at present how the turgidity can influence growth in the tentacles of an Actinian.

The observations on Cerianthus are comparable with those on Tubularia if we realize that the body wall in Cerianthus consists of a series of hollow cylinders or spaces each of which ends in a tentacle.

The idea of an animal body consisting of a series of comparatively independent longitudinal elements recommends itself also for the understanding of a phenomenon of regeneration in Ascidians. The Ascidian, Ciona intestinalis, has eyes

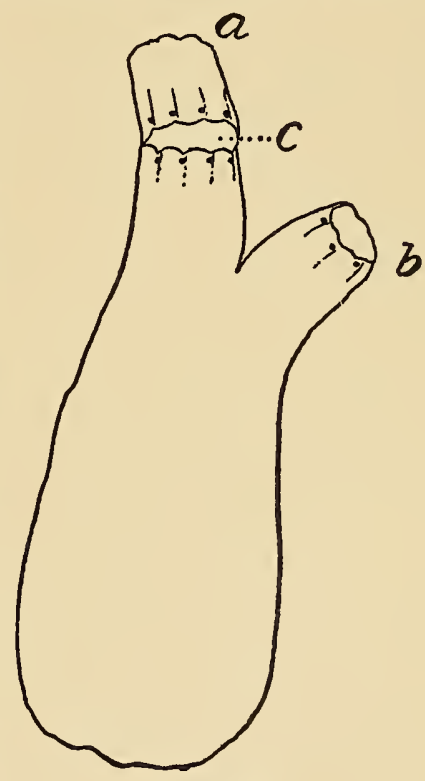

FIG. 48.

An incision was made at $c$ and new ocelli develop at both ends of the cut. (ocelli) at the oral as well as at the aboral opening of the body (Fig. 48). We may imagine that each ocellus is the end of one of the 
longitudinal elements to which reference was just made. If a lateral incision be made in the body at $c$, not too far from the openings, ocelli will be formed at each free end of these elements. Here the longitudinal elements show heteromorphosis, inasmuch as they are capable of forming ocelli at both ends.

I am inclined to believe that in each of these cases the individual longitudinal element represents a conductor for nutritive material or specific morphogenic substances in the sense of Sachs. It must remain undecided for the present whether this flow occurs through the hollow space or through the tissue or certain cells of the tissue.

\section{Regeneration and Heteromorphosis in Fresh-water Planarians}

It had been known for a long time that if the head and the tail be cut off from a fresh-water Planarian, at the front end a new normal

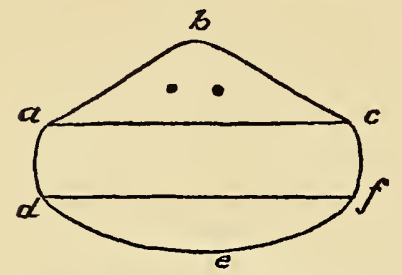

Fig. 49.-AFTER MORGaN. head, at the back end a new tail, will be regenerated (Fig. 49). Morgan* made the interesting observation that if a piece acdf be cut obliquely (Fig. 50) instead of at right angles to the longitudinal axis from a Planarian, a tiny head is formed at the foremost corner of the piece $a$ and a tiny tail at the hindmost corner $f$, Fig. $5 \mathrm{I}$. Why is it that in the oblique piece the head is formed in the corner and not all along the cut surface as is the case when the cut is made at right angles to the longitudinal axis? I am inclined to believe that the right answer to this question has been given by Bardeen. $f$ Bardeen has pointed out the apparent rôle that the circulatory (or so-called digestive) canals in Planarians play in the locali-

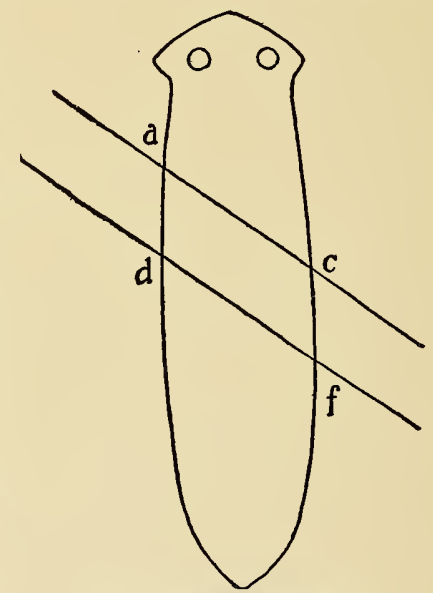

FIG. 50. - AFTER MORGAN. zation of the phenomena of regeneration, inasmuch as the new head always forms symmetrically at the opening of the circulatory vessel

* Morgan, Regeneration, New York, Igor.

+ Bardeen, Am. Jour. Physiology, Vol. 5, p. I, 1901 ; and Archiv für Entwickelungs. mechanik, Vol. I6, p. I, 1903. 
or branch which is situated as much as possible at the foremost end of the regenerating piece of worm. He assumes that through the muscular action the liquids of the body are forced to stream toward this end, and that this fact has some connection with the formation of a new head. There can be no doubt that the facts here mentioned agree with Bardeen's suggestion. The oblique pieces in Morgan's experiments, which have at first the heads and tails outside the line of symmetry of the middle piece, gradually assume afterward a normal position (Figs. $5^{\mathrm{I}-54}$ ). I am inclined to believe as Child
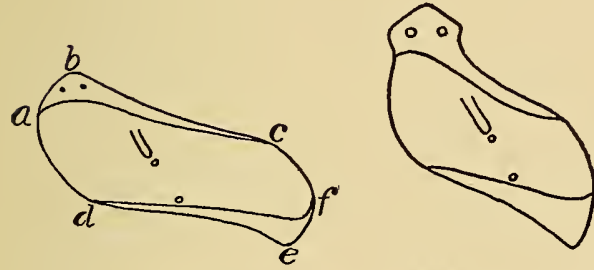

FIGS. 5I-54.-AFTER MORGaN.

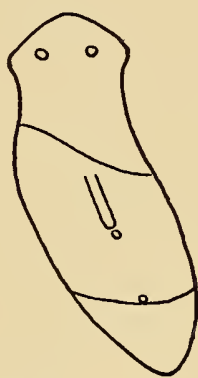

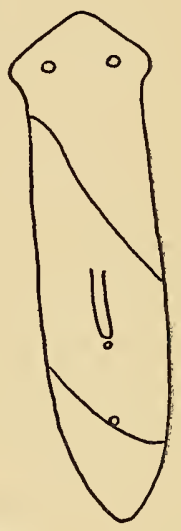

Successive stages in the regeneration of the oblique piece adcf of Fig. $5^{\circ}$.

does that this is due to purely mechanical conditions. The head of such an oblique piece is asymmetrical, the one side $a b$ being less stretched than the other side $b c$. The higher tension of the piece $b c$ will have the effect of bringing $b$ nearer $c$. The reverse is true for the tail def, and the effect will here be that $e$ will be pulled nearer $d$. In this way purely mechanical conditions are responsible for the fact that the soft tissues of the animal are gradually restored to their true orientation.*

It was of interest to find out whether heteromorphosis could be produced in Planarians. At my request Dr. Van Duyne undertook experiments in this direction and succeeded in a few cases. $\dagger$ Figure 55 shows one of these instances. On the right side of the animal the posterior part had been cut off. A new head which was directed backward was regenerated in place of the amputated part. Morgan was more successful later on. He obtained a larger number of heteromorphoses by cutting short pieces out of a Planarian than by cutting out long pieces. $\ddagger$

* It is in my opinion not only unnecessary but directly confusing to introduce for the explanation of these phenomena of restitution such mystical forces or conceptions as Noll's "Morphæsthesia," and similar things.

† Van Duyne, Pfiugger's Archiv, Vol. 64, p. 569, I896.

$\ddagger$ Morgan, Archiv fïr Entwickelungsmechanik, Vol. I7, p. 683, 1904 . 
He mentions that in the short pieces less "polarity" exists than in the long pieces; but as the conception of heteromorphosis is the opposite of polarity, Morgan's statement is only a different way of expressing

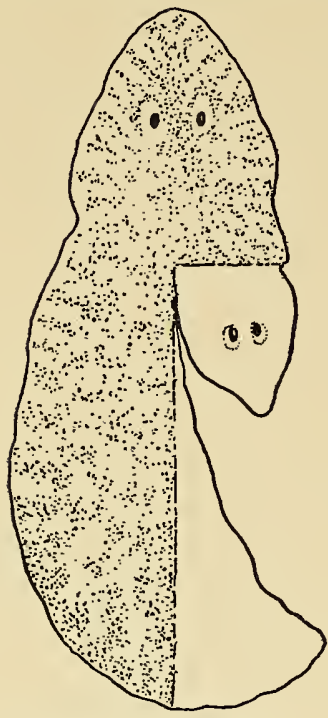

FIG. 55. - AFTER VAN DUYNE. the same fact. I remember that when Miss Bickford made her experiments on regeneration in Tubularians in my laboratory, I was struck with the fact that in the very small pieces cut out of a stem the polyps at the oral and the aboral end developed practically simultaneously. Here, too, polarity was less pronounced in small pieces than in large pieces. I believe the reason for this lies in the rôle which processes of the character of a current or a flow of material play in these phenomena. The red pigment, and possibly other substances which are of importance for regeneration, gather not in one point but in an area of the length of several millimeters, where a polyp is to be formed. If the regenerating piece is in itself only a few millimeters long, the pigment must remain scattered equally over the small piece, and hence the polarity must disappear. Something similar may occur in the case of a Planarian. If the piece is very small, the head-forming material will remain equally distributed through the whole length of the piece, and hence the chance for the simultaneous formation of the head at either end is greater than in a large piece.

It is a general experience that in order to get a duplication of organs, the regenerating animal must be split into two pieces. Thus, in order to obtain two larvæ from one egg, the egg must be cut into two, or the heap of cells must be separated into two parts. One might believe that in order to get two heads in front of a Planarian, the front end would have to be separated into two by a longitudinal incision. Two heads, however, often develop in front of a Planarian whose head has been cut off without such an incision. The explanation is obvious on the basis of Sachs's hypothesis. If the gathering of certain substances at the front end is the cause of the formation of a head, and if we assume with Bardeen that these substances are carried to the cut by the circulatory system, it is comprehensible that in two different spots at the front end substances necessary for the formation of the head may gather. 
5. On the Influence of the Central Nervous System upon Regeneration and on Phenomena of Correlation in RegenERATION

It is rather remarkable that the central nervous system plays an important rôle in phenomena of regeneration. In I889 I noticed that in Thysanozoön Brochii, a marine Planarian, the isolated head containing the ganglia is capable of rapid regeneration while the body without the ganglia shows less, or a slower regeneration.* The taking up of food is not responsible for this difference, since the head cannot take up food. That the taking up of food is not essential for regeneration follows also from the observations on the regeneration of pieces cut from the walls of Cerianthus. We must not overlook the fact that the reversible chemical processes in the cells of an animal are liable to provide material for regeneration in the same way as the taking up of food.

A number of observers - T. H. Morgan, Child, Lillie, and Lillian Morgan - have since found that the œsophageal ganglia exercise a considerable influence upon regeneration in marine Planarians. $\dagger$

It is therefore obvious that there exists a typical difference between fresh-water and marine Planarians, since in the fresh-water Planarians the presence of the œsophageal ganglia is not required for complete and rapid regeneration.

This difference in the influence of the œsophageal ganglia in marine and fresh-water Planarians upon regeneration finds a probable explanation in a fact to which Bardeen has called attention; namely, that the longitudinal nerves which go through the whole body of the Planarians are very rich in ganglia in the fresh-water Planarians and very poor in ganglia in Thysanozoön.

Herbst $\ddagger$ has discovered the most beautiful case of heteromorphosis thus far known; namely, that in Crustaceans in

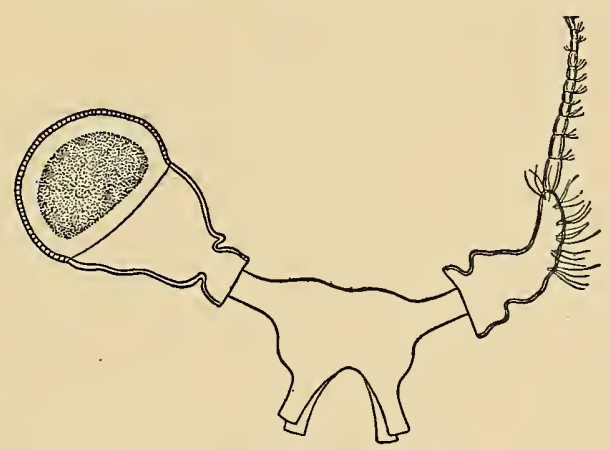

Fig. 56. - AfTER HERBST. the place of an eye which has been cut off, an entirely different organ, an antenna, can be formed (Fig. 56). Herbst proved, moreover, that

* Loeb, Pfüger's Archiv, Vol. 56, p. 247, 1894.

† Lillian Morgan, Biological Bulletin, Vol. 8, 1905. 1901.

$\ddagger$ Herbst, Archiv für Entwickelungsmechanik, Vol. 9, p. 215, 1900; and Vol. 13, p. 436, 
the experimenter has it entirely in his power to determine whether the Crustacean shall regenerate an eye in the place of the eye which has been cut off, or an antenna. It depends upon the fact whether or not in the operation the optic ganglion is removed with the eye. If the optic ganglion is removed with the eye, an antenna is regenerated in the place of the eye. If the optic ganglion is left intact, a new eye is formed. These experiments were carried on successfully in Palæmon, Palæmonetes, Sicyonia, Palinurus, and other Crustaceans. Herbst says that the optic ganglion exercises a "formative stimulus" upon the hypodermic cells of the wound. It is certain that an explanation of the rôle of the ganglion can only be given in physical or chemical terms; that as long as this is not possible we possess no explanation.

Morgan has made a somewhat similar observation on earthworms, in which he found that a new head is only possible at the anterior cut end of the nerve cord.* The following
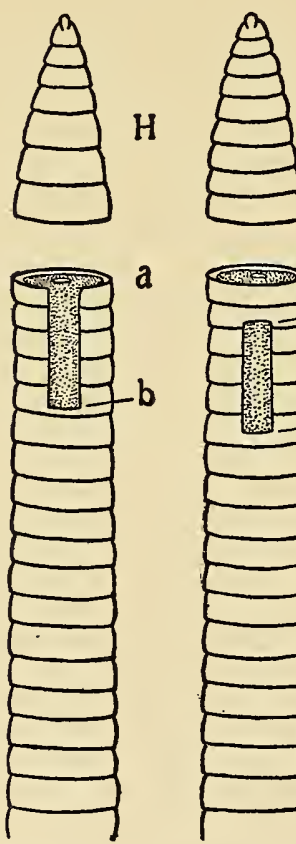
FIG. 57. 57.58.
AFTER MORGAN. AFTER MORGAN. formed, one at each of the anterior ends of

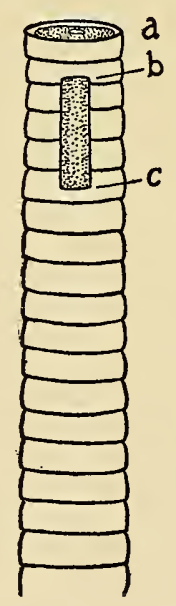
FIG. 57. 57.58.
AFTER MORGAN. AFTER MORGan. formed, one at each of the anterior ends of case may be mentioned by way of illustration. A few of the anterior segments of an earthworm were cut off, $H$, Fig. 57 , and from the remaining body a piece $a b$ was cut from the anterior part of the nerve cord (see Fig. 57), while all the other tissues remained unaltered. The anterior cut end $a$ of the worm healed, and no new head formed at this place. Instead, a new head was formed in some such cases at $b$, at the anterior cut end of the nervous system. If the head alone is cut off in an earthworm without the excision of the anterior piece of the nerve cord, a new head is formed at the anterior end of the body. In another series of experiments Morgan cut off the head $H$ of an earthworm and in addition (Fig. 58) excised a piece $b c$ from the nerve cord, so that now two anterior cut ends, $a$ and $c$, Fig. 58, of the nerve cord existed. In a few of these cases two new heads were the nerve cord, at $a$ and at $c$.

Another example of the dependence of the regeneration of one organ upon the presence of another is found in the formation of the lens of the eye. As is well known, the formation of the lens in the eye is pre- 
ceded by the formation of the optic vesicles, and where the latter touch the ectoderm a proliferation of cells begins, from which later the lens is formed. Spemann* has shown in the salamander that if the optic vesicle does not reach the ectoderm, no lens is formed. The same author showed, moreover, that if in the embryo the optic vesicle is destroyed, no lens is formed, but that if afterward the optic vesicle is regenerated, a lens is formed as soon at this vesicle touches the ectoderm. Lewis confirmed and enlarged Spemann's observations. $\dagger$

He showed that the ectoderm in frogs can form a lens at any place in the body if the optic vesicle is transplanted and allowed to come in contact with the ectoderm. He suggests that definite chemical reactions may occur between certain substances of the optic vesicles and the cells of the ectoderm; that these substances determine the formation and the peculiar character of the cells of the lens. This suggestion is in harmony with the ideas of Sachs, and I am inclined to believe that it will lead to further discoveries. Lewis's experiments also throw light upon an earlier observation made on salamanders. It was found that if a lens is removed in a salamander it can be regenerated from the iris. Inasmuch as the edge of the iris is naturally in contact with the retina (optic vesicle), this is about what should be expected from Lewis's experiments.

It is well known that the skeletal muscles degenerate if separated from the centers of their motor nerves. Goltz and Ewald have cut long pieces from the spinal cord in dogs, and observed that all the muscles belonging to the excised segments of the spinal cord degenerated, as was to be expected. This may be due to some chemical change in the muscles, owing to their inactivity after the motor nerves are cut or separated from their ganglia.

We have already discussed one case of an apparent action at a distance in Tubularians, where the suppression of the process of regeneration at the oral pole accelerated the formation of a polyp at the aboral pole. Przibram found a case of distance action which is not so easy to explain. $\ddagger$ In a Crustacean, Alpheus, the right and left chelæ are not equal in size and form. The same type of chela is not always on the same side, but in about one half of the cases the one type is on the right side, in the other half, the other type. Przibram found that if the larger of these chelæ is removed in such a Crustacean, the remaining chela assumes after the next moulting the shape of the removed chela, and the regenerating chela assumes the shape which the remain-

* Spemann, Sitzungsber. der physik. med. Gesellschaft in Würzburg, 1901.

+ Lewis, Am. Jour. Anatomy, Vol. 3, I904.

$\ddagger$ H. Przibram, Archiv für Entwickelungsmechanik, Vol. I I, p. 329, I90I. 
ing smaller chela originally had. Thus the animal is normal again, but the relative position of the two chelæ is now reversed. If later on in such an animal the larger chela is cut, the original order can be obtained again.

E. B. Wilson has repeated the experiments of Przibram, and made the important discovery that the growth of the smaller chela after the removal of the larger one does not occur if the nerve of the former is previously cut.* The number of the successful operations was small, but the results were significant. This brings Przibram's experiments into a line with Herbst's and Morgan's.

It seems to follow from these facts that the nerves have a function which is different from that of a mere conductor of stimuli; namely, that of causing the growth or development of certain organs. It has been argued that these two functions are not different, inasmuch as in both cases the nerve acts only as a conductor of stimuli and that these stimuli determine the phenomena of regeneration mentioned here. Child expresses such a view, and Herbst's idea of "formative stimuli " is only a somewhat less definite expression of the same view. It seems to me that there exists a still different possibility; namely, that the nerve may also act as conductor for certain substances which go from the periphery to the ganglion cells or in the reverse direction and are carried through the axis cylinder. Especially the observations of Lewis and possibly those of Herbst and Przibram suggest such a possibility. But before we admit the possibility that the axis cylinder can act as a conductor for the passage of definite substances, we must look for facts which warrant such an assumption. Such facts are given by the beautiful discovery of Hans Meyert that the tetanus toxin is carried from the wound to the central nervous system through the axis cylinder of the nerves, and neither through the blood vessels nor the lymphatics nor the sheaths of the nerves. It is hardly necessary to emphasize the fact that through this discovery an entirely new light is thrown upon the rôle which the nerves or ganglion cells may play in the phenomena of regeneration. The possibility now arises that the axis cylinder may act as a conducting path for certain substances which in some animals may be necessary for the starting of a process of regeneration or which may modify the nature of the organ which is to be regenerated.

A few words may finally be said about the well-known effects of certain organs like the hypophysis and the thyroid gland on phenomena of growth. Certain parts of the body - namely, the lower jaw, the

* E. B. Wilson, Biological Bulletin, Vol. 4, p. 197.

$\dagger$ Hans Meyer, Festschrift für Jaffi, Igor. Meyer und Ransom, Archiv für Experim. Pathol. und Pharmacol., Vol. 49, p. 369, 1903. 
fore arm, the hand, and the leg from the knee down - may suddenly begin to grow even if the body had already reached its final size. This phenomenon, known as acromegaly, is comparable to the process of regeneration, inasmuch as the problem in this case is also what causes this sudden growth which normally does not occur. It has been observed that this disease is often connected with a degeneration of the hypophysis, a small organ of enigmatic function. An attempt has been made (Von Cyon) to cure this disease by feeding the patient on normal hypophyses. This idea is based on experiences made in regard to the thyroid gland. Complete extirpation or degeneration of the thyroid gland in growing persons causes a standstill of growth and sexual and mental development. It has been found that if such patients be fed on thyroid glands, the growth and development can be again started. This seems to speak in favor of the idea that the action of specific substances may cause the post-adult growth of arms and legs in the case of acromegaly. It may, however, be a case of growth due to nervous influences comparable to the experiences of Przibram in Alpheus.

\section{The Effect of Some External Conditions upon Regeneration AND the Transformation of Organs}

If we cut a piece $a b$, Fig. 59, from the stem ss of Antennularia antennina (Fig. 60), a hydroid, and put it into the water in a horizontal position, new stems $c d$, Fig. 59, may arise on its upper side. The small branches on the under side of the old stem $a b$ begin suddenly to grow vertically downward.* In appearance and function these downward-growing elements are entirely different from the branches of the normal Antennularia; they are roots. In order to understand

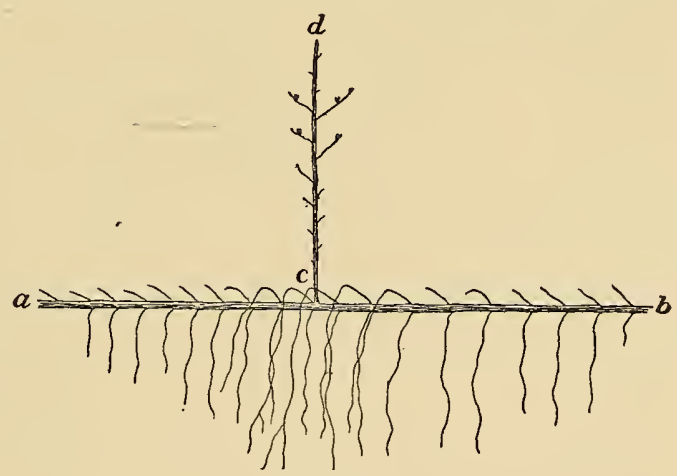

FIG. 59 . better the transformation which thus occurs in these branches, it may be stated that under normal conditions they have a limited growth (see Fig. 60), are directed upward, and have polyps on their upper side

* Loeb, Untersuchungen zur physiologische Morphologie der Thiere, II, I89I. 
(Fig. 60). The parts which grow down (Fig. 59) have no polyps, but attach themselves like true roots to solid bodies. Thus the changed position of the stem alone, without any operation, suffices to transform the lateral branches, whose growth is limited, into roots with unlimited growth. The lateral branches on the upper side of the stem do not undergo such a transformation except in the immediate surroundings of the place where a new stem arises. It seems that the formation of a new stem also causes an excessive growth of roots, possibly because the formation of new branches causes the removal of substances which naturally inhibit the formation of roots. If a piece from the stem be put vertically into the water with top downward, the uppermost point may continue to grow as a stem, while the lowest point may give rise to roots. In this case, therefore, a change in the orientation of organs has the effect of changing the character of organs.

We have already mentioned the fact that in Eudendrium the formation or regeneration of polyps is only possible in the light.

In many hydroids, contact with solid bodies seems to favor the formation of stolons, although such contact is not the only

FIG. 60 . condition that brings about this result. Figure 6 I shows a piece of a stem of Pennaria, a hydroid, which was lying on the bottom of an aquarium, and which formed

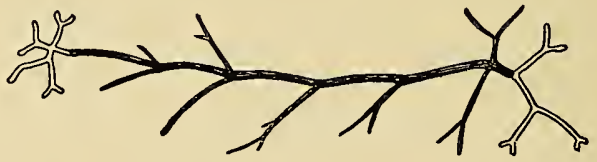

FIG. 6I. stolons at both ends. In Margelis, another hydroid, I observed that, without any operation, the apical ends of the branches which were in contact with solid bodies continued to grow as roots, while those surrounded by sea water continued to grow as stems.

\section{The Rôle of Reversible Processes in Phenomena of REGENERATION}

In all the cases mentioned thus far one point has not yet been discussed; namely, where the material of which the new organs consist comes from. In the case of plants, where the green leaves assimilate, and the salts are taken up from the soil or water, this source is evident, as it is also in the case of the animals which take up food; but in the 
case of a piece from the body wall of an Actinian which has no digestive organs, the material of the new tentacle can come only from one of two sources, viz. from the chlorophyll (or parasitic algæ?) which are contained in the ectoderm, or through a hydrolysis of material contained in the cells of the Actinian itself; this latter case would be comparable to Miescher's observation of the growth of the sexual glands at the expense of muscular tissue. In the case of the polyp formation in Tubularia, the transformation of the material of the stem into the polyp can be directly observed (Bickford, Driesch, and others). It is even doubtful in these cases whether a hydrolysis is necessary in any considerable amount, and it looks as if the tissues could be utilized directly for the formation of the polyp; some hydrolysis may however occur. In the above-mentioned case of the transformation of a branch of Antennularia into a root, the polyps that were on that branch first disappear. I cannot make any definite statement as regards their fate, but it is not impossible that the material of the polyps is used for the formation of the new roots.

I have observed more closely the transformation of an organ into more undifferentiated material in Campanularia, Fig. 62, a hydroid.* This organism shows a remarkable stereotropism. Its stolons attach themselves to solid bodies, and the stems appear on the side of the stolon exactly opposite the point or area of contact with the solid body. The stems grow, moreover, exactly at right angles to the solid surface element to which the stolon is attached. If such a stem be cut and put into a watch glass with sea

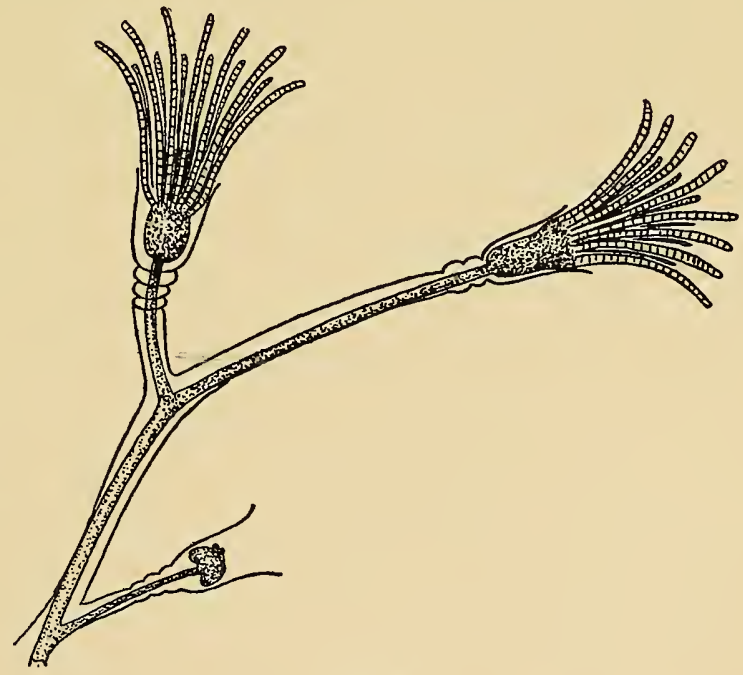

FIG. 62. water, it can be observed that those polyps which do not fall off go through a series of changes which make it appear as if the differentiated material of the polyp were transformed into undifferentiated material. The tentacles are first put together like the hairs of a 
camel's-hair brush (Fig. 63), and gradually the whole fuses to a more or less shapeless mass which flows back into the periderm, Fig. 64 . It follows from this that in this process certain solid constituents of the polyp, e.g. the cell walls, must be liquefied. I pointed out the analogy of these phenomena with Miescher's observations in the salmon. This undifferentiated material formed from the polyp may afterward flow out again, giving rise to a stem or a polyp; to the former where it comes in contact with a solid body, to the latter where it is surrounded by sea

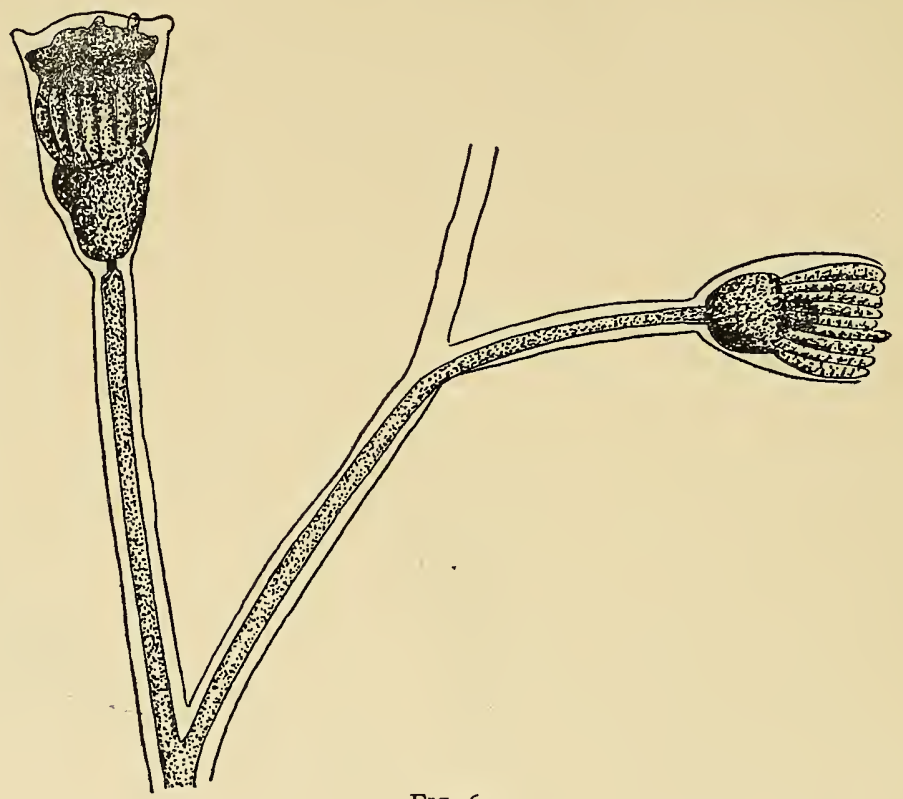

FIG. 63 .

water. This observation seems to indicate the possibility that the processes of organization are reversible, in some cases at least.

Giard and Caullery have found that a regressive metamorphosis occurs in Synascidians, and that the animals hibernate in this condition. The muscles of the gills of these animals are decomposed in their individual cells. The result is the formation of a parenchyma which consists of single cells and of cell aggregates resembling a morula.*

Driesch found that when he isolated Clavellina that part of the animal containing the gills underwent a retrogressive transformation similar to that observed by Giard and Caullery, and that afterward these masses gave rise to a new Ascidian. $\dagger$ The phenomena observed by

* I quote this after Driesch, Archiv für Entwickelungsmechanik, Vol, 14, p. 247, 1902.

$\dagger$ Driesch, loc. cit. 
Giard and Caullery, as well as the experiments of Driesch, resemble those in Campanularia, and Driesch also expresses the opinion that this is a case of reversibility of the processes of development.

The idea that the process of development is in certain forms reversible is also supported by the experiments of Frank Lillie on fresh-water Planarians. Lillie found that adult freshwater Planarians if exposed to starvation not only become gradually smaller in size but ultimately return to an embryonic form! These experiments have been repeated and confirmed by Schultze.

There is a possibility that a definite kind of chemical substances must be present in order to make development, regeneration, and growth possible. Such tissues as contain these substances (or mixture of substances) may be called embryonic. If this idea be correct, and if it be true that phenomena of development are reversible, - to a great extent in a few forms, and to some extent perhaps generally, - the question might be raised whether or not one of the conditions of regeneration is the transformation of adult tissue into more embryonic tissue. If this were true, the power of regeneration of an organism might depend upon the degree

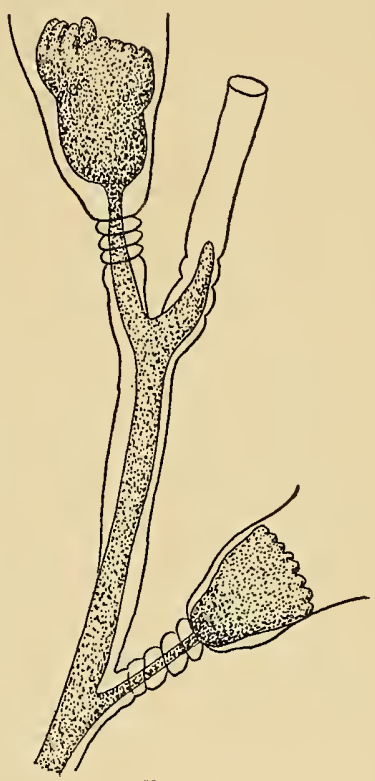

FIG. 64. of reversibility of the processes of development in such a form. It is certainly in harmony with such an idea that forms like Hydroids, Ascidians, and fresh-water Planarians, where the reversibility of the process of development is most outspoken, possess also the greatest power of regeneration among animals. The idea suggested is further supported by the fact that the power of regeneration by the embryo is often considerably greater than the power of regeneration of the same form in the adult stage. The tadpole of a frog is capable of regenerating a leg, while this is impossible in the adult frog.

This removes the contradictions into which we fall if we try to represent the power of regeneration as parallel to the position of an animal in the natural system. We find Annelids, such as the leech, whose power of regeneration is decidedly less than that of some vertebrates, e.g. the salamander. If we cut off the tail of the salamander, a complete regeneration of this organ with all its parts, bones as well as spinal cord, occurs. If we cut off a number of segments from a leech, the wound is 
covered with epidermis and thus heals, but no regeneration of the lost segment occurs. I have kept headless pieces of a leech alive for almost a year, without any trace of a regeneration occurring. We thus see that an Annelid may possess a much lower power of regeneration than a vertebrate.

It has been maintained that the power of regeneration is due to natural selection, and, therefore, runs parallel to the liability of an animal to injury. I do not believe that such ideas are of more value in biology than they are in physics or chemistry. It is not very obvious either why "nature" should care so much more to preserve the tail of a salamander than the foot of the leech. Morgan has treated this subject exhaustively, and I refer the reader to his writings.*

* T. H. Morgan, Regeneration, New York, IgoI ; and Evolution and Adaptation, New York, Igo3. 


\section{LECTURE XII}

\section{CONCLUDING REMARKS}

Biologrsts are confronted with two problems of transformation; namely, the artificial transformation of dead into living matter, and the artificial transformation of one species of plants or animals into another. Will it be possible to solve these problems? It is certain that nobody has thus far observed the transformation of dead into living matter, and for this reason we cannot form a definite plan for the solution of this problem of transformation. But we see that plants and animals during their growth continually transform dead into living matter, and that the chemical processes in living matter do not differ in principle from those in dead matter. There is, therefore, no reason to predict that abiogenesis is impossible, and I believe that it can only help science if the younger investigators realize that experimental abiogenesis is the goal of biology. On the other hand, our lectures show clearly that we can only consider the problem of abiogenesis solved when the artificially produced substance is capable of development, growth, and reproduction: It is not sufficient for this purpose to make proteins synthetically, or to produce in gelatine or other colloidal material round granules which have an external resemblance to living cells.

In this connection another problem may be mentioned; namely, whether there exists a natural death or, in other words, whether death is the necessary outcome of development, and whether rejuvenation and the beginning of a new cycle of life are impossible. In man and higher mammalians death seems to be caused directly or indirectly through microörganisms, or other injuries to vital organs. The example of certain plants, e.g. the Sequoia in California, shows that certain organisms may live thousands of years.

I pointed out a few years ago that the egg is a valuable object for the study of this problem. The process of fertilization of the egg is a life-saving act. The mature egg which is not fertilized dies as a rule very quickly under conditions under which the immature or the fertilized egg remains alive. If, e.g., fertilized and unfertilized eggs of the same female of Fundulus (a marine fish) are kept in the same vessel with sea water or distilled water, the fertilized eggs remain all alive and develop, while the unfertilized eggs die in a few hours and become putrid in a 
day or two. The case of starfish eggs is possibly still more striking. The egg of a starfish, Asterias Forbesii, is, as a rule, immature when taken from the ovary, and maturates when put into sea water. Very often not all the eggs of a female undergo maturation in sea water, and I have found that maturation can be inhibited by putting the eggs into slightly acid sea water. It was found that the eggs which maturate but are not caused to develop die in a few hours, while the eggs that are caused to develop or the eggs which fail to maturate (or are prevented from so doing) will not die, even if kept in the same dish of sea-water.* The eggs which are allowed to maturate, but are not caused to develop, die just as well in perfectly sterilized sea water, in which the eggs keep free from putrefaction for months, as in normal sea water or in sea water to which cultures of bacteria of putrefaction have been added. These and other facts indicate that in the mature egg processes occur which lead invariably to the death of the egg under circumstances under which the fertilized egg invariably keeps alive.

As far as the second problem of transformation is concerned, namely, the transformation at desire of one species into another, conditions are more favorable since De Vries has succeeded in actually observing the transformation of one species into another.

De Vries discovered in experiments which have been carried on since I886 in the most painstaking and laborious way, that from the seeds of a certain plant, Enothera Lamarckiana, there arise always a very small number of plants which differ from the mother plants in definite characteristics. $\dagger$ "These plants are from the very first true to seed!" De Vries thus discovered that new forms arise from Enothera Lamarckiana, not by gradual variation, as Darwin and Wallace had assumed, but by a sudden jump. As an instance, the origin of the species Enothera gigas from Enothera Lamarckiana may be mentioned. It originated in De Vries's culture of 1895 in a single specimen, and this first specimen was, as soon as it flowered, fertilized with its own pollen. The action of insects was absolutely excluded. The following spring the pure seed was sown (I897). The several hundred plants which thus originated all differed in the same way from CEnothera Lamarckiana, resembling the mother plant of Enothera gigas. The species has since remained constant. In the same sudden manner the other new species of Enothera originated from Enothera Lamarckiana. To this sudden, discontinuous form of evolution De Vries gave the term "mutation." The observations of De Vries also explain the fact which Darwin's idea of gradual evolution failed to explain; namely, that species can and usually do remain constant for thousands of years. The plants

* Loeb, Pfiügers Archiv, Vol. 93, p. 59, 1902.

† Hugo de Vries, Die Mrutationstheorie, Leipzig, r9or. 
found in Egyptian tombs do not differ from the species existing to-day. According to De Vries, a period of constancy may be followed by an explosive tendency to mutate, whereby new species arise suddenly, while the original species continues to exist.

The most important fact, however, from our point of view is the perfect harmony between De Vries's theory of mutation and Mendel's experiments on hybridization. The latter lead to the idea that hereditary characteristics are transmitted by specific determinants in the sexual cells, and that each characteristic must be represented by such a determinant in the sexual cells. No two forms can have a closer resemblance than corresponds to the difference between two determinants. If the latter are comparable to the members of a series of compounds, e.g. of alcohols, there is no more a transition possible between two species separated by a difference in only one determinant than there is a transition possible between the two neighboring alcohols of the same series. This means that evolution must be discontinuous, as De Vries has actually discovered it to be.

Not all the new species which originate from Enothera Lamarckiana are capable of existence. The first mutation De Vries observed was a form having pollen unfit for fertilization. It goes without saying that such a form cannot exist in nature. But other forms can exist, and do propagate side by side with Enothera Lamarckiana. The limitation for newly produced species is not the struggle for existence, but a faulty construction. The idea that mutation is working in a definite direction is a mere anthropomorphism, and like all anthropomorphisms is in contradiction with the facts. 



\section{INDEX}

Abiogenesis, 223.

Acids, effect on heliotropism, I 32 .

Action currents, 69 .

Alpheus, 215.

Amblystoma, galvanotropism in, I46. skin secretion caused by constant

Amoba, 57 . current, I03. imitation of movements of, $5^{6}$.

Amphipyra, stereotropism of, 157.

Amphoteric character of proteins, 35 .

Anæsthetics, 6.

Antagonistic effects of salts, 46 . of $\mathrm{K}$ and $\mathrm{Ca}$ salts, 86 .

of $\mathrm{Na}$ and $\mathrm{Ca}$ or $\mathrm{Mg}$ salts, 79 .

of salts with univalent cations and bivalent or trivalent cations, 47 .

Antennularia, geotropism of, I48. regeneration in, 217 .

Aphides, 4, I65, I87.

Araki, I8.

Arbacia egg, absence of complicated structure, I93.

artificial parthenogenesis in, I67. development of deformed egg, I93. effect of $\mathrm{NaHCO}_{3}$ on development of, 97 .

limit of divisibility of, 167 .

Arrhenius, I08, II3.

D'Arsonval, 55, 58.

Artificial hybridization, 162.

Artificial parthenogenesis, 165 .

Aspergillus, 72.

Assimilation in plants, effects of light of certain wave lengths, II5.

Associative memory. 6 .

Asterias, speedy death of unfertilized maturated eggs, 224 .

sperm of, used to fertilize eggs of sea urchin, I62.

Asterina, artificial parthenogenesis, I72. sperm used to fertilize sea-urchin egg, I62.

Astrospheres, orientation of, 65 .

Autoxidizable substances, I3.

Von Baer, I6r. 。

Bancroft, IO3, I4I.

Bardeen, 210, 2 I3.
Barium salts, effects of, on peristalsis, 93. on Polyorchis, 93.

on rhythmical contraction of muscle,

87.

on secretion, 93

Barrat, Ior.

Bataillon, I75.

Bateson, 186.

Van Bemmelen, 43.

Bernard, $2 \mathrm{I}$.

Bernstein, 55, 57, 69 .

Berthold, 57 .

Berzelius, 7.

Bicarbonates, rôle of, in preservation of life, 96,97 .

Bickford, Miss, 204.

Von Biebra, 4I.

Blasius, I 45 .

Blastomeres, differentiation of, ro6. isolated, development of, 30 .

Blue rays most effective in heliotropism, I 27.

Bock, 94.

Bordet, 23, I54, I82.

Born, I62, I90.

Boveri, 30, 60, I64, I8I, I94.

Brachystola, $\mathrm{I} 88$.

Bredig, 27, 37 .

Brenner, I45.

Broca, 19.

Brünings, 69 .

De Bruyn, 26.

Buchner, 2 I.

Budgett, 21, 104, I43.

Bugarsky, 96.

Buller, I 53 .

Bullot, 5I, I 75 .

Bunge, 23 .

Bütschli, 32 .

Butterflies, 139 .

larvæ of, I26.

Calcium precipitants, 8o.

in phenomenon of contact reaction, 83 .

Calcium salts, in muscular contraction, 79 . in coagulation of milk, 89 .

Campanularia, transformation of organs in, 219 .

Carbonates in blood, 96. 
Carbon dioxide, as plant food, 62 .

effect of temperature on production of, 108 .

production in active nerve, 68 . in cell division, 62 .

in lack of oxygen, in seeds, 22. in muscles in absence of oxygen, 23 .

Carroll, 27. through enzyme action, $2 \mathrm{r}$.

Castle, I64, I86.

Catalase, 27.

Catalytic artion, 8.

of lipase, 9 .

of platinum-black, II.

inhibited by poisons, 27 .

in respiration, 13 .

Catelectrotonus imitated through action of calcium precipitants, IO2.

Caullery, 220.

Cell division, chemical processes in, 6r. chromosomes in, 60 .

effect of temperature on, 59 .

oxygen in, 16.

physical phenomena of, 62 .

dependence on of size of cell, 59 .

Centrosome, 64 .

Cerianthus, 207, 209.

Chabry, 197.

Chetopterus, artificial parthenogenesis produced by $\mathrm{K}$-salts, I66, 174 .

Chemotropism, ${ }^{5} 5^{2}$.

biological significance of, 155 .

reaction of bacteria and Infusoria to oxygen, I 53 .

reaction of antherozoa of ferns to malic acid, 153 .

Chevreul, I07.

Child, 209, 2 I 3.

Chilomonas, chemotropism of, 154 .

Chlorophyl, I 5 .

Christen, 107.

Chromosomes, 60, 61, 176 .

Chun, I95.

Ciona, 209.

Cladocera, 187.

Clark, I49.

Clausen, I08.

Clavellina, 220.

Cleavage plane, centrosomes in relation to, 64 .

Hertwig's law, 64 .

Cohen, I Io.

Cohnheim, 23.

Colloidal character of living matter, I.

Colloidal solutions, 34 . electrical charge of, 34 . precipitation by salts, 36 . relation to cell life, 37 . amphoteric colloids, 35 .

Colloids, nature of, I, 33 . dissociated, 99.

Compensatory hypertrophia, $20 \mathrm{r}$.

Compensatory motions, I49.
Conklin, 196.

Consciousness, 6.

Constant current, 99.

stimulation at cathode on making, 99, 102.

stimulation at cathode in Infusorians, I03.

disintegration by, $\mathbf{1 0 3 .}$

Contact irritability, produced by substances which precipitate calcium, 83 . effect of K-salts on, 84 .

Copepods, heliotropism of, 129. phosphorescence of, 67 .

Correlation in regeneration, 2 I 3 .

Correns, 183 .

Cottrell, 95 .

Crampton, I9I, I96.

Cramer, 107.

Cremer, 12, 25, I 76.

Ctenolabrus egg, effect of lack of oxygen, I 7, 19 .

Ctenolabrus, heart of embryo, I9.

Ctenophores, structure in egg of, 195.

Cucumaria, geotropism of, 149 .

Cuénot, 186.

Cushny, 93.

Von Cyon, 217.

Cytotropism, 159 .

Czapek, I48.

Darwin, I19, 225.

Death, natural, 4, 223 .

Delage, I5I, I52, 164, I 73, I79, I86.

Dentalium, I97.

Determinants, in heredity, 3,184 . in the sexual cells, 225 .

Development, rate affected by temperature, IIo.

Dewitz, I53, I56, 166.

Dinophilus, 187 .

Disoxidizable substances, I 3 .

Distilled water, toxicity of, 46, 51 .

Divisibility of living matter, 29 .

Dominant characteristics, 184 .

Driesch, 30, 59, 6r, 64, I I5, I58, I81, 192, 194, 220.

Duclaux, Ir, I6, 106, I I3.

Duhamel, 200.

Van Duyne, 2 II.

Dzierzon, I65.

Earthworm, regeneration in, 214 .

Egg structure, 2, 3I, I01, I94, 195. simple character of, 193, 195 .

Ehrlich, 23.

Electrical phenomena, in muscle and nerve, 68.

in plants, 69 .

general occurrence in connection with life processes, 70.

Electrical stimulation, 98 .

by constant current, 99 .

by induction, 99 . 
Electrical stimulation (continued)

in Infusoria at cathode of constant current, I03.

Electrolytes in liquids of the body, 68 . rôle of in living matter, $7 \mathrm{I}-\mathrm{I} 06$. rhythmical contractions only in, 78 .

Elvove, I 9 .

Embryos, from deformed eggs, 193. from fused eggs, 194.

from isolated blastomeres, I92.

Emulsion structure of protoplasm, 3 $\mathrm{r}$.

Engelmann, I7, 54, $\mathrm{I}_{53}$.

Engler, I4.

Enzymes, stereochemical theories of, 24 . theory of intermediary reactions, 26. reversible action of, 9 .

Eudendrium, effect of light in organ formation, II 5 .

heliotropism of, $\mathrm{I} 20$.

Ewald, 2 I5.

Eyes, compensatory motions of, I 49 .

Faraday, 66.

Farkas, 95 .

Fermentation, alcoholic, $2 \mathrm{I}$.

Fertilization, I6I.

membrane, I 62 .

produced in unfertilized eggs by fatty acids, 168.

produced by hydrocarbons, r6g.

formation of, antagonized by $\mathrm{H}$-ion, 170.

Fischel, 195.

Fischer, Aiffred, 37, 65 .

Fischer, Emil, 24.

Fischer, M. H., 94.

Foam structure, $3 \mathrm{r}$.

Forteg, II4.

Fraenckel, 95 .

Freundlich, 35, 36 .

Friedenthal, 95, 182 .

Fundulus egg and embryo, effect of lack of oxygen, 17.

effect of salts, 46,50 .

effect of distilled water, 45 .

Fungi, nutritive solutions for, 7 I.

Galvani, 68 .

Galvanotropism, I40.

in Amblystoma, 146.

in Palomonetes, I44.

in Paramcecium, $\mathbf{1 4 2}$.

in Polyorchis, I4I.

in seedling plants, 145 .

Gammarus, 46, 50, 5I, 74, 77, 97, I28.

Ganglion cells, effect of lack of oxygen, 18.

Garrey, 'I54.

Gaule, 97 .

Gels, I, 37 .

Geotropism, 147 .

in Antennularia, 148 .

in Cucumaria, 149 .

in crustaceans, I49.
Geotropism (continued)

in plants, 147 .

possible connection with internal ear, "I 5 I.

Geppert, 21, 27.

Gerassimow, 59 .

Giant embryos, I94.

Giard, 220.

Gies, 175 .

Giesebrecht, 67 .

Glycogen, I 2.

Godlewski, 1 7, 22, 204.

Goltz, 6, 150, I58, 2 I 5 .

Gonionemus, 8I, 9 r.

Gordon, 50.

Gotschlich, I47.

Graham, I.

Greeley, II 2 .

Growth, need of oxygen in, I 7 .

Gruenbaum, 182 .

Guyer, I86.

Hamburger, 44.

Hardesty, 2 I.

Hardy, 3I, 32, 33, 35, 43.

Harless, 4I.

Heart of Ctenolabrus embryo, 20.

Heartbeat, conditions in normal, $9 \mathrm{I}$. reaction velocity in, I09.

Heat, effects of, ro6.

biological effects, $\operatorname{rrr}$.

chemical effect, Io6.

coagulation of proteins, 107.

coagulation of colloids a function of time, 108 .

effect on coefficient of partition, III. poisons, activity of, influenced by, III.

Heliotropic reactions, sense of, Izo.

reaction velocity in, I3o.

effect of differences of intensity of light, $\mathrm{I} 3 \mathrm{I}$.

sense of heliotropism reversed by chemical substances, I 3 I.

changes in intensity of heliotropism by chemical substances, I 32 .

intensity of reaction at certain stages in life history, I33.

sense of reaction changed in certain stages of development, I33.

in larvæ of Limulus, I33.

effect of temperature on sense of reaction in Polygordius, and in Coppods, I33.

effect of light on sense of reaction in nauplii of Balanus, I 34 .

Heliotropism, of sessile organisms, II 7 . green, blue, and violet end of spectrum most effective, II 7 .

theory of heliotropic bending, 118 .

in Eudendrium, 120.

in Spirographis, 122.

in Serpula, I23. 
Heliotropism (continued)

of free-moving organisms, I24.

in larvæ of Eudendrium, I25.

in Aphides, 126.

in caterpillars of Porthesia, 126.

direction of motion determined by direction of light rays and not by intensity, 126 .

negative heliotropism in animals, I 28 .

Helmholtz, 53 .

Hemiptera, spermatozoa of two kinds in, I 88.

Hemolysis, 182 .

Henking, I 88.

Herbst, 75,158, I69, 213.

Hereditary effects of the spermatozoön and the egg, r 7 ?.

Heredity, prevailing influence of the egg in early stages of development, I 79 .

influence of egg and spermatozoon in adult, 180 .

influence of the nucleus in, 180 .

Mendel's experiments, I8o, 183 .

chemical compounds in, 180 .

determination of sex, 186 .

egg structure in heredity, I9I.

Hermann, 22, $58,70,145$.

Hertwig, O., I 1о, I 79 .

Hertwig, O. and R., 64, 65, 164, 166, I69.

Hertwig, R., 63, 166.

Hertzian waves, I I 2 .

Herzog, I3.

Heteromorphosis, $20 \mathrm{I} \mathrm{ff}$.

in Ciona, 209.

in Planarians, 2 Iо.

Hildebrandt, I 24 .

Hill, 9, I I, I2.

Hippiscus, 188 .

Höber, 44, 5०, 95.

Van't Hoff, 108.

Hoffmann, 94.

Holmes, I 34, I $39, x_{5} 8$.

Hoppe-Seyler, I6, I I4.

Hybridization, 3, I6 I ff.

in vertebrates, $16 \mathrm{r}$.

Mendel's experiments, 183 .

heterogeneous, in Echinoderms, 162.

Hydatina, I go.

Hypertonic solutions, nuclear division in, 63.

in artificial parthenogenesis, 170.

Hypophysis, 216.

Imbert, 55,57 .

Instinctive reactions, 158 .

Instincts, 5, 186, 189 .

Ion-colloids, 82, 95 .

Ion-proteids, 78,167 .

Irritability, theory of, 78 .

Jacquet, I4, I5.

Janssens, I64.
Jennings, 155 .

Jones, 27.

Jorissen, I 4 .

Kastle, 9, IO, I I, I4, I9, 26, 28.

Kellogg, I33, I90.

Kirchoff, 8.

Knight, I47.

Knop's solution, 7r.

Kofoid, 196.

Kölliker, 66.

Korschelt, 187 .

Kostanecki, I75.

Krafft, 34.

Kreidl, I5I, I52.

Kühne, I03.

Kulagin, I 66.

Kuliabko, 18.

Kutscher, 12.

Laminaria, 206.

Landois, 182.

Lanice, 196.

La Place, 7 .

Lavoisier, 7 .

Lefevre, I 74 .

Lenhossék, I 87.

Lens, regeneration of, 215 .

Leuckart, 165.

Leuwenhock, I6I.

Lewis, 215 .

Liebermann, 96.

Liebig, 24.

Von Liebig, G., 22.

Light, photochemical effects, II 3 .

effect on assimilation in green plants, II4.

waves effective in assimilation, II5. heliotropic effects, II 7 .

waves most effective in heliotropism, I I 7 .

reactions of animals to changes of intensity, $\mathrm{I} 35$.

Lillie, Frank, I 75 .

Lillie, Ralph, r6, 65 .

Limulus larvæ, negative heliotropism in, I 28 .

reversal of heliotropism, 133 .

Linder, $5 \mathrm{I}$.

Lingle, 8I, 83 .

Lipase action, reversible, 9 .

imitated by platinum-black, I I.

Liquefactions in absence of oxygen, 20.

Living matter, limit of divisibility, 29. foam structure and emulsions, $3 \mathbf{I}$. colloidal character of, 3.3 .

Locke, 5I, 76 .

Loevenhart, 9, 10, II, I4, 26, 28, 88 .

Loew, 26.

Ludloff, I42.

Lymnans, I06.

Lyon, 62, ${ }_{150}{ }_{152}, 159$. 
MacCallum, 44, 93.

Mach, I 45, I5I.

Maltase, I I.

Margelis, $2 \mathrm{I} 8$.

Massart, 154 .

Mathews, 92, 173 .

Maupas, I90.

Maxwell, IO3, I44, I57.

Mayer, 53.

McClung, I88, 190.

Mead, I66.

Medusa, analogy of contractions to heartbeat, $8 \mathrm{I}$.

Membrane, fertilization, I62.

Membranes of precipitation, 38 .

Mendel, 3, I80, I83, I84, I86.

Von Mering, 23.

Merogony, I64, I79.

Metabolism, different in presence and in lack of oxygen, 18.

Metal proteids, 78 .

Meyer, 6, 40, 216.

Miescher, 4 .

Minkowski, 23.

Mollusks, artificial parthenogenesis in, 175 .

Morgan, 59, 63, I59, I64, I66, I92, I94, 206, $210,213,214,222$.

Mortality of hybrids, 183 .

Müller-Hettlingen, I45.

Muscle, electrical phenomena in, 68. $\mathrm{CO}_{2}$ produced in, 68 . tone affected by $\mathrm{K}$ and $\mathrm{Ca}, 86$.

Muscular contraction, $5^{2}$. hypotheses of, 53 .

Engelmann's hypothesis, 54 .

Bernstein's hypothesis, 57 .

Imbert's hypothesis, 57 .

Mutation theory, De Vries', 3, 224.

Narcotics, 40.

Negative wave, I69.

Neilson, I I.

Nereis, stereotropism of, 157 .

Nernst, 40, 100.

Nerve, $\mathrm{CO}_{2}$, produced in, 68. electrical phenomena, 68 . impulse, 70 .

Nervous disease, possible chemical cause of, 92 .

Nervous system, influence on regeneration, 213,216 .

may convey chemical substances, 2 I 6 .

Norman, 63, 166.

Nuclear membrane, 65 .

Nucleus, in cell division, 60 . division of, without division of protoplasm, 63.

in heredity, 180 .

Nussbaum, I6, 29, I65, 190.

Nutritive solutions for green plants, $7 \mathbf{I}$. for fungi, 72 .

for animals, 74 .

Nuttall, 182.
Ocneria, 190.

Enothera, 224.

Oker-Blom, 69 .

Oligodynamic effects, 73 .

Ophelia, artificial parthenogenesis in, I75.

Organisms as chemical machines, $I$.

Ortloptera, spermatozoa of, 188 .

Osmotic pressure and exchange of liquids between the cells and surrounding liquids, $4 \mathrm{I}$.

effect on cell division, 63 .

Osterhout, 207 .

Ostwald, Wilhelm, 8, 9, 69 .

Ostwald, Wo., 5I, 97, I49.

Otolith organs, I5I.

Oudemans, I9o.

Overton, 6, 40.

Oxidases, I3.

Oxidation, in living matter, $7, \mathrm{I} 3 \mathrm{ff}$.

through peroxides, I4.

in mature egg, 177 .

Oxygen, in cell division, 16.

in fermentation, $I 6$.

in segmenting eggs, I 7 .

in growth and regeneration, 17 .

in Infusorians, $2 \mathrm{I}$.

in phosphorescence, 67 .

in rhythmical contraction of heart muscle, 82 .

as a protective substance, 18 .

irreversible changes in lack of, I8.

bacterial poisons more virulent in absence of, I9.

structural changes in lack of, Io.

effect of certain poisons resembles effect of lack of oxygen, 21 .

Palamon, otoliths in, $\mathbf{I} 5 \mathbf{I}$.

Palcmonetes, galvanotropism in, I44.

Parancecium, galvanotropism in, I42.

Parker, I39.

Parthenogenesis, natural, in Aphides, 165.

in bees, 165 .

in starfish, 173 .

artificial, by raising concentration of sea water, I67.

in Chatopterus by addition of a $\mathrm{K}$-salt, $\mathrm{I} 74$.

in asterias, 173 .

in Strongylocentrotus, $167 \mathrm{ff}$.

in Thalassema, 174 .

in Ophelia, I75.

in mollusks, I 75 .

in vertebrates, 175 .

Pasteur, I7, 19, 21, 24 .

Pauli, 32, 78, I08.

Pemsel, 96.

Pennaria, $2 \mathrm{I} 8$.

Permeability of plant cells, $4 \mathrm{I}$. of muscle, 42.

Peroxides in oxidation processes, I4.

Petromyzon, I75.

Petrunkewitsch, I65. 
Pfeffer, 153.

Pflüger, 66.

Phosphorescence, 66.

Photochemical reactions, in assimilation in plants, II4.

in heliotropism, I I9.

Pictet, III.

Picton, 5 I.

Piéri, I 75 .

Pigment granules in Tubularia, 205.

Planarians, reactions to light, $\mathrm{I} 36$.

heteromorphosis and regeneration in, 210.

Planorbis, 196.

Plants, nutritive solutions for, $7 \mathrm{I}$.

Platinum-black, enzyme action of, II.

Polarity in Tubularia, due to a current, 203.

Polygordius, heliotropism in, 133 .

Polyorchis, effect of ions on, $87,88,91$. galvanotropism in, I4I.

Poizeniusz, 22.

Porthesia, heliotropism of, 126.

Potassium, non-dissociable compounds with protoplasm, 73 .

Prentiss, 152.

Protective solutions, 77 .

Proteins, amphoteric character, 35.

Proteolytic enzymes, general occurrence of, 12 .

Protoplasm, structure of, 3 I.

Protoplasmic motion, 55.

Przibram, 2 I 5.

Psychology of lower forms, 158 .

Purgative effects of salts, inhibited by $\mathrm{Ca}, 93$.

produced by $\mathrm{Ca}$ precipitants, 93 .

Purkinje, I45.

Pycnopodia, I62.

Pyrrhocoris, spermatozoa of, I88.

Quincke, 32, 38, 40, 55 .

Radiant energy, origin of in organisms, 66 general effects on living matter, II2.

Radiation pressure, I I 3 .

Rádl, I I3, I5०.

Radziszewski, ${ }^{7} 7$.

Ramsden, 38 .

Raulin, 72, 79 .

Rayleigh, 32.

Reaction of living matter, 95.

of sea water, 95 .

effect of green plants on, 08 .

Reaction velocity, effect of heat on, 108 . in biological processes, 109.

in heartbeat, rog.

in heliotropism, $\mathbf{z} 3$.

Recessive characteristics, 184 .

Regeneration, in plants, 200, 207.

in Cerianthus, 207.

in Planarians, 2 IO.

in earthworm, 214.

influence of central nervous system, 2 I 3 .
Regeneration (continued)

correlation in, 2 I 3 .

effect of external conditions or, 2 I 7 .

distribution in animal kingdom, $22 \mathrm{I}$. and natural selection, 222 .

Regenerative processes, I99.

Reid, 34 .

Respiration as a catalytic process, I3.

Reversible processes, in enzyme action, 9. in regeneration, 218 .

in Campanularia, 2 I9.

in Planarians, 22 I.

Rheotropism, 159.

Rhythmical contractions, of skeletal muscie, 78 .

effects of salts of univalent metals, 78 .

effects of $\mathrm{Ca}$ and $\mathrm{Mg}, 79$.

absence in non-electrolytes, 82 .

effect of Ba salts, 87 .

Richardson, I I 4 .

Richet, I9.

Ringer, 87.

Ringer's solution, 75 .

Rogers, 75, 97.

Romanes, 80.

Rotifers, 187 .

Roux, 64, 66, I59.

Rusch, 76.

Sachs, 59, I21, I99, 200, 201.

Salmon, 4, 198.

Salts, antagonistic effects of, $46,75 \mathrm{ff}$. diffusion into cells, 42 .

Schmiedeberg, I 7, 93 .

Schoenbein, 2 I, 24, 27, II4.

Schultze, I97.

Schweitzer, 145.

Secretion, 44,50 . produced by galvanic current, 93 . produced by Ca precipitants, 93 . formation of egg membrane resembles secretion, 174,177 .

Segmentation, need of oxygen in, I 7 .

Selective power of cells, 72 .

Semicircular canals, 150.

Semipermeable membranes, 39, 69, IоI.

Sensory nerves, irritability increased by Ca precipitants, $9 \mathrm{I}$.

Sequoia, 5, 223.

Serpula, 123 .

Setchell, го6, гіг.

Sex, determination of, 186 .

in $\mathrm{egg}, \mathrm{I} 87$.

in spermatozoön, 188 .

attempts to influence, 190.

Sexual characters, secondary, 190.

Siebold, I 65 .

Snyder, I09.

Sodium, unimportant for plants, 72 .

importance in muscular contractions, 79.

Sols, I.

Spallanzani, I6r. 
Specics, transformation of, 224 .

Speck, 6.

Spemann, 2 r5.

Spermatozoa, stereotropism of, $\mathrm{I}_{5} 6$. specific nature of, $162, \mathrm{r}_{3}$. effect of alkali on, 163 . nature of action, 176,178 .

Spiro, 96.

Spirographis, I22.

Spitzer, 15 .

Starling, 34.

Starvation, effect on Planarians, 221.

Stereochemistry and enzymc action, 24.

Stereotropism, I55 ff.

in spermatozoa of Periplanata, ${ }_{5} 6$. in Tuhularia, ${ }_{5} 6$.

in Amphipyra, ${ }^{157 .}$

in worms, 157 .

Stevens, Miss, 206.

Stimulation, 98, 105, I8o.

Stoklasa, 22.

Strassburger, I30.

Streaming phenomena, 65, 204.

Strongylocentrotus eggs, fertilization imitated artificially, 2, ${ }^{6} 67 \mathrm{ff}$.

structure of, $3 \mathrm{r}$.

effect of electroiytes on development of, 75 .

effeci of $\mathrm{NaHCO}_{3}$ on development of, 75,97 .

fertilized with starfish sperm, I62.

Surface films, 32,38 .

Surface tension, 55 .

in protoplasmic motion, 55 .

in muscular contraction, 57 .

in fertilization process, 163 .

Taylor, 9, то.

Temperature, upper limit of life, ro6. coagulation of proteids, 107 .

effect on reaction velocity, 108.

effect on $\mathrm{CO}_{2}$ production, 108 .

effect on rate of heartbeat, Iog.

effect on development of frog's eggs, IIo.

lower limit of life, rto.

other biological effects, II2.

effect on heliotropism, $13 \mathrm{r}$.

Tetanus toxin, 216.
Thalassema, 174 .

Thénard, 8.

Thigmotropism, I55.

Thyroid gland, 2 r6.

Tichomiroff, 165 .

Towle, Miss, I34.

Transfusion of blood, 182 .

Traube, 13, 24, 33, 38, 45 .

Traube's artificial membranes, 39.

Tropeolum, I99.

Tropisms, 5 . theory of, ${ }^{3} 3^{8}$.

Tschagovetz, 69 .

Tschermak, 183 .

Tubularia, necessity of oxygen in regeneration, I 7 .

influence of bicarbonates on, 96 .

stereotropism of, ${ }_{15} 6$.

regeneration in, 202 .

polarity in, 202.

heteromorphosis, 203 .

Turgidity in tentacles of Cerianthus, 208.

Twins, 186.

Verworn, I42.

Vogel, II 3, II4.

Volta, 68.

De Vries, 3, 183, 186, 224, 225 .

Waller, 68, 70.

Warburg, IOI.

Whitman, I97.

Wild, I 4 .

Willow twig, regeneration in, 207.

Wilson, 32, 178, 189, 192, 196, 216.

Winkler, 175 .

Winter eggs, 187 .

Woehler, 7 .

Wortmann, II9.

Yeast, I2.

Yōung, $2 \mathrm{r}$.

Von Zeynek, Iог.

Zinc, in nutrient solution for Aspergillus, 73 .

Zoethout, 84, 86.

Zur Strassen, 194 .

Zymase, 2 I. 



\section{COLUMBIA UNIVERSITY BIOLOGICAL SERIES}

Discussions of Current Biological Problems. Modern Text and Reference Works. Adapted for General Reading, also for Advanced Courses in High Schools,

Colleges, Universities, and Medical Schools. Founded upon

University Courses of Lectures delivered at Columbia

EDITED BY

\section{HENRY FAIRFIELD OSBORN and EDMUND B. WILSON}

Published in 1894. Second Edition, 1897

\section{Vol. I. FROM THE GREEKS TO DARWIN}

\section{An Outline of the Development of the Evolution Idea}

By Henry FAirfield Osborn, LL.D., D.Sc., DaCosta Professor of Zoology, Columbia University. 250 pages. $\$ 2.00$, riet.

I. The Anticipation and Interpretation of Nature. II. Among the Greeks. III. The Theologians and the Natural Philosophers. IV. The Evolutionists of the Eighteenth Century. V. From Lamarck to St. Hilaire. VI. Darwin. Index.

"But whether the thread be broken or continuous, the history of thought upon this all-important subject is of the deepest interest, and Professor Osborn's work will be welcomed by all who take an intelligent interest in Evolution. Up to the present, the pre-Darwinian evolutionists have been for the most part considered singly, the claims of particular naturalists being urged often with too warm an enthusiasn. Professor Osborn has undertaken a more comprehensive work, and with well-balanced judgment assigns a place to each writer." - Professor Edward B. Poulton, in Nature, London.

Published October, 1894. NOW OUT OF PRINT

\section{Vol. II. AMPHIOXUS AND THE ANCESTRY OF THE VERTEBRATES}

By ARTHUR WILLEV, Sc.D., formerly Balfour Student of the University of Cambridge; Tutor in Zoölogy, Columbia University; now Curator of the Museum of Colombo, Ceylon. 316 pages ; I36 iilustrations. Price $\$ 2.50$, net.

Contents. - Introduction. I. Anatomy of Amphioxus. II. Anatomy of Amphioxus (cont.). III. Development of Amphioxus. IV. The Ascidians. V. The Protochordata in their Relation to the Problem of Vertebrate Descent.

"The observations on Amphioxus made before the second half of the present century, amongst which those of Johannes Muller take a foremost place, showed that this remarkable animal bears certain resemblances to Vertebrates; and since then its interest in this respect has gradually become more apparent ... A consecutive history of the more recent observations was, therefore, greatly needed by those whose opportunities did not permit them to follow out the matter for themselves, and who will welcome a book written in an extremely lucid style by a naturalist who can speak with authori y on the subject." - Professor W. NEWTON PARKER, in Nature, London.

Publlshed June, 1895. NOW OUT OF PRINT

\section{Vol. III. FISHES, LIVING AND FOSSIL}

\section{An Introductory Study}

By BAShFord DEAn, Ph.D., Professor of Vertebrate Zoölogy, Columbia University. 300 pages ; 344 illustrations. Price $\$ 2.50$, net.

Contents. - I. Introductory. The form and movement of Fishes. Their classification ; geological distribution; mode of evolution. The survival of generalized forms II. The evolution of Structures characteristic of Fishes; e.s. (I) gills, (2) skin defences, teeth, (3) fins, and (4) sense organs III. The Lampreys and their allies; their structures and probable relationships. The Ostracoderms and Palæospondylus. IV. The Sharks. Their plan of structure; prominent forms, living and extinct; their interrelationships. V. The Chimæroids. Their characteristic structures, their representatives and relationships VI. The Lungfishes. Their structures; extinct and recent forms; the evolution of the group. VII. The Teleostomes ( $i$ e. Ganoids and Teleosts). Typical members; their structures and interrelationships; their probable descent. VIII. The Groups of Fishes contrasted from the Standpoint of Embryology. Their eggs and breeding habits. Outlines of the development of Lamprey, Shark, Lung-fish, Ganoid, and Teleost. Their larval development. Derivation of Names. - Bibliography. - Explanatory Tables. - Index.

This work has been prepared to meet the need of the general student for a concise knowledge of the living and extinct Fishes. It covers the recent advances in the comparative anatomy, embryology, and palæontology of the five larger groups of Lampreys, Sharks, Chimærords, Teleostomes, and Dipnoans - the aim being to 
furnish a well-marked ground plan of Ichthyology. The figures are mainly original and designed to aid in practical work as well as to illustrate the contrasts in the development of the principal organs through the five groups.

"Dr. Bashford Dean is known to zoologists, first, as the author of exhaustive and critical articles in the publications of the United States Fish Commission, on the systems of oyster culture pursued in Europe; and secondly, as an embryologist who has lately been doing good work on the development of various Ganoid fishes and the comparison that may be instituted with Teleostei. His recent addition to the well-known 'Columbia University Biological Series,' now being brought out by The Macmillan Company, under the editorship of Professor H. F. Osborn, is an interesting volume upon fishes, in which considerable prominence is given to the fossil forms, and the whole subject is presented to us from the point of view of the evolutionist. This is the characteristic feature of the book. From the very first page of the Introduction to the last page in the voltime, preceding the index, which is a table of the supposed descent of the groups of fishes, the book is full of the spirit and the language of evolution."- Professor W. A. Herdman, in Nature, London.

\section{Published in 1896. Second Edition Revised and Enlarged 1900}

\section{Vol. IV. THE CELL IN DEVELOPIMENT AND INHERITANCE}

By EDmund B. Wilson, Ph.D., LL.D., Professor of Zoölogy, Columbia University. 370 pages; $\mathrm{I}_{4} 2$ figures in the text. Price $\$ 3.50$, net.

Introduction. Chapters: I. General Sketch of the Cell. II. Cell Division. III. The Germ Cells. I 7 Fertilization of the Ovum. V. Reduction of the Chromosomes, Oofgenesis and Spermatogenesis. VI. Some Problems of Cell Organization V11. Some Aspects of Cell Chemistry and Cell Physiology. VIII. CellDivision and Development. IX. Theories of Inheritance and Development.

" During the few years which have elapsed since the appearance of the first edition of Professor Wilson's book on the cell, the rapid accumulation of new facts has resulted in the modification, in many important respects, of the views which were enterrained concerning many cell phenomena even so lately as five years ago. Hence, though the volume before us is issued as a second edition, it has not only been considerably enlarged, but also much of the original matier has been replaced to make room for new treatment which shall more faithfully reflect the attitude of cytologists teward the problems which confront them at the present time. And we may fairly say, that the author's efforts have not only been largely successful, but they have resulted in the production of one of the best works which it has been our good fortune to meet with for a long time. The whole subject is handled in an easy and masterly fashion, and the reader is enabled readily to grasp the leading facts and to obtain a clear insight into the nature of the chief questions of cytological importance." J. B. FARMER, Nature, IgoI.

\section{Published in 1899 \\ Vol. V. THE FOUNDATIONS OF ZOÖLOGY}

By William Keith Brooks, Ph.D., LL.D., Professor of Zoölogy in the Johns Hopkins University. 339 pages. Price $\$ 2.50$, net.

Contents. - Lectures I. Introductory. II. Huxley and the Problem of the Naturalist. III. Nature and Nurture. IV. Lamarck. V. Migration in its bearing on Lamarckism. VI (I) Zoology and the Philosophy of Evolution. V1. (iI) An Inherent Error in the Views of Galton and Weismann on Inheritance. VII. Galton and the Statistical Study of Inheritance. VIII. Darwin and the Origin of Species. IX. Natural Selection and the Antiquity of Life. $X$ Natural Selection and Natural Theology. XI. Paley and the Argument from Contrivance. X1I. The Mechanism of Nature. XIII. Louis Agassiz and George Berkeley.

"It is a peculiar pleasure to a British naturalist to find the Darwinian principle illustrated and defended with sich remarkable force and success by a distinghished American zoologist." -Nature, October I8, Inoo.

"Brooks' lectures on 'The Foundation of Biology'constitute a book that will live as a permanent addition to the common sense of science. It belongs to literature as well as to science. It belongs to philosophy as much as to either, for it is full of that fundamental wis lom about realities which alone is worthy of the name of philosophy." - Science, April I4 1899.

"Without copious extracts it is impossible to do justice to this masterly presentation of the subject. The chapter abounds in aphorisms as indeed do other portions of the work; and these alone, if serially collected with their contexts, would make a valuabie little handbook for the student of biology." - Popular Science Monthly. June, r89g.

\section{Published in 1901}

\section{Vol. VI. THE PROTOZOA}

By Gary N. Calkins, Ph.D., Professor of Invertebrate Zoölogy, Columbia University; Biologist, State Cancer Laboratory, Buffalo, N.Y. 347 pages. Price, \$3.00, net.

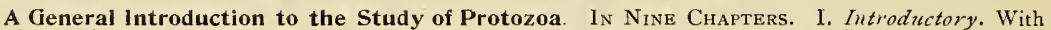
historical review: modern classification: animals and plants, and generation de novo. II. General Sketch. Including general morphology; general physiology, and economic aspects. IlI. The Sarcodina. Shells and tests, and special locomotor and other organs. IV. The Mastigophora. General and special organization. V The Spirozoa. General and special organization; mode of life, and relations VI The lufusoria. General organization of ciliata and suctoria. V1lI. Sexual Phenomena. Significance of conjugation and rise of sex. VIII. The Protozoan Nuclens. Special Morphology. The phylogenetic relations of the nucleus and mitotic figure. IX Some Problens in the Physiolosy of the Protozoa. The phenomena of digestion. respiration, secretion, and irritability.

"The author has not aimed at putting forward an exhaustive, severely scientific treatise upon the group in question. His work may be described rather as a simple and intelligible introduction to the study of the Protozoa and of the many fascinating biological problems connected with, or illustrated by, this subdivision of the animal kingdom, in such a way as to awaken the interest of the beginner, no less than to strengthen the hands of the expert." - Nature. 


\title{
Vol. VII. REGENERATION
}

By Thomas Hunt Morgan, Professor of Experimental Zoölogy, Columbia University. 316 pages; 66 illustrations. Price $\$ 3.00$, net.

Contents. - I. General Introduction. I1. The External Factors of Regeneration in Animals. III. The Internal Factors of Regeneration in Animals. IV. Regeneration in Plants. V. Regeneration and Liability to Injury VI. Regeneration of Internal Organs. Hypertrophy. Atrophy. VII. Physiological Regeneration. VIII. Self-division and Regeneration. Budding and Regeneration. Autotomy. Theories of Autotomy. IX. Grafting and Regeneration X. The Origin of New Cells and Tissues. XI. Regeneration in Egg and Embryo. XII. Theories of Development, XIII. Theories of Regeneration. XIV. General Considerations and Conclusions.

"The high character of the Columbia University Biological Series is more than maintained by its latest publication - Professor Morgan's book on 'Regeneration.' It is rare indeed to find a book which colltains so large an amount of research work and which is at the same time of such general interest and importance. This is no mere discription of the peculiar and bizarre 'dime museum experiments' of experimental zoology, but rather a thorough treatise on some of the more important methods and results of the new morphology.

"In this work the author has been one of the most productive and at the same rime one of the most careful investigators. He saw, as apparently few others did, that the development of fragments of eggs and embryos was at bottom the same problem as the regeneration of parts of adult organisms, and during the past ten years he and his pupils have done a surprising amount of work on the regeneration of embryos and adults. There is probably no other living man so well fitted to treat this subject."-Science, April, Igoz.

\section{ORDER FORM, COLUMBIA UNIVERSITY BIOLOGICAL SERIES}

\section{THE MACMILLAN COMPANY, 64 and 66 Fifth Avenue, New York}

\author{
or
}

MACMILLAN \& COMPANY, Ltd., London, England

Please send the undersigned,

Vol. I. From the Greeks to Darwin. OSBORN . . . . . \$2.00, net

Vol. IV. The Cell in Development and Inheritance. WILSON . . 3.50, net

Vol. V. The Foundations of Zoology. BROOKS .

Vol. VI. The Protozoa. CALKINS.

Vol. VII. Regeneration. MORGAN

Vol. VIII. Dynamics of Living rlatter. LOEB

NEW VOLUMES IN PREPARATION, 1906

Vol. IX. Structure and Habits of Ants. Professor W. M. WHEELER, of the American Museum of Natural History, Lectures delivered in 1905

Vol. X. Behavior of the Lower Organisms. Professor H. S. JENNINGS, of the University of PenasyJvania, Lectures to be delivered in 1906.

Please find enclosed check or postal order for
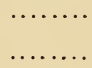








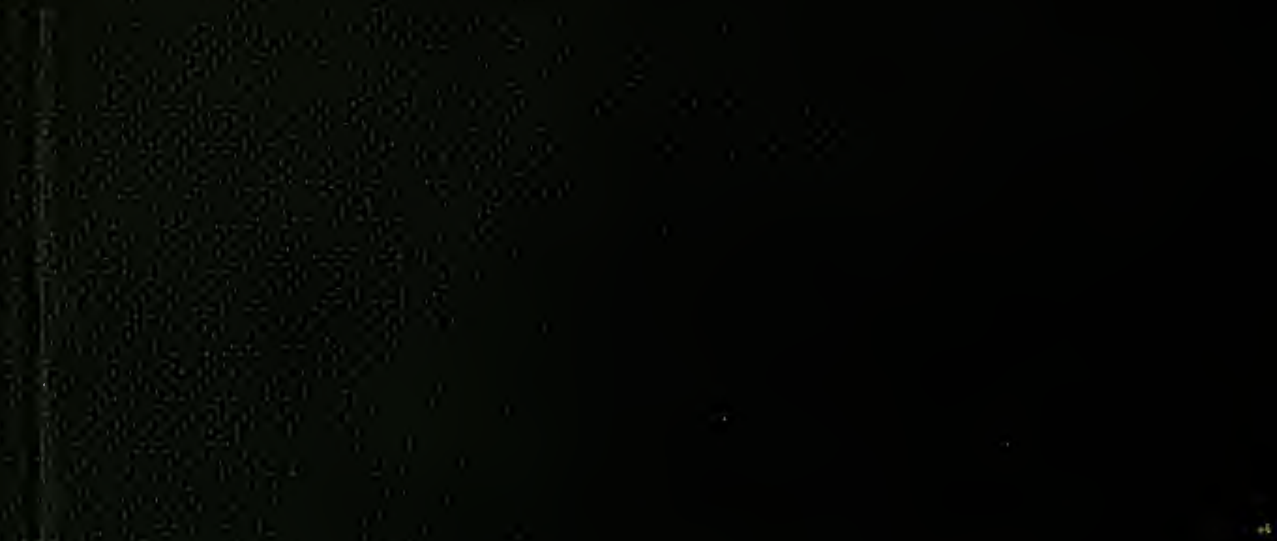

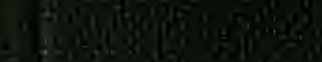

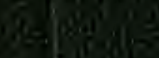

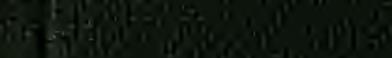

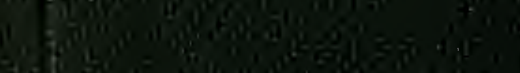

a)

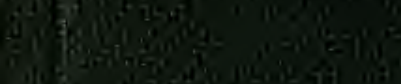

do

3) 3 -

(-1)

80

7.

ing 